\title{
Creep-fatigue Behavior and Damage Accumulation of a Candidate Structural Material for Concentrating Solar Power Solar Thermal Receiver Final Technical Report
}




\section{DISCLAIMER}

This information was prepared as an account of work sponsored by an agency of the U.S. Government. Neither the U.S. Government nor any agency thereof, nor any of their employees, makes any warranty, expressed or implied, or assumes any legal liability or responsibility for the accuracy, completeness, or usefulness, of any information, apparatus, product, or process disclosed, or represents that its use would not infringe privately owned rights. References herein to any specific commercial product, process, or service by trade name, trade mark, manufacturer, or otherwise, does not necessarily constitute or imply its endorsement, recommendation, or favoring by the U.S. Government or any agency thereof. The views and opinions of authors expressed herein do not necessarily state or reflect those of the U.S. Government or any agency thereof. 


\section{Creep-fatigue Behavior and Damage Accumulation of a Candidate Structural Material for Concentrating Solar Power Solar Thermal Receiver Final Technical Report}

Michael D McMurtrey, Ryann E Rupp, Bipul Barua, Mark Messner

February 2021

Idaho National Laboratory

Idaho Falls, Idaho 83415

http://www.inl.gov

Prepared for the

U.S. Department of Energy

Under DOE Idaho Operations Office

Contract DE-AC07-05ID14517 
Final Technical Report (FTR) Template

\begin{tabular}{|l|l|}
\hline Agency/Office/Program & DOE/EERE/Solar Energy Technology Office \\
\hline Award Number & DE-EE0033872 \\
\hline Project Title & $\begin{array}{l}\text { Creep-fatigue Behavior and Damage Accumulation of } \\
\text { a Candidate Structural Material for Concentrating } \\
\text { Solar Power Solar Thermal Receiver }\end{array}$ \\
\hline Principal Investigator & $\begin{array}{l}\text { Michael McMurtrey, Materials Scientist, } \\
\text { Michael.mcmurtrey@inl.gov, 208 526-2327 }\end{array}$ \\
\hline Business Contact & $\begin{array}{l}\text { Gabriel Ilevbare, Materials Science \& Engineering } \\
\text { Manager, Gabriel.ilevbare@inl.gov, 208 526-3735 }\end{array}$ \\
\hline Submission Date & 2/15/21 \\
\hline DUNS Number & DUNS Number \\
\hline Recipient Organization & Idaho National Laboratory \\
\hline Project Period & Start: 2/1/18 \\
\hline Project Budget & Total \$1,000,000 (DOE: \$1,000,000) \\
\hline Submitting Official Signature & \multicolumn{2}{|l}{} \\
\hline
\end{tabular}

1. Acknowledgement: "This material is based upon work supported by the U.S. Department of Energy's Office of Energy Efficiency and Renewable Energy (EERE) under the Generation 3 Concentrating Solar Power Lab Call Award Number 33872."

2. Disclaimer: "This report was prepared as an account of work sponsored by an agency of the United States Government. Neither the United States Government nor any agency thereof, nor any of their employees, makes any warranty, express or implied, or assumes any legal liability or responsibility for the accuracy, completeness, or usefulness of any information, apparatus, product, or process disclosed, or represents that its use would not infringe privately owned rights. Reference herein to any specific commercial product, process, or service by trade name, trademark, manufacturer, or otherwise does not necessarily constitute or imply its endorsement, recommendation, or favoring by the United States Government or any agency thereof. The views and opinions of authors expressed herein do not necessarily state or reflect those of the United States Government or any agency thereof." 


\section{Executive Summary:}

Creep-fatigue deformation is an important consideration for a thermal receiver in Concentrating Solar Power systems due to the constant static stress or pressure, diurnal cycling, and elevated service temperatures required for efficient operation. An accurate description of the creep-fatigue behavior, not available for five of the six candidate materials, is important for assessment of preliminary designs. This project has provided a detailed analysis of the creep-fatigue behavior and damage accumulation of Alloy $740 \mathrm{H}$, a candidate structural material for a CSP solar thermal receiver to address a critical knowledge barrier for receiver designs identified in the CSP Gen3 Demonstration Roadmap.

This project was divided in to three tasks, split between two general categories: Experimental and design methodology. Tasks 1 and 3, relating to the collection of data on Alloy $740 \mathrm{H}$ plate and sheet forms, respectively, were performed at the Idaho National Laboratory and used as input to Task 2, the development of design methodology performed at Argonne National Laboratory.

Experimental work covered limited tensile and creep testing to fill gaps in available data that is currently available and to demonstrate how the plate of Alloy $740 \mathrm{H}$ tested in this work compared to historical data. A more substantial testing program for fatigue and creep-fatigue was performed, with particular emphasis on creep-fatigue as there is little available data and it is necessary to understand the creep-fatigue interaction and develop related design models.

This effort includes the development of rules for the design of solar receiver components against high temperature creep-fatigue and ratcheting failure modes. The ASME Code rules for high temperature nuclear components was used to the basis of the method but adjustments will be made to reflect the generally shorter, diurnal operating cycles of thermal receivers and the relative consequences of failure, comparing nuclear to solar components. This work has provided guidance for the design of components for concentrating power facilities operating at high temperatures and undergoing high, secondary thermal stresses relative to the applied primary pressure stress. The design rules were developed for the design of Generation 3 CSP tubular receivers manufactured from Alloy $740 \mathrm{H}$, but are generally applicable to a wide range of component types undergoing similar loads. Procedural design rules for components to be used in conjunction with the 2019 edition of the ASME Boiler \& Pressure Vessel Code and the corresponding design data for Alloy $740 \mathrm{H}$ have been developed. A commentary describing the rationale behind the design rules and the data underlying the design material properties, as well as an extensive set of worked sample problems detailing the application of the rules to CSP components were developed as a part of this project, with a separate report covering these aspects in detail and included in the Appendix of this report. 
4. Table of Contents:

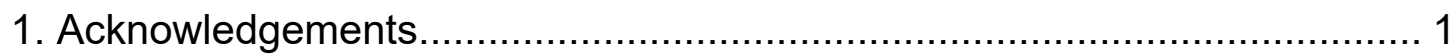

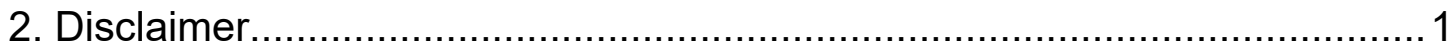

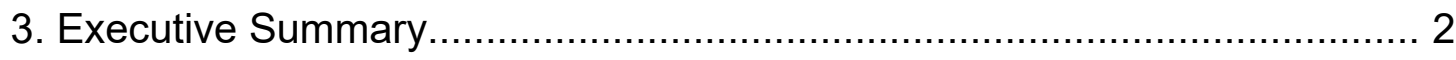

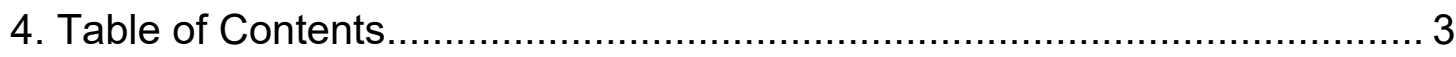

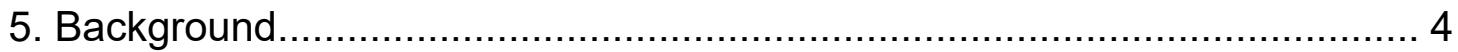

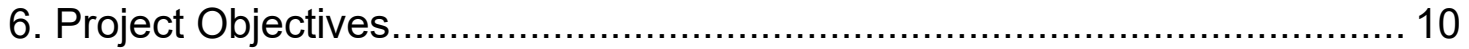

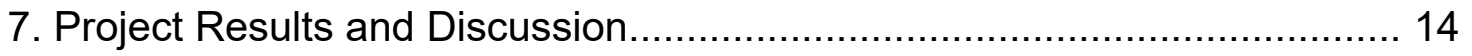

8. Significant Accomplishments and Conclusions............................................ 34

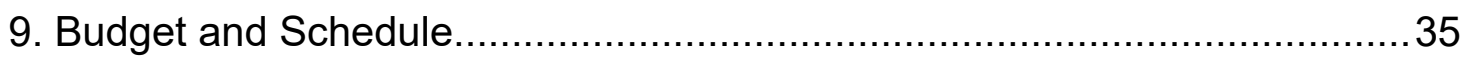

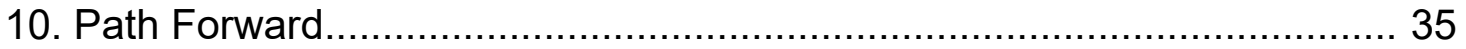

11. Inventions, Patents, Publications, and Other Results.............................. 35

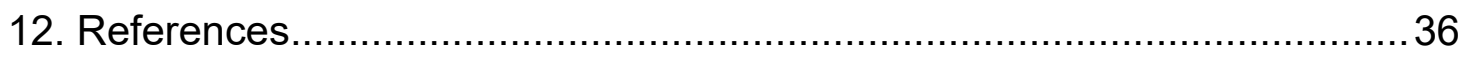

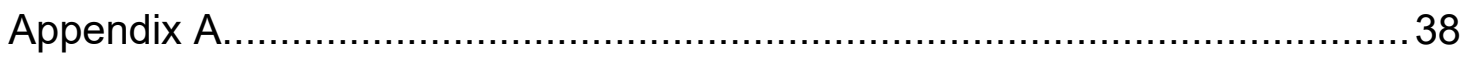




\section{Background:}

The goal of this project has been to provide a detailed analysis of the creep-fatigue behavior and damage accumulation of Alloy $740 \mathrm{H}$, a candidate structural material for a Concentrating Solar Power (CSP) solar thermal receiver to enable preliminary design analyses. This is to address a critical knowledge barrier for receiver design in both the gas phase (GP) and molten salt/metal pathway concepts identified in the CSP Gen3 Demonstration Roadmap [1]. Creep-fatigue deformation is an important consideration for a thermal receiver of a GP CSP system due to the constant static stress or pressure, diurnal cycling, and elevated service temperatures required for efficient operation [1].

The CSP thermal receiver structural material of a Gen3 plant must withstand the combined effect of high temperature creep and diurnal temperature cycling [2, 3]. An assessment of a solar thermal receiver design for the high temperature Gen3 concepts included quantification of the expected creep-fatigue damage to evaluate whether a candidate material is capable of meeting cost and lifetime goals [2, 3]. Experimentally creep-fatigue testing, which introduces a strain-controlled hold time in a fatigue cycle, is often used to approximate the intermittent cycling during high temperature service. Creep-fatigue deformation is known to accelerate failure relative to that expected from isolated creep and fatigue cycling as a result of interaction between the deformation modes [4-6].

A component of the overall CSP technology meeting cost goals is the material of construction for the receiver and the receiver's ability to meet lifetime requirements, in this case 30 years or 10,000 cycles [2, 3]. Candidate materials for a thermal receiver include commercial nickel-base alloys such as Inconel 625 , Inconel $740 \mathrm{H}$, Haynes 230 , and Haynes 282 [1], with Alloy 617 and Alloy $X$ also being of interest. These alloys are relatively expensive in comparison to stainless steels. They are predominantly strengthened by solid solution strengthening and have appreciable amounts of $\mathrm{Cr}[7,8]$. While many of the physical and mechanical properties such as the creep and low cycle fatigue are readily available [7-11], the creep-fatigue properties are generally not.

Creep-fatigue data is critical for design as it is the basis of the creep-fatigue interaction diagram, otherwise known as a D-diagram, constructed using a linear damage summation of the individual creep and fatigue terms, such as in the case of the ASME BPVC Section III, Division 5 (Subection HB, Subpart B for Class A components at elevated temperatures) [9]. The interaction is accounted for empirically by summing, then plotting, the two types of damage. The interaction is represented by bilinear curves, which vary for different materials, forming the damage envelopes within which the calculated damage for a design must fall. A reproduction from [12] of the creepfatigue interaction diagram for the ASME Section III Division 5 materials [9] is shown in Figure 1(a). While these rules may be more conservative than necessary for a CSP application [3,13], a linear summation damage assessment is typically utilized for creep-fatigue [14] and an accurate assessment of a CSP thermal receiver material will likely require a valid $\mathrm{D}$-diagram to assess preliminary designs. 


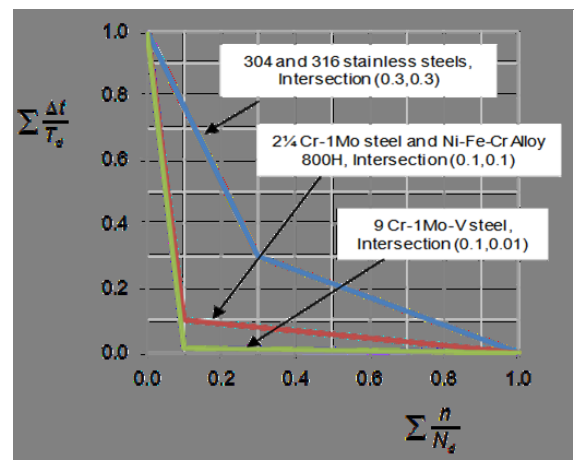

(a)

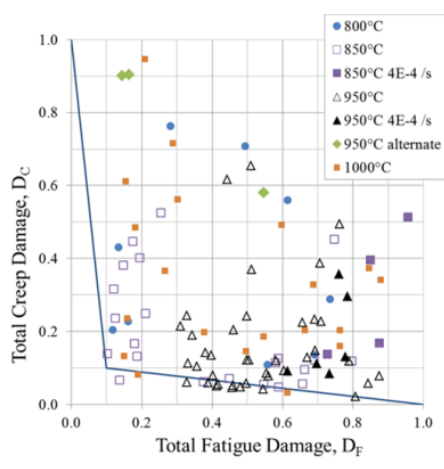

(b)

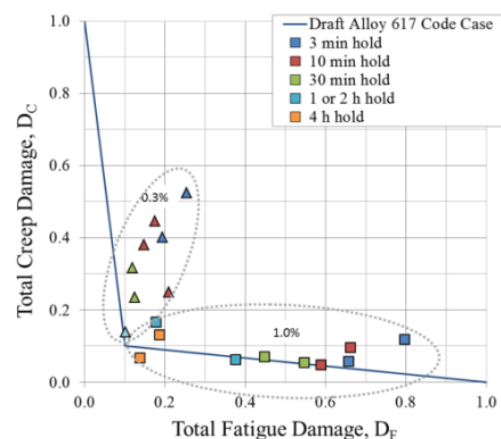

(c)

Figure 1. (a) Creep-fatigue interaction diagram reproduced [12] from ASME Section III, Division 5, Subsection HB, Subpart B [9]. Nickel-base alloy, Alloy 617, creep-fatigue interaction diagram [12] developed from (b) all available data points in references [15-18] and (c) with only data generated at $850{ }^{\circ} \mathrm{C}$ for the two strain ranges, $0.3 \%$ total strain and $1.0 \%$ total strain.

There are three manuscripts available that detail the modeling of the expected creep-fatigue damage in a solar thermal receiver [2, 3, 13]. Ortega et al. [3] have modeled a s-CO2 tubular thermal receiver design using Inconel 625 and considered the lifetime cycling requirement as 10,000 diurnal cycles (30 years), a 9 to 10 hour day from [13], a maximum temperature of $800{ }^{\circ} \mathrm{C}$, and pressure of $30 \mathrm{MPa}$. The creep-fatigue analysis [3] is done according to simplified design rules based on the nuclear Code and assumes no creep-fatigue interaction, i.e. a line passing through the point $0.5,0.5$ on the creep-fatigue interaction diagram. The basis for the latter assumption is not clear since the Special Metals technical data sheet for Inconel 625 [7] is referenced but does not provide creep-fatigue property data or a damage parameter. This modeling to assess feasibility of the receiver resulted in the creep damage equaling approximately 0.9 and the fatigue damage approximately 0.1 , thus outside of the design envelop for all Section III, Division 5 materials shown in Figure 1(a). The most similar alloy, Alloy $800 \mathrm{H}$, in Figure 1(a) has an intersection point of $0.1,0.1$.

Similarly, Neises et al. [13] considered Haynes 230 for a tubular receiver operating at $650{ }^{\circ} \mathrm{C}$ and again assumed no creep-fatigue interaction based upon the work of Chen et al. [14]. The D-diagram in reference [14] was constructed based upon a very limited number of creep-fatigue data points. Chen et al. acknowledge that for a similar nickelbase alloy, Alloy 617, also investigated, many of these still very limited data points fall to the left of a line with an intersection point of $0.5,0.5$ [14]. This assumption of no creepfatigue interaction, instead of accounting for one through a lower intersection point, leads to the conclusions that the design/material is capable of the 30 year lifetime with an accumulated damage of 0.9962 . Although considering much higher temperatures, Fork et al. investigated an Alloy 617 solar thermal receiver for an air Brayton cycle and found the operating conditions would be challenging and likely not feasible at $980{ }^{\circ} \mathrm{C}$ but may at $870{ }^{\circ} \mathrm{C}[2]$.

The assumptions made regarding the creep-fatigue design analyses for s-CO2 CSP thermal receiver designs may not be sufficiently conservative thus it is likely they have a much lower creep-fatigue life than calculated. Therefore, a better understanding of the creep-fatigue behavior of a candidate material and the associated design rules should be developed. An accurate description of the creep-fatigue behavior is important for assessment of preliminary designs. 
Recently, the Advanced Reactor Technologies program, funded through the Department of Energy (DOE) Office of Nuclear Energy, supported the ASME Code qualification of Alloy 617 into Section III, Division 5 Subsection HB, Subpart B [9]. Alloy 617 creep-fatigue behavior is likely similar to CSP receiver candidate structural materials and an extensive amount of data at 850 and $950^{\circ} \mathrm{C}$ [15-19] has been compiled and a creep-fatigue interaction diagram constructed [12], as shown in Figure 1(b). The results support those of the ASME Code Case for Alloy 617 recommending a D-diagram intersection point of $0.1,0.1$ [20]. As shown in Figure 1(c), at the lower temperature, $850{ }^{\circ} \mathrm{C}$, many of the longer hold durations showed the accumulation of significant creep damage and reside near the $0.1,0.1$ bi-linear curve intersection. The lower strain range condition and the longer hold time durations, more applicable to thermal receivers, were not investigated by Chen et al [14] in the development of their published Haynes 230 creep-fatigue interaction diagram. The latter is important because of the lack of creep-fatigue saturation at long hold times at $850^{\circ} \mathrm{C}$, i.e. increasing hold time duration results in decreasing cycle life for all investigated hold times [18]. This recent work on Alloy 617 was the motivation behind this project to more thoroughly investigation of the creep-fatigue behavior of a candidate thermal receiver alloy at the expected service temperatures of 750 to $850^{\circ} \mathrm{C}$ and the associated creepfatigue design rules.

This work focused on Alloy $740 \mathrm{H}$, which was decided in the first quarter of the project, after an analysis of the relevant properties and available data of these potential materials was performed. As this did not include any novel analysis or experimental work, but rather a study of existing literature and data, the work of the first quarter is included in here in the introduction of this report, with the body of the report focusing on newly generated data, analysis and design models.

As part of the alloy selection, the availability of creep-fatigue and creep property data, alloy strength, and heat treatment schedule were considered. The goal was to select an alloy for creep-fatigue investigation that would ultimately be impactful to the Gen3 effort and receiver developers and manufactures. The availability of creep data is particularly important as the scope of length of this project would not permit extensive creep testing.

While the physical and mechanical properties such as the creep and low cycle fatigue are often readily available, the creep-fatigue properties for most of the candidate alloys are not. The main exception is for Alloy 617 for which there is a published creepfatigue interaction diagram [12] based upon data from four sources [15-16,18,21] in the temperature range from 800 to $1000 \circ \mathrm{C}$ [12]. Additionally, a Larson-Miller creep equation developed for Alloy 617 from 348 rupture specimens from multiple heats and product forms and tested at temperatures from 593 to $1093 \circ \mathrm{C}$ exists. There are also additional sources of continuous-cycle and creep-fatigue data from tests at temperatures from 700 to $850 \circ \mathrm{C}[7,22-26]$. Only limited creep-fatigue tests at specific conditions in the lower temperature regime would be necessary to assess solar-specific design rules.

In the case of Alloy 230, continuous cycle fatigue [25, 27-30] and creep-fatigue [30-31] data is available from which to begin constructing a creep-fatigue interaction diagram, however, additional creep-fatigue tests at test conditions differing from those in the literature would be necessary for a complete design model. A published creepfatigue diagram for Alloy 230 includes limited data from a single source tested at a single temperature, $850^{\circ} \mathrm{C}$ [26]. Some creep tests would be necessary to verify the 
existing $1 \%$ creep and creep rupture life regression model [32], applicable for times up to $175,000 \mathrm{~h}$ and at temperatures from 527 to $927{ }^{\circ} \mathrm{C}$.

In contrast, there is not an available creep-fatigue interaction diagram or a creep regression equation for Alloy 282. Some creep data is published [8, 10-11,33-34], however, the available Larson-Miller equation is specifically for sheet material [8] and much of the data $[8,11,33-34]$ is for the material with a double step ageing treatment. A single step ageing treatment has been investigated; findings suggest that the creep strength, at temperatures between 700 and $800^{\circ} \mathrm{C}$, was similar, however, no conclusions were drawn on the creep ductility [10]. For a creep-fatigue interaction diagram to be developed as part of this project, only creep data from material with a single step ageing treatment would be utilized, thereby reducing the amount of available creep data. Furthermore, there is no creep-fatigue data available in the open literature for Alloy 282, but a limited amount of lower temperature continuous-cycle fatigue data does exist [8,35-38]. Clearly, more extensive creep-fatigue testing and creep testing of single step aged material would be necessary to develop applicable creep-fatigue design rules and an associated creep-fatigue interaction diagram.

For Alloy $740 \mathrm{H}$, with the exception of limited data at $700{ }^{\circ} \mathrm{C}$ [22], there is also no creep-fatigue data, nor an associated creep-fatigue interaction diagram. A vast amount of creep testing was completed at temperatures up to $850^{\circ} \mathrm{C}[10,39]$ and creep rupture equations are available $[7,10]$. These sources additionally contain a sufficient set of complete creep curves to construct isochronous curves at least at $700{ }^{\circ} \mathrm{C}$. Furthermore, there has been an analysis of the creep-fatigue design rules for Alloy $740 \mathrm{H}$ [22]. Zhang and Takahashi [22] have published creep-fatigue properties and the assessment of three life prediction methods, time fraction, ductility exhaustion, and modified ductility exhaustion. Minimal creep testing would likely be necessary for validation of the existing creep models, yet a substantial amount of creep-fatigue testing would be required.

Unlike Alloys $740 \mathrm{H}$ and 282 , there is creep-fatigue data available for Alloy $X$ at temperatures above $800 \circ \mathrm{C}[31,40-41]$. There is also a Larson-Miller regression equation developed from 276 data points with test temperatures ranging from 600 to $1000{ }^{\circ} \mathrm{C}$ [42]. Data for Alloy XR (modified alloy X composition, particularly in $\mathrm{Si}$, Ti, and $\mathrm{Mn}$ content) was utilized to develop the equation. There are other sources of creep data for Alloy $X[8,40,43]$, but it is not clear whether they were included in developing the regression equation. The current assessment of creep and creep-fatigue data available from published articles and material suppliers for candidate alloys is depicted in Table 1.

Table 1. Qualitative summary of the amount of creep and creep-fatigue property data available for Alloys $617,230,282,740 \mathrm{H}$, and $\mathrm{X}$. Red indicates limited or no data, yellow means some data available, and green that considerable data exists. 


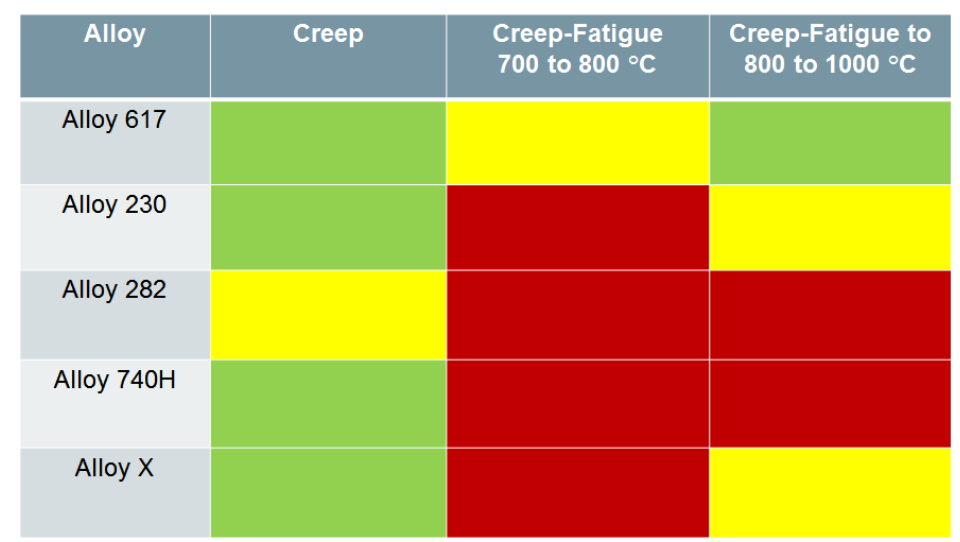

While there currently is only limited cyclic data, Alloys $740 \mathrm{H}$ and 282 are substantially stronger than Alloys $230,617,625$, and X. The former two alloys have significantly higher 100,000 h rupture creep strengths in comparison to Alloys $617, \mathrm{X}$, and 230 [44]. A comparison of ASME BVPC Section I [9] Stress Allowables (including the Alloy 617 Code Case data [20]) for seamless tubing for all alloys except Alloy 282 (where no such values exist) are showed together in Figure 2 for comparison. One point of concern for this program is the rapid decrease in strength (or Allowable Stress) for all Inconel alloys starting around $600-650^{\circ} \mathrm{C}$. By $800^{\circ} \mathrm{C}$, all alloys possess similar Allowable Stresses.

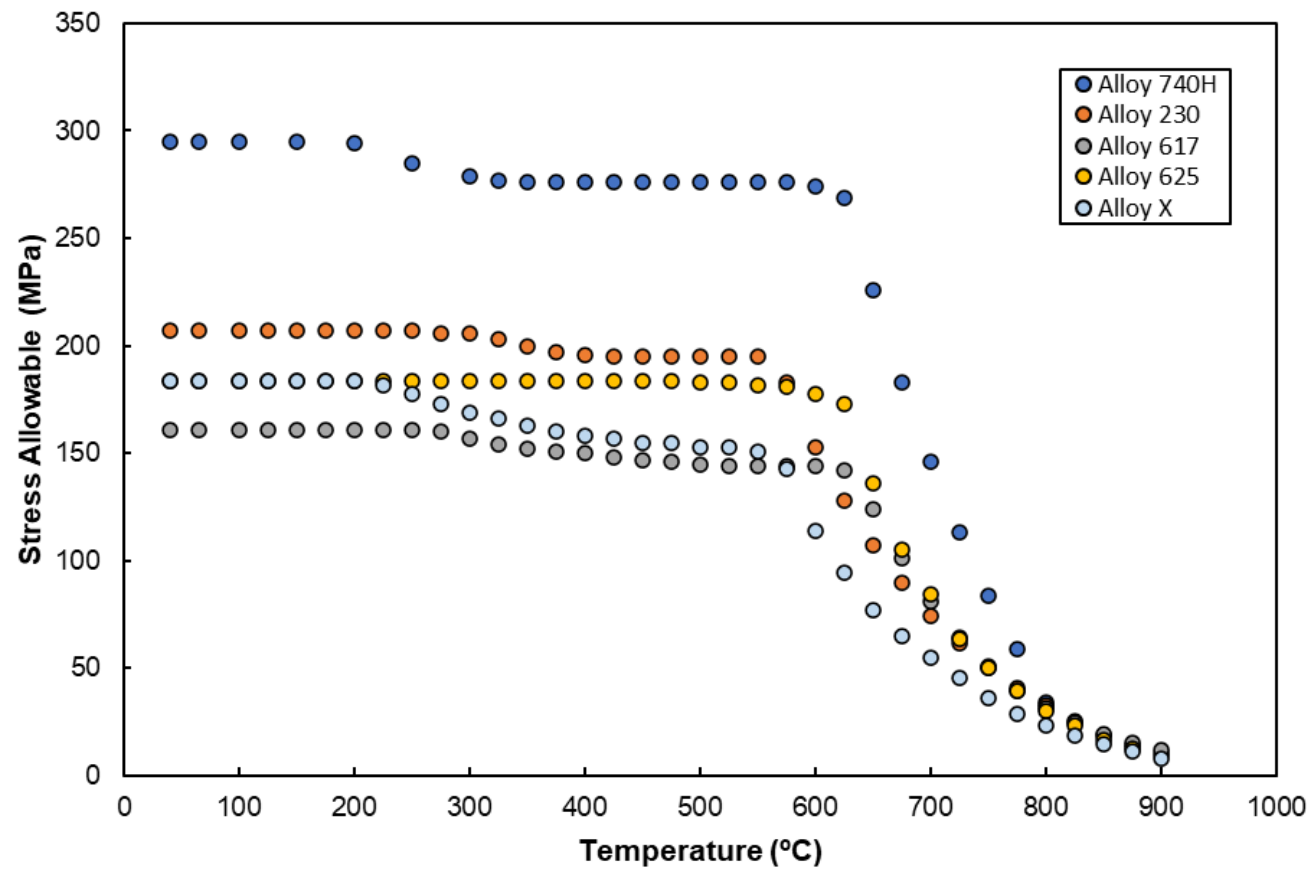

Figure 2. ASME BPVC Section I Stress Allowables for Alloys 740H, 230, 617, 625 and X [9,20].

The compositions of Alloys $740 \mathrm{H}$ and 282 are similar, with approximately $50 \mathrm{wt} \% \mathrm{Ni}$ and at least $20 \mathrm{wt} \% \mathrm{Cr}$, while also containing $\gamma$ forming elements Co and Mo and $\gamma^{\prime}$ forming elements Al and Ti. The lower high temperature strength of Alloys 617, 230, and $\mathrm{X}$ is due to the fact that they are predominately solid solution strengthened, whereas Alloys $740 \mathrm{H}$ and 282 are also strengthened by $\gamma^{\prime}$ precipitates. The 
microstructural stability with regard to these strengthening precipitates, for which an initial investigation has been carried out [45], will also need to be considered, particularly at temperatures above $800^{\circ} \mathrm{C}$. While Alloy 282 is not qualified in the ASME $\mathrm{BPVC}$, there is some data available to give an idea of the high temperature strength. Figure 3 shows a collection of creep data [8,10-11] at approximately 700,750 and 800 ${ }^{\circ} \mathrm{C}$. From this data, it appears that the creep strength of Alloys $740 \mathrm{H}$ and 282 are similar. Note that this is just one indication of the overall high temperature strength and does not necessarily indicate that Alloys $740 \mathrm{H}$ and 282 will have similar design limits once all properties are considered.
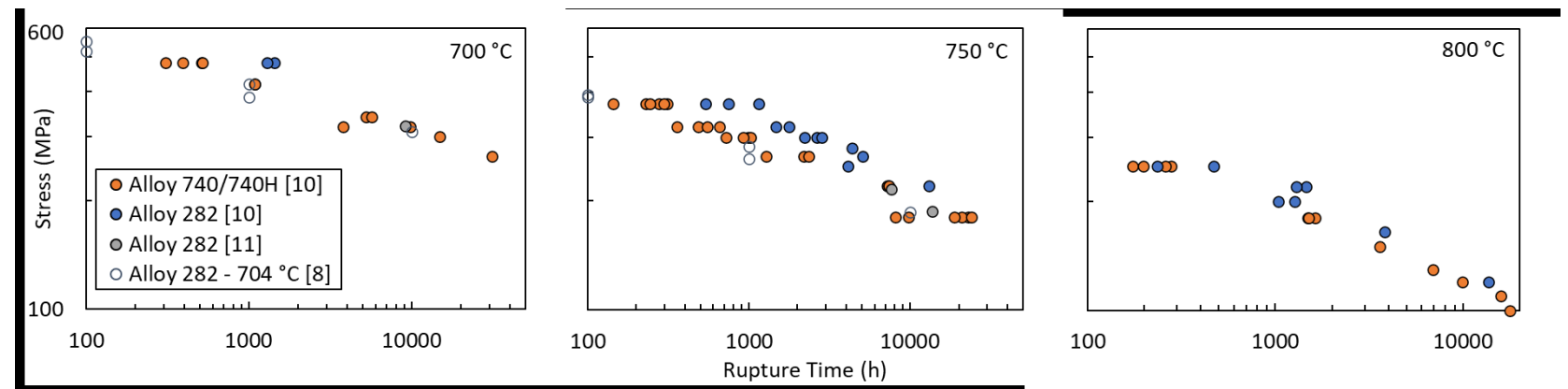

Figure 3. Creep data for Alloys $740 / 740 \mathrm{H}$ and 282 at 700,750 and $800{ }^{\circ} \mathrm{C}[8,10,11]$.

The considerable amount of research focused on Alloys $740 \mathrm{H}$ and 282 has been motivated by advanced-ultrasupercritical (A-USC) power plant applications and is part of a large DOE Fossil Energy program [44]. For A-USC applications, materials would need to withstand steam temperatures of up to $760^{\circ} \mathrm{C}$ placing them in a similar temperature regime to CSP thermal receivers. It has been recognized that nickel-base alloys are necessary to provide adequate strength at temperature, thus not surprisingly, a similar set of alloys to those being considered for CSP thermal receivers were assessed. As part of this assessment, the creep properties of weldments have been investigated and the weld strength reduction factor is likely near 1 for Alloy 282, whereas it 0.7 for Alloy $740 \mathrm{H}$ [10]. However, Alloy $740 \mathrm{H}$ has a single step ageing treatment and has recently been accepted into the ASME Boiler and Pressure Vessel Code Case 2702, which includes tensile properties, allowable stresses, and physical properties [45]. As part of the A-USC program, research on Alloy $740 \mathrm{H}$ has focused on the creep properties [10, 45], fabricability and weldability [44], influence of deformation and aging on creep rupture properties and the tensile properties [10]. Further research will be necessary on the propensity of Alloy $740 \mathrm{H}$ to form extraneous phases, particularly the eta phase [46], at temperatures of $800^{\circ} \mathrm{C}$ and above. The research conducted as part of the A-USC program has furthered the knowledge base of both Alloy $740 \mathrm{H}$ and Alloy 282 and provides a starting point for future CSP efforts.

Based on the data available for the potential materials, a weighted ranking table was formed, shown in Table 2. Weighting factors were employed to give preference to properties of particular interest (e.g. high temperature strength was more important than room temperature (RT) strength). Scores were assigned with values between 1 and 4, 4 being the best. Alloy $740 \mathrm{H}$ and Alloy 282 scored nearly the same, and either alloy would be of interest to the solar program. However, given the limited ability of this program to perform the large amount of testing needed to create design models, Alloy $740 \mathrm{H}$ was selected over Alloy 282 due to the larger pre-existing database (creep data being 
particularly important), including an American Society of Mechanical Engineers (ASME) Boiler and Pressure Vessel Code (BPVC) Code Case. It is noted, however, that since this project began, work has started on an Alloy 282 Code Case.

Table 2. Results of the first quarter material analysis which led to the selection of Alloy $740 \mathrm{H}$ as the focus for this project.

\begin{tabular}{|c|c|c|c|c|c|c|c|c|c|c|c|c|c|}
\hline \multirow[b]{2}{*}{ Criteria } & \multirow[b]{2}{*}{$\begin{array}{c}\text { Weighting } \\
\text { Factor }\end{array}$} & \multicolumn{2}{|c|}{ Alloy 625} & \multicolumn{2}{|c|}{ Alloy 617} & \multicolumn{2}{|c|}{ Alloy 230} & \multicolumn{2}{|c|}{ Alloy $\mathrm{X}$} & \multicolumn{2}{|c|}{ Alloy $740 \mathrm{H}$} & \multicolumn{2}{|c|}{ Alloy 282} \\
\hline & & Score & Rating & Score & Rating & Score & Rating & Score & Rating & Score & Rating & Score & Rating \\
\hline Strength at RT & 0.07 & 2 & 0.14 & 1 & 0.07 & 3 & 0.21 & 2 & 0.14 & 3 & 0.21 & 3 & 0.21 \\
\hline Strength at $750^{\circ} \mathrm{C}$ & 0.25 & 2 & 0.5 & 2 & 0.5 & 2 & 0.5 & 1 & 0.25 & 3 & 0.75 & 3 & 0.75 \\
\hline Strength at $800^{\circ} \mathrm{C}$ & 0.25 & 2 & 0.5 & 2 & 0.5 & 2 & 0.5 & 2 & 0.5 & 2 & 0.5 & 2 & 0.5 \\
\hline Weld strength reduction factor & 0.18 & 3 & 0.54 & 3 & 0.54 & 2 & 0.36 & & 0 & 2 & 0.36 & 4 & 0.72 \\
\hline Complexity of aging treatment & 0.12 & 3 & 0.36 & 4 & 0.48 & 4 & 0.48 & 4 & 0.48 & 3 & 0.36 & 2 & 0.24 \\
\hline Alloy weldability & 0.13 & 3 & 0.39 & 3 & 0.39 & 3 & 0.39 & 3 & 0.39 & 3 & 0.39 & 1 & 0.13 \\
\hline TOTAL & 1 & & 2.43 & & 2.48 & & 2.44 & & 1.76 & & 2.57 & & 2.55 \\
\hline
\end{tabular}

\section{Project Objectives:}

Creep-fatigue deformation is an important consideration for a thermal receiver of a gas phase (GP) Concentrating Solar Power (CSP) system due to the constant static stress or pressure, diurnal cycling, and elevated service temperatures required for efficient operation. An accurate description of the creep-fatigue behavior is important for assessment of preliminary designs and is not available for Alloy $740 \mathrm{H}$, a candidate receiver material. This project sought to provide a detailed analysis of the creep-fatigue behavior and damage accumulation of Alloy $740 \mathrm{H}$ for a CSP solar thermal receiver. This effort included the development of rules for the design of solar receiver components against high temperature creep-fatigue and ratcheting failure modes. The ASME Code rules for high temperature nuclear components formed the basis of the method but adjustments had to be made to reflect the generally shorter, diurnal operating cycles of thermal receivers and the relative consequences of failure, comparing nuclear to solar components.

The objective of this project were to provide (1) a description of the creep-fatigue behavior of a candidate alloy (Alloy $740 \mathrm{H}$ ) for a solar thermal receiver and (2) a set of proposed design rules to provide a more accurate assessment of creep-fatigue damage in solar thermal receivers for preliminary CSP designs. The description of the creepfatigue behavior would include a preliminary recommendation of a creep-fatigue interaction diagram (D-diagram) for a candidate structural material based upon an assessment of the materials' creep-fatigue response in the temperature range of 700 to $850^{\circ} \mathrm{C}$ as well as a description of the progression of creep-fatigue deformation in the material. For the second objective, the collected test data was to be synthesized into a creep-fatigue design methodology applicable to high temperature solar thermal receiver components using an approach based on a simplified method for the design of high temperature nuclear components, the elastic-plastic (EPP) analysis. The final method recommended for design was adjusted to reflect the differing consequences of failure between solar and nuclear systems.

This work was a collaboration between Idaho National Laboratory (INL) and Argonne National Laboratory (ANL) and was divided in to three tasks: Task 1 (INL) - CreepFatigue Testing and Metallographic Analysis, Task 2 (ANL) - Analysis of Design Methodology, and Task 3 (INL) - Assessment of Materials Form. These are described 
in detail below.

Task 1 focused on experimental data collection (tensile, creep, fatigue and creepfatigue), which would feed into the design models of Task 2. Most testing was performed between temperatures of $750-850{ }^{\circ} \mathrm{C}$. Tensile and creep testing was limited and performed to validate that the current heat was statistically similar to already available creep data. The bulk of the testing was fatigue and creep-fatigue testing.

The primary effort in Task 2 was the development of rules for the design of solar receiver components against high temperature creep-fatigue and ratcheting failure modes. Broadly, a design method requires three types of data: creep, fatigue, and creep-fatigue interaction. These data were integrated into isochronous stress-strain curves, fatigue life curves, rupture life curves, and interaction diagrams for the investigated candidate structural material in the relevant temperature range. From this data a design method for ratcheting and creep-fatigue was developed. The ASME Code rules for high temperature nuclear components will form the basis of the method but adjustments will be made to reflect the generally shorter, diurnal operating cycles of thermal receivers and the relative consequences of failure, comparing nuclear to solar components. An evaluation of the design margin in the current rules will be used to guide appropriate modifications for solar receiver components and the method will be summarized in a set of proposed design rules. The candidate design method will be applied to a concept design to evaluate the viability of different operating temperatures.

Finally, an existing candidate design was evaluated using these proposed design rules to assess the viability of different operating temperatures under creep-fatigue conditions. The focus was on the evaluation of an existing design under various solar energies and operating temperatures. The outcome was an assessment of the feasibility of the design with the selected structural material and a bounding of the potential operating regimes.

Task 3 was to perform a preliminary assessment of the potential influence of material form other than plate on the mechanical behavior of a candidate receiver alloy. For this work, Alloy $740 \mathrm{H}$ sheet was used for testing. The milestones associated with these tasks are shown in Table 3 below.

Table 3. List of milestones associated with the project.

\begin{tabular}{|l|l|l|l|}
\hline \multicolumn{1}{|c|}{$\begin{array}{c}\text { Mile- } \\
\text { stone \# }\end{array}$} & $\begin{array}{c}\text { Milestone } \\
\text { Name/Description }\end{array}$ & Criteria & \\
\hline $\begin{array}{l}\text { First } \\
\text { number }\end{array}$ & & 1. Metric & \\
shows & & 2. Success & \\
Task \#. & & 3. Assurance & \\
\hline
\end{tabular}




\begin{tabular}{|c|c|c|c|}
\hline 1.1 & Alloy Selection & $\begin{array}{l}\text { 1. Alloy selected for creep-fatigue testing } \\
\text { and for design model is valuable and } \\
\text { impactful to the Gen } 3 \text { effort. } \\
\text { 2. Leading receiver developers, ASME code } \\
\text { expert, and DOE concur on alloy selection } \\
\text { 3. Three (3) parties who are either } \\
\text { developers or manufacturers in consultation } \\
\text { with ASME code SME, agree to selected } \\
\text { alloy as first or second choice. }\end{array}$ & End of Q1 \\
\hline 1.2 & $\begin{array}{l}\text { Completion of } \\
\text { fatigue and } \\
\text { preliminary creep- } \\
\text { fatigue testing, } \\
\text { data available for } \\
\text { dissemination }\end{array}$ & $\begin{array}{l}\text { 1. Fatigue and preliminary creep-fatigue } \\
\text { testing data, satisfy the ASME design curve } \\
\text { requirements. } \\
\text { 2. Testing completed in accordance with } \\
\text { ASTM standard. } \\
3 \text {. Data will be compared to existing test } \\
\text { data showing results fall within the precision } \\
\text { recommended by ASTM (E606), i.e. } \pm 6.32 \% \\
\text { of the log of the fatigue life. }\end{array}$ & End of Q4 \\
\hline 2.1 & $\begin{array}{l}\text { Receiver design } \\
\text { rules are aligned } \\
\text { with industry } \\
\text { practice / } \\
\text { requirements. }\end{array}$ & $\begin{array}{l}\text { 1. Design rules encompass anticipated } \\
\text { components failure modes. } \\
\text { 2. Leading receiver developers, ASME code } \\
\text { expert, and DOE concur on selected design } \\
\text { rules / failure modes. } \\
\text { 3. Three ( } 3 \text { ) parties who are either } \\
\text { developers or manufacturers in consultation } \\
\text { with ASME code SME, agree to design } \\
\text { rules. }\end{array}$ & End of Q1 \\
\hline 2.2 & $\begin{array}{l}\text { Compilation and } \\
\text { analysis of } \\
\text { available creep } \\
\text { data, conduct } \\
\text { additional creep } \\
\text { testing as needed. }\end{array}$ & $\begin{array}{l}\text { 1. Isochronous curves are produced for use } \\
\text { by industry designers to initiate designing. } \\
\text { 2. IF: existing data sufficient, generate } \\
\text { isochronous curves } \\
\text { ELSE: Partial isochronous curves and data } \\
\text { requirements defined and perform additional } \\
\text { INL tests as required. } \\
\text { 3. Isochronous curves that cover expected } \\
\text { component temperature and design life. } \\
\text { Curves will be compared to existing Alloy } \\
617 \text { ASME Code Case curves to ensure } \\
\text { similar trends, as concurred by expert. }\end{array}$ & $\begin{array}{l}\text { ELSE IF: } \\
\text { End of Q6 }\end{array}$ \\
\hline 2.3 & $\begin{array}{l}\text { Design curves } \\
\text {-stress/strain } \\
\text { (ICC), fatigue life, }\end{array}$ & $\begin{array}{l}\text { 1. Remaining design curves in milestone } \\
\text { description are adequate to establish design } \\
\text { rules. }\end{array}$ & End of Q5 \\
\hline
\end{tabular}




\begin{tabular}{|c|c|c|c|}
\hline & $\begin{array}{l}\text { rupture life, and } \\
\text { preliminary creep- } \\
\text { fatigue interaction } \\
\text { developed }\end{array}$ & $\begin{array}{l}\text { 2. Curves incorporate INL and literature } \\
\text { data. } \\
\text { 3. Curves will be compared to existing Alloy } \\
617 \text { ASME Code Case curves to ensure } \\
\text { similar trends, as concurred by expert. }\end{array}$ & \\
\hline 2.4 & $\begin{array}{l}\text { Initial design } \\
\text { method developed }\end{array}$ & $\begin{array}{l}\text { 1. Design procedure executable by } \\
\text { practicing engineer. } \\
\text { 2. Initial procedure }+ \text { example problems } \\
\text { disseminated to vendor/designer community } \\
\text { and feedback acknowledges ability to be } \\
\text { executed. } \\
\text { 3. Three independent design analysis from } \\
\text { reference sample problem produce correct } \\
\text { pass/fail results. }\end{array}$ & End of Q6 \\
\hline 2.5 & $\begin{array}{l}\text { Design method } \\
\text { finalized }\end{array}$ & $\begin{array}{l}\text { 1. Executable design procedure that } \\
\text { produces designs that consistently exceed } \\
\text { design life. } \\
\text { 2. Tested life of actual or simplified } \\
\text { component exceeds predicted design life. } \\
\text { 3. Minimum of } 3 \text { component tests pass. }\end{array}$ & $\begin{array}{l}\text { Beginning } \\
\text { of Q8 }\end{array}$ \\
\hline 3.1 & $\begin{array}{l}\text { Assessment of the } \\
\text { material form }\end{array}$ & $\begin{array}{l}\text { 1. Specimens from sheet material } \\
\text { consistently meet (or exceed) design life. } \\
\text { 2. Test life for mechanical testing indicates } \\
\text { developed design curves are accurate for } \\
\text { material forms other than plate, or allows for } \\
\text { a proposed correction factor. } \\
\text { 3. Data consistent with allowable scatter } \\
\text { from ASTM standards (E606) for single lab } \\
\text { testing ( } \pm 2.41 \% \text { of the log of the fatigue life). } \\
\text { Metallurgical analysis identifies potential } \\
\text { cause if inconsistent fracture mechanism. }\end{array}$ & End of Q8 \\
\hline
\end{tabular}

The major Go/No-Go decision occurred after the initial assessment of the available data. If sufficient creep data did not exist for the selected receiver material (Alloy $740 \mathrm{H}$ ), then design curves would not be possible within the scope of the budget and time of this project. It was determined, however, after the first quarter of the project, that sufficient creep data existed so that the project could move forward.

The project outcomes delivered essential knowledge of the creep-fatigue behavior of Alloy $740 \mathrm{H}$ for a solar thermal receiver. This included the recommendation of design models, such as the creep-fatigue interaction diagram (D-diagram), based upon an assessment of Alloy 740H's creep-fatigue response in the temperature range of 750 to $850{ }^{\circ} \mathrm{C}$. An example of how to use the design models was also performed as part of this project. 


\section{Project Results and Discussion:}

Results from this project can be split in to two large sections: experimental results (Tasks 1 and 3 ) and analysis of design models (Task 2). Experimental results will be covered first in this report. A report covering design methodology was released prior to this Final Technical Report and prior to the completion of the final experiments [47]. That report is included in Appendix A of this report, with updates in this section. It should be noted up front, the updates to the design methodology are to include the final experimental data, which did not change any design models or recommendations.

\subsection{Experimental Results}

While the bulk of the focus was on creep-fatigue testing to complete the needed data sets for the design methods, four types of mechanical testing were performed during this project: Tensile, creep, fatigue and creep-fatigue testing.

\subsubsection{Tensile results}

Elevated temperature testing was performed at $700,750,800$ and $850{ }^{\circ} \mathrm{C}$ in accordance with ASTM E21 (Standard Test Methods for Elevated Temperature Tension Tests of Metallic Materials). Due to a computer failure, the first test at $850^{\circ} \mathrm{C}$ was terminated prematurely, shortly after yielding. A duplicate test was performed with a new specimen at the same condition to capture the entire tensile curve. The tensile curves are shown in Figure 4. Important properties determined from the tension tests are listed in Table 4. In general, the values for the 700 and $800{ }^{\circ} \mathrm{C}$ tests were in good agreement with the values found in the Special Metals $740 \mathrm{H}$ Brochure [7], with the exception of the elongation and reduction in area of the $800{ }^{\circ} \mathrm{C}$ test.

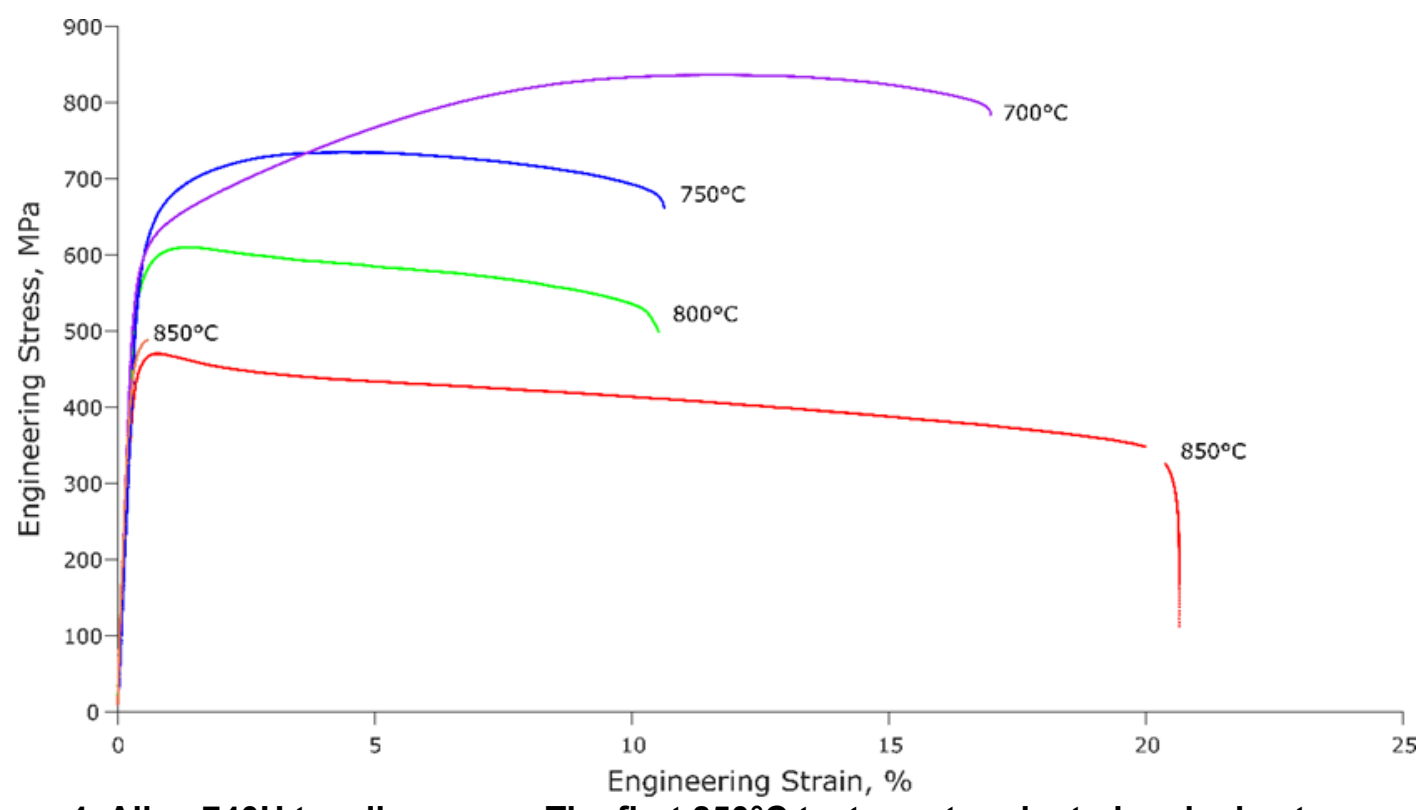

Figure 4. Alloy $740 \mathrm{H}$ tensile curves. The first $850^{\circ} \mathrm{C}$ test was terminated early due to computer error. 
Table 4. Alloy $740 \mathrm{H}$ tensile data. Data from rows marked SM in the temperature column are from the Special Metals website [7].

\begin{tabular}{|c|c|c|c|c|c|}
\hline $\begin{array}{c}\text { Test } \\
\text { Temperature } \\
{ }^{\circ} \mathrm{C}\end{array}$ & $\begin{array}{c}\text { Young's } \\
\text { modulus } \\
\mathrm{GPa}\end{array}$ & $\begin{array}{c}\text { Yield } \\
\text { Strength } \\
\mathrm{MPa}\end{array}$ & $\begin{array}{c}\text { Ultimate Tensile } \\
\text { Strength } \\
\mathrm{MPa}\end{array}$ & $\begin{array}{c}\text { Reduction } \\
\text { Elongation } \\
\%\end{array}$ & $\begin{array}{c}\text { in Area } \\
\%\end{array}$ \\
\hline 700 & 171 & 601.1 & 835.9 & 16.6 & 19.3 \\
$700(\mathrm{SM})$ & 178 & 567 & 861 & 17.0 & 23.1 \\
750 & 147 & 627.9 & 734.2 & 11.9 & 9.6 \\
800 & 154 & 576.5 & 609.6 & 12.7 & 10.5 \\
$800(\mathrm{SM})$ & 169 & 594 & 691 & 23.5 & 31.2 \\
850 & 159 & 481.7 & - & - & - \\
850 & 144 & 460.5 & 469.9 & 23.6 & 21 \\
\hline
\end{tabular}

\subsubsection{Creep results}

Creep results (both the final rupture time, as well as the strain vs. time data) are important inputs for the design models. Four creep tests were performed as a part of this project, following ASTM E139 (Standard Test Methods for Conducting Creep, Creep Rupture, and Stress Rupture Tests of Metallic Materials). This is not a significant number in terms of creation of design models, but allows our material to be compared to existing data sets prior to using those data sets in our design models. While limited, the additional testing is still useful as data input for the design models. The results are shown in Figure 5 and Table 5 . Applied stresses were chosen for relatively short tests (rupture lives around 1,000-3,000 hours).

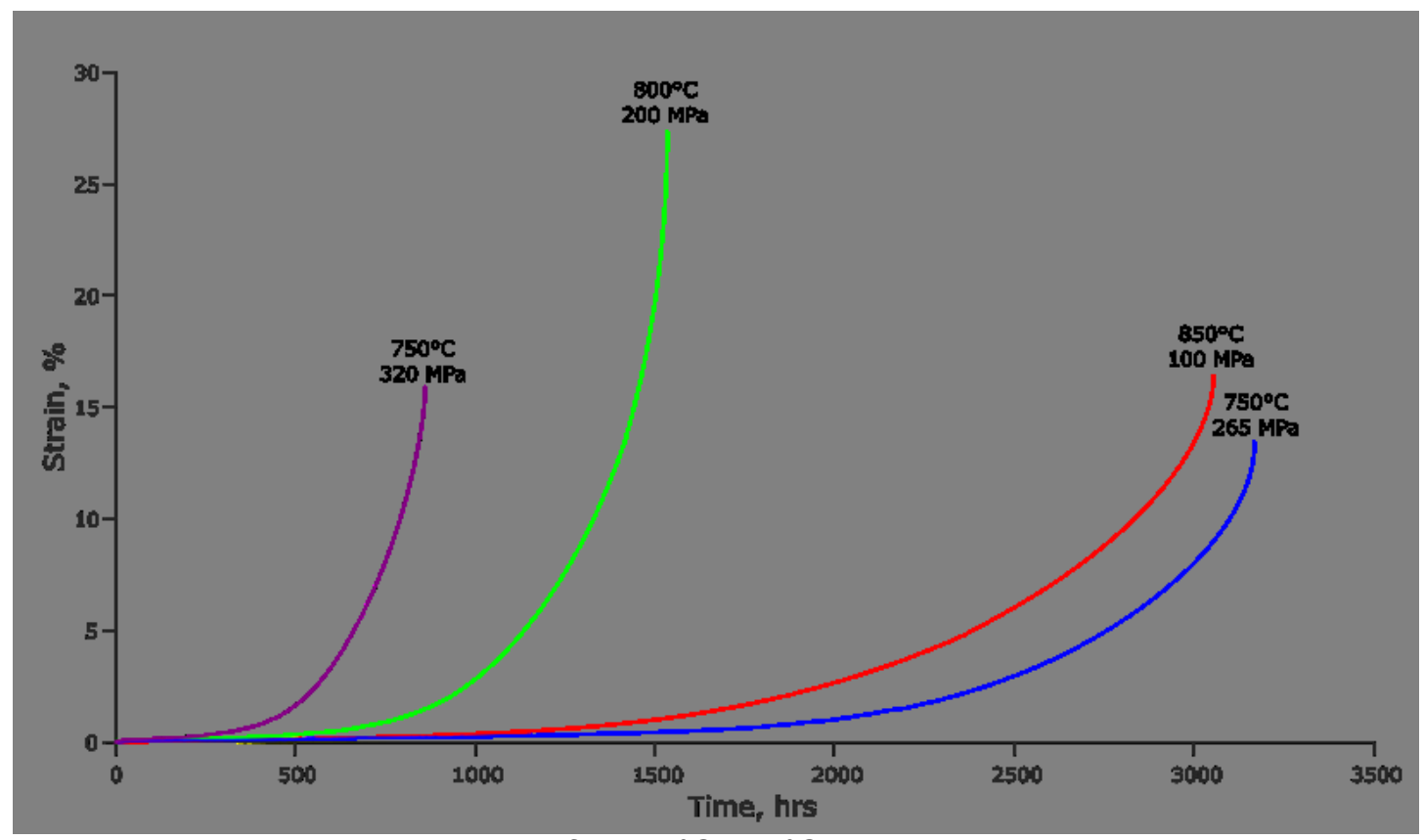

Figure 5. Alloy $740 \mathrm{H}$ creep curves for $750^{\circ} \mathrm{C}-850^{\circ} \mathrm{C}$ tests. All tests are completed.

Table 5. Alloy $740 \mathrm{H}$ creep rupture data from INL tests. 


\begin{tabular}{|c|c|c|c|c|}
\hline $\begin{array}{c}\text { Temp. } \\
{ }^{\circ} \mathrm{C}\end{array}$ & $\begin{array}{c}\text { Applied } \\
\text { Stress } \\
(\mathrm{MPa})\end{array}$ & $\begin{array}{c}\text { Rupture } \\
\text { Time } \\
(\mathrm{hrs})\end{array}$ & $\begin{array}{c}\text { Extensometer } \\
\text { Elongation } \\
(\%)\end{array}$ & $\begin{array}{c}\text { Larson-Miller } \\
\text { Parameter }\end{array}$ \\
\hline 750.0 & 265 & 3168 & 13.43 & $2.35 \mathrm{E}+04$ \\
750.0 & 320 & 861 & 15.88 & $2.29 \mathrm{E}+04$ \\
800.0 & 200 & 1535 & 27.31 & $2.43 \mathrm{E}+04$ \\
850.0 & 100 & 3053 & 16.37 & $2.58 \mathrm{E}+04$ \\
\hline
\end{tabular}

Larson-Miller Parameters were calculated according to

with being the temperature in $\mathrm{K}$, the rupture time in hours, and a parameter, generally correlates to the logarithm of the stress to rupture. This parameter is a convenient way to combine rupture time and temperature to plot against stress and create a correlation that can be used to interpolate and extrapolate creep rupture data. The Larson-Miller Parameter for the four INL tests are shown in Table 5, calculated with the $C$ constant recommended by the ASME BPVC Code Case (2702) [9] of 19.472. A comparison of the INL tests with the Larson-Miller Curve of the Alloy $740 \mathrm{H}$ Code Case is shown in Figure 6. There is good agreement between the INL test data and the expected LarsonMiller Curve, showing that the heat of material tested at INL reasonably represents the expected Alloy $740 \mathrm{H}$ data. There is the added benefit of adding additional creep data to the design models, as creep data above $750{ }^{\circ} \mathrm{C}$ was more sparse. However, the limited scope of the project did not permit extensive creep testing. This is particularly true for data that reports the creep curves rather than just the rupture time, which is important for aspects such as ratcheting considerations. 


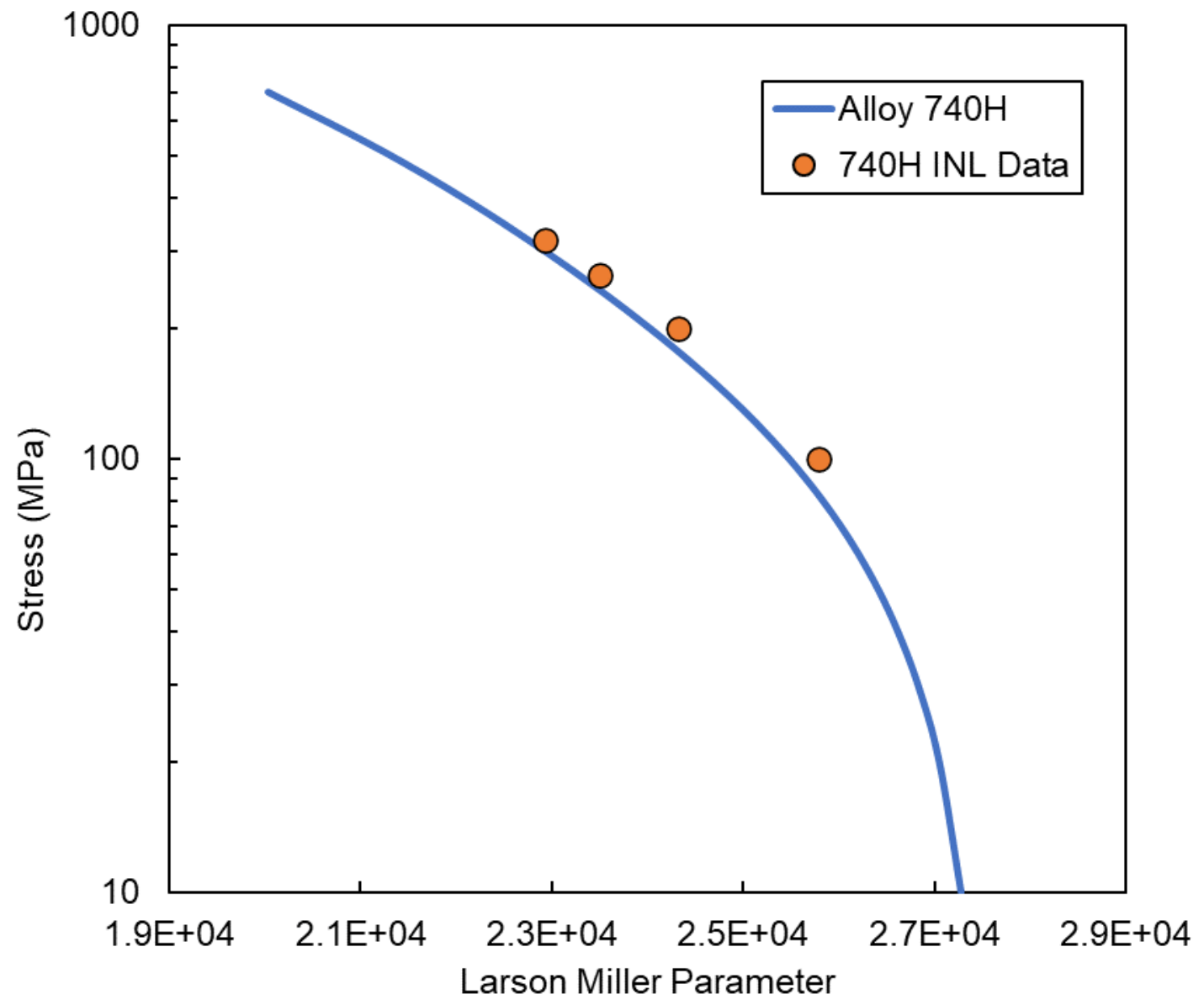

Figure 6. INL test data compared to the Alloy $740 \mathrm{H}$ Code Case suggested Larson-Miller Curve [9].

\subsubsection{Fatigue and creep-fatigue results}

Fatigue and creep-fatigue, both cyclic testing performed on the same machines, will be shown together, as there are many similarities (fatigue tests are essentially creepfatigue tests with a zero minute hold time). Cyclic testing at INL is usually performed using three-zone furnaces, as shown in Figure 7a. Each zone may be controlled independently and allows for tight control over the temperature gradient across the specimen. MTS servo-hydraulic test frames were set up for this type of high temperature testing. In order to increase the number of tests performed for this project, additional frames were considered for use that employ induction heaters (shown in figure $7 \mathrm{~b}$ ). Induction heating allows for rapid heating to temperature and reduces the amount of heat put into the grips/load train. The extensometers, which are used to measure stain in the gage section (and can be seen in Figure 7, the white posts that touch the gage section of the specimen) are less noisy in an induction system. In a furnace setup, a window must be cut in the furnace insulation to allow the extensometer posts to reach the sample, and the hot air flowing from this window tends to cause a noisier signal. The disadvantage of induction heaters is that temperature control is more difficult, and a larger gradient along the length of the gage section is typical. 


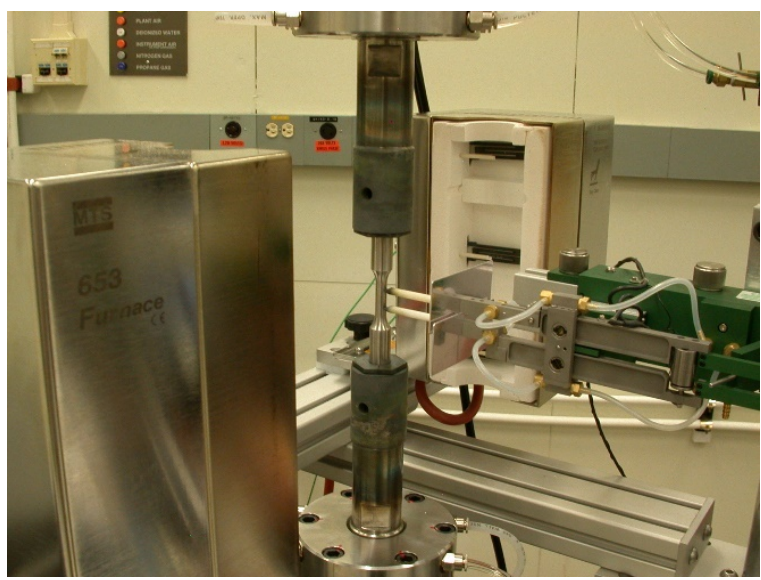

(a)

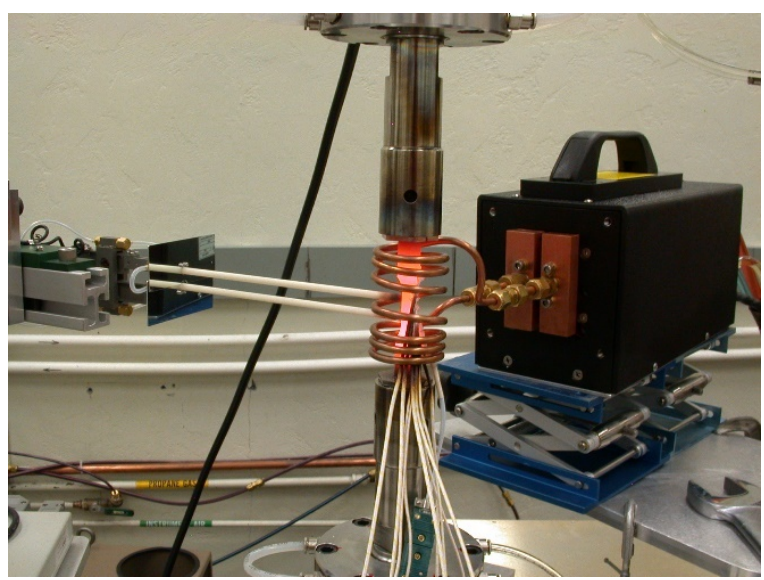

(b)

Figure 7. Test setup showing a) the three zone furnace and b) the induction heater methods for reaching specimen temperatures.

For temperature control in both systems, thermocouples (typically $R$ type) are spot welded onto both shoulders of the specimen. As the shoulder temperature typically varies from the temperature in the gage section, a calibration sample is used, shown in Figure 8, to determine the appropriate shoulder temperature for a given desired gage temperature. The calibration sample has thermocouples on the shoulder, as well as along the length of the gage to measure the temperature profile for the length of the gage as well as the shoulder temperature.

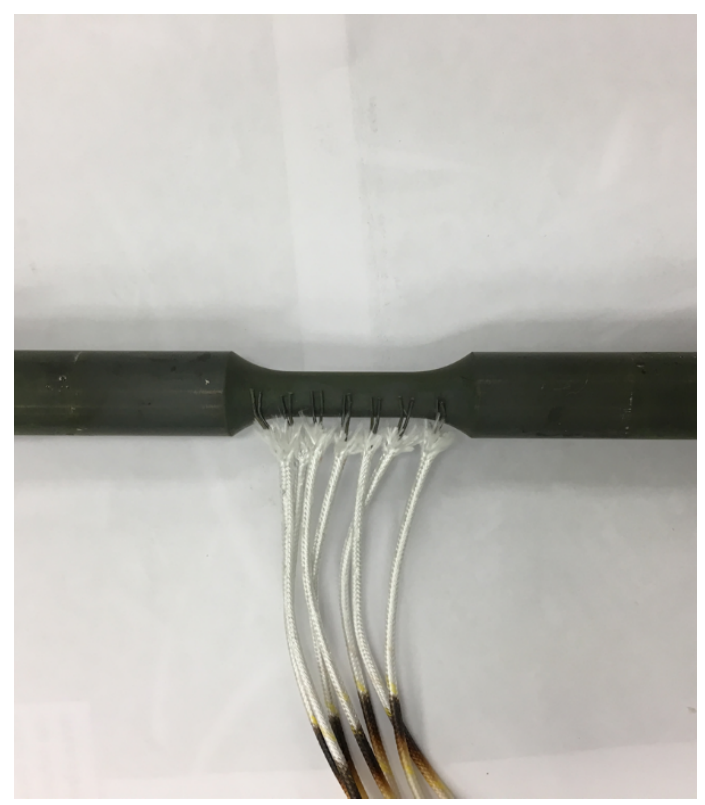

Figure 8. A temperature calibration sample with thermocouples on the shoulders and five thermocouples along the length of the gage section.

Fatigue and creep-fatigue tests were performed in accordance with ASTM E606 (Standard Test Method for Strain-Controlled Fatigue Testing) and ASTM 2714 (Standard Test Method for Creep-Fatigue Testing), respectively, at a temperature range from $750^{\circ} \mathrm{C}$ to $850^{\circ} \mathrm{C}$, and were strain controlled with strain ranges $(\Delta \varepsilon)$ between $0.4 \%$ and $1 \%$ total strain. The tests were fully reversed, so the $\Delta \varepsilon$ of $1 \%$ tests were 
performed from a $-0.5 \%$ peak compressive strain up to a $0.5 \%$ peak tensile strain. Tests were typically stopped prior to specimen fracture to protect the fracture surface and the extensometer. To consistently determine fatigue life, $\mathrm{N}_{25}$ is used, which represents fatigue life as the cycle that is $25 \%$ lower in stress from the point where the stress vs cycle plot deviates from linearity (the cycle where this deviation occurs is referred to as $\mathrm{N}_{0}$ ). For creep-fatigue testing, hold times between 10 minutes and 600 minutes were used, with 600 minutes representing actual component conditions with the diurnal thermal cycle.

Replicate fatigue testing of the $750^{\circ} \mathrm{C}, \Delta \varepsilon$ of $1 \%$ were performed on the induction heater frames to ensure that the data was equivalent to the testing performed in the 3zone furnaces. Specimens heated by the induction heater were found to have shorter lives and to reach peak stresses lower than expected for the conditions, as shown in Figure 9. These results are similar to tests performed at higher temperatures, and so it was determined that the temperature control was likely not performing correctly. Several attempts were made to correct this (e.g. thermocouple types were changed from an R type, to a thicker $\mathrm{K}$ type, to determine if eddy currents from the induction process were affecting the thin R-type wires), but no improvement was noted. Rather than expend additional resources attempting to determine the problem, it was decided that inductively heated tests would not be used for this project and all testing would continue on furnace frames. This was based on the determination that there would be sufficient time available on the furnace frames to complete the needed test matrix.

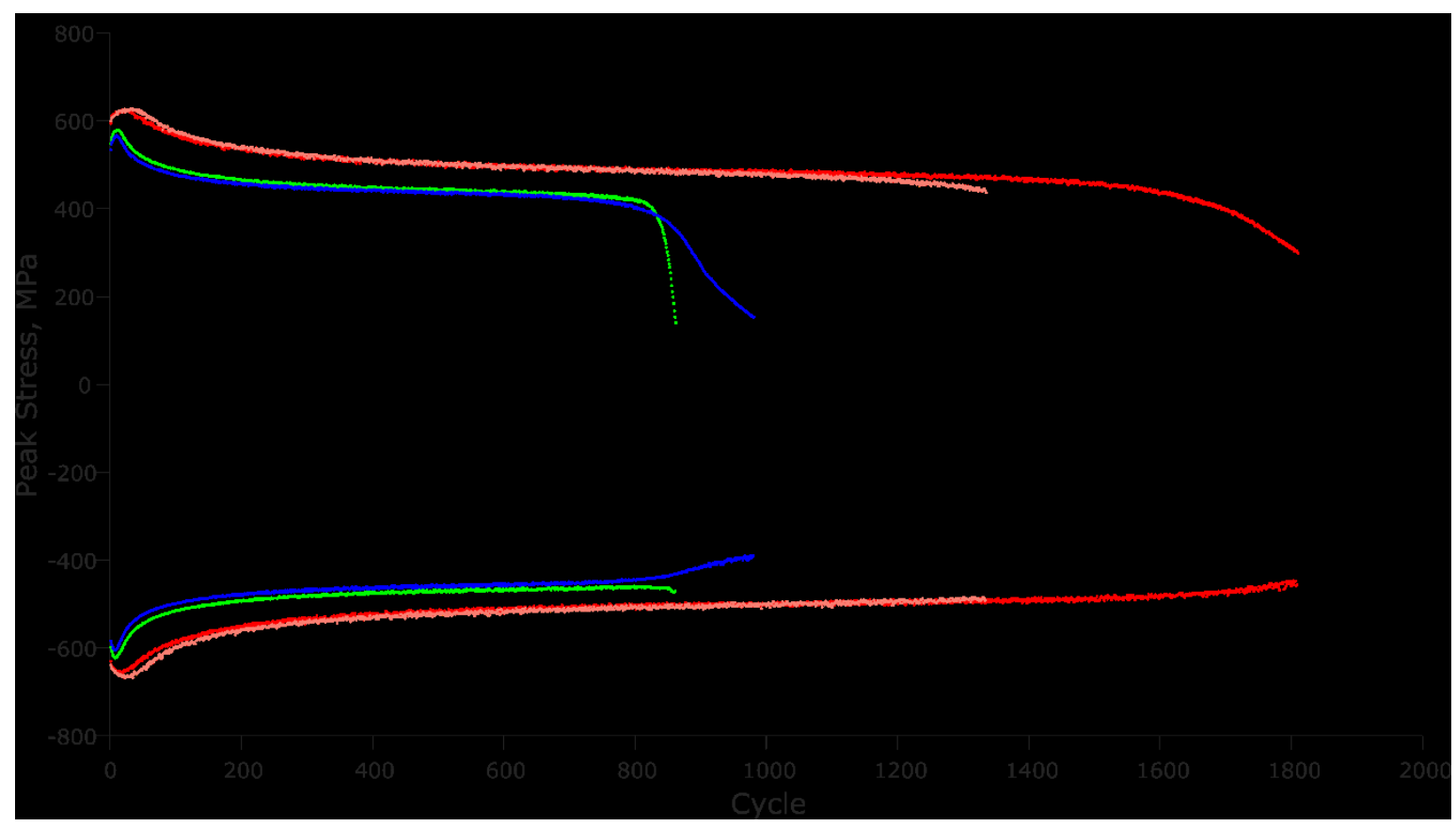

Figure 9. Comparison of fatigue results from two inductively heated specimens to two furnace heated specimens, with testing performed at $750^{\circ} \mathrm{C}$ with a $1 \% \Delta \varepsilon$.

The final preliminary test prior to completion of the actual test matrix was related to a concern with regards to the hold time during the creep-fatigue tests. Creep-fatigue tests are similar to fatigue tests but include a hold time (the creep portion of the test) typically at either the peak tensile or compressive stress. The creep-fatigue life, as well as the stress relaxation during the hold time, provide important inputs into the design models 
such as the creep-fatigue interaction diagram (the D-diagram). The choice of performing the hold time while in compression or tension should be based on which hold is more detrimental to the life of the specimen (this ensures that the design models are conservative rather than over-predicting the expected life).

Two initial tests were performed, one with a compressive stress hold and one with a tensile stress hold. For austenitic materials, the tensile stress hold is typically more detrimental and results in a shorter life, however, prior to moving forward with the entire test matrix, this needed to be confirmed. The results (peak stress vs cycle, hysteresis loops at cycle 10 and the mid cycle) are shown in Figure 10. The stress relaxation during the hold can be seen in the hysteresis loop in the form of the vertical line at the peak strains as stress decreases while strain is held constant. This is more clearly shown in the form of a stress relaxation curve (stress vs. time) as shown in Figure 11. From these results, the tensile hold is clearly the more detrimental of the two. All creepfatigue testing performed within this project for the formation of design models were performed with the hold time in tension.

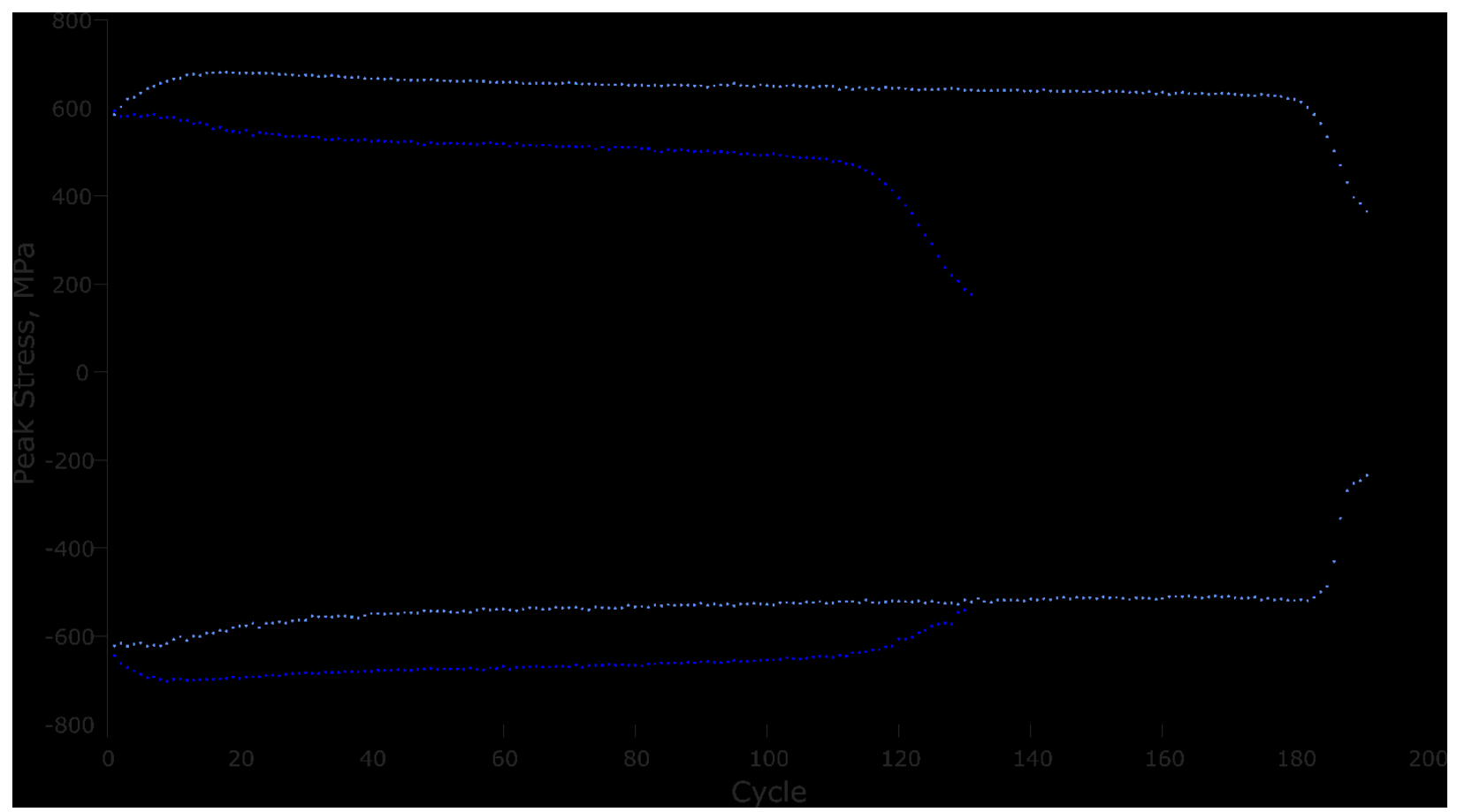

(a) 


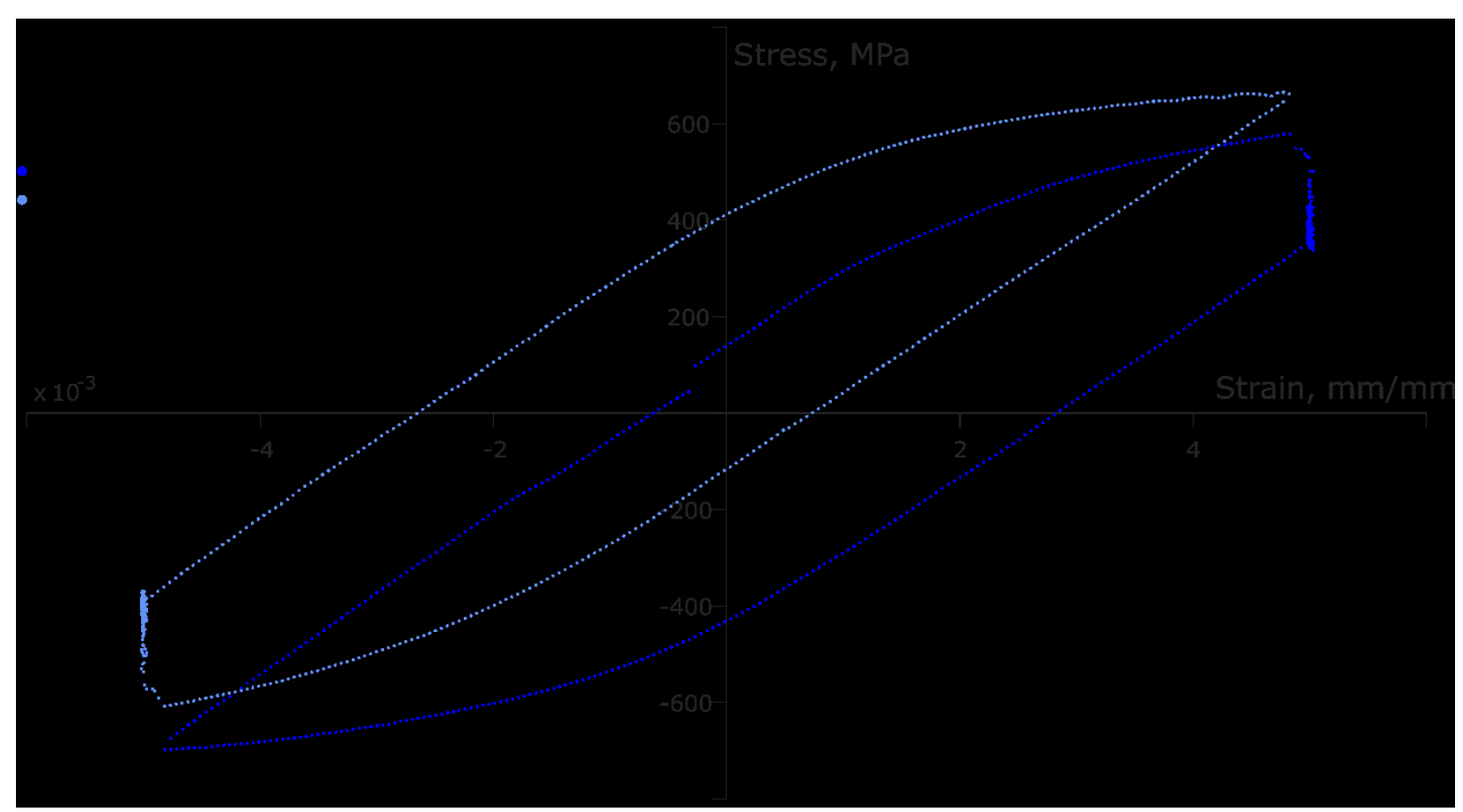

\section{(b)}

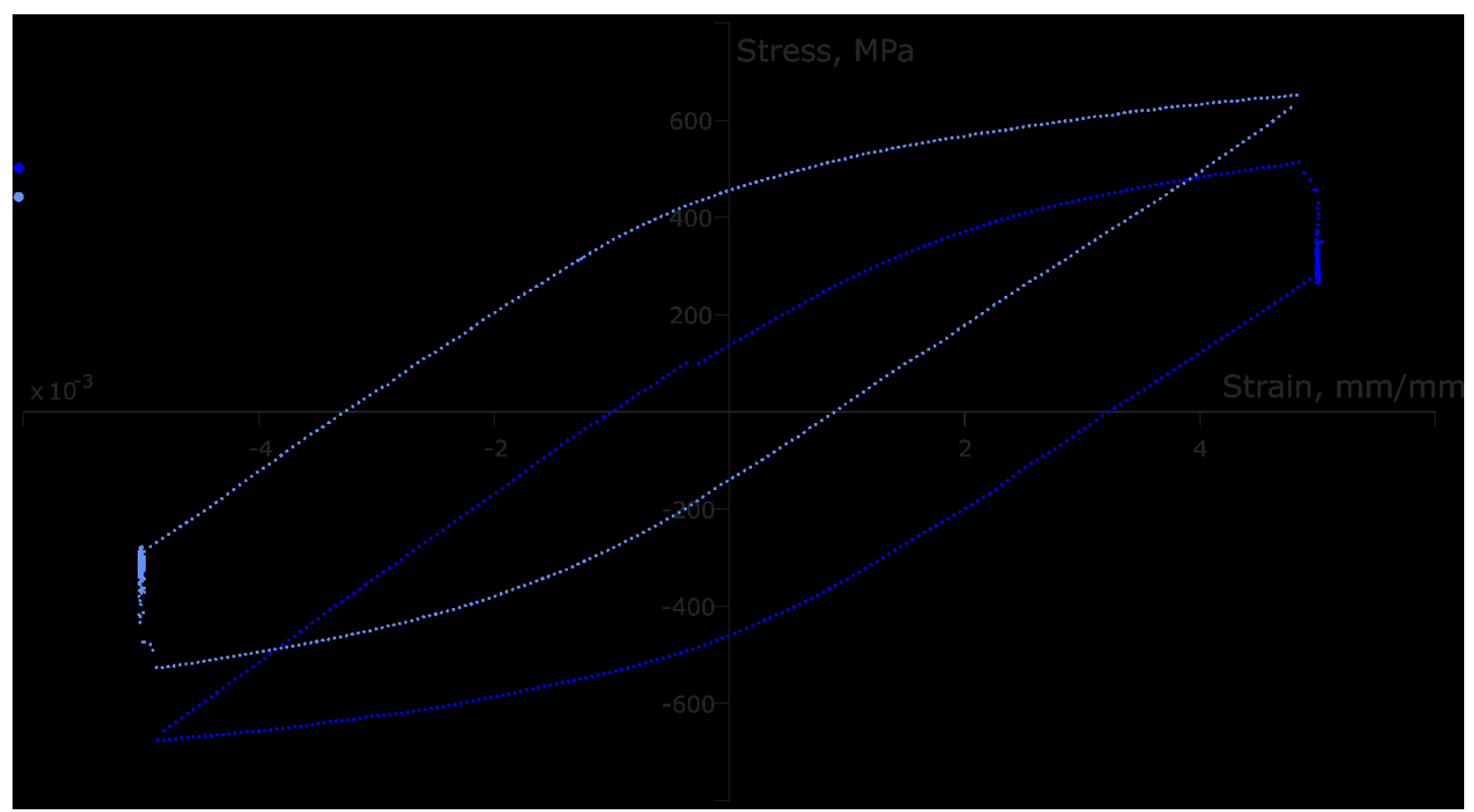

(c)

Figure 10. Creep-fatigue results for tests performed with a $\Delta \varepsilon$ of $1 \%$ and a 60 minute hold time. The graphs show (a) peak stresses vs cycle, (b) the hysteresis loop at cycle 10 and (c) the hysteresis loop at the mid cycle. 


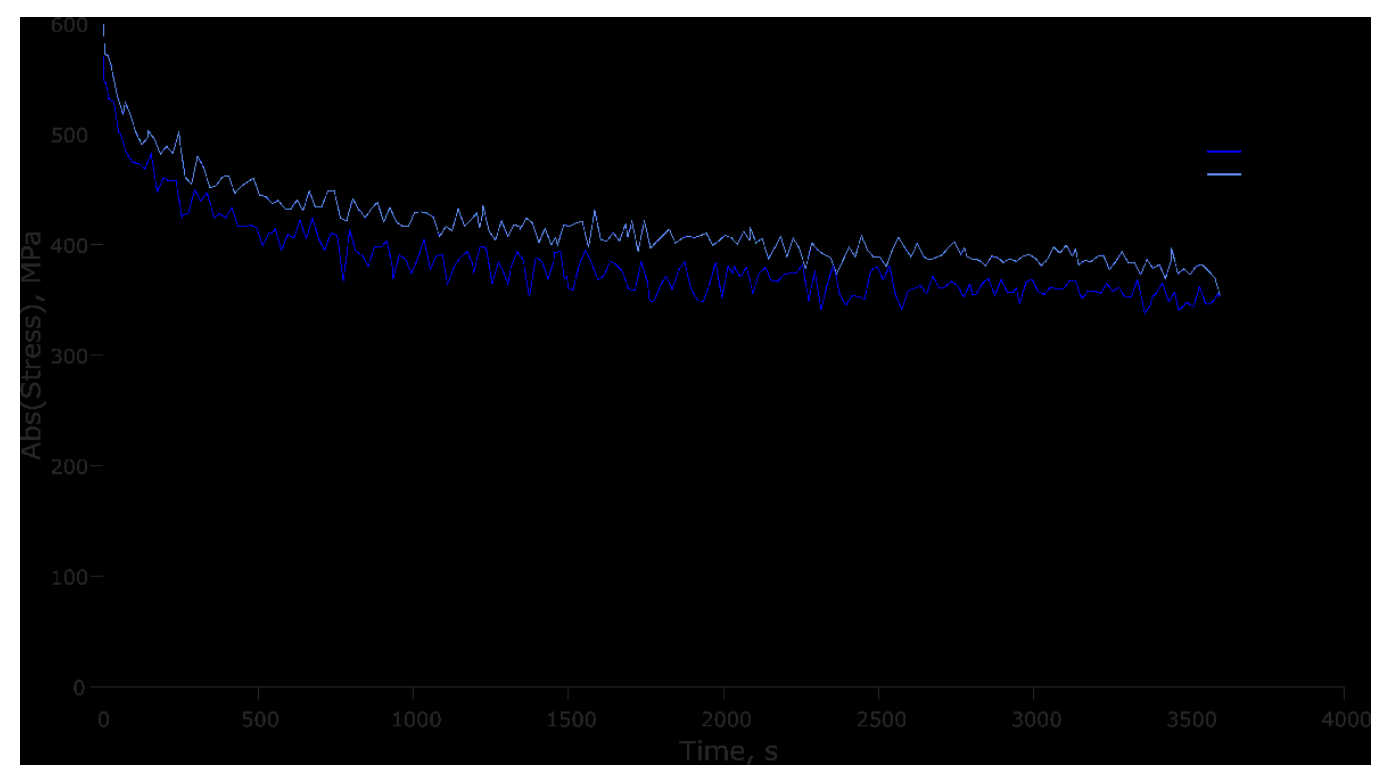

(a)

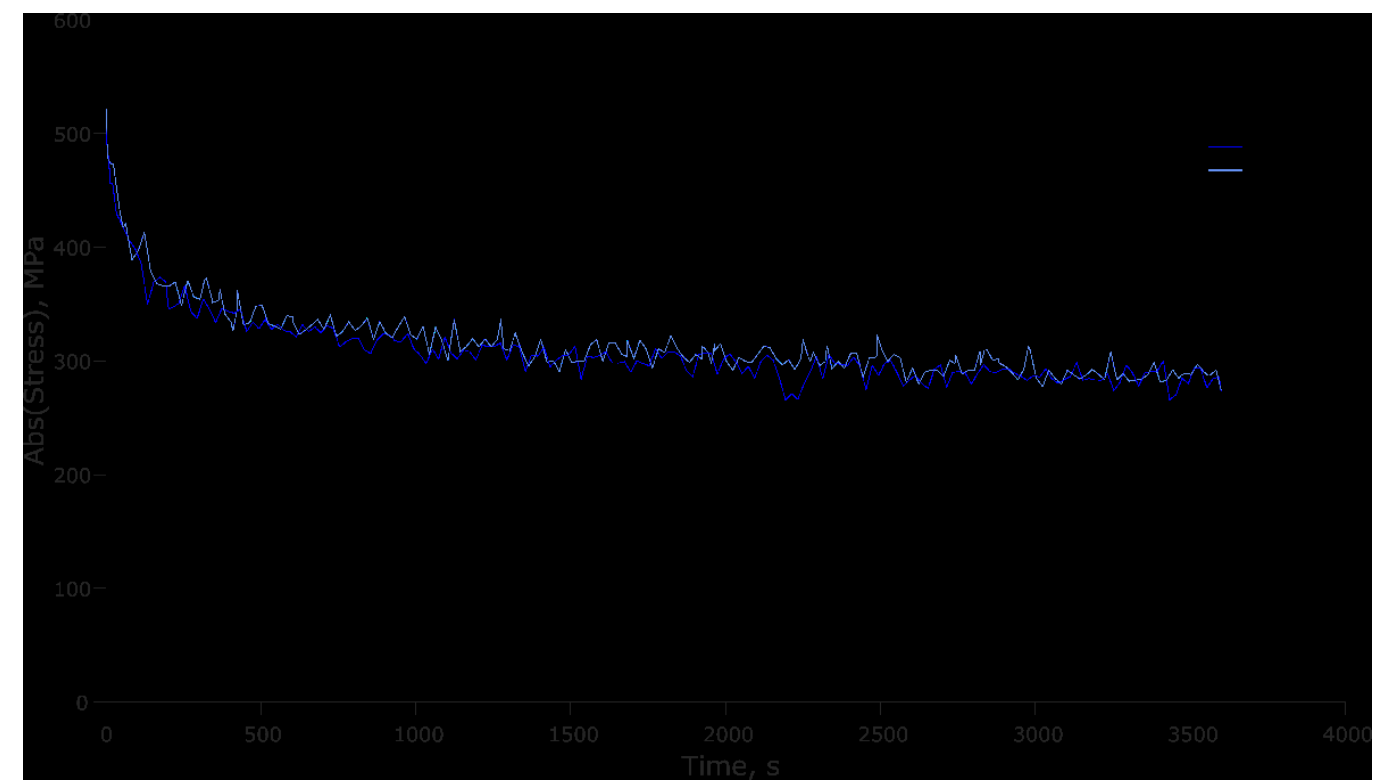

(b)

Figure 11. Stress relaxation for the hold time at (a) cycle 10 and (b) the mid-cycle.

Data from a total of 11 fatigue and 15 creep-fatigue tests performed on Alloy $740 \mathrm{H}$ plate were used in Task 2 of this project to recommend design models. Five additional fatigue tests were discarded due to the use of induction heating, which, as stated, was found to be inconsistent and less reliable than the furnace testing. The entire data set is shown in Table 6. 
Table 6. Summary of Alloy $740 \mathrm{H}$ fatigue and creep-fatigue testing performed at INL. Tests that were not used in the design models are highlighted in red. 


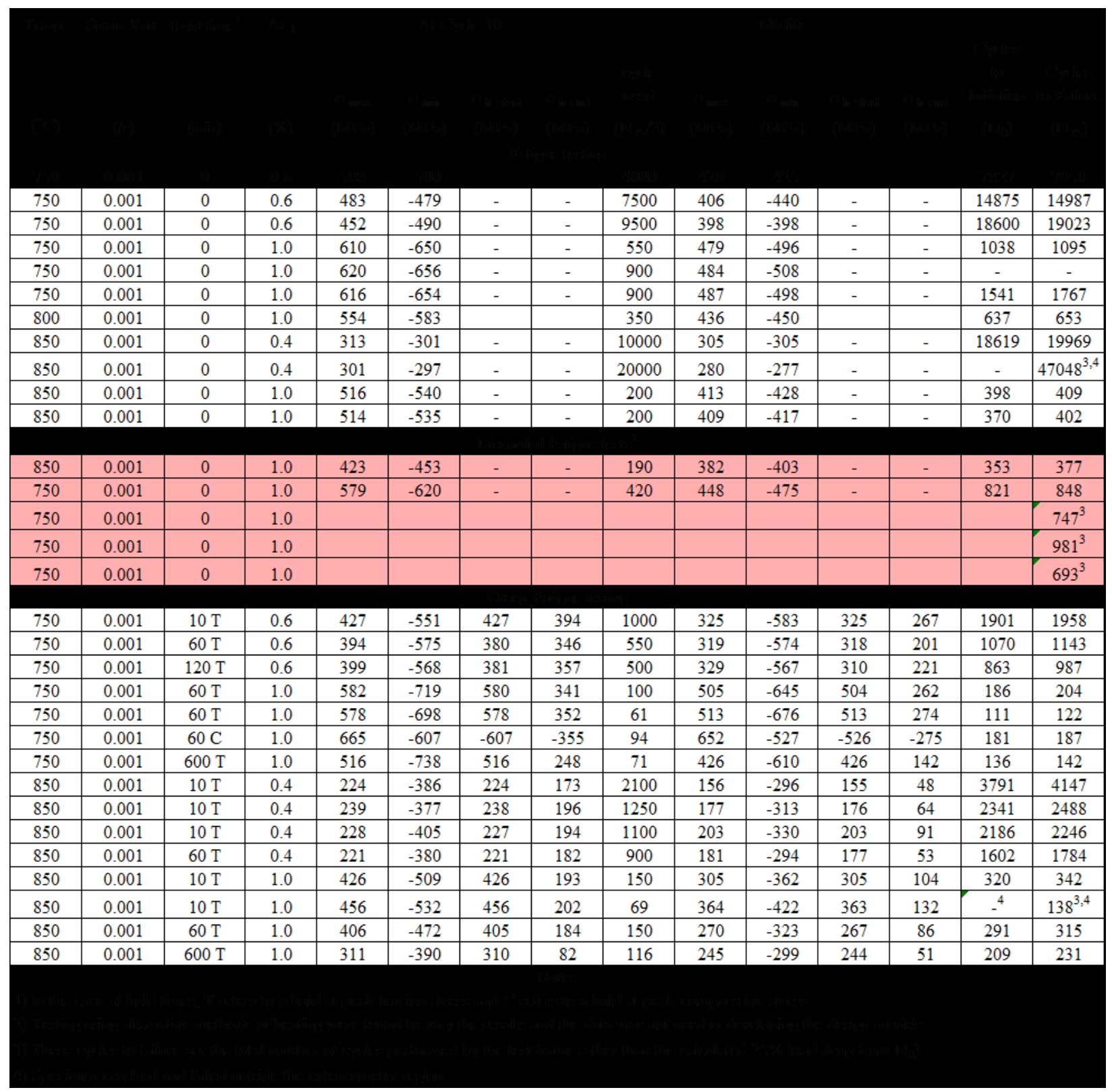

In creep-fatigue testing, cycles to failure, the shape of the hysteresis loop and the stress relaxation curve all contribute to the resulting design models. All of the fatigue and creep-fatigue results from this testing program are shown in figures 12, 14, 16 and 18. Fatigue and creep fatigue at similar conditions are shown in the same figure for comparison with creep-fatigue. In all cases, creep-fatigue caused a decrease in total cycles to failure when compared to fatigue at similar conditions. It is a significant decrease in life ( $80 \%$ decrease in life cycles) in all cases, with the exception of the tests at $850{ }^{\circ} \mathrm{C}$ and a strain range of $1 \%$. This is likely a result of the extremely aggressive test condition, even in pure fatigue - the fatigue life is approximately 425 cycles, as compared to 1700 cycles, the approximate life at $750{ }^{\circ} \mathrm{C}$ with the same strain range.

Figure 13, 15, 17 and 19 show examples of the hysteresis loops (strain vs stress) for cycle 10 and at the mid-life cycle (approximately half of the final life). The specimens 
undergo work softening, indicative by the increase in plastic strain (width of the loop) in the mid-life cycle as compared to cycle 10.

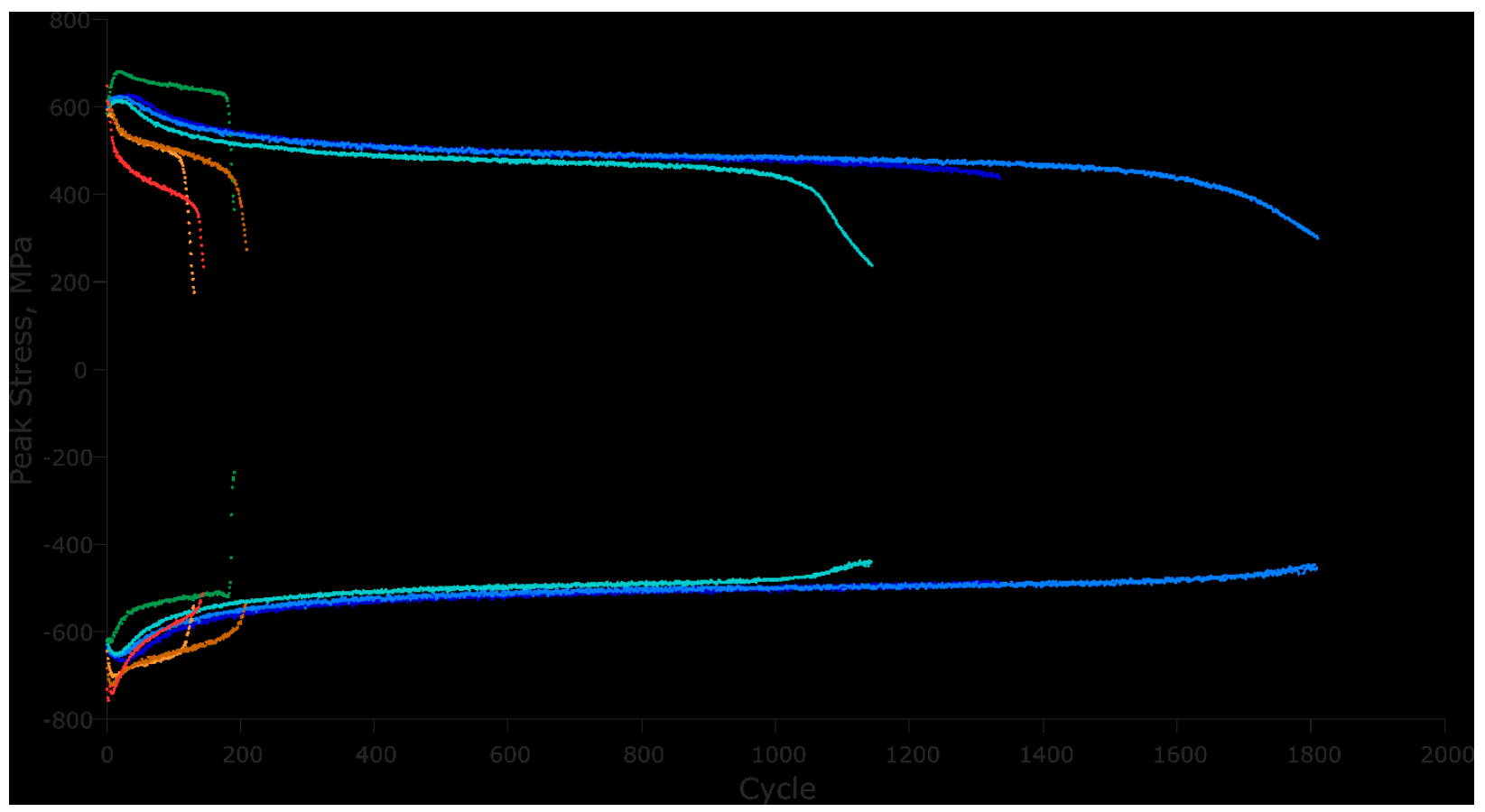

Figure 12: Peak stress vs cycle of fatigue and creep fatigue testing on Alloy $740 \mathrm{H}$ at $750{ }^{\circ} \mathrm{C}$ and a strain range of $1 \%$.

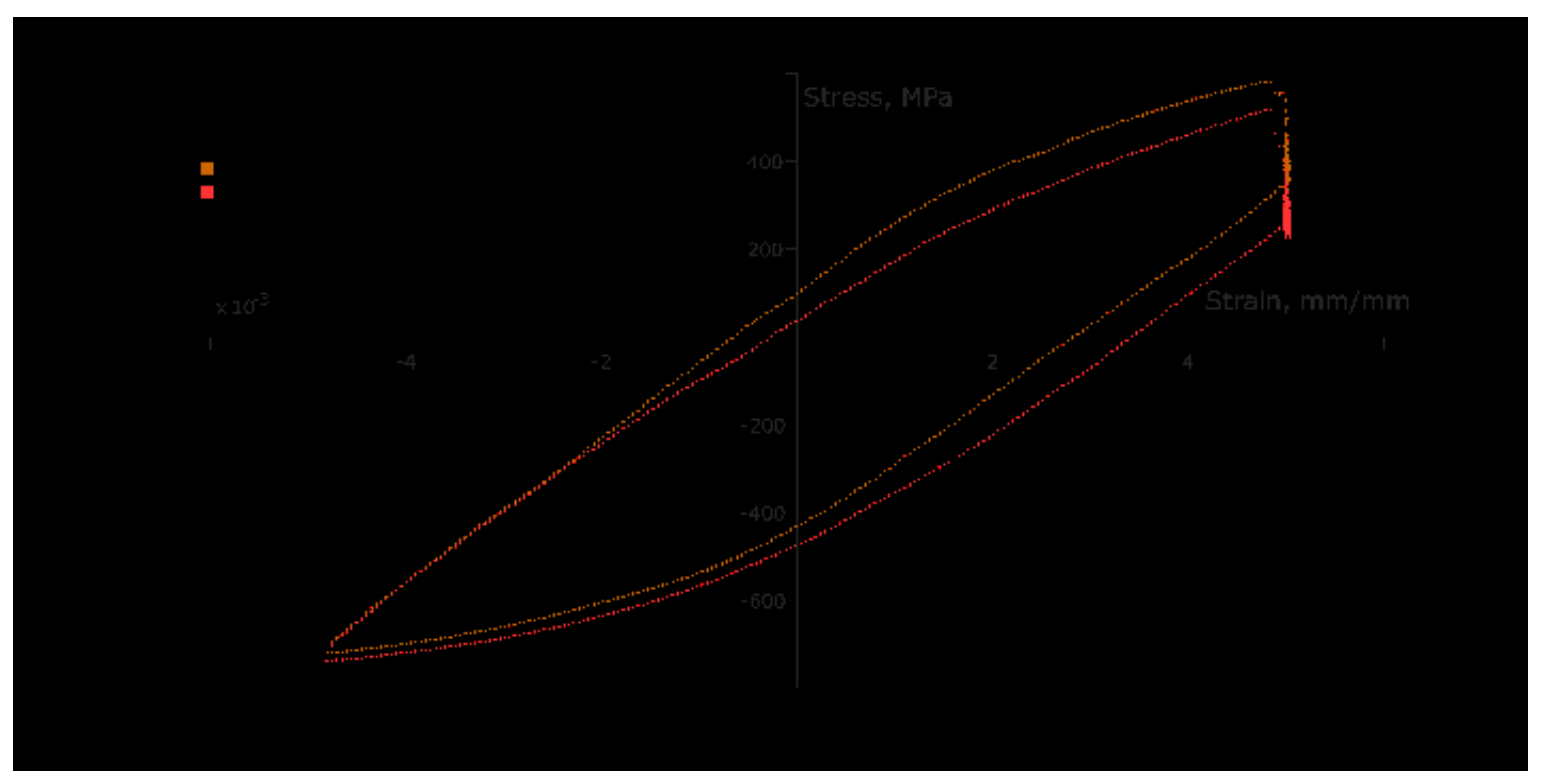

(a) 


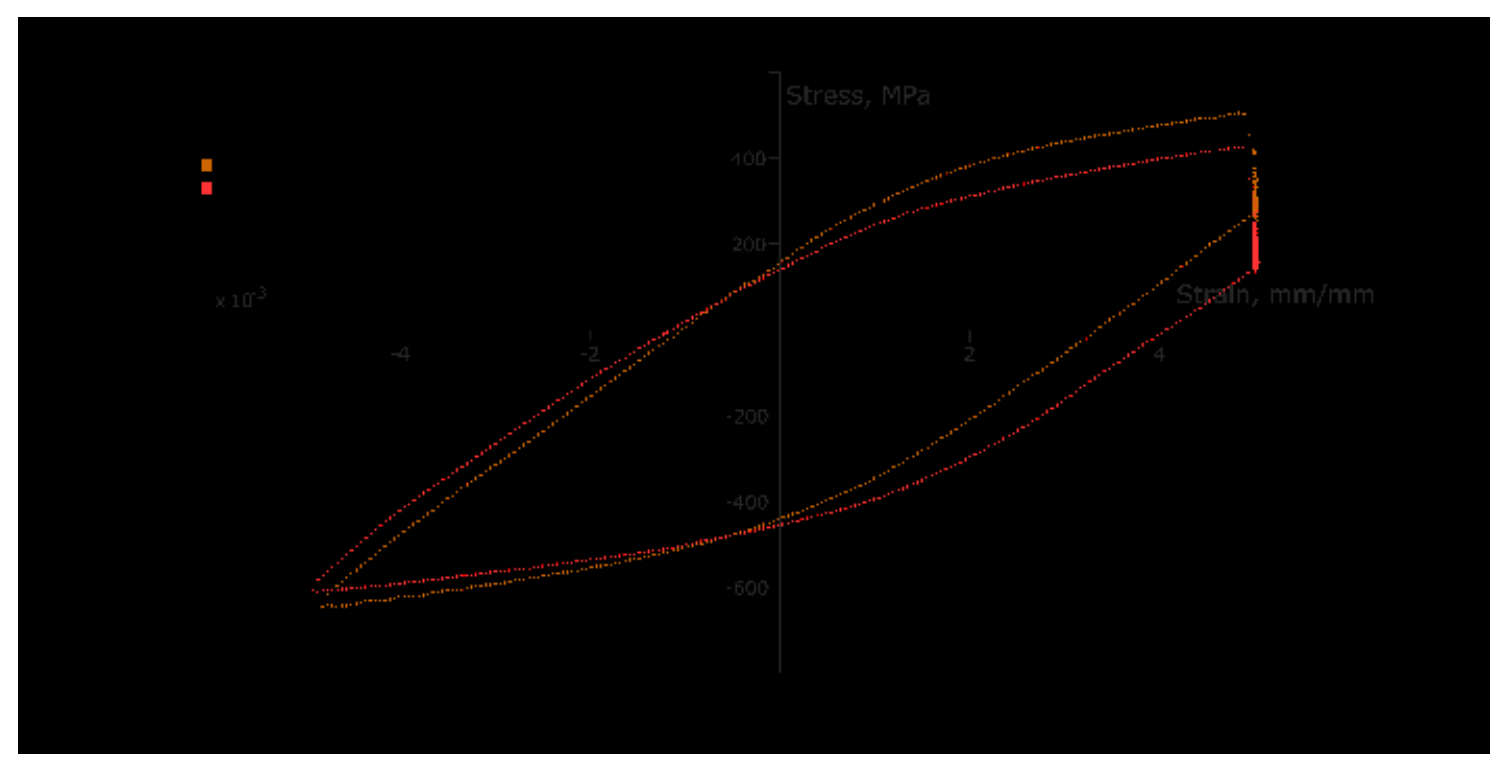

(b)

Figure 13: Example hysteresis loops at cycle 10 (a) and the mid-life cycle (b) for Alloy $740 \mathrm{H}$ tested at $750^{\circ} \mathrm{C}$ and a strain range of $1 \%$.

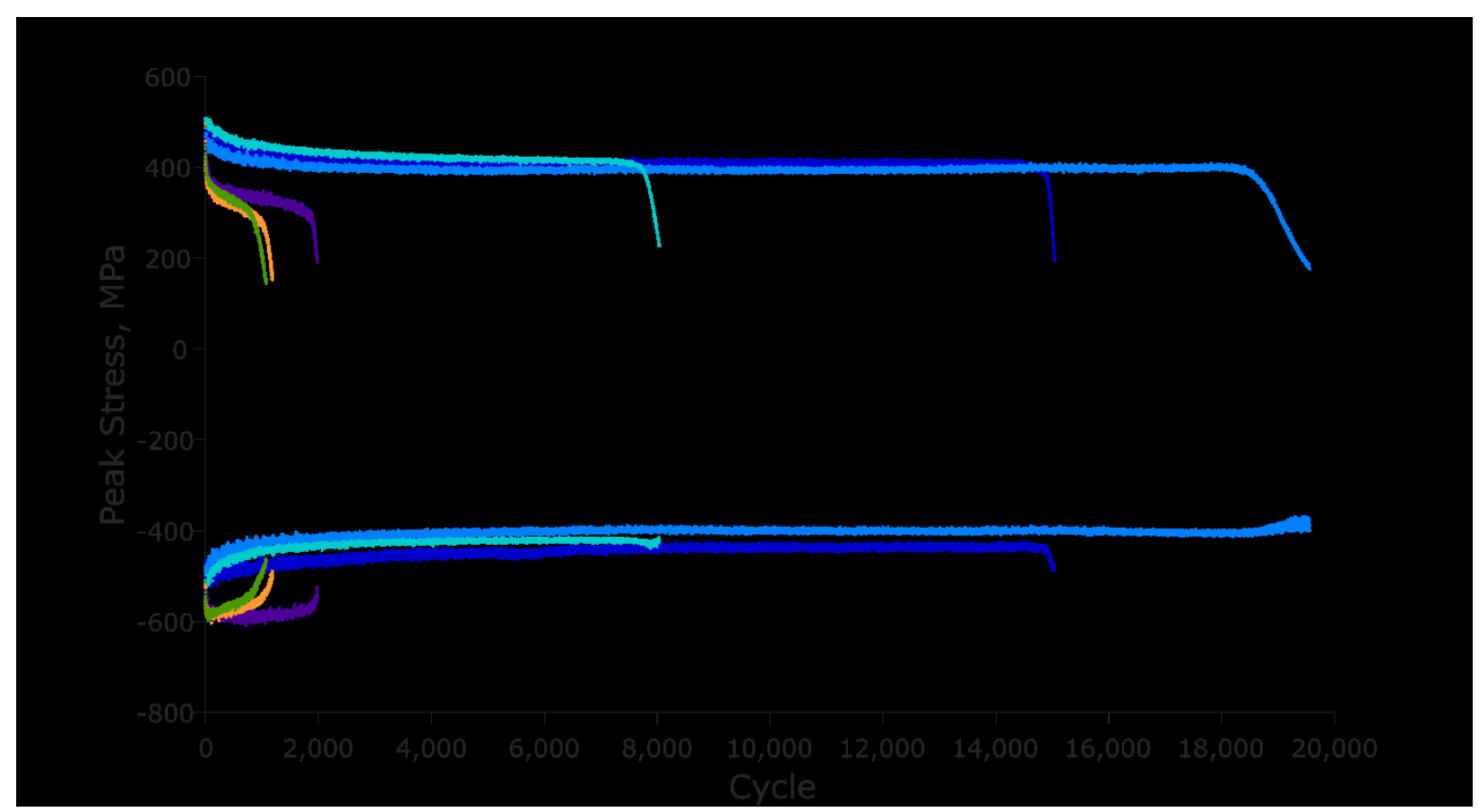

Figure 14: Peak stress vs cycle of fatigue and creep fatigue testing on Alloy $740 \mathrm{H}$ at $750{ }^{\circ} \mathrm{C}$ and a strain range of $0.6 \%$. 


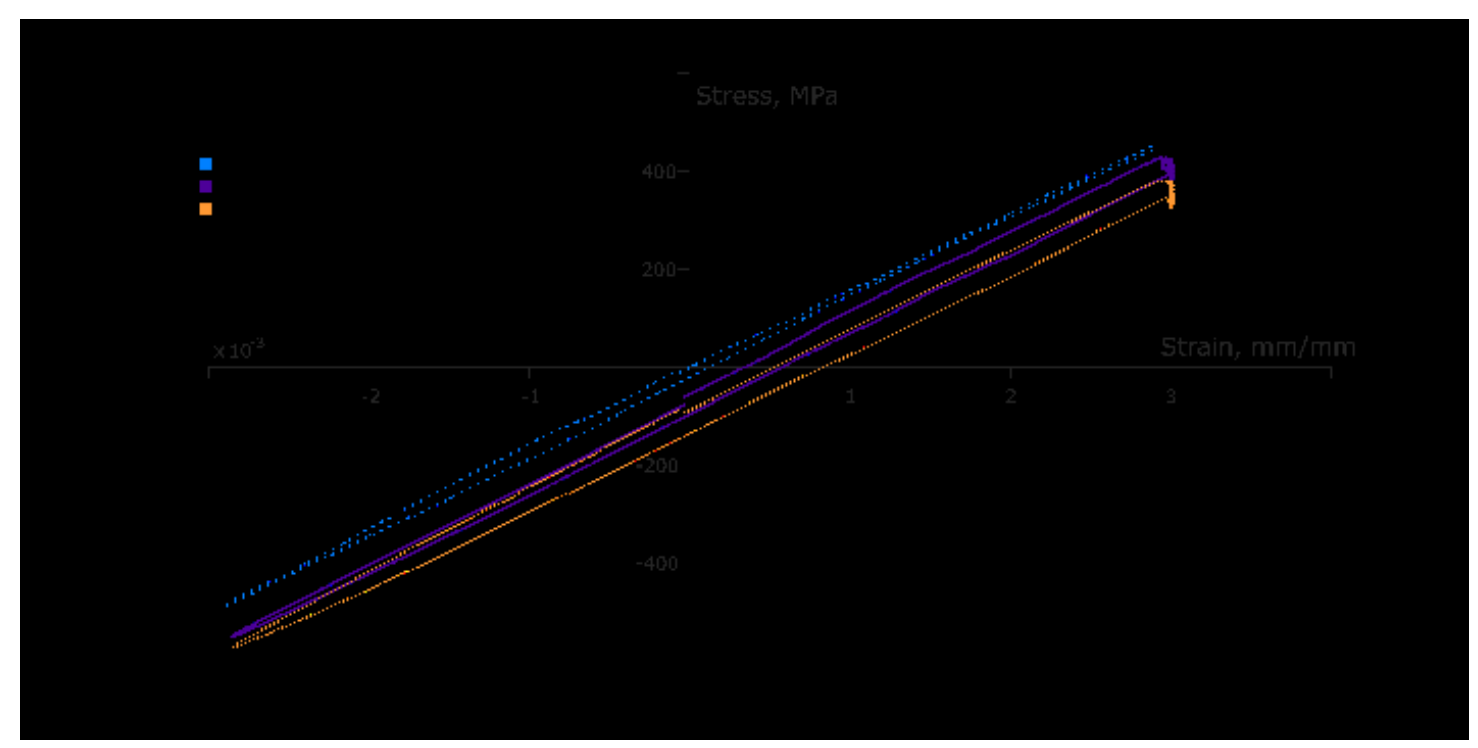

(a)

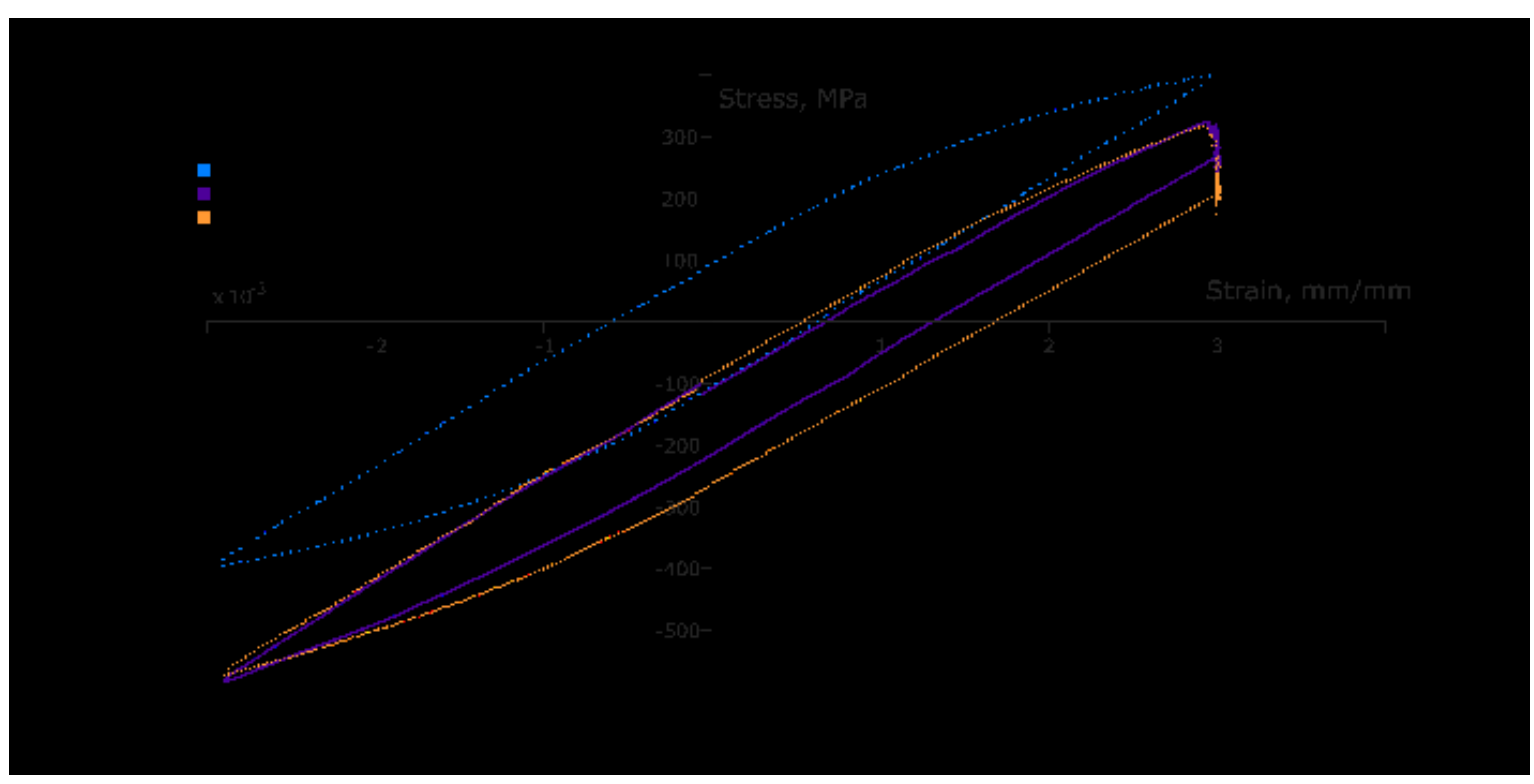

(b)

Figure 15: Examples of hysteresis loops at cycle 10 (a) and the mid-life cycle (b) for Alloy $740 \mathrm{H}$ tested at $750^{\circ} \mathrm{C}$ and a strain range of $0.6 \%$. 


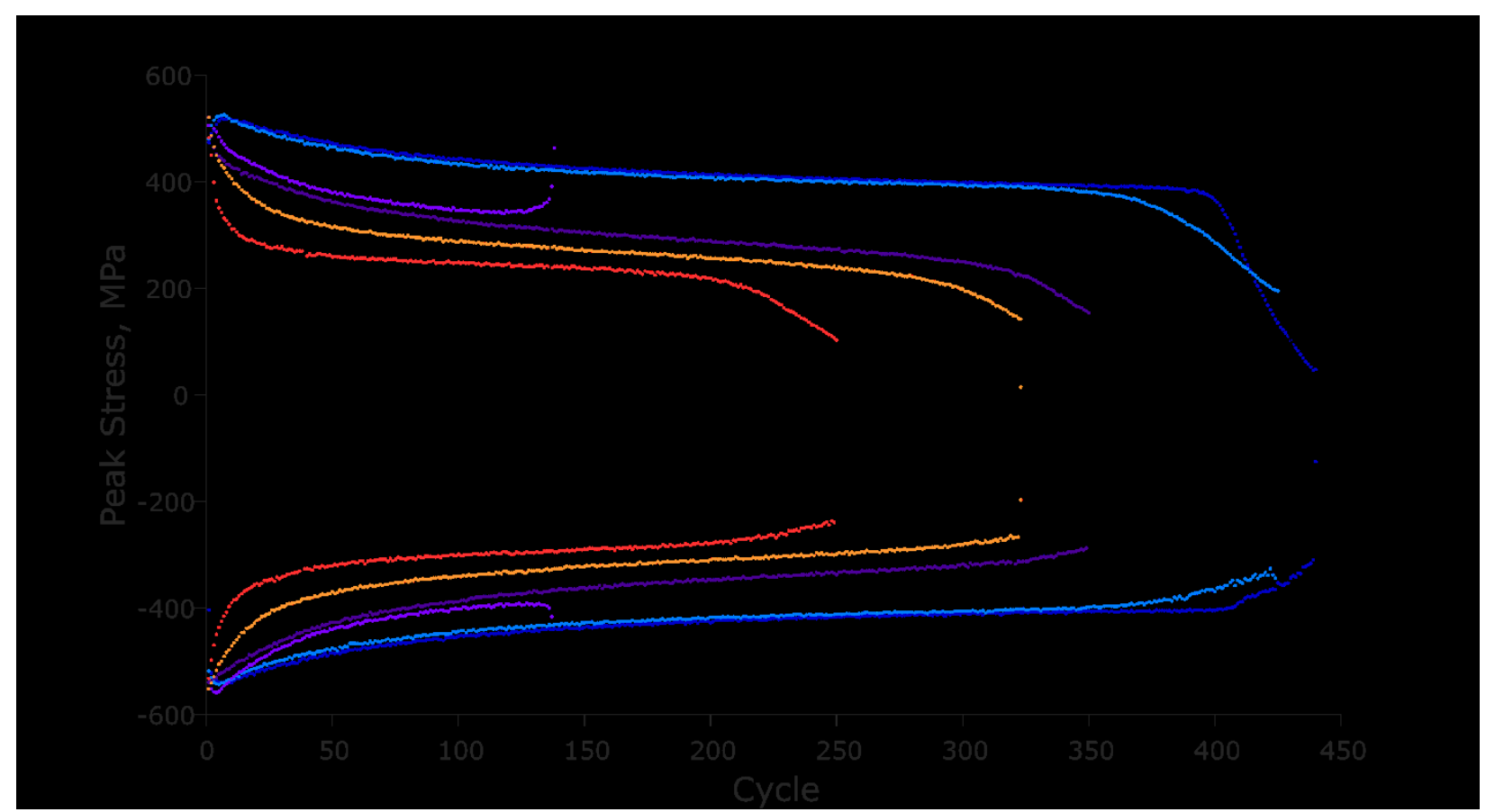

Figure 16: Peak stress vs cycle of fatigue and creep fatigue testing on Alloy $740 \mathrm{H}$ at $850{ }^{\circ} \mathrm{C}$ and a strain range of $1 \%$.

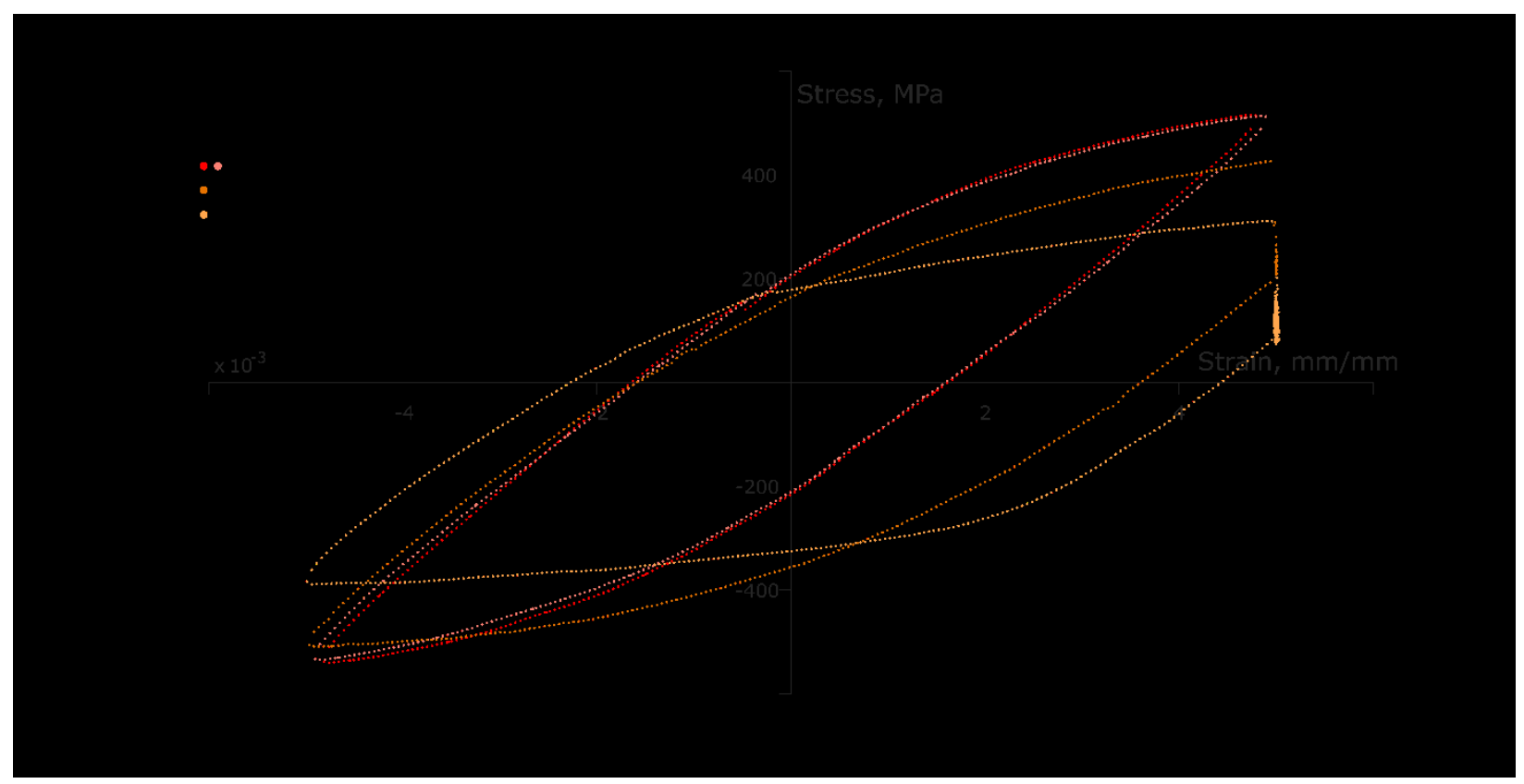

(a) 


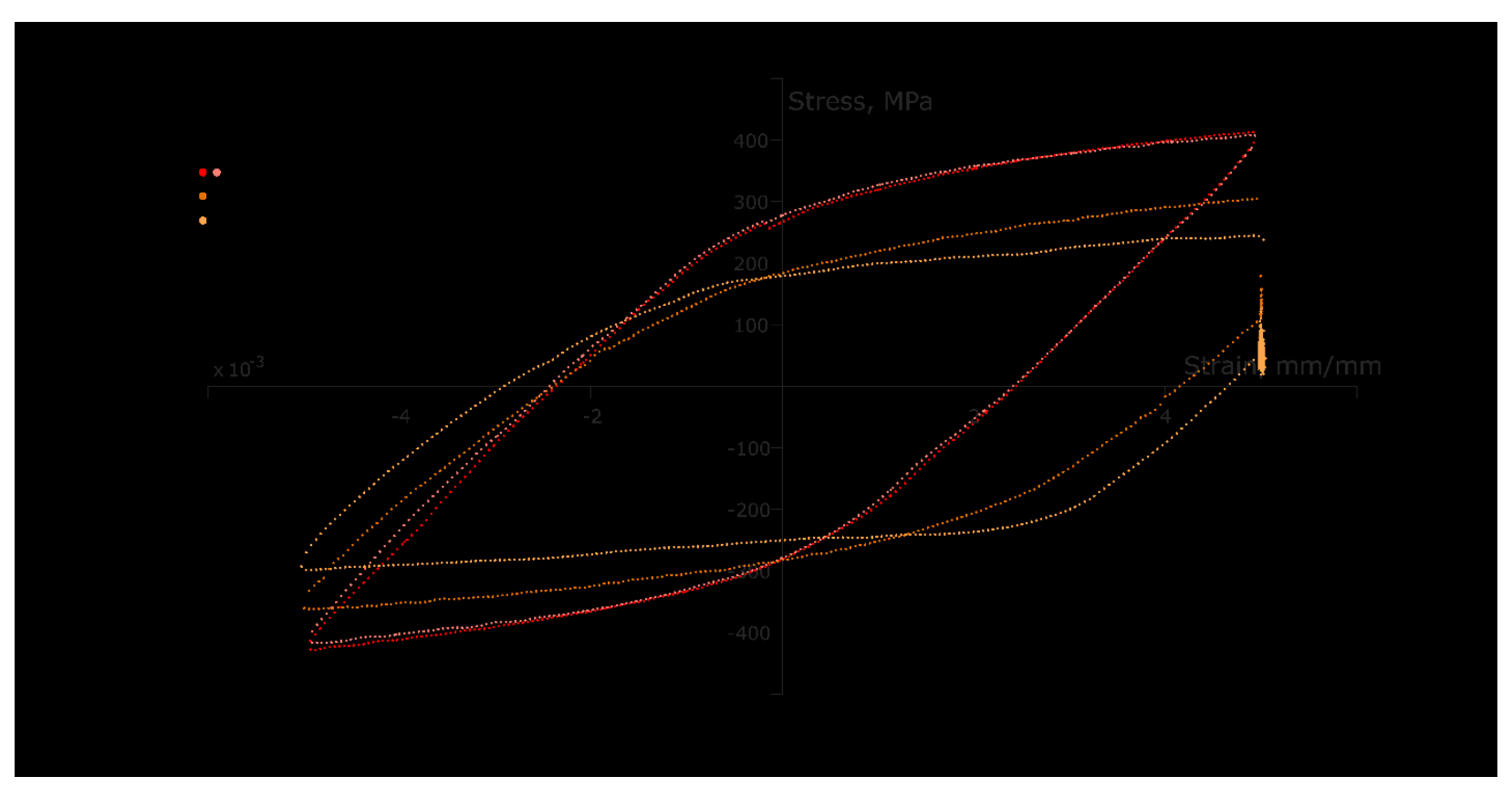

(b)

Figure 17: Examples of hysteresis loops at cycle 10 (a) and the mid-life cycle (b) for Alloy $740 \mathrm{H}$ tested at $850^{\circ} \mathrm{C}$ and a strain range of $1 \%$.

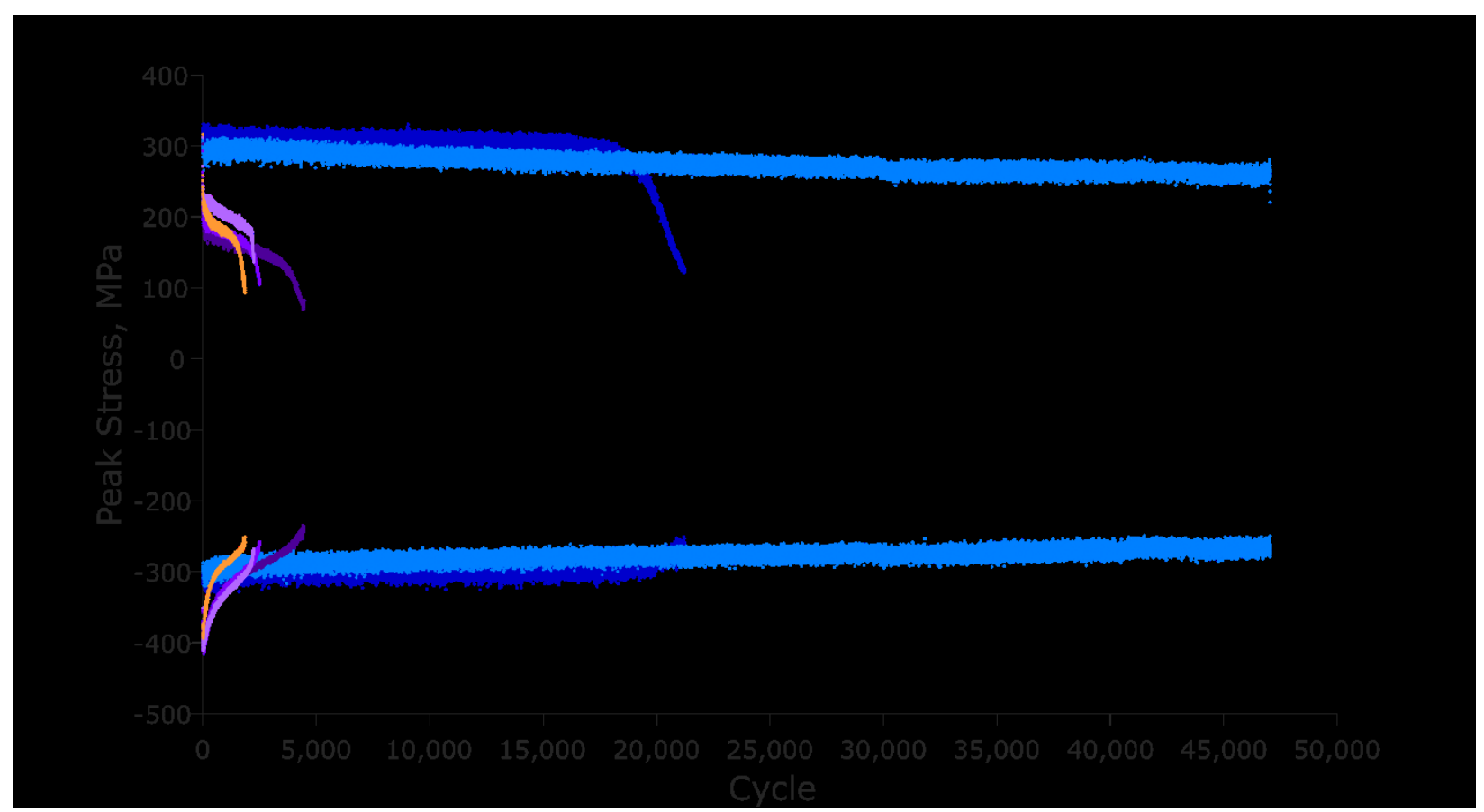

Figure 18: Peak stress vs cycle of fatigue and creep fatigue testing on Alloy $740 \mathrm{H}$ at $850{ }^{\circ} \mathrm{C}$ and a strain range of $0.4 \%$. 


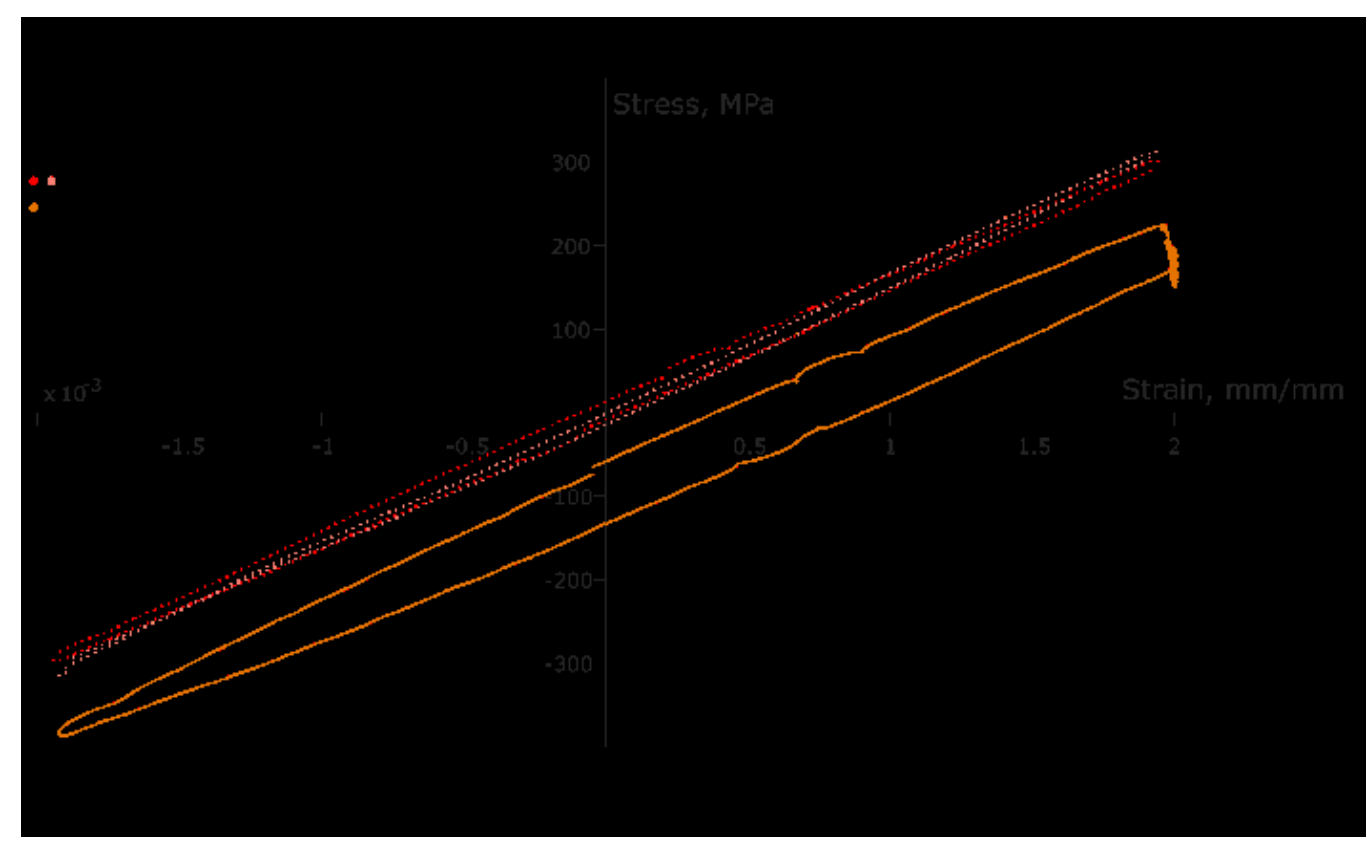

(a)

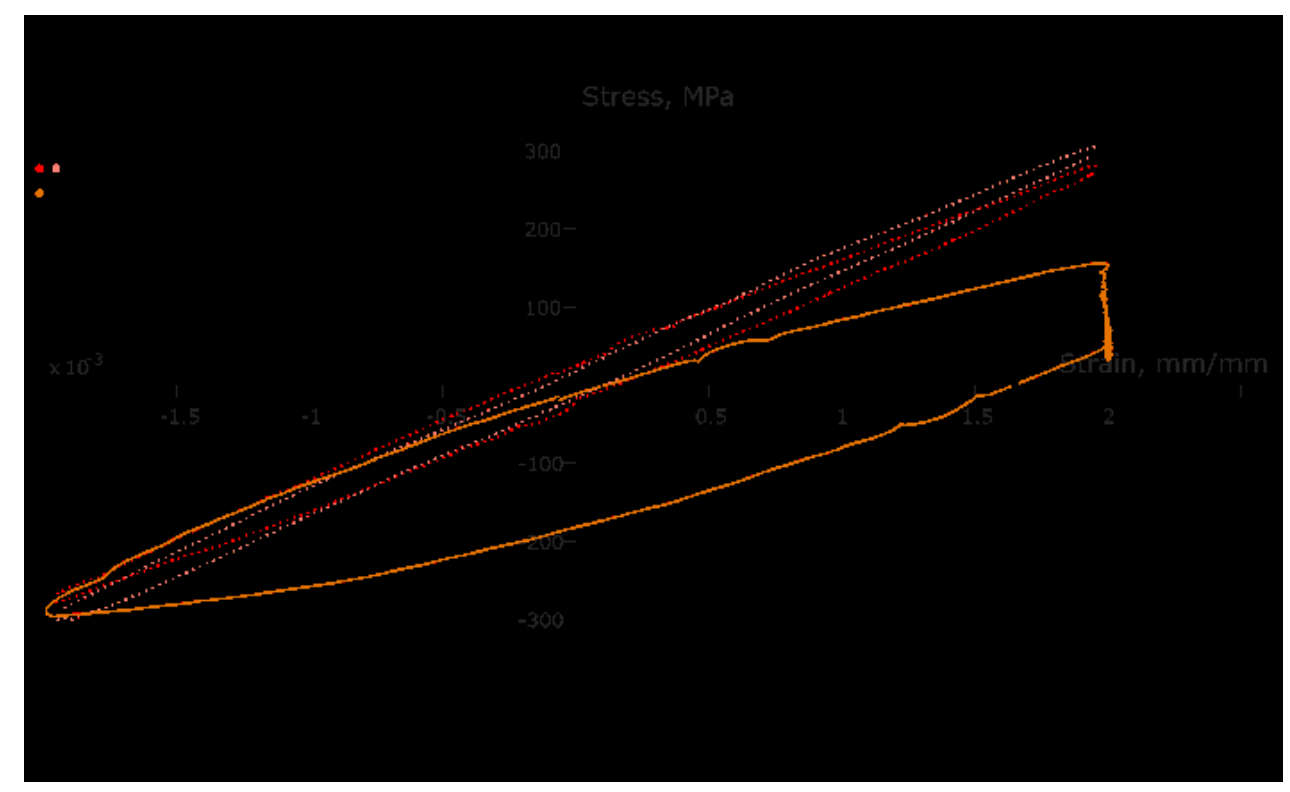

(b)

Figure 19: Examples of hysteresis loops at cycle 10 (a) and the mid-life cycle (b) for Alloy $740 \mathrm{H}$ tested at $850^{\circ} \mathrm{C}$ and a strain range of $0.4 \%$.

Figures 20-25 show the stress relaxation during the peak tension hold for the new creep-fatigue tests. In some cases, such as Figures 22 and 24, there is little relaxation until the material has work softened (which has happened by the mid-cycle - Figures 23 and 25), at which point, there is significant stress relaxation occurring immediately at the start of the hold. 


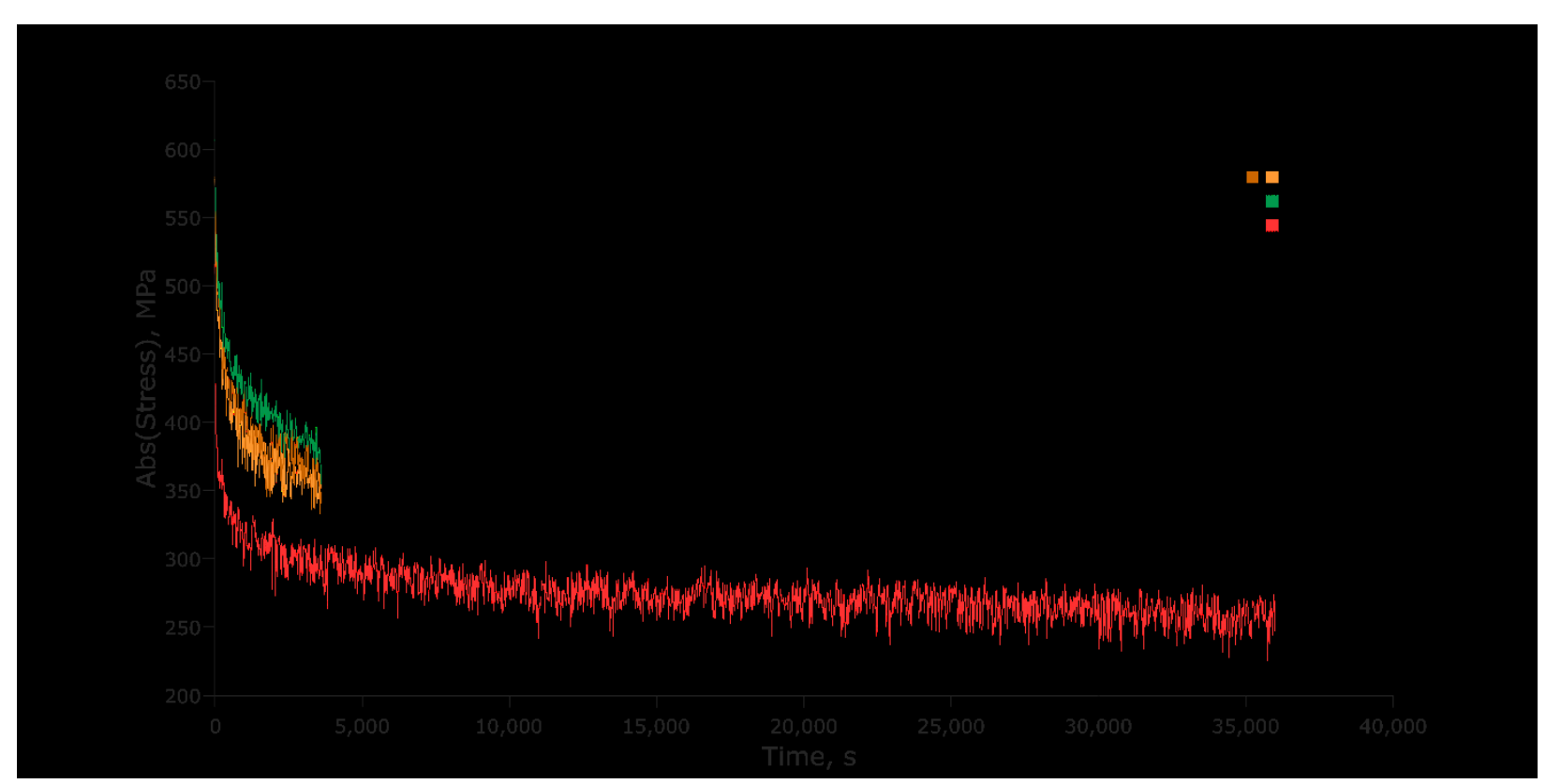

Figure 20: Stress relaxation during creep hold portion of creep-fatigue test on cycle 10 for Alloy $740 \mathrm{H}$ tested at $750^{\circ} \mathrm{C}$ with a strain range of $1 \%$.

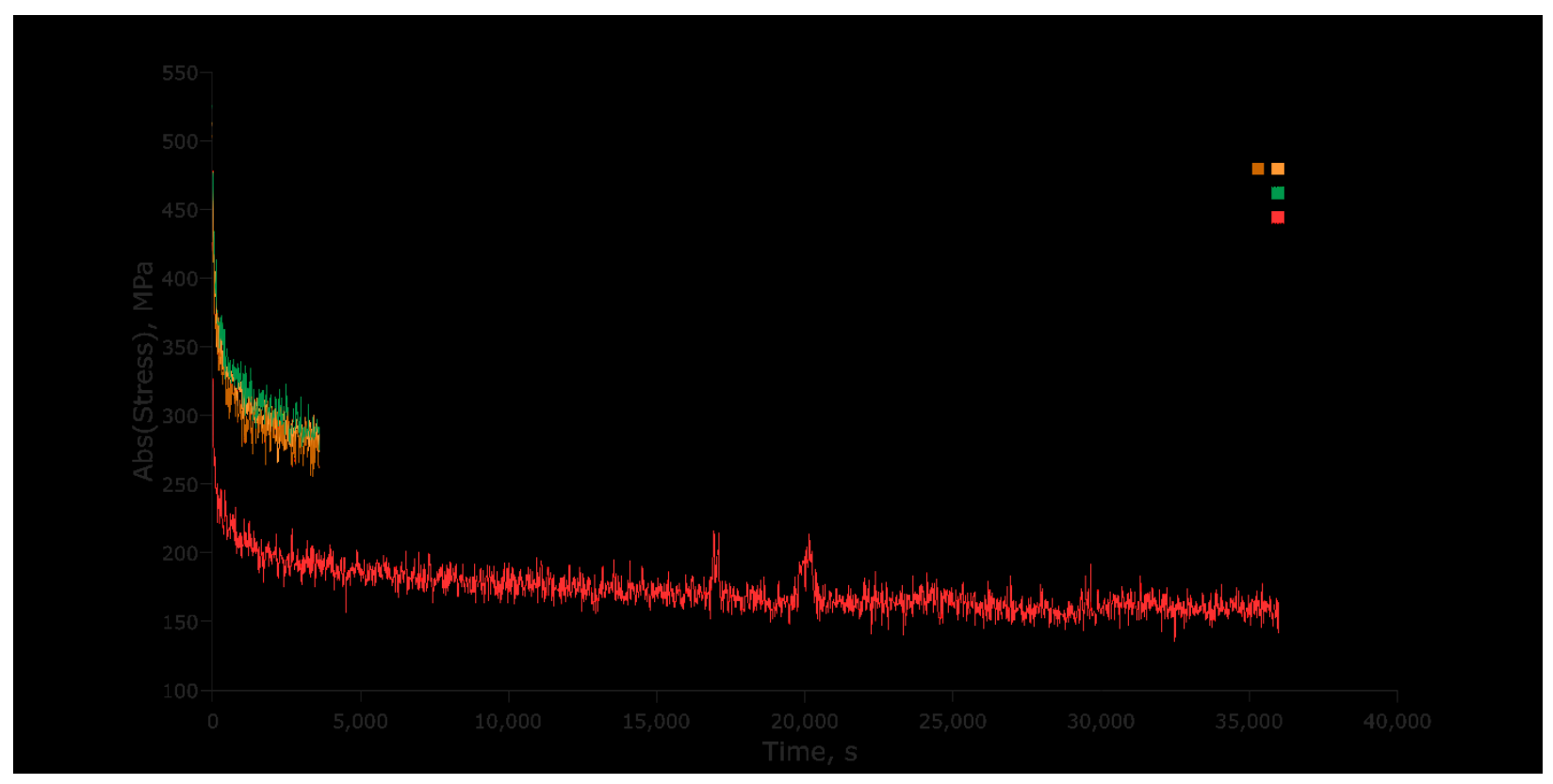

Figure 21: Stress relaxation during creep hold portion of creep-fatigue test on the mid-life cycle for Alloy $740 \mathrm{H}$ tested at $750^{\circ} \mathrm{C}$ with a strain range of $1 \%$. 


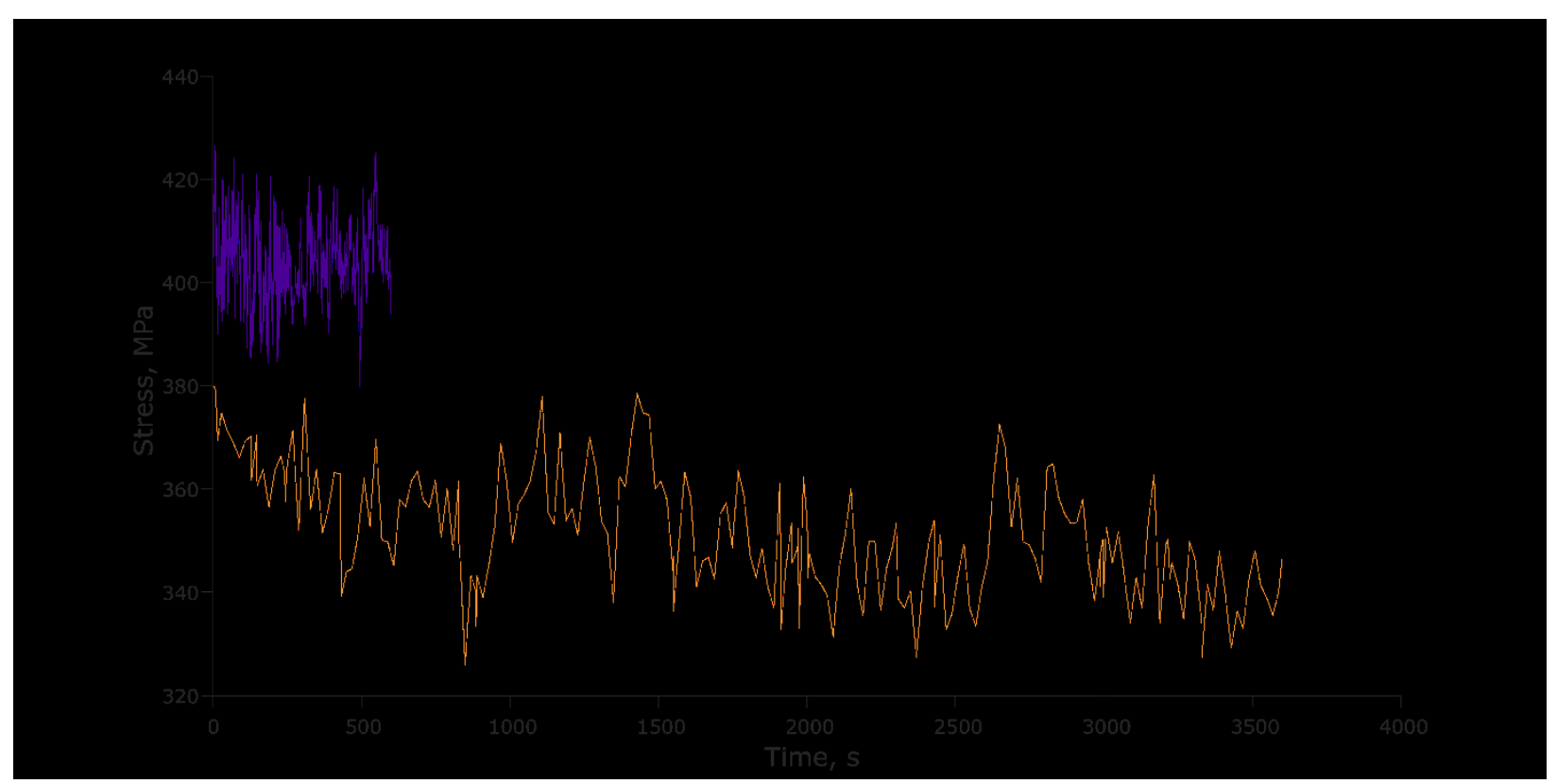

Figure 22: Stress relaxation during creep hold portion of creep-fatigue test on cycle 10 for Alloy $740 \mathrm{H}$ tested at $750^{\circ} \mathrm{C}$ with a strain range of $0.6 \%$.

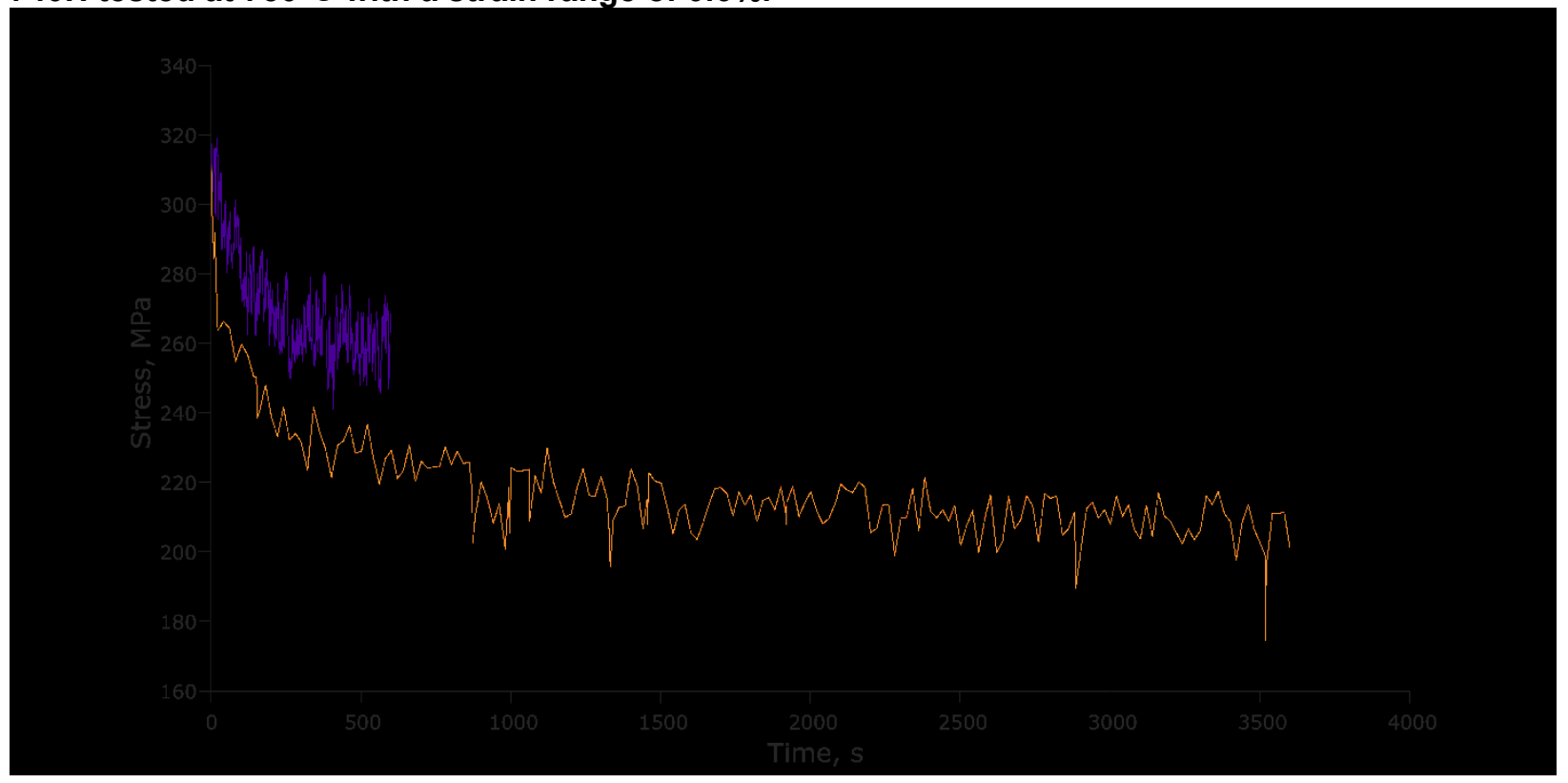

Figure 23: Stress relaxation during creep hold portion of creep-fatigue test on the mid-life cycle for Alloy $740 \mathrm{H}$ tested at $750^{\circ} \mathrm{C}$ with a strain range of $0.6 \%$. 


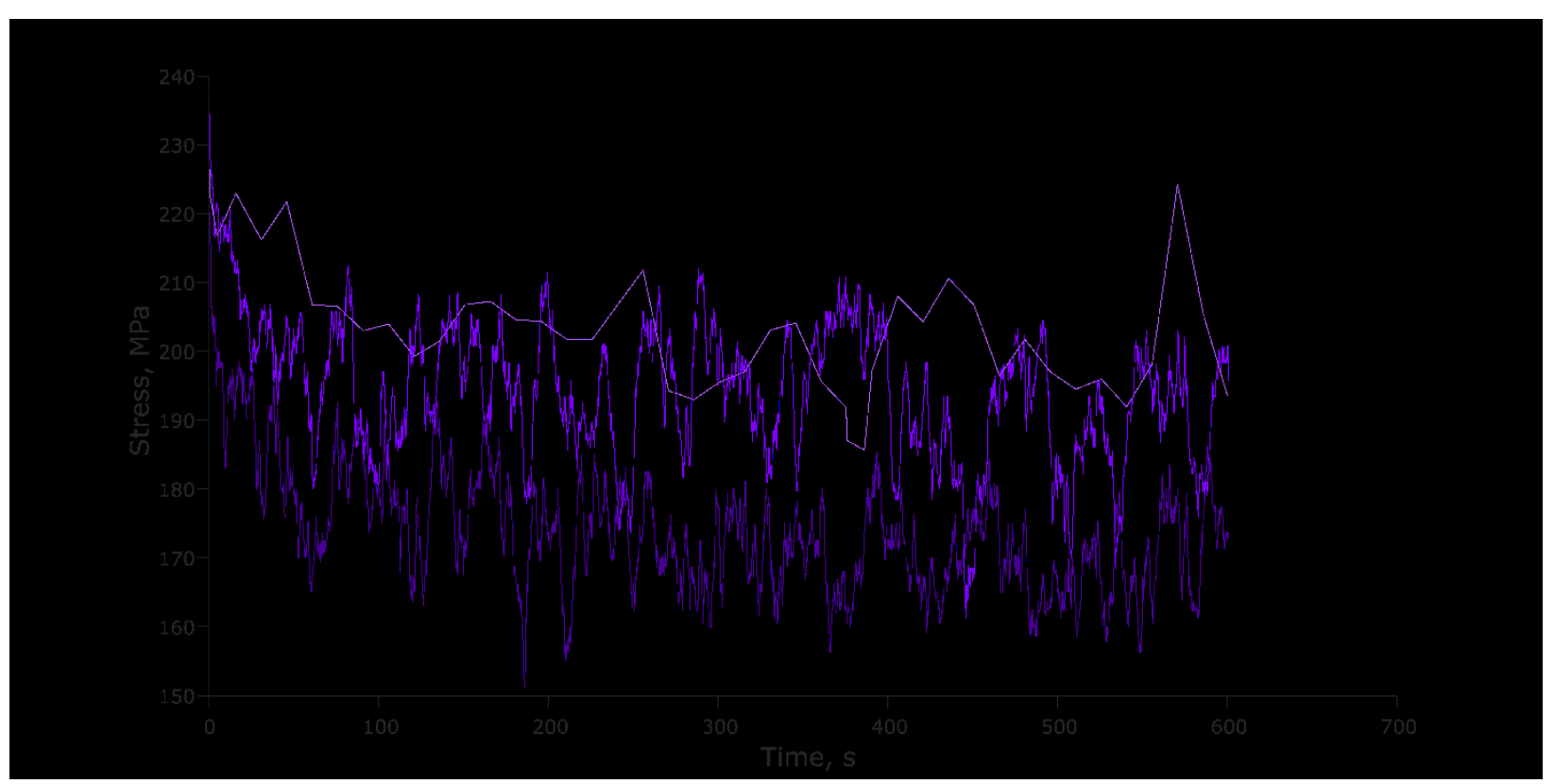

Figure 24: Stress relaxation during creep hold portion of creep-fatigue test on cycle 10 for Alloy $740 \mathrm{H}$ tested at $850^{\circ} \mathrm{C}$ with a strain range of $0.4 \%$.

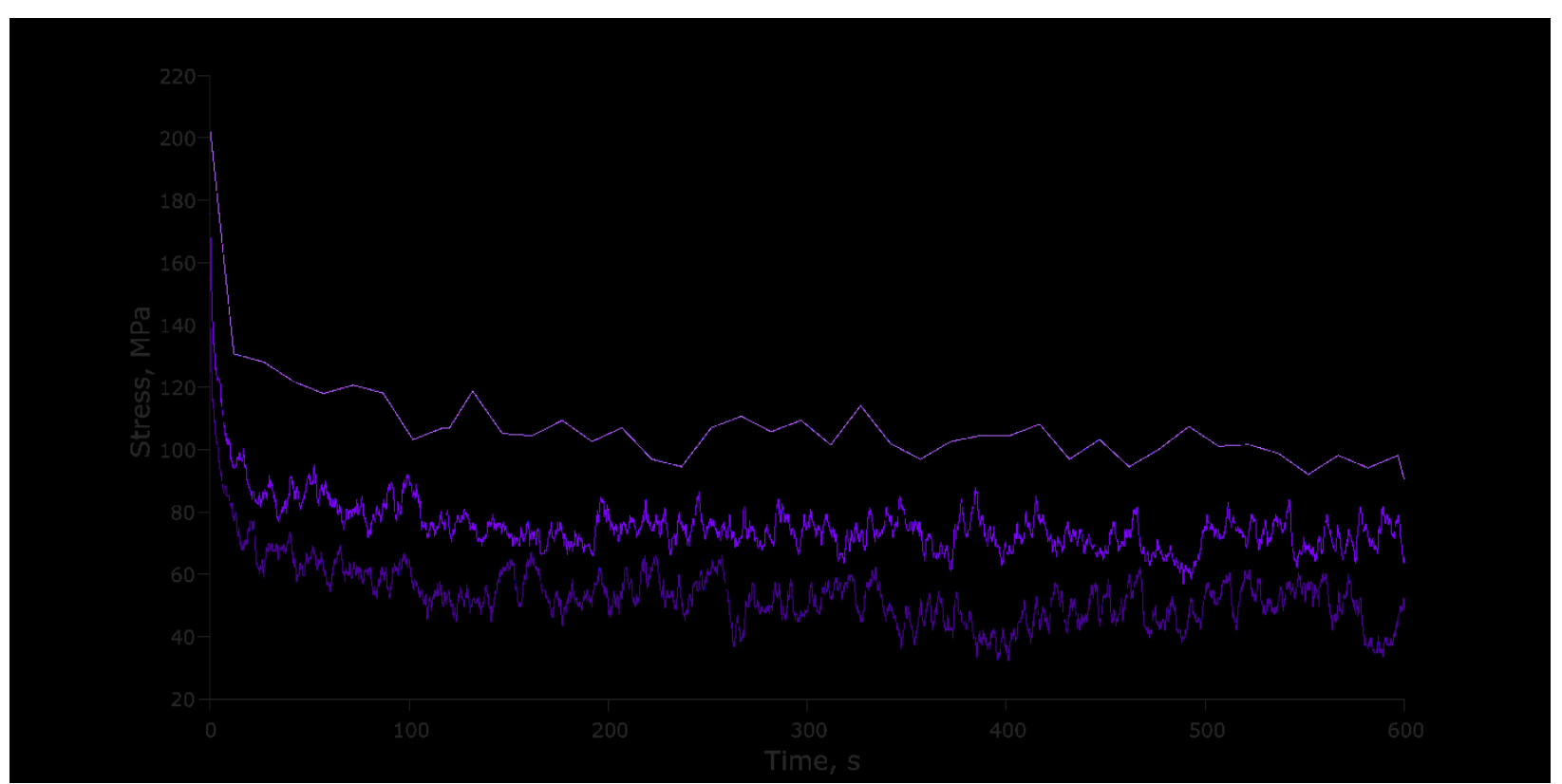

Figure 25: Stress relaxation during creep hold portion of creep-fatigue test on the mid-life cycle for Alloy $740 \mathrm{H}$ tested at $850^{\circ} \mathrm{C}$ with a strain range of $0.4 \%$.

7.1.4 Alloy $740 \mathrm{H}$ sheet testing and load controlled results 
The focus of Task 3 was to examine the effect of different material forms (Alloy $740 \mathrm{H}$ sheet metal, 0.065 in thickness) on the design models. Due to the nature of sheet fatigue testing, it is not feasible to do fully reversed, strain controlled testing, as the material would buckle during the compression. Furthermore, it is more difficult to measure strain directly from the sheet specimens without causing deformation from the pressure imposed by the extensometers onto the specimen. As a result, the sheet metal testing was performed in load control, with an $\mathrm{R}=0.1$ (minimum stress will be $10 \%$ of maximum stress). To allow for a more direct comparison of tests, several load controlled, $\mathrm{R}=0.1$ tests were performed on plate material. Loads were chosen based on strain controlled test results to mimic general stresses experienced in those tests. The experimental setup for the sheet testing is shown in Figure 26.

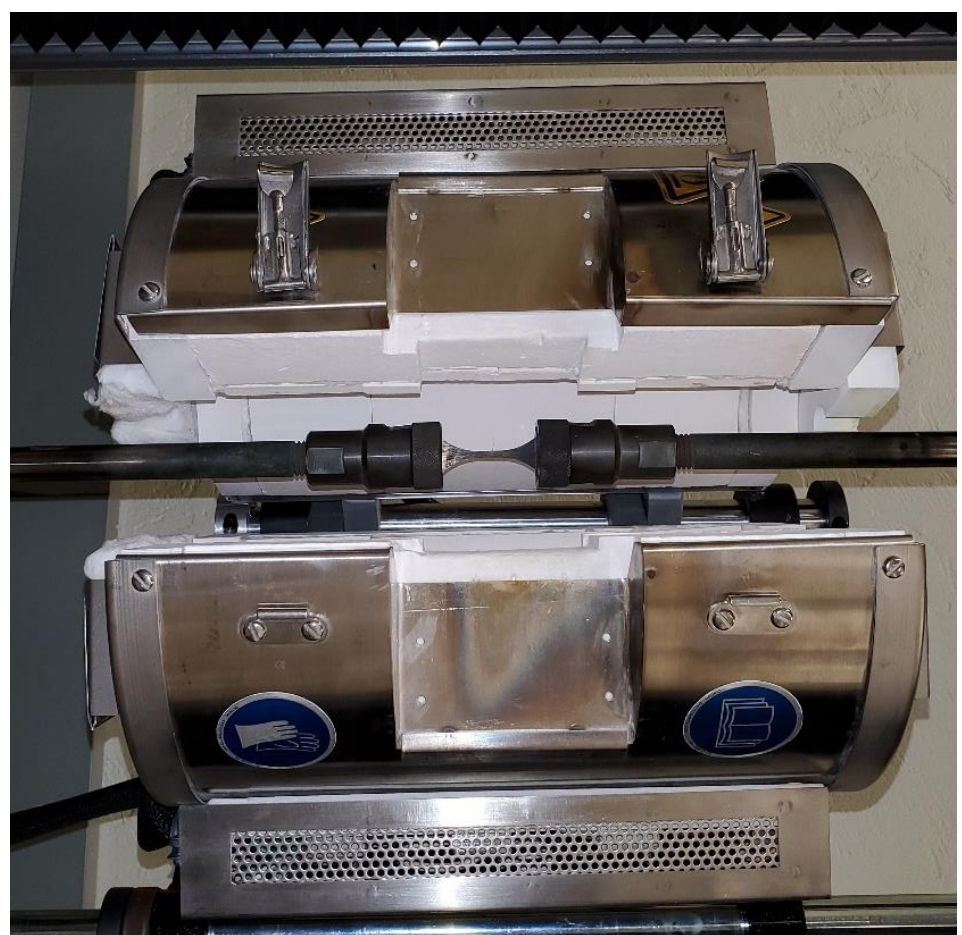

Figure 26. Load train and furnace in the test frame where sheet testing (specimen visible in picture) was performed.

Testing performed on the plate material provided a basis for expectation of the sheet metal testing. A summary of the load controlled, Alloy $740 \mathrm{H}$ plate tests is shown in Table 7 and Figure 27. 
Table 7. Results of load controlled, Alloy $740 \mathrm{H}$ plate material tested.

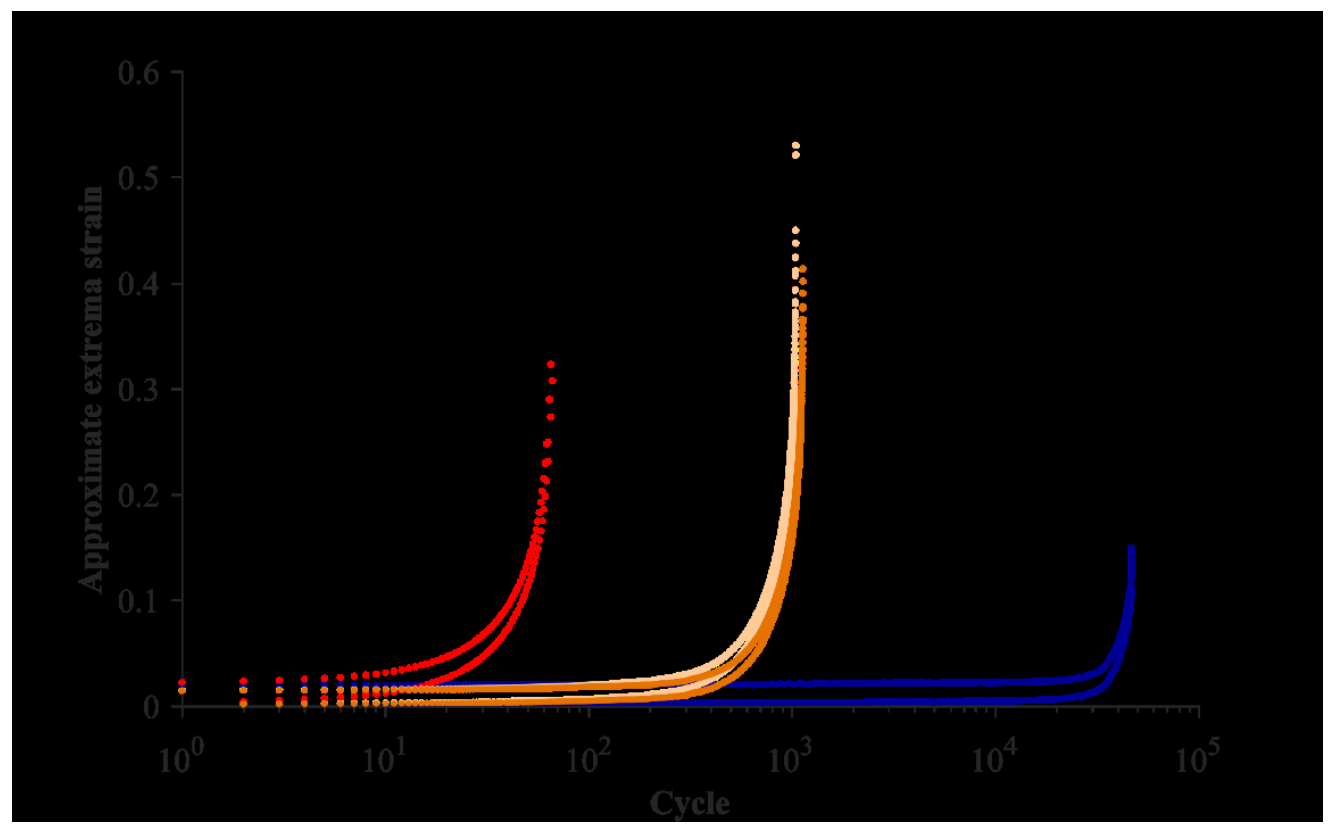

Figure 27. Load-controlled Alloy $740 \mathrm{H}$ plate fatigue testing results.

While there was some deficiencies in the testing setup and time/budget restraints prohibited a more suitable setup for sheet testing, the results from this work can help inform design engineers of potential concerns with use of the proposed design models that are based largely on plate data. Figures 28 and 29 show the Alloy $740 \mathrm{H}$ sheet fatigue test results as compared to similar conditions from the plate testing. These results show that the Alloy $740 \mathrm{H}$ sheet fatigue life is approximately a factor of 3-4 times lower than the Alloy $740 \mathrm{H}$ plate fatigue life. There are two potential approaches to resolving this reduction in life. With additional testing, a strength reduction factor could be included for thin material forms. The second option would be to accept that material form may affect strength, but is already accounted for in the factor of 10 safety factor that is already placed on the fatigue design models (based on the Alloy $740 \mathrm{H}$ plate data). 


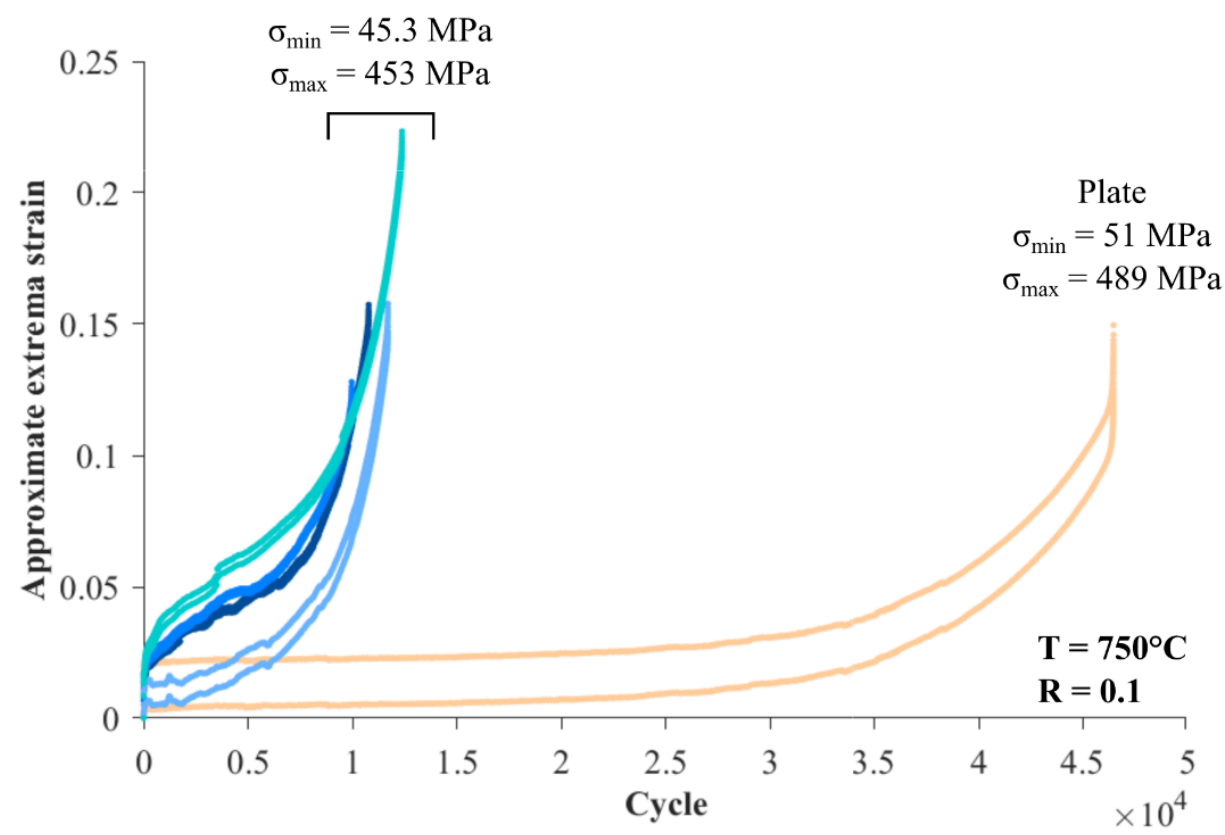

Figure 28. Load-controlled Alloy $740 \mathrm{H}$ sheet fatigue testing results compared to plate results for $750{ }^{\circ} \mathrm{C}$ tests.

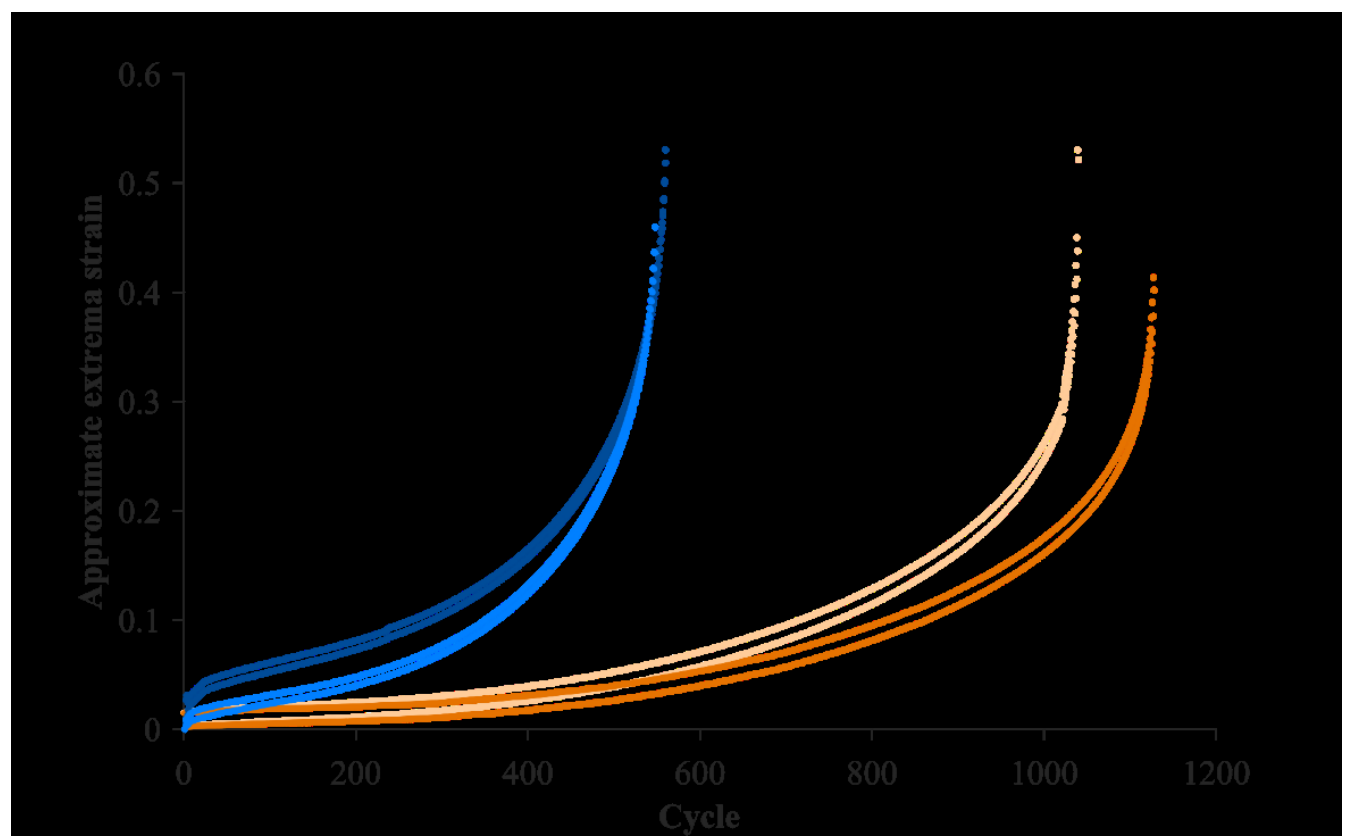

Figure 29. Load-controlled Alloy $740 \mathrm{H}$ sheet fatigue testing results compared to plate results for $850^{\circ} \mathrm{C}$ test.

\subsection{Design Methodology}

The ANL technical report "Design Guidance for High Temperature Concentrating Solar Power Components" [47] includes design data for Alloy $740 \mathrm{H}$ based on the INL testing. Since the publication of that report INL completed two additional creep-fatigue tests on wrought material, not included in the original test database used in developing the design data. 
Figure 30 plots the new data (red circle), the total dataset including the new data (black $\mathrm{x}$ ), and the interaction point recommended in the original ANL report (black lines). The creep-fatigue data points on the plot were calculated by determining the Miner's rule fatigue damage based on the nominal fatigue curve for Alloy $740 \mathrm{H}$ and the creep damage was calculated using the relaxation profile at mid-life, the nominal rupture correlation for Alloy $740 \mathrm{H}$, and the time-fraction damage rule. This calculation method is consistent with the original analysis used to formulate the design intersection point.

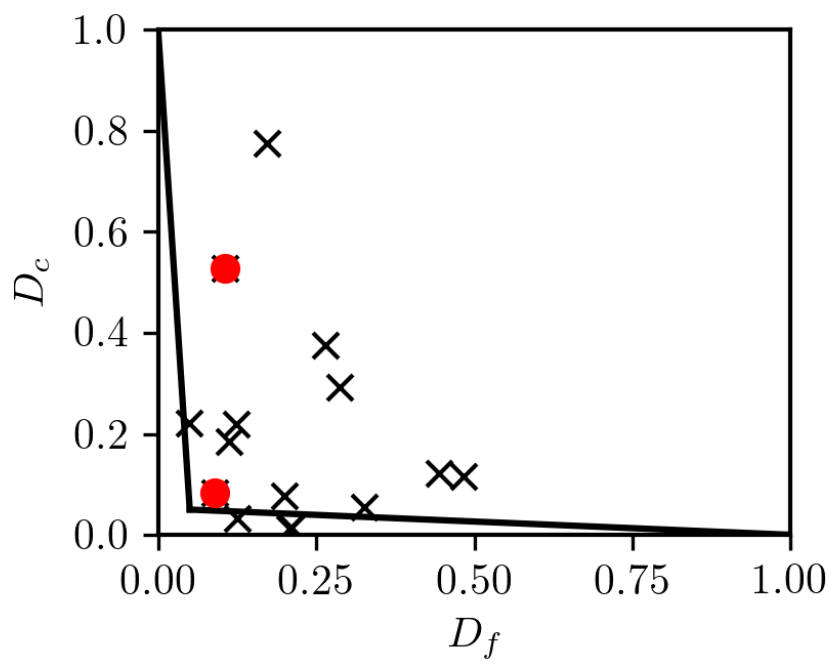

Figure 30. Damage diagram plotting the new creep-fatigue results (red circle), the total creepfatigue dataset for Alloy $740 \mathrm{H}$ (black $\mathrm{x}$ ), and the original design D-diagram.

The new data generally conforms to the trend of the original dataset. As such, we recommend retaining the $(0.05,0.05)$ intersection point for Alloy $740 \mathrm{H}$ originally specified in [47].

\section{Significant Accomplishments and Conclusions:}

The design models developed within this program will assist industry as new Gen3 CSP systems are designed to ensure safe and reliable operation. While the results of this work have highlighted the challenges of the desired operating temperatures (as high as $840^{\circ} \mathrm{C}$ on the outside of the thermal receivers), this is an important result so that designers can carefully consider these potential failure mechanisms. Failure to accurately account for creep-fatigue, as well as creep and fatigue separately, would likely result in premature failure of systems and could potentially result in serious safety concerns as these components failed. Through use of the design models developed here, engineers have the tools to create designs that will avoid these potential premature failures.

\section{Budget and Schedule:}


The original budget plan is shown in the tables below for INL and ANL. There were some delays near the end of the project that lead to a no-cost extension, extending the project to September 2020 rather than ending in February 2020. The entire budget was spent by the end of the no-cost extension.

\section{Idaho National Laboratory}

\begin{tabular}{|l|r|r|}
\hline \multicolumn{1}{|c|}{ Category } & Year 1 Cost (2/18-1/19) & Year 2 Cost (2/19-1/20) \\
\hline In-House Labor & $\$ 342$ & $\$ 250$ \\
\hline Subcontracts & $\$ 10$ & $\$ 0$ \\
\hline Travel & $\$ 8$ & $\$ 8$ \\
\hline Capital Equipment & $\$ 0$ & $\$ 0$ \\
\hline Supplies & $\$ 10$ & $\$ 7$ \\
\hline Other & $\$ 15$ & $\$ 0$ \\
\hline Total & $\$ 385$ & $\$ 265$ \\
\hline
\end{tabular}

Argonne National Laboratory

\begin{tabular}{|l|r|r|}
\hline \multicolumn{1}{|c|}{ Category } & Year 1 Cost (2/18-1/19) & Year 2 Cost (2/19-1/20) \\
\hline In-House Labor & $\$ 183$ & $\$ 139$ \\
\hline Subcontracts & $\$ 16$ & $\$ 0$ \\
\hline Travel & $\$ 6$ & $\$ 6$ \\
\hline Capital Equipment & $\$ 0$ & $\$ 0$ \\
\hline Supplies & $\$ 0$ & $\$ 0$ \\
\hline Other & $\$ 0$ & $\$ 0$ \\
\hline Total & $\mathbf{\$ 2 0 5}$ & $\mathbf{\$ 1 4 5}$ \\
\hline
\end{tabular}

\section{Path Forward:}

Future work will move towards an all-inclusive design tool produced by ANL in a second DOE-SETO funded project. In addition to including the Alloy $740 \mathrm{H}$ results from this project in the design tool, additional work will be funded to do a similar study and analysis on Alloy 282, which is now feasible thanks in large part to the recent ASME BPVC Code Case being produced. This design tool will make the design models easily applied by design engineers for their CSP system.

\section{Inventions, Patents, Publications, and Other Results:}

B. Barua, M. Messner, M. McMurtrey, Proceedings of the ASME 2019 Pressure Vessels and Piping Conference, PVP2019-93572, San Antonio, Texas, USA. July 14-19, 2019. 
Two additional journal papers are in preparation covering lessons learned during the design methodology development and the experimental testing of Alloy $740 \mathrm{H}$.

\section{References:}

[1] M. Mehos, C. Turchi et al., Concentrating Solar Power Gen3 Demonstration Roadmap NREL/TP-5500-67464 (2017).

[2] D.K. Fork, J. Fitch, S. Ziaei, R.I. Jetter, J. of Solar Energy Engin. 134 (2012).

[3] J. Ortega, S. Khivsara, J. Christian, C. Ho, P. Dutta, Applied Thermal Engin. 109 (2016) 979-987.

[4] P. Rodriguez, K.B.S. Rao, Prog. Mater. Sci. 37 (1993) 403-480.

[5] R. Hales, Fatigue of Eng. Mater. Struct. 3 (1980) 339-356.

[6] W.J. Plumbridge, E.G. Ellison, Mater. Sci. Technol. 3 (1987) 706-714.

[7] Special Metals website - www.specialmetals.com

[8] Haynes International website - www.haynesintl.com

[9] ASME, ASME Boiler and Pressure Vessel Code, 2019, ASME, New York.

[10] R. Purgert et al. Boiler Materials for Ultra Supercritical Coal Power Plants Final Technical Report for DOE Award DE-FG26-01NT41175., Dec. 2015.

[11] X. Song, L. Tang, Z. Chen, R. Zhou, J. Material Science 52, April 2017.

[12] J.K. Wright, L.J. Carroll, et al., Proceedings of the ASME 2016 Pressure Vessels and Piping Conference PVP2016-63704 July 17-21, 2016, Vancouver, British Columbia, Canada.

[13] T.W. Neises, M.J. Wagner, A.K. Gray, Proceedings of the ASME 2014 8th Inter. Conference on Energy Sustainability ES2014 June 30-July 2, 2014, Boston, Massachusetts, USA.

[14] X. Chen, M.A. Sokolov, et al., Journal of Nuclear Materials 432 (2013) 94-101.

[15] L.J. Carroll, C. Cabet, M.C. Carroll, R.N. Wright, Inter. J. Fatigue, 47, 115-125 (2013).

[16] L. Carroll, INL/EXT-15-35132 Rev. 1, August 2015.

[17] T.C.Totemeier, CREEP8, $8^{\text {th }}$ Inter. Conference on Creep and Fatigue at Elevated Temp., San Antonio, TX, July 22-26, 2007.

[18] P.G. Pritchard, L. Carroll, T. Hassan, Trans. of the Amer. Nuclear Soc., 109 (2013) 562-565.

[19] J.M. Corum, J.J. Blass, PVP Pressure Vessel Piping Fatigue Fracture and Risk ASME 215 (1999) 147-153.

[20] R. Wright, INL/EXT-17-42999 Rev001, 2018

[21] T. Totemeier, H. Tian, Mater. Sci. Engin. A 468-470 (2007) 81-87.

[22] S. Zhang, Y. Takahashi, Adv. Mater. Tech. Fossil Power Plants Proc., Albufeira, Algarve, Portugal (2016).

[23] K. Kubushiro, H. Yoshizawa, T. Itou, H. Nakagawa, Proc. of CREEP8, July 22-26, 2007, San Antonio, Texas.

[24] J.P. Strizak et al, Oak Ridge National Laboratory, ORNL/TM-8130 (April 1982).

[25] R. Seeley et al., Fatigue in Modern Nickel-Base Alloys for Gas Turbine Applications, Life Assessment of Hot Section Gas Turbine Components, Cambridge University Press, UK (2000) 61-82.

[26] X. Chen et al. J. Nuc. Mater. 444 (2014) 393-403.

[27] P.R. Barrett et al., Inter. J. Solids Struc. 88-89 (2016) 146-164. 
[28] B.R. Antoun, K.J. Connelly, S.H. Goods, G.B, Sartor, Mechanics of TimeDependent Materials Springer International Publishing 2(10) (2015) 81-87.

[29] S.K. Srivastava, D.L. Klarstrom, ASME Paper 90-GT-80, Inter. Gas Turbine Conf., Brussels, Belgium, June 11-14, 1990.

[30] L.J. Carroll, W.R. Lloyd, J.A. Simpson, R.N. Wright, Mater. High Temp. 27(4) 313-323.

[31] S.Y. Lee et al., Mater. Sci. Engin. A 504 (2009) 64-72.

[32] D.R. Eno, G.A. Young, T.L. Sham, ASME 2008 Press. Vessels Piping Conf. 6 Chicago, Illinois, USA, July 27-31, 2008.

[33] C.J. Boehlert, S.C. Longanbach, Mater. Sci. Engin. A 528 (2011) 4888-4898.

[34] P.J. Maziasz, et al., Adv. Mater. Tech. Fossil Power Plants Proc. $8^{\text {th }}$ Inter. Conf. Oct. 11-14, 2016, Albufcira, Algarve, Portugal.

[35] R. Brommesson, M. Ekh, Mater. High Temp. 31 (2014) 121-130.

[36] M. Hornqvist, C. Joseph, C. Persson, J. Weidow, H. Lai, MATEC Web of Conf. 14, 16002 (2014).

[37] L.M. Pike, ASME Turbo Expo, GT2007-28267, ASME Publication, New York, NY, 2007.

[38] J. He, R. Sandstrom, S. Notargiacomo, J. Mater. Engin. Performance 26 (2017) 2257-2263.

[39] J.P. Shingledecker, Metallurgical Effects of Long-Term Stress Rupture in a New Nickel-Base Alloy, Doctoral Dissertation, U. Tennessee, Knoxville, May, 2012

[40] Y. Muto, H. Nakajima, M. Eto, Nucl. Engin. Design 144 (1993) 305-315.

[41] H. Tsuji, T. Kondo, T., J. Nucl. Mater. 150 (1987) 259-265.

[42] S.N. Yin, Exper. Mech. Nano Biotech. Key Engin. Mater. 326-328 Trans Tech Publications (2006) 1105-1108.

[43] M.K. Booker, Oak Ridge National Laboratory, ORNL-5479 (February 1979).

[44] J. Shingledecker, R. Purgert, P. Rawls, Adv. Mater. Tech. Fossil Power Plants Proc. October 22-25, 2013, Waikoloa, Hawaii.

[45] J.P. Shingledecker, G.M. Pharr, Metall. Mater. Trans. A 43 (2012) 1902-1910.

[46] J.P. Shingledecker, N.D. Evans, G.M. Pharr, Mater. Sci. Engin. A 578 (2013) 277-286.

[47] B. Barua, M. McMurtrey, R. Rupp, M. Messner, ANL-20/02, https://doi.org/10.2172/1582656, 2020 


\title{
Appendix A
}

Final Design Report (Official stand-alone version available at: https://www.osti.gov/biblio/1582656-design-guidance-high-temperatureconcentrating-solar-power-components)

\section{Design Guidance for High Temperature Concentrating Solar Power Components}

\author{
B. Barua, M. McMurtrey, R. Rupp, M. Messner
}

\begin{abstract}
This report provides guidance for the design of components for concentrating power facilities operating at high temperatures and undergoing high, secondary thermal stresses relative to the applied primary pressure stress. The design rules were developed for the design of Generation 3 CSP tubular receivers manufactured from Alloy $740 \mathrm{H}$, but are generally applicable to a wide range of component types undergoing similar loads. Part 1 of the report provides procedural design rules for components to be used in conjunction with the 2019 edition of the ASME Boiler \& Pressure Vessel Code. Part 2 provides corresponding design data for Alloy $740 \mathrm{H}$. Part 3 of the report is a commentary describing the rationale behind the design rules and the data underlying the design material properties. Finally, Part 4 provides an extensive set of worked sample problems detailing the application of the rules to CSP components.
\end{abstract}





\section{Part 1: Design Rules}

\section{1-1. General criteria}

\section{1-1.1. Applicability}

These design criteria apply to components in concentrating solar power facilities at temperatures above $370^{\circ} \mathrm{C}$ for ferritic and ferritic-martensitic steels and $425^{\circ} \mathrm{C}$ for austenitic stainless steels and nickel-based alloys where creep-fatigue damage in cyclic service or stress relaxation damage caused by reoccurring application of secondary load is a significant design consideration. The designer may select any of the following three design options listed in Articles 1-2, 1-3, and 1-4. A design is required to pass all the checks contained in the selected option to pass the design criteria.

The design criteria were developed for structures undergoing daily cycling. The rules below are not suited for structures that see service cycles with holds at constant load longer than 1,000 hours at temperatures greater than those listed in Part 2, Article 2-10.1.

All references to the ASME Boiler and Pressure Vessel Code (ASME B\&PV Code) are to the 2019 Edition.

\section{1-1.2. Design Cycle and Design Life}

All three methods require the designer to use a single design composite loading cycle to represent or bound the service conditions experienced in operation. The definition of this Design Cycle consists of periodic pressure, thermal, and mechanical force boundary conditions sufficient to complete a thermal-mechanical analysis of the component along with the number of times this composite loading cycle will be repeated in service - defined as quantity. These boundary condition histories must include times of application including all relevant hold periods at constant load. The composite cycle period is defined as .

The Design Specification shall specify a Design Life denoted as. The composite loading cycle used for design must cover the entire design life so that .

\section{1-1.3. Material Data}

The following design criteria are to be used in conjunction with the design material data provided in Part 2.

\section{1-1.4. Limitations}

These criteria only cover the design of components and do not provide construction, welding, examination, or inspection criteria. These additional requirements shall be provided in the Design Specification, possibly by reference to ASME Section III, Section V, Section VIII, Section IX, or Section XI or other codes and standards documents, as 
appropriate.

\section{1-2. Design Option A: Design by Elastic Analysis using ASME Section III, Division 5}

This option can be applied to any type of component using any material provided in Part 2 up to the maximum metal temperatures provided in the tabulated design data.

\section{1-2.1. Primary Load}

Primary load analysis is to be completed using a steady-state thermal analysis of the Design Cycle and a linear elastic stress analysis using the material properties provided in Articles 0 and 2-3 of Part 2.

The component shall meet the criteria of the ASME B\&PV Code Section III, Division 5, HBB-3222.1 with the following modifications:

1. The Design Loading shall be determined using Section III, Division 5, HBB-3113.1 expect references to "Service Level A Loadings" are replaced by references to the "Design Cycle" defined in Article 1-1.2.

2. The values of the allowable stress are provided in Article 2-5.1 of Part 2.

3. The provisions of HBB-3222.1(c) do not apply.

\section{1-2.2. Ratcheting Strain Accumulation}

The temperatures used in the ratcheting analysis are to be obtained from a transient thermal analysis of the component subject to the Design Cycle. The stresses and strains are to be obtained using a small-deformation linear elastic analysis. Material properties are provided in Articles 0 and 2-3 of Part 2.

The component shall meet the criteria of the ASME B\&PV Code Section III, Division 5, HBB-T-1332 Test B-1, including the General Requirements of HBB-T-1331, with the following modifications:

1. The designer will only analyze a single cycle, the Design Cycle defined in Article 1-1.2. References to the Section III, Division 5 Service Loadings are replaced by references to the Design Cycle.

2. The values of are provided in Article 2-4.1 of Part 2.

3. The temperature limit provided by Table HBB-1323 is instead provided in Article 2-10.2 in Part 2.

4. For HBB-T-1332(b) calculate the accumulated strain using a stress of , rather than the in the ASME Code.

5. For HBB-T-1332(b) the isochronous stress strain curves are provided in Article 0 of Part 2.

6. The strain limits in HBB-T-1332(b) are increased to $2 \%$ for base metal and $1 \%$ for weld metal. 


\section{1-2.3. Creep-fatigue Criteria}

The temperatures used in the creep-fatigue analysis are to be obtained from a transient thermal analysis of the component subject to the Design Cycle. The stresses and strains are to be obtained using a small-deformation linear elastic analysis. Material properties are provided in Articles 0 and 2-3 of Part 2.

The component shall meet the criteria contained in the ASME B\&PV Code Section III, Division 5, HBB-T-1430 with the following modifications:

1. The designer will only analyze a single cycle, the Design Cycle defined in Article 1-1.2. References to the Section III, Division 5 Service Loadings are replaced by references to the Design Cycle.

2. The design fatigue curves are provided in Article 2-6.2 of Part 2.

3. The minimum stress to rupture data are provided in Article 2-6.1 in Part 2.

4. The values of the allowable stress, required for calculating the quantity, are provided in Article 0 in Part 2.

5. The values of the relaxation strength and, required for calculating the quantity, are provided in Article 0 in Part 2.

6. The isochronous stress-strain curves are provided in Article 0 in Part 2.

7. For HBB-T-1432 the designer shall use HBB-T-1413 for calculating the effective strain range and not any of the other options allowed in HBB-T-1432(a).

8. The creep-fatigue damage envelope is provided in Article 0 in Part 2.

9. When calculating the creep strain increment in HBB-T-1432(g) use a stress equal to , rather than as in Section III, Division 5.

10. When using HBB-T-1433(a) Step 5(b) to evaluate creep damage the value of shall be , rather than as in Section III, Division 5.

11. The alternate creep damage calculation procedure in HBB-T-1433(b) shall not be used. The designer must use the process defined in HBB-T-1433(a).

12. Creep damage shall be calculated from the stress history using a factor .

13. The alternative criteria in HBB-T-1435 shall not be used.

14. The additional factors on weld material properties defined in HBB-T-1710 shall be applied to weldments. Applicable weld strength reduction factors are provided in Article 2-7 of Part 2.

\section{1-2.4. Time Independent Buckling}

For this analysis the Design Cycle loads, defined in Article 1-1.2, shall be increased by a factor of 1.5. This includes thermal stresses which can be increased by factoring the material coefficient of thermal expansion.

Additionally, the Design Cycle shall be supplemented by intermittent loads, such as wind lateral loads, that are not periodic. The method for calculating lateral loads shall be specified in the Design Specification. If this method includes load factors accounting for uncertainty in the applied loading these load factors shall be used for the lateral loads if they exceed the generic load factor of 1.5 provided in this Article. If the lateral loads specified in the Design Specification are not factored or if the load factor is less than 1.5, the intermittent loads shall be increased by a factor of 1.5 . 
The factored Design Cycle plus factored intermittent loads shall be used to perform a time-independent, large deformations, incremental plastic analysis of the component using a von Mises flow theory and a temperature-dependent flow stress defined by the zero-time, hot-tensile isochronous stress strain curves given in Part 2, Article 0 . If the analysis converges for one application of the combined load history, i.e. the structure does not undergo plastic collapse or buckling, the time independent buckling design criteria are satisfied.

\section{1-2.5. Time Dependent Buckling}

For many CSP systems time dependent buckling will not be a significant design issue as primary stresses and steady, load-controlled lateral loads are typically small. However, if a design has high primary loads or significant steady, load controlled loadings, such as large lateral self-weight, that could cause buckling, time dependent buckling may be assessed with the following procedure. Note that such steady load controlled forces should already be included in the Design Cycle, as they are primary loads.

For this analysis the Design Cycle loads, defined in Article 1-1.2, shall be increased by a factor of 1.5. This includes thermal stresses, which can be increased by factoring the material coefficient of thermal expansion.

This factored Design Cycle shall be used to perform a time-independent, large deformations, incremental plastic analysis of the component using a von Mises flow theory and a temperature-dependent flow stress defined by isochronous curve for a time equal to the component Design Life given in Part 2, Article 0 . If the analysis converges for one application of the factored Design Cycle, i.e. the structure does not undergo plastic collapse or buckling, the time dependent buckling design criteria are satisfied.

\section{1-3. Design Option B: Design by Elastic Analysis using ASME Section III, Division 5 with Reduced Margin and Simplified Creep-Fatigue evaluation}

This method shall only be applied to Alloy $740 \mathrm{H}$ material and to components where the peak stress is minimal.

\section{1-3.1. Primary Load}

The primary load provisions of Article 1-2.1 shall be used.

\section{1-3.2. Ratcheting Strain Accumulation}

The ratcheting provisions of Article 1-2.2 shall be used.

\section{1-3.3. Creep-fatigue Criteria}


The temperatures used in the creep-fatigue analysis are to be obtained from a transient thermal analysis of the component subject to the Design Cycle. The stresses and strains are to be obtained using a small-deformation linear elastic analysis. Material properties are provided in Articles 0 and 2-3 of Part 2.

Consider the total stress intensity $(P+Q+F)$ from the linear elastic analysis. If at any point during the Design Cycle the total stress intensity exceeds the temperaturedependent value of for the material, given in Part 2, Article 2-4.1 then Design Option B cannot be used to assess the component.

To evaluate creep-fatigue damage use the following procedure. The stresses used in these steps correspond to the maximum total stress $(P+Q+F)$ in the linear elastic analysis.

1. Determine the maximum elastic strain range during the Design Cycle using the elastically calculated mechanical strains from the analysis and the definition of the strain range given in HBB-T-1413. Call this strain range .

2. Calculate a strain range increase due to creep by taking the total creep strain used to evaluate the ratcheting strain criteria in Article 1-3.2 (using HBB-T-1332 Test B-1), labeled and dividing it by the number of repetitions of the design cycle , i.e. . As the structure will already have passed the requirements of Article 1-3.2 the designer may alternatively conservatively use .

3. Sum the two strain ranges and use this total strain range to determine the number of cycles to failure using the design fatigue diagrams given in Part 2, Article 2-6.2. The appropriate diagram corresponds to the maximum metal temperature in the Design Cycle. Use the design fatigue curve to determine the number of allowable cycles. Calculate the fatigue damage fraction using the equation .

4. Calculate the von Mises stress history, corresponding to the total stress history determined in the linear elastic analysis. Use this von Mises stress history to calculate the creep damage fraction for a single repetition of the Design Cycle using HBB-T-1411(10) with a factor . That is, the scalar stress used to determine the time-to-rupture for each time increment is the von Mises stress, not the effective stress given in HBB-T-1411 or the design by elastic analysis procedure given in HBB-T-1433. The minimum stress to rupture tables are provided in Part 2, Article 2-6.1. Call this single cycle creep damage fraction. The total creep damage fraction is .

5. Use the creep-fatigue damage envelope provided in Part 2, Article 0 with the fatigue and creep damage fractions and to determine the acceptability of the component.

In this procedure the modifications to the weld material properties defined in HBBT-1710 shall be applied to weldments. Applicable weld strength reduction factors are provided in Article 2-7 of Part 2.

\section{1-3.4. Time Independent Buckling}


The time independent buckling criteria of Article 1-2.4 shall be used.

\section{1-3.5. Time Dependent Buckling}

If applicable, the time-dependent buckling criteria of Article 1-2.5 shall be used.

\section{1-4. Design Option C: Design by Simple Inelastic Analysis}

This method may be applied to any material for which Part 2, Article 2-9 provides a constitutive model.

\section{1-4.1. Primary Load}

The primary load provisions of Article 1-2.1 shall be used.

\section{1-4.2. Ratcheting Strain Accumulation}

Perform a transient thermal analysis of the component under the Design Cycle using the properties in Part 2, Article 2-3. Use these temperatures to perform a small deformation inelastic stress analysis of the component under the Design Cycle loads using the inelastic constitutive model defined in Part 2, Article 2-9. For each location in the component, , this process produces a time history of stress values , mechanical strain values, and temperature values .

The analysis must repeat the Design Cycle loading until the structure achieves a steady-state response. This steady-state response is defined by the conditions, for some arbitrary time :

1.

2.

for all times in the current repetition of the Design Cycle. Both conditions must be met. Once the analysis reaches this steady-state condition no additional repetitions of the Design Cycle are required. Extract the stress, strain, and temperature histories from the analysis corresponding to the final repetitions of the design cycle. Shift these histories in time so that the final stress, strain, and temperature histories start at time 0 and extend to time. These histories, , , and, will be used to determine the acceptability of the component.

To assess the component against the ratcheting criteria for each location in the component calculate the local ratcheting rate

which is the net effective strain accumulated over one cycle in the steady state condition. The ':' in this equation represents tensor contraction. For each point calculate the total ratcheting strain:

This total ratcheting strain must be less than $10 \%$ for base metal and $5 \%$ for weldments at all points in the structure. If this criteria is met the structure passes the ratcheting design criteria. 


\section{1-4.3. Creep-fatigue Criteria}

The analysis is identical to the analysis required for the ratcheting check defined in Article 1-4.2. The design analysis begins with the time-shifted histories, , and .

For each point in the component:

1. Use HBB-T-1413 with to calculate the effective strain range from the strain history

2. Use the design fatigue curves provided in Part 2, Article 2-6.2 to determine the maximum allowable number of cycles. Use the curve corresponding to the maximum metal temperature at the point under consideration.

3. Calculate the fatigue damage fraction using the equation .

4. Use the stress history to calculate the von Mises effective stress history at each point in the structure using the equation .

5. Use the resulting von Mises stress history, with, and the local metal temperature to calculate a time history of allowable time to rupture using the minimum stress to rupture provided in Part 2, Article 2-6.1.

6. Calculate the creep damage fraction using the equation. The integral may be discretized into individual time steps.

7. Use the creep-fatigue damage envelope, provided in Part 2, Article 0 , to determine whether each point in the structure passes or fails the acceptance criteria using the fatigue and creep damage fractions and .

The structure passes the creep-fatigue design provisions if each point individually passes the criteria described in 1-7 above.

\section{1-4.4. Time Independent Buckling}

The time independent buckling criteria of Article 1-2.4 shall be used.

\section{1-4.5. Time Dependent Buckling}

If applicable, the time-dependent buckling criteria of Article 1-2.5 shall be used. 


\section{Part 2: Design Material Data}

\section{2-1. General Criteria}

2-1.1. Data tables, charts, and equations

Depending on the property, the data below is provided as tables, charts, or equations or some combination thereof. If more than one form of the data is presented the designer may use either the equations or interpolation from table or chart data. For the case where the material property depends on time or a number of cycle repetitions log-linear interpolation shall be used for that variable. Because of differences in interpolation versus the mathematical formula and because the tabulated values are rounded the three sources of data may not precisely agree.

\section{2-2. Material Specification}

The following table links the short material name used in this Part 2 to material specification(s) and product forms allowed for use with these design criteria.

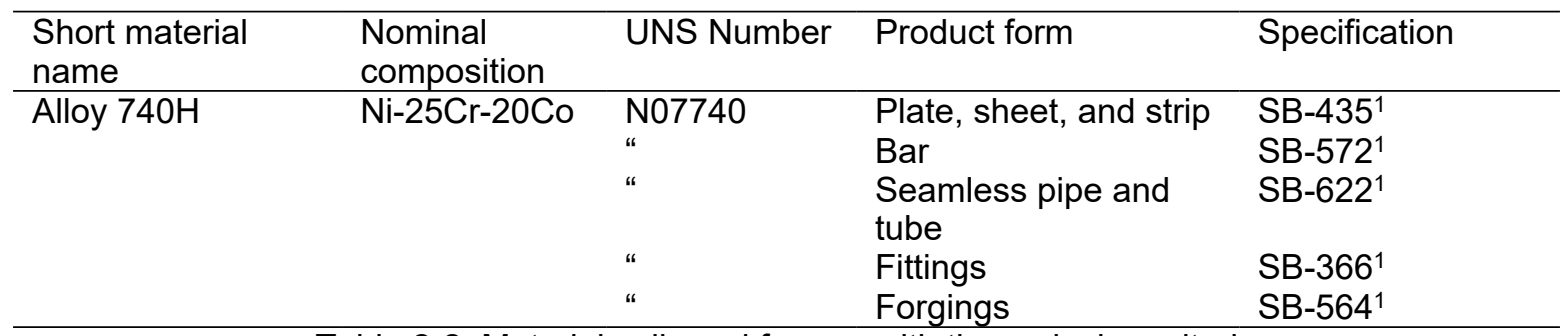

Table 2-2. Materials allowed for use with these design criteria

Notes:

1 These materials shall also meet the additional requirements listed in part (a) or (b) in ASME B\&PV Code Case 2702. 
Elastic constants

2-2.1. Young's modulus

2-2.1.1. Alloy $740 \mathrm{H}$

\begin{tabular}{ll}
\hline $\begin{array}{l}\text { Temperature } \\
\left({ }^{\circ} \mathrm{C}\right)\end{array}$ & $\begin{array}{l}\text { Modulus } \\
(\mathrm{GPa})\end{array}$ \\
\hline 20 & 221 \\
100 & 218 \\
200 & 212 \\
300 & 206 \\
400 & 200 \\
500 & 193 \\
600 & 186 \\
700 & 178 \\
800 & 169 \\
900 & 160 \\
\hline
\end{tabular}

Table 2-2.1.1. Design Young's modulus for Alloy $740 \mathrm{H}$.

2-2.2. Poisson's ratio

2-2.2.1. Alloy $740 \mathrm{H}$

The design Poisson's ratio for Alloy $740 \mathrm{H}$ is 0.31 for all temperatures.

2-3. Thermal properties

2-3.1. Alloy $740 \mathrm{H}$

\begin{tabular}{lllll}
\hline $\begin{array}{l}\text { Temperature } \\
\left({ }^{\circ} \mathrm{C}\right)\end{array}$ & $\begin{array}{l}\text { Mean CTE } \\
\left(\mu \mathrm{m} / \mathrm{mm} /{ }^{\circ} \mathrm{C}\right)\end{array}$ & $\begin{array}{l}\text { Instantaneous } \\
\mathrm{CTE}\left(\mu \mathrm{m} / \mathrm{mm} /{ }^{\circ} \mathrm{C}\right)\end{array}$ & $\begin{array}{l}\text { Conductivity } \\
\left(\mathrm{W} /\left(\mathrm{m}^{\circ} \mathrm{C}\right)\right)\end{array}$ & $\begin{array}{l}\text { Specific heat } \\
\left(\mathrm{J} /\left(\mathrm{kg}{ }^{\circ} \mathrm{C}\right)\right)\end{array}$ \\
\hline 20 & & 12.38 & 10.2 & 449 \\
100 & 12.38 & 12.38 & 11.7 & 476 \\
200 & 13.04 & 13.55 & 13.0 & 489 \\
300 & 13.50 & 14.32 & 14.5 & 496 \\
400 & 13.93 & 15.12 & 15.7 & 503 \\
500 & 14.27 & 15.55 & 17.1 & 513 \\
600 & 14.57 & 16.00 & 18.4 & 519 \\
700 & 15.03 & 17.68 & 20.2 & 542 \\
800 & 15.72 & 20.39 & 22.1 & 573 \\
900 & 16.41 & 16.51 & 23.8 & 635 \\
\hline
\end{tabular}

Table 2-3.1. Design thermal properties for Alloy $740 \mathrm{H}$ 
2-4. Mechanical properties

2-4.1. Yield strength

2-4.1.1. Alloy $740 \mathrm{H}$

\begin{tabular}{ll}
\hline $\begin{array}{l}\text { Temperature } \\
\left({ }^{\circ} \mathrm{C}\right)\end{array}$ & $(\mathrm{MPa})$ \\
\hline 40 & 621 \\
100 & 594 \\
150 & 577 \\
200 & 562 \\
250 & 548 \\
300 & 538 \\
350 & 531 \\
400 & 529 \\
450 & 529 \\
500 & 529 \\
550 & 529 \\
600 & 529 \\
650 & 529 \\
700 & 529 \\
750 & 508 \\
800 & 463 \\
850 & 418 \\
\hline
\end{tabular}

Table 2-4.1.1. Design values of yield strength () for Alloy $740 \mathrm{H}$. 
2-4.2. Tensile strength

2-4.2.1. Alloy $740 \mathrm{H}$

\begin{tabular}{ll}
\hline $\begin{array}{l}\text { Temperature } \\
\left({ }^{\circ} \mathrm{C}\right)\end{array}$ & $(\mathrm{MPa})$ \\
\hline 40 & 1034 \\
100 & 1034 \\
150 & 1034 \\
200 & 1030 \\
250 & 998 \\
300 & 976 \\
350 & 967 \\
400 & 966 \\
450 & 966 \\
500 & 966 \\
550 & 966 \\
600 & 957 \\
650 & 921 \\
700 & 860 \\
750 & 771 \\
800 & 651 \\
850 & 531 \\
\hline
\end{tabular}

Table 2-4.2.1. Design values of tensile strength () for Alloy $740 \mathrm{H}$. 
2-5. Allowable Stresses

2-5.1. Allowable Stress

2-5.1.1. Alloy 740

\begin{tabular}{ll}
\hline $\begin{array}{l}\text { Temperature } \\
\left({ }^{\circ} \mathrm{C}\right)\end{array}$ & $(\mathrm{MPa})$ \\
\hline 40 & 295 \\
100 & 295 \\
150 & 295 \\
200 & 279 \\
250 & 276 \\
300 & 276 \\
350 & 276 \\
400 & 276 \\
450 & 276 \\
500 & 276 \\
550 & 276 \\
600 & 274 \\
650 & 226 \\
700 & 146 \\
750 & 84.1 \\
800 & 34.5 \\
850 & 21.8 \\
\hline 2-5.1.1. Allowable stress in MPa for Alloy $740 \mathrm{H}$.
\end{tabular}


2-5.2. Allowable Stress

2-5.2.1. Alloy 740

\begin{tabular}{ll}
\hline $\begin{array}{l}\text { Temperature } \\
\left({ }^{\circ} \mathrm{C}\right)\end{array}$ & $(\mathrm{MPa})$ \\
\hline 40 & 345 \\
100 & 345 \\
150 & 345 \\
200 & 343 \\
250 & 333 \\
300 & 325 \\
350 & 322 \\
400 & 322 \\
450 & 322 \\
500 & 322 \\
550 & 322 \\
600 & 319 \\
650 & 307 \\
700 & 287 \\
750 & 257 \\
800 & 217 \\
850 & 177 \\
\hline 2-5.2.1. Allowable stress in MPa for Alloy $740 \mathrm{H}$.
\end{tabular}




\section{2-5.3. Relaxation Strength}

\section{2-5.3.1. Alloy 740}

\begin{tabular}{|c|c|c|c|c|c|c|c|c|c|}
\hline & \multicolumn{8}{|c|}{ Time (hours) } \\
\hline & & 1 & 10 & 30 & 100 & 300 & 1000 & 3000 & 10000 \\
\hline \multirow{18}{*}{$\begin{array}{c}\text { Temp. } \\
\left({ }^{\circ} \mathrm{C}\right)\end{array}$} & 425 & 483 & 483 & 483 & 483 & 483 & 483 & 483 & 483 \\
\hline & 450 & 483 & 483 & 483 & 483 & 483 & 483 & 483 & 483 \\
\hline & 475 & 483 & 483 & 483 & 483 & 483 & 483 & 483 & 483 \\
\hline & 500 & 483 & 483 & 483 & 483 & 483 & 483 & 483 & 483 \\
\hline & 525 & 483 & 483 & 483 & 483 & 483 & 483 & 483 & 483 \\
\hline & 550 & 483 & 483 & 483 & 483 & 483 & 483 & 483 & 483 \\
\hline & 575 & 481 & 481 & 481 & 481 & 481 & 481 & 481 & 481 \\
\hline & 600 & 478 & 478 & 478 & 478 & 478 & 476 & 472 & 459 \\
\hline & 625 & 469 & 469 & 469 & 468 & 466 & 460 & 445 & 412 \\
\hline & 650 & 460 & 460 & 459 & 456 & 449 & 428 & 394 & 345 \\
\hline & 675 & 445 & 444 & 441 & 432 & 412 & 374 & 328 & 278 \\
\hline & 700 & 430 & 425 & 417 & 395 & 360 & 310 & 265 & 221 \\
\hline & 725 & 406 & 395 & 377 & 340 & 296 & 248 & 208 & 172 \\
\hline & 750 & 382 & 358 & 326 & 280 & 237 & 195 & 162 & 132 \\
\hline & 775 & 348 & 308 & 270 & 224 & 186 & 151 & 124 & 101 \\
\hline & 800 & 312 & 256 & 217 & 176 & 145 & 116 & 95 & 76 \\
\hline & 825 & 272 & 207 & 171 & 137 & 111 & 88 & 71 & 57 \\
\hline & 850 & 231 & 164 & 133 & 105 & 84 & 66 & 53 & 42 \\
\hline
\end{tabular}

Table 2-5.3.1. Relaxation strength as a function of time and temperature for Alloy $740 \mathrm{H}$. Values are in $\mathrm{MPa}$.

\section{2-6. Creep, fatigue, and creep-fatigue properties}

\section{2-6.1. Minimum stress-to-rupture}

\section{2-6.1.1. Alloy 740}

The minimum stress to rupture for Alloy 740 is given by the equation

where the temperature is given in units of degrees Celsius, the time is given in units of hours, and the rupture stress is provided in units of MPa.

Alternatively, the minimum stress to rupture is tabulated in Table 2-6.1.1. 
Idaho National Laboratory

\begin{tabular}{|c|c|c|c|c|c|c|c|c|c|c|c|}
\hline & \multicolumn{10}{|c|}{ Time (hours) } \\
\hline & & 1 & 10 & 30 & 100 & 300 & 1000 & 3000 & 10000 & 30000 & 100000 \\
\hline Temp. & 425 & 966 & 966 & 966 & 966 & 966 & 966 & 966 & 966 & 966 & 966 \\
\hline$\left({ }^{\circ} \mathrm{C}\right)$ & 450 & 966 & 966 & 966 & 966 & 966 & 966 & 966 & 966 & 966 & 966 \\
\hline & 475 & 966 & 966 & 966 & 966 & 966 & 966 & 966 & 966 & 966 & 966 \\
\hline & 500 & 966 & 966 & 966 & 966 & 966 & 966 & 966 & 966 & 966 & 966 \\
\hline & 525 & 966 & 966 & 966 & 966 & 966 & 966 & 966 & 966 & 966 & 923 \\
\hline & 550 & 966 & 966 & 966 & 966 & 966 & 966 & 966 & 966 & 864 & 736 \\
\hline & 575 & 962 & 962 & 962 & 962 & 962 & 962 & 950 & 805 & 692 & 586 \\
\hline & 600 & 957 & 957 & 957 & 957 & 957 & 898 & 768 & 647 & 554 & 467 \\
\hline & 625 & 939 & 939 & 939 & 939 & 869 & 729 & 621 & 521 & 444 & 372 \\
\hline & 650 & 921 & 921 & 921 & 836 & 709 & 592 & 502 & 419 & 355 & 296 \\
\hline & 675 & 891 & 891 & 824 & 685 & 578 & 480 & 405 & 337 & 284 & 236 \\
\hline & 700 & 860 & 808 & 679 & 561 & 472 & 390 & 328 & 271 & 228 & 188 \\
\hline & 725 & 816 & 668 & 559 & 460 & 385 & 316 & 265 & 218 & 182 & 150 \\
\hline & 750 & 771 & 553 & 460 & 377 & 314 & 257 & 214 & 175 & 146 & 119 \\
\hline & 775 & 677 & 457 & 379 & 309 & 256 & 208 & 173 & 141 & 117 & 95 \\
\hline & 800 & 565 & 378 & 312 & 253 & 209 & 169 & 140 & 113 & 93 & 76 \\
\hline & 825 & 472 & 313 & 257 & 207 & 170 & 137 & 113 & 91 & 75 & 60 \\
\hline & 850 & 394 & 259 & 212 & 170 & 139 & 111 & 91 & 73 & 60 & 48 \\
\hline
\end{tabular}

2-6.2. Fatigue diagrams

2-6.2.1. Alloy $740 \mathrm{H}$

The design fatigue relation for Alloy $740 \mathrm{H}$ is defined by the equation:

for and by

for .

Table 2-6.2.1 tabulates the design fatigue relation for $740 \mathrm{H}$. 


\begin{tabular}{lll}
\hline Cycles & $\begin{array}{c}\text { Strain range } \\
(\mathrm{mm} / \mathrm{mm})\end{array}$ & $\begin{array}{c}\text { Strain range } \\
(\mathrm{mm} / \mathrm{mm})\end{array}$ \\
\hline 10 & 0.018733 & 0.014665 \\
20 & 0.015615 & 0.012790 \\
40 & 0.013220 & 0.011154 \\
100 & 0.010855 & 0.009308 \\
200 & 0.009504 & 0.008118 \\
400 & 0.008427 & 0.007080 \\
1000 & 0.007236 & 0.005908 \\
2000 & 0.006336 & 0.005153 \\
4000 & 0.005618 & 0.004494 \\
10000 & 0.004875 & 0.003750 \\
20000 & 0.004427 & 0.003271 \\
40000 & 0.004051 & 0.002852 \\
100000 & 0.003639 & 0.002380 \\
\hline
\end{tabular}

Table 2-7.2.1. Design fatigue relation for Alloy $740 \mathrm{H}$.

Figure 2-6.2.1 plots the design fatigue relation for $740 \mathrm{H}$.

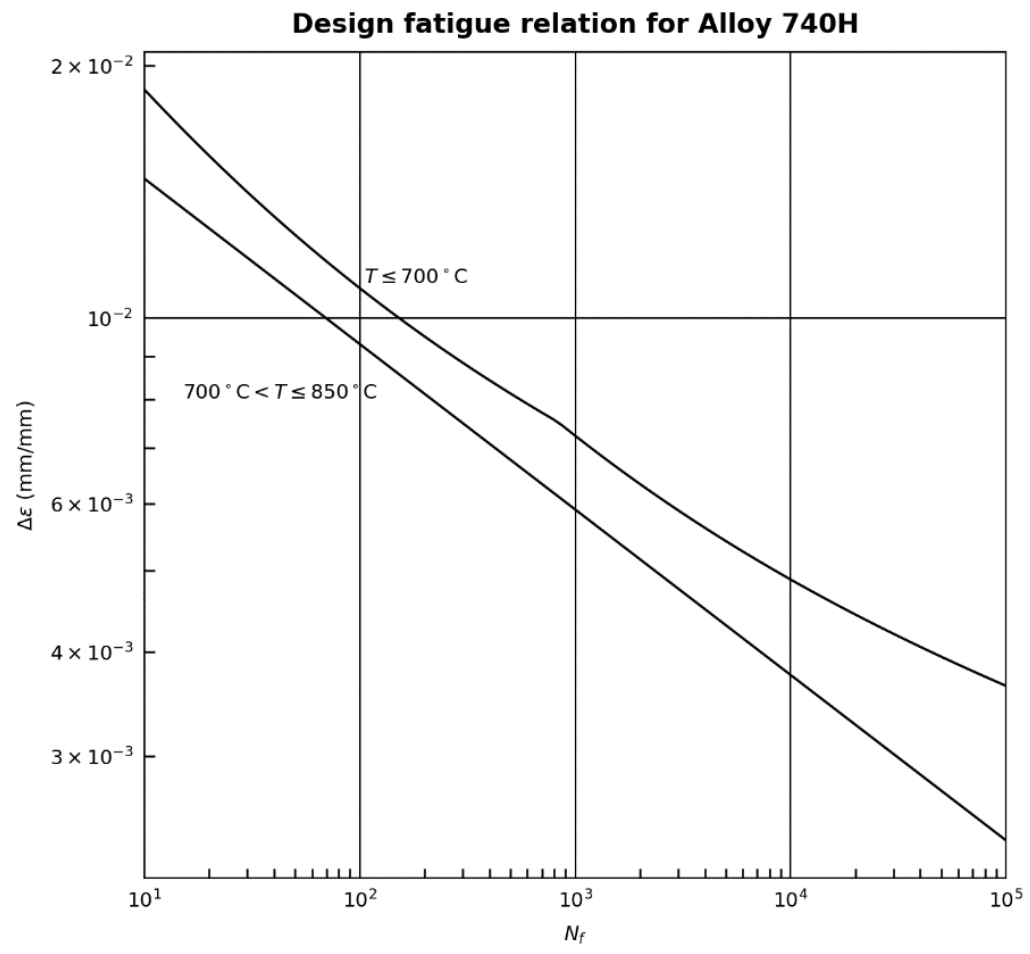

Figure 2-6.2.1. Design fatigue relation for Alloy $740 \mathrm{H}$. 


\section{2-6.3. Creep-fatigue damage envelopes}

\section{2-6.3.1. Alloy $740 \mathrm{H}$}

Figure 2-6.3.1 provides the creep-fatigue damage envelope for Alloy $740 \mathrm{H}$. Regions below the curve are acceptable.

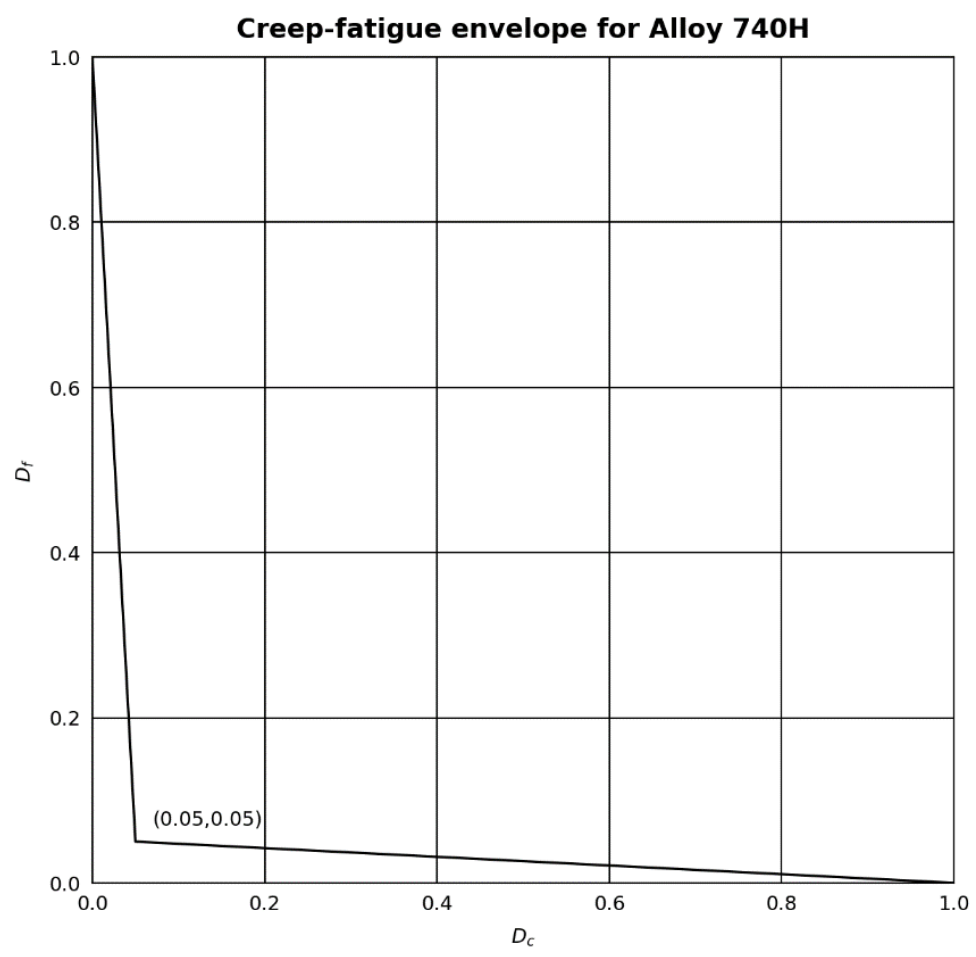

Figure 2-6.3.1. Creep-fatigue damage envelope for Alloy $740 \mathrm{H}$.

\section{2-7. Weld strength reduction factors}

\section{2-7.1. Alloy $740 \mathrm{H}$}

Table 2-7.1 lists weld strength reduction factor corresponding to each allowable Alloy $740 \mathrm{H}$ weld type:

\begin{tabular}{ccc}
\hline Weld type & Temperature & Stress rupture factor \\
\hline GTAW or GMAW, matching filler & & 0.7 \\
\hline Table 2-7.1. Weld stress rupture factors for Alloy $740 \mathrm{H}$
\end{tabular}

Notes:

Table 2-7.1. Weld stress rupture factors for Alloy $740 \mathrm{H}$

1 Welds shall be post-weld heat treated according to the criteria described in ASME B\&PV Code Case $2702(\mathrm{e})$. 


\section{2-8. Isochronous stress-strain relations}

\section{2-8.1. Alloy $740 \mathrm{H}$}

The isochronous stress-strain relations for Alloy $740 \mathrm{H}$ are described by the following equations where is the total strain, the stress, temperature, and time:

Article 2-2.1.1 provides the Young's modulus, . Tables 2-8.1.1 and 2-8.1.2 lists the parameters for the equations. For Table 2-8.1.1 parameters shall be interpolated linearly between temperatures in the table. The units for temperature are, stress is in $\mathrm{MPa}$, time in hours, and strains in $\mathrm{mm} / \mathrm{mm}$. The relations shall not be used for temperatures outside those provided in Table 2-8.1.1, i.e. the relations are only valid for . In these equations the shear modulus shall be calculated with the formula

with the Young's modulus defined in Article 2-2.1.1 and the Poisson's ratio defined in Article 2-2.2.1.

\begin{tabular}{|c|c|c|c|c|c|c|}
\hline \multirow{2}{*}{ Temperatures } & \multicolumn{3}{|c|}{ Ramberg-Osgood model parameters } & \multicolumn{3}{|c|}{ Voce hardening model parameters } \\
\hline & (MPa) & $\mathrm{K}$ & $\mathrm{n}$ & (MPa) & (MPa) & \\
\hline $600^{\circ} \mathrm{C}-700^{\circ} \mathrm{C}$ & 400.24 & 0.0704 & 6.6480 & & & \\
\hline $725^{\circ} \mathrm{C}$ & 374.20 & 0.0357 & 7.1315 & & & \\
\hline $750^{\circ} \mathrm{C}$ & 348.16 & 0.0181 & 7.6150 & & & \\
\hline $775^{\circ} \mathrm{C}$ & 312.255 & 0.0055 & 10.971 & & & \\
\hline $800^{\circ} \mathrm{C}$ & 276.35 & 0.0017 & 14.327 & 574.991 & 455.850 & 908.324 \\
\hline $825^{\circ} \mathrm{C}$ & & & & 521.631 & 319.315 & 2212.205 \\
\hline $850^{\circ} \mathrm{C}$ & & & & 468.271 & 182.780 & 3516.087 \\
\hline
\end{tabular}

Table 2-8.1.1. Parameters for the contribution to the Alloy $740 \mathrm{H}$ isochronous stress-strain relation. 


\begin{tabular}{ll}
\hline Parameter & Value \\
\hline & $1.19 \times 10^{10} \mathrm{hr}^{-1}$ \\
$\mathrm{k}$ & $1.38064 \times 10^{-20} \mathrm{~mJ} / \mathrm{K}$ \\
$\mathrm{b}$ & $2.53 \times 10^{-07} \mathrm{~mm}$ \\
$\mathrm{~A}$ & -10.98557 \\
$\mathrm{~B}$ & -0.53098
\end{tabular}

Table 2-8.1.2. Parameters for the contribution to the Alloy $740 \mathrm{H}$ isochronous stress-strain relation.

Figures 2-8.1.1 to 2-8.1.11 plot the isochronous stress-strain relations for Alloy $740 \mathrm{H}$. 


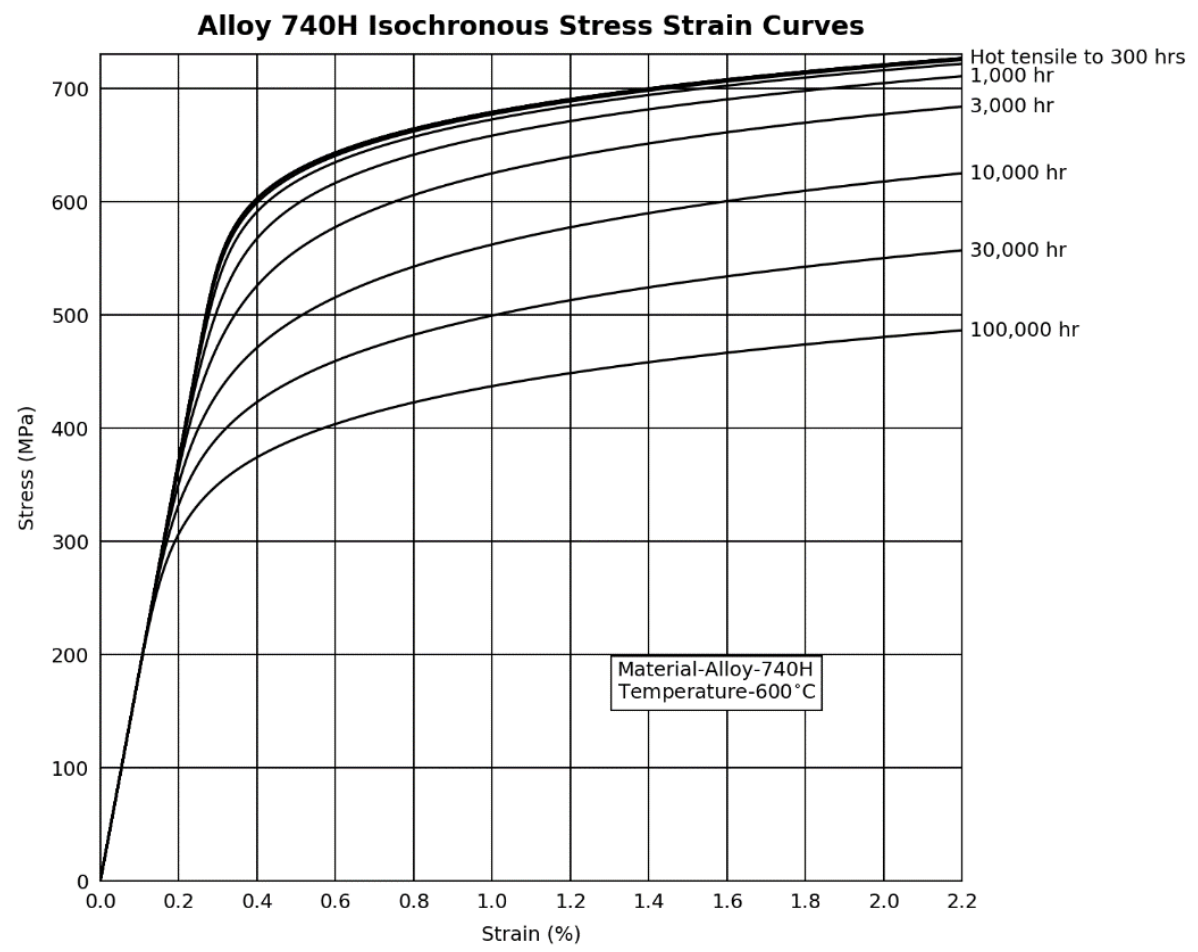

Figure 2-8.1.1. Design isochronous stress-strain curve for Alloy $740 \mathrm{H}$ at $600^{\circ} \mathrm{C}$.

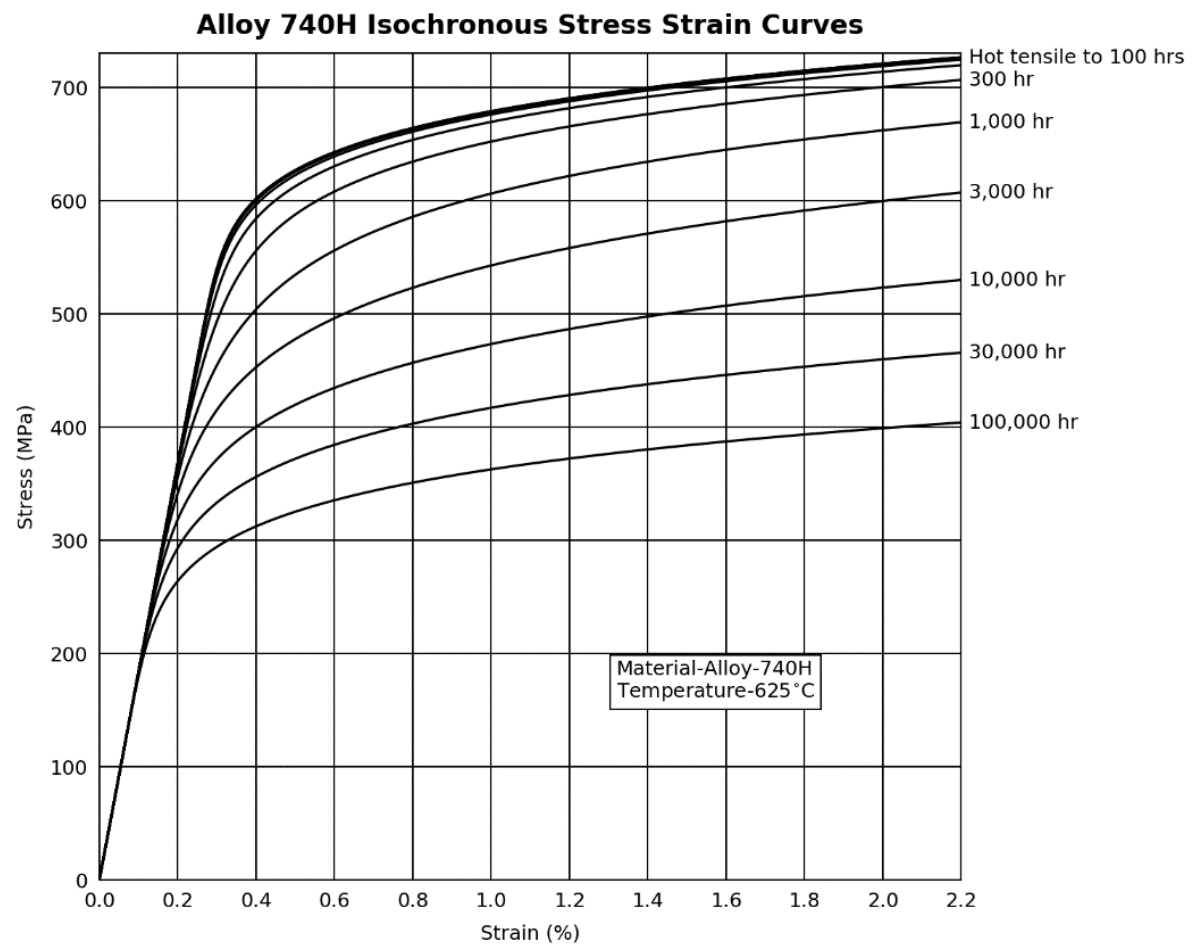

Figure 2-8.1.2. Design isochronous stress-strain curve for Alloy $740 \mathrm{H}$ at $625^{\circ} \mathrm{C}$. 


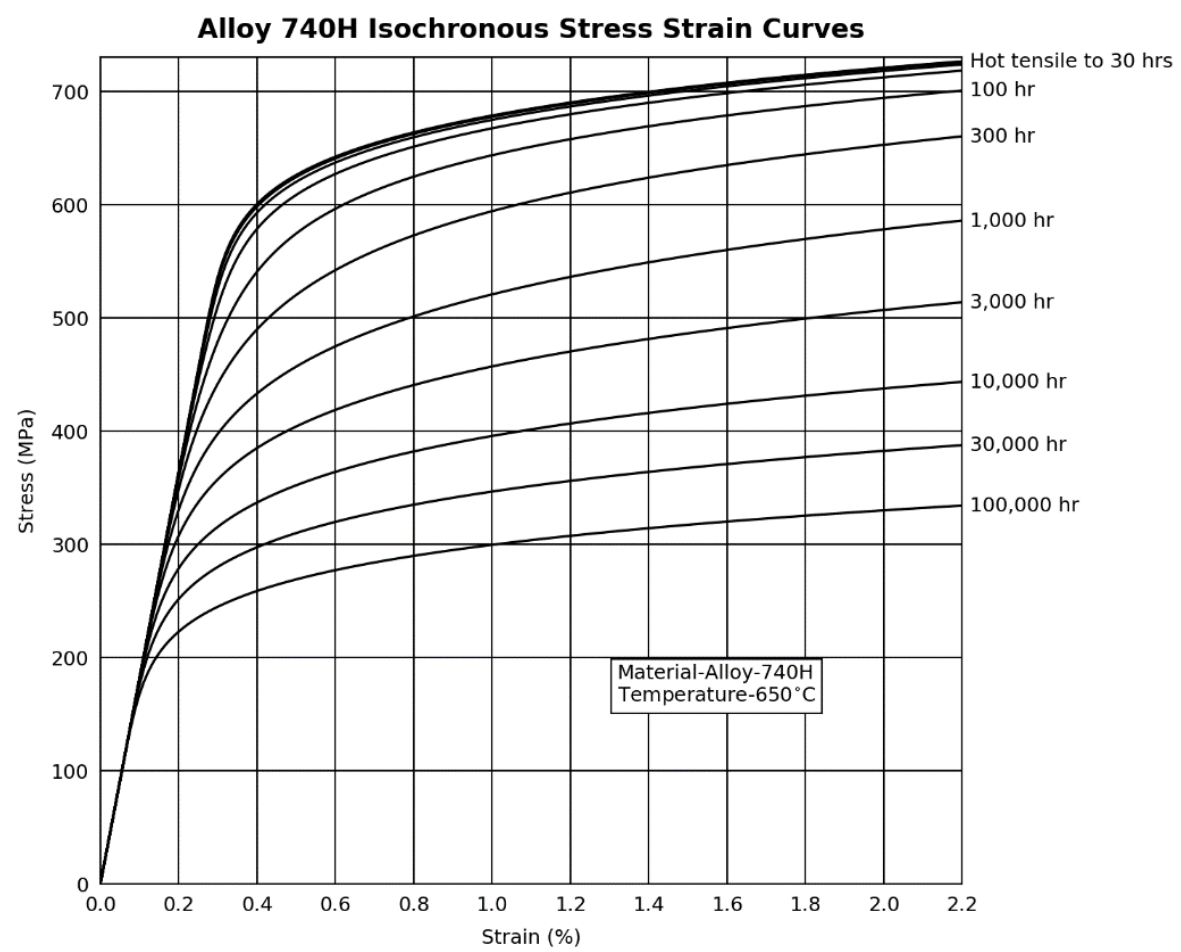

Figure 2-8.1.3. Design isochronous stress-strain curve for Alloy $740 \mathrm{H}$ at $650^{\circ} \mathrm{C}$.

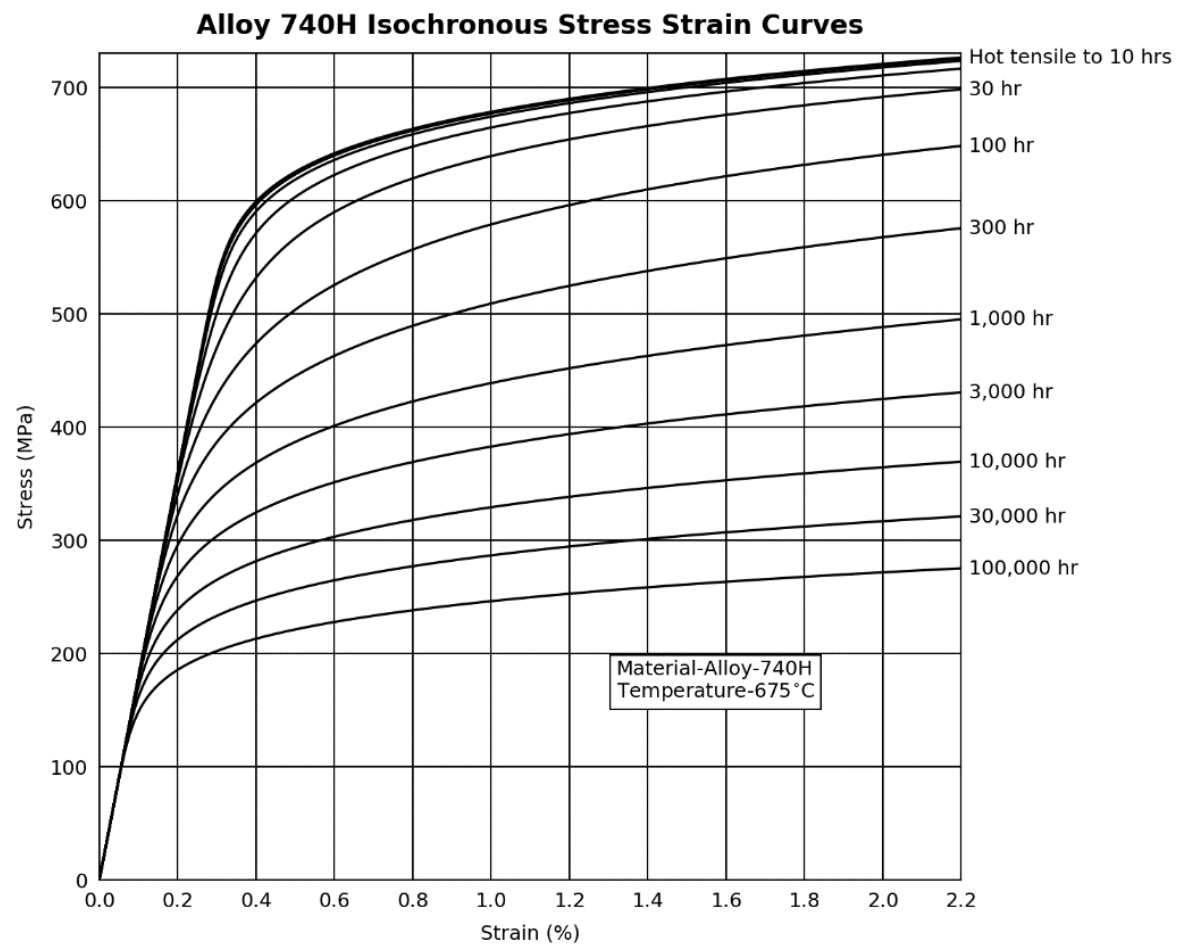

Figure 2-8.1.4. Design isochronous stress-strain curve for Alloy $740 \mathrm{H}$ at $675^{\circ} \mathrm{C}$. 


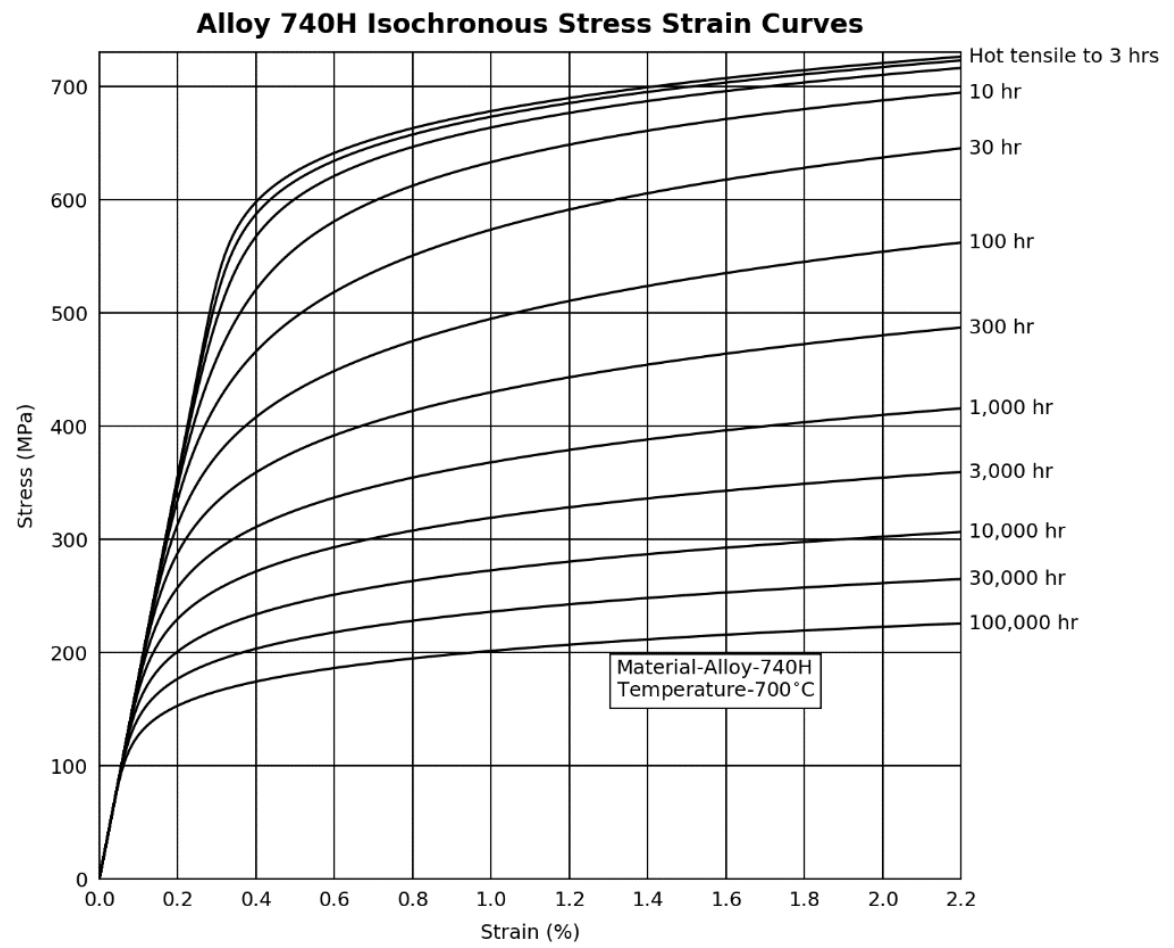

Figure 2-8.1.5. Design isochronous stress-strain curve for Alloy $740 \mathrm{H}$ at $700^{\circ} \mathrm{C}$.

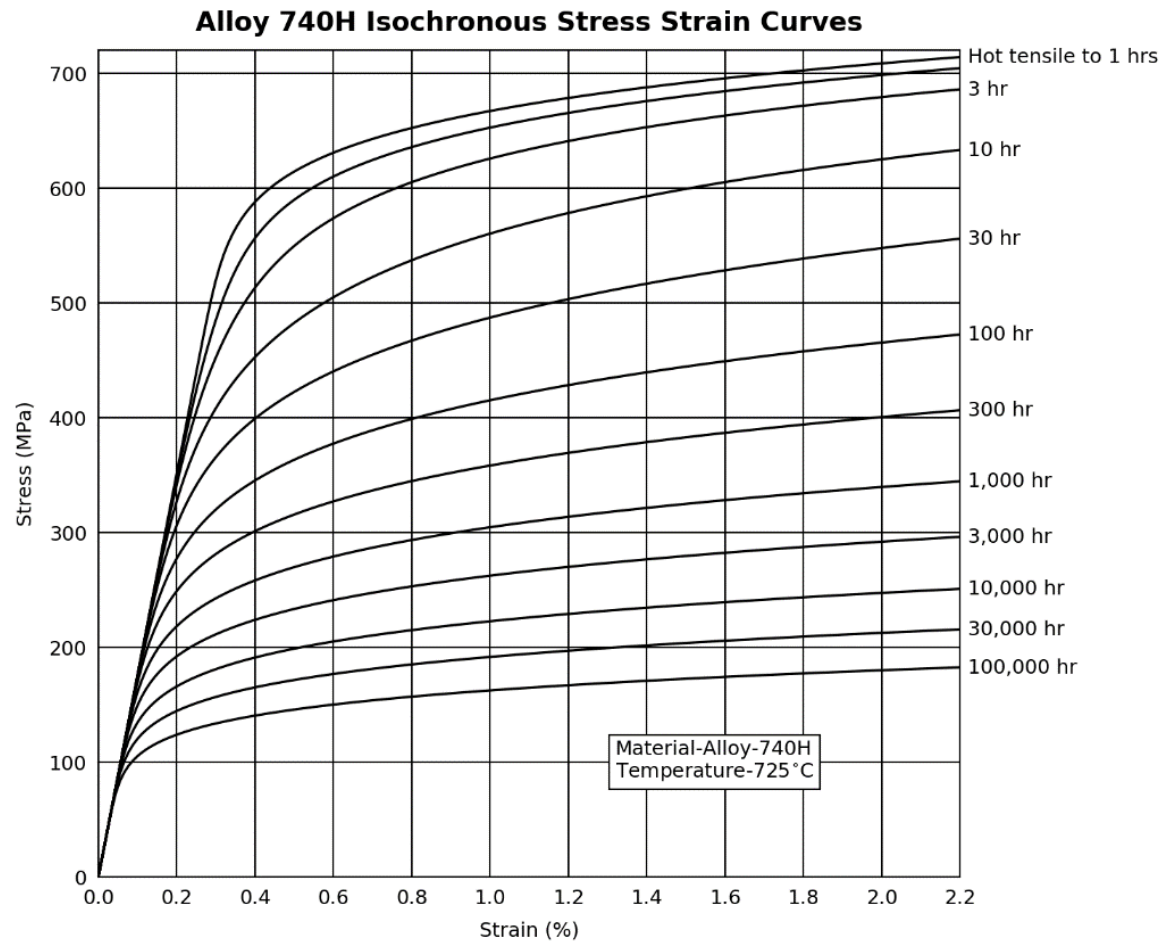

Figure 2-8.1.6. Design isochronous stress-strain curve for Alloy $740 \mathrm{H}$ at $725^{\circ} \mathrm{C}$. 


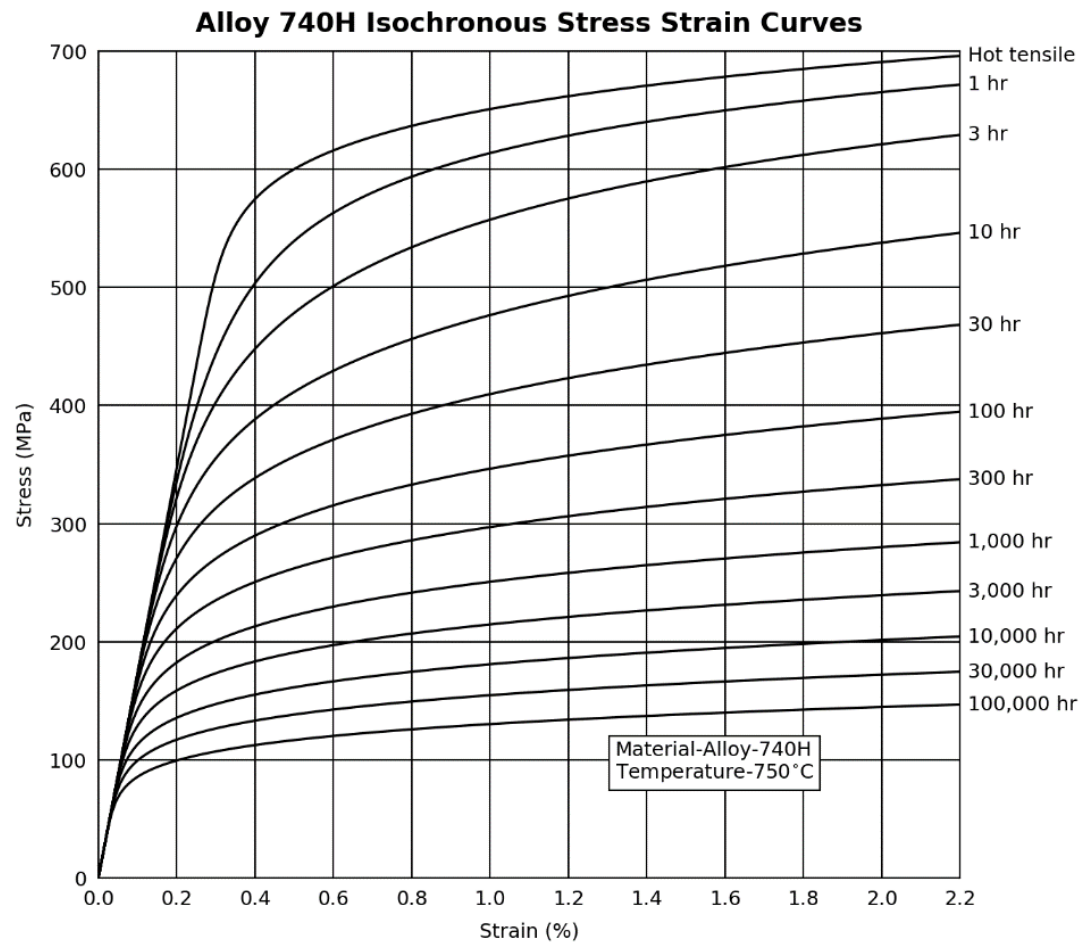

Figure 2-8.1.7. Design isochronous stress-strain curve for Alloy $740 \mathrm{H}$ at $750^{\circ} \mathrm{C}$.

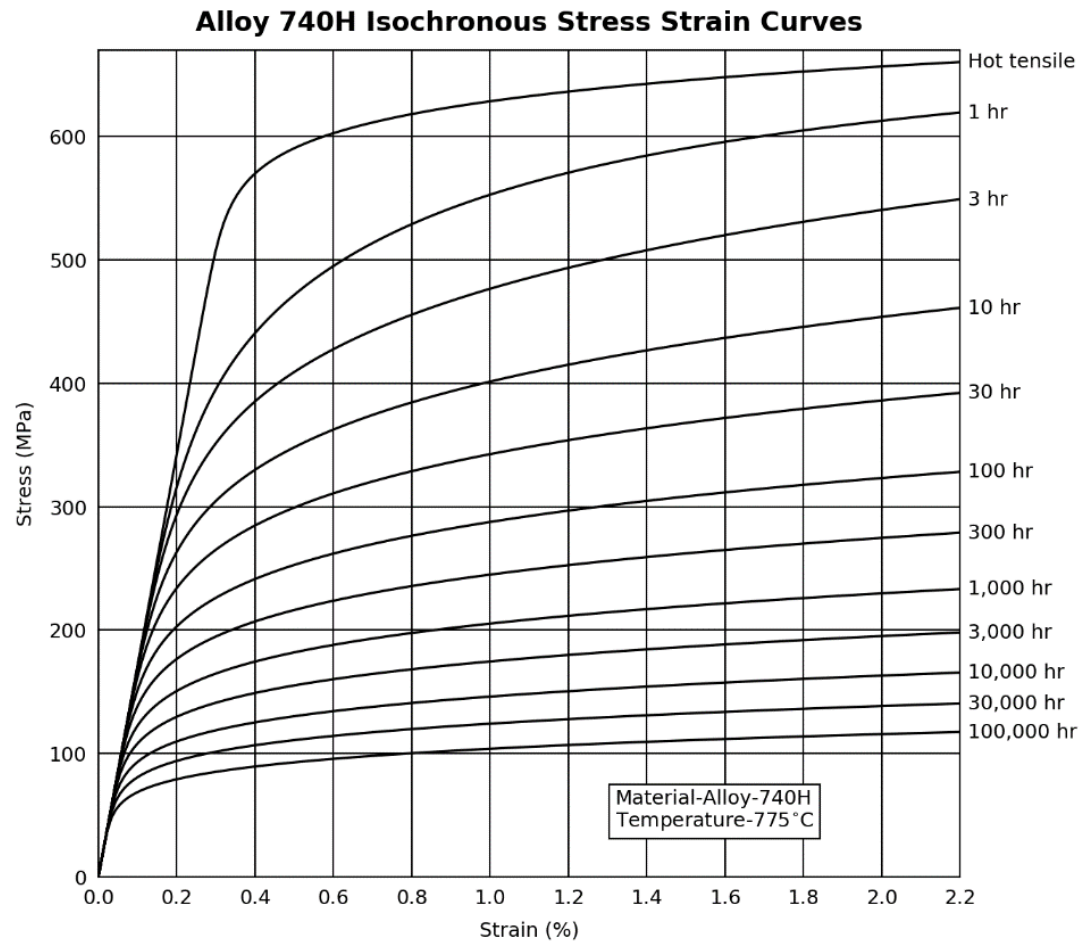

Figure 2-8.1.8. Design isochronous stress-strain curve for Alloy $740 \mathrm{H}$ at $775^{\circ} \mathrm{C}$. 


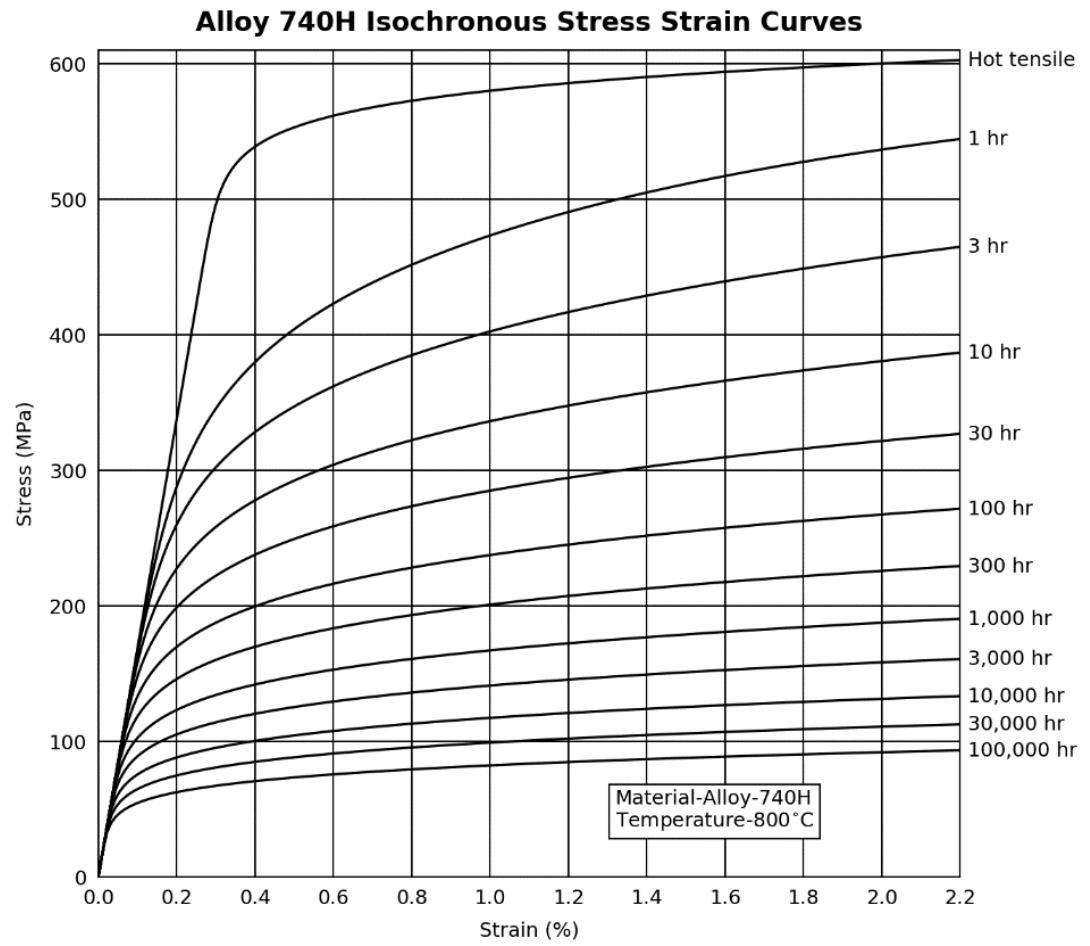

Figure 2-8.1.9. Design isochronous stress-strain curve for Alloy $740 \mathrm{H}$ at $800^{\circ} \mathrm{C}$.

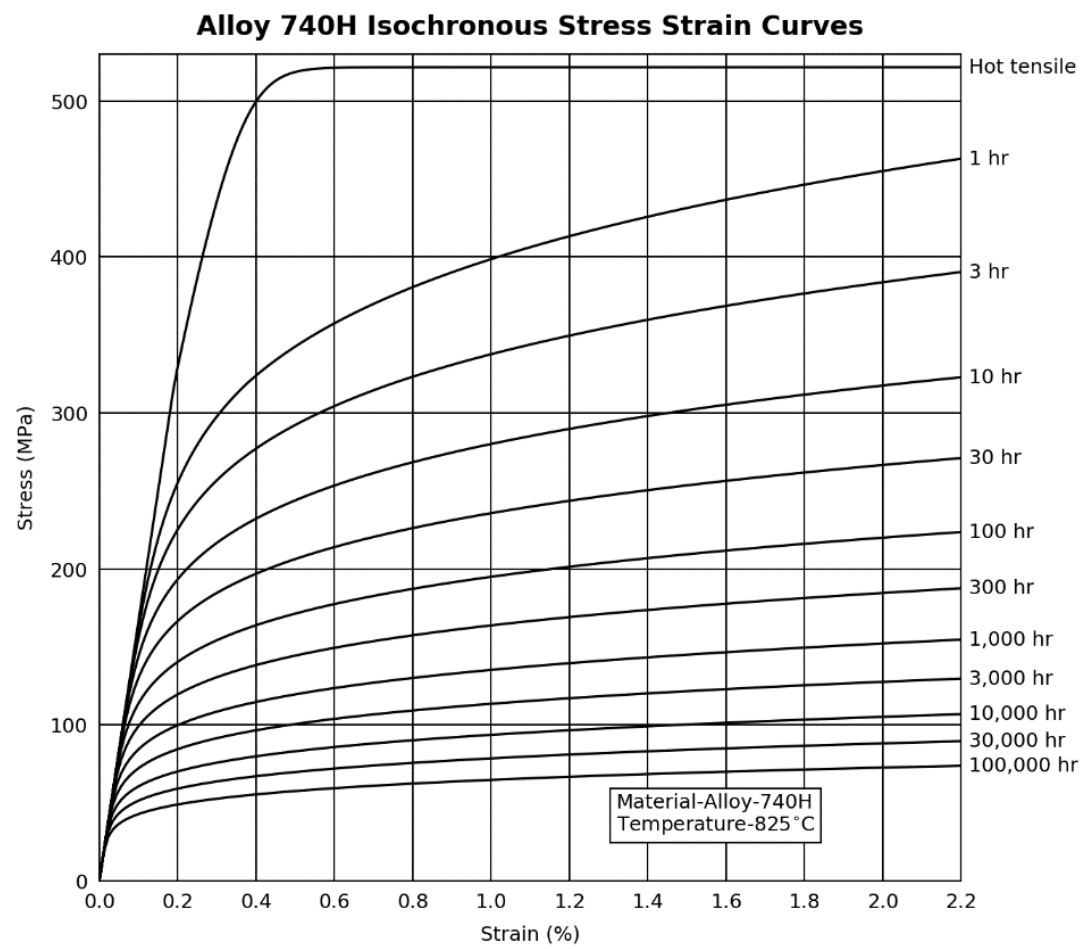

Figure 2-8.1.10. Design isochronous stress-strain curve for Alloy $740 \mathrm{H}$ at $825^{\circ} \mathrm{C}$. 


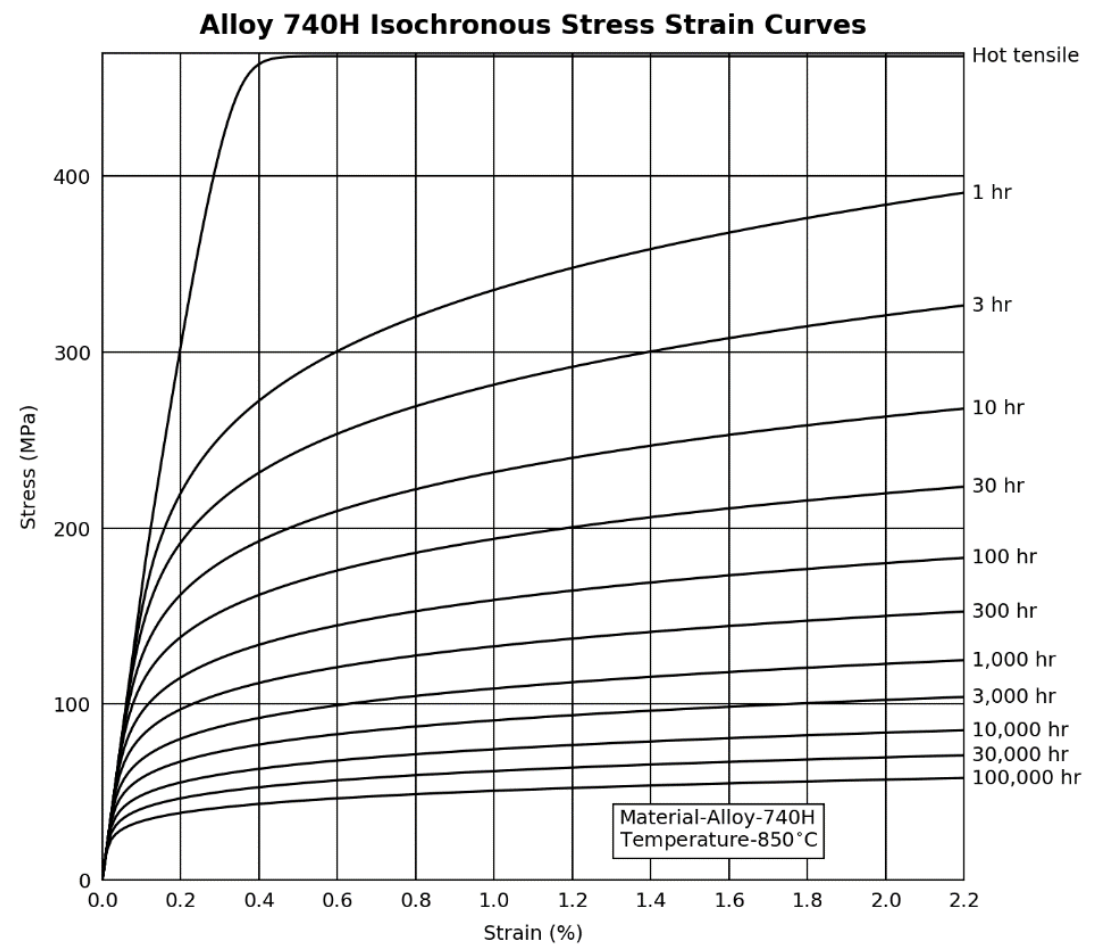

Figure 2-8.1.11. Design isochronous stress-strain curve for Alloy $740 \mathrm{H}$ at $850^{\circ} \mathrm{C}$.

\section{2-9. Inelastic constitutive models}

\section{2-9.1. Alloy $740 \mathrm{H}$}

The follow inelastic constitutive model may be used for Alloy $740 \mathrm{H}$ for :

with the rate of the Cauchy stress tensor, the isotropic elasticity tensor constructed using the temperature-dependent Young's modulus provided in Article 2-2.1.1 and Poisson's ratio provided in Article 2-2.2.1, is the total strain rate, is the thermal strain rate provided by the equation

with the instantaneous coefficient of thermal expansion provided in Article 2-3.1, the temperature rate, and the identity tensor, and is the creep strain rate provided by the equation

where Article 2-8.1 defines the parameters in this equation, , and is the deviatoric stress tensor. 
2-10. Temperature limits

2-10.1. Minimal creep threshold

2-10.1.1. Alloy $740 \mathrm{H}$

The temperature at which Alloy $740 \mathrm{H}$ accumulates $0.1 \%$ strain at a stress of over 100,000 hours life is $595^{\circ} \mathrm{C}$.

2-10.2. Limit on O'Donnell-Porowski method

2-10.2.1. Alloy $740 \mathrm{H}$

The cutoff temperature for the B-1 and B-2 tests in ASME Section III, Division 5, HBB$\mathrm{T}-1332$ is $600^{\circ} \mathrm{C}$ for Alloy 740 . 


\section{Part 3: Commentary}

\section{3-1. Overview}

The purpose of the design methods and material data contained in this report is to enable the design of components for solar receivers that operate in conditions where secondary stresses can cause significant creep or creep-fatigue damage. In the context of solar systems, secondary stresses are typically thermal stresses and primary stresses are typically caused by pressure. Therefore, these design criteria are shaped towards structures that see low pressures but high thermal gradients, operate at high temperatures in the creep regime, and see daily load cycling. These conditions point towards eventual component failure via creep or creep-fatigue damage accumulated during daily application and relaxation of the thermal stress, rather than creep failure caused by long times at constant pressure loads.

Commercial practice, for example Sections I and VIII of the ASME Boiler and Pressure Vessel Code, guards against creep failure under primary loads by including creep rupture properties in the high temperature allowable stresses. This approach is reasonable for components that see long periods of hold time at fixed conditions and limited numbers of load cycles. It is less reasonable for components which see large numbers of load cycles, like CSP systems, as it does not account for the damaging effect of secondary load. Figure 3-1.1 illustrates the differences between steady state load conditions, traditional high temperature nuclear systems assuming a moderate amount of load cycling interspersed with relatively long hold periods, and CSP systems by illustrating representative stress/time histories

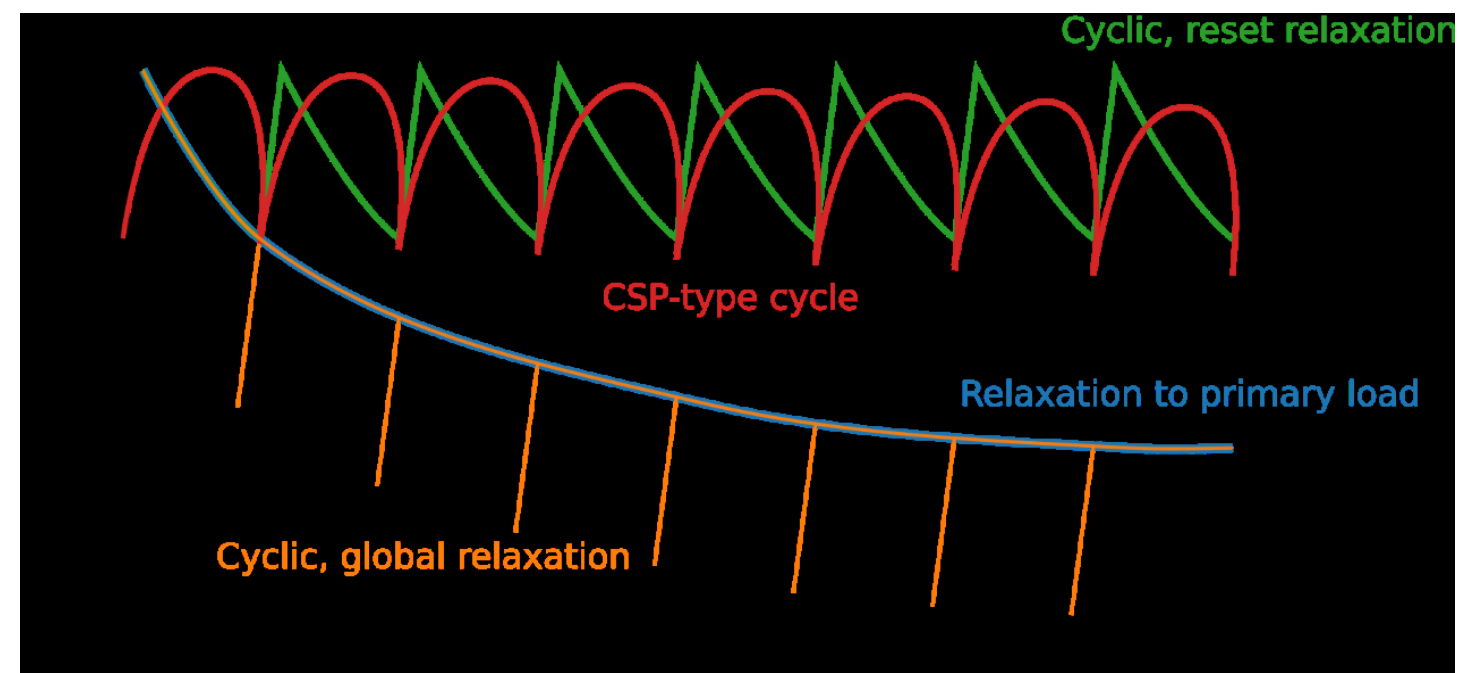

Figure 3-1.1. Illustration of four different types of loading histories: (1) Steady-state, non-cyclic loading where the component stresses relax to the primary load. (2) Cyclic load where the secondary stresses do not cause the component to reset to the initial value of load. (3) Cyclic load where the secondary stresses cause the component to reset to the initial, high level of stress each cycle. (4) A prototypical

CSP load cycle where the loads increase and decrease gradually throughout the cycle period. Conventional Section I and Section VIII design assumes a load of type (1), Section III, Division 5 high temperature nuclear design assumes either (2) or (3) with criteria to determine if the global relaxation mode occurs. This report provides design rules suitable for load type (4). 
The key challenge to address in developing an adequate high temperature CSP design method is to guard against creep and creep-fatigue damage caused by cyclic secondary stresses. In the context of a tubular receiver these stresses would be the daily application of the thermal stress caused by both the through-wall and circumferential thermal gradients. However, the design criteria also provide:

1. allowable stress criteria for steady-state primary loads to maintain compatibility with current commercial practice and to provide a minimum section thickness;

2. ratcheting design criteria to prevent service failures caused by excess deformation;

3. buckling criteria, to prevent both time-independent elastic-plastic buckling and time-dependent buckling caused by creep deformation.

However, for the sample designs considered in Part IV it is creep damage caused by the daily application of secondary thermal stresses that dictates the maximum design life of the component. The design rules below lump this damage mechanism in with creep-fatigue design. Indeed, as Figure 3-1.2 illustrates, creep-relaxation damage caused by secondary loads is one end of the spectrum of loadings encompassed by the creep-fatigue design procedures. On the other end of the spectrum is pure fatigue damage and in between lies creep-fatigue interaction. If the components sampled in Part IV operated at somewhat lower metal temperatures then creep-fatigue interaction would control the component life. If they operated at much lower temperatures then pure fatigue damage would control the life. The creep-fatigue interaction diagram therefore encompasses the full range of failure mechanism for low pressure, high thermal stress components.

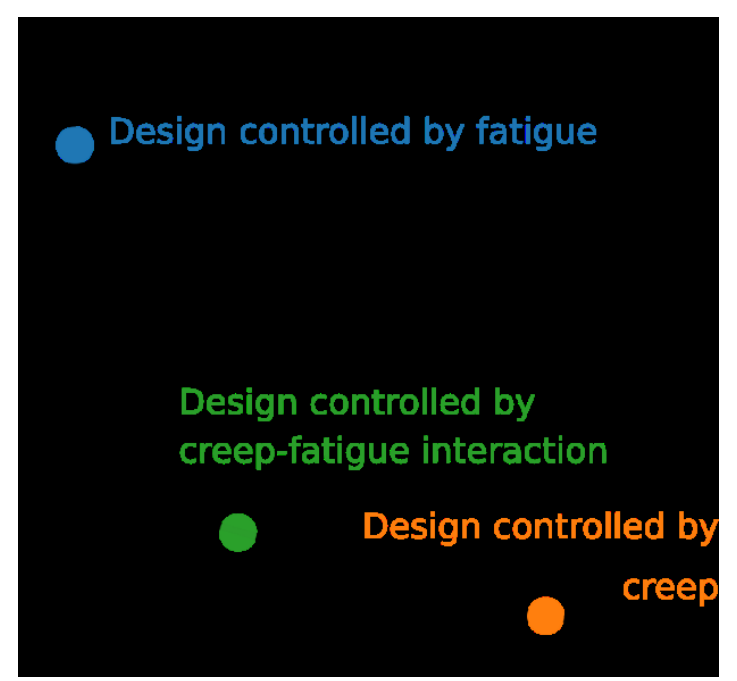

Figure 3-1.2. Illustration of how the creep-fatigue checks used here encompass failure by pure fatigue, failure by pure creep, and failure by creep-fatigue interaction. The region of the design envelope an efficient component occupies depends on the relative severity of the primary and secondary load, the type of load cycle, and the average metal temperature.

The design rules in Part I are given procedurally and the component must pass all the required design checks to be considered adequate. However, for the types of CSP components envisioned when creating these design processes a more practical process 
would be to first find the minimum component thickness using the primary load, allowable stress design procedures. If the primary stress is low, as for the sample problems in Part IV, this minimum thickness might be too thin to feasibly manufacture. If so, this minimum thickness should be increased to the thinnest manufacturable section.

Once this thinnest section has been determined the designer should evaluate creepfatigue damage using one of the options presented in Part I. If the component passes the creep-fatigue criteria using the minimum section thickness determined above then the designer can proceed to evaluating the remaining criteria (ratcheting and buckling). These will only rarely constrain the design - most often the design thickness will be determined by the tradeoff between the primary load allowable stresses and the secondary creep-fatigue checks.

Figure 3-1.3 illustrates this tradeoff and demonstrates that if the design does not pass the creep-fatigue check for the minimum section thickness determined by the primary load design then the component will need to be reconfigured - increasing the section thickness will only increase the secondary load on the component and make it more difficult to pass the creep-fatigue criteria. At high metal temperatures CSP components will be constrained by the minimum section thickness provided by the primary load design criteria and the maximum section thickness provided by the creep-fatigue design criteria.

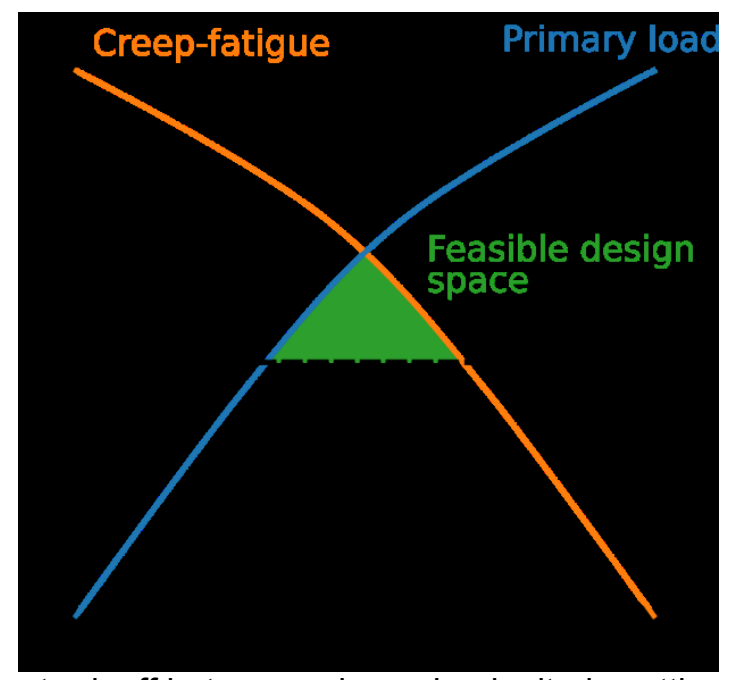

Figure 3-1.3. Illustration of the tradeoff between primary load criteria setting a minimum section thickness and creep-fatigue criteria setting a maximum section thickness. The green shaded region is that feasible design space - the thicknesses that meet or exceed the target design life. Note that the minimum primary load section thickness provides the most economic design, hence the design strategy suggested here.

The ratcheting and buckling criteria represent important potential failure modes but rarely constrain the design of CSP components. The design should check these criteria only after they achieve a feasible design considering the primary load and creep-fatigue design provisions. 


\section{3-2. Commentary on the Design Rules}

\section{3-2.1. General Criteria}

The high temperature/low temperature cutoff is standard ASME practice $-370^{\circ} \mathrm{C}$ for ferritic and ferritic-martensitic steels and $425^{\circ} \mathrm{C}$ for austenitic stainless steels and nickel-based alloys. CSP components are likely to spend most or all of their service life in the creep regime and so these rules focus exclusively on high temperature applications.

The design provisions here are focused on CSP structures undergoing daily cycling. They may not be adequate for structures with long hold times. The threshold temperature was based on the temperature at which the material accumulates $0.1 \%$ strain at the allowable stress over 100,000 hours. This is essentially a negligible creep criteria.

Several of the Design Options are modifications of the Section III, Division 5 ASME Boiler and Pressure Vessel Code rules covering the design of high temperature nuclear reactor components. These modifications were developed starting from the 2019 edition of the ASME Code.

To simplify the design process these rules work with a single, representative Design Cycle. This is a collection of periodic structural and thermal boundary conditions that adequately represent the operating cycle of the component. For a CSP system this would likely be a daily cycle that reasonably represents the standard operation of the facility. An example for a solar receiver could be the service conditions on the solar equinox. Section III, Division 5 of the ASME Code contains rules for evaluating several different types of loading cycles with different expected frequencies. The current rules could be extended to cover multiple cycle types at the expense of a more complicated design process.

The design methods here use a similar database of material properties to the ASME rules, but alter the design margin encoded in the ASME data to reflect the relative consequences of failure between CSP and nuclear systems. As such, the design rules should be used with the provided material data, not the information in Section III of the ASME Code.

The rules here only cover component design. A complete design and construction code would require rules for construction, welding, examination, and inspection. The Design Specification could provide these criteria by reference to the ASME Code. Structures passing these design rules should also pass the Section VIII, Division 2 design by analysis criteria. These provisions could then be used to supplement the design of a Code-stamped component to ensure the component will perform well under cyclic conditions at high temperatures - conditions not currently considered in detail by either Section I or Section VIII.

\section{3-2.2. Design Option A}


This design option is based on the Section III, Division 5 ASME Boiler and Pressure Vessel Code covering the design and construction of high temperature nuclear reactors. The design methods contained in Section III, Division 5 are well documented ${ }^{1,2}$ and so this commentary only provides a general overview of the approach. The focus of the commentary is on the modifications made to the base ASME method to account for the unconventional operating cycles and temperatures of CSP systems as well as modifications made to account for the lower consequences of failure when comparing nuclear reactors to CSP facilities.

The Section III, Division 5 checks mirror those used in these design rules. The Code mandates a primary load check against allowable stresses plus checks for ratcheting, creep-fatigue, and buckling. The methods used in Design Option A are those from the ASME Code simplified, modified, and with reduced design margin.

\section{3-2.2.1. Primary load}

Section III, Division 5 actually contains two primary load design checks: one mirroring the Section I / Section VIII allowable stress checks where the primary stress is compared to some temperature-dependent but time-independent allowable stress . This check uses a design temperature and pressure that bound the standard, nonfaulted service conditions. The Code also has second primary stress check against a time- and temperature-dependent allowable stress. This check uses the Service Loads provided by the Owner's Design Specification. The nuclear code accounts for different expected frequencies and severities of loading by providing A, B, C, and D Service Load categories. The time-dependent primary load check uses different margins depending on the load category. Finally, Section III, Division 5 requires not only that each individual Service Load pass the allowable stress check but also that the timefraction of all the service loadings combined remains less than one.

As discussed above, these rules for CSP components operate only with a single Design Cycle. This is a compromise between Section I and VIII practice, which only typically use Design Conditions and do not account explicitly for cyclic service, and the Section III, Division 5 practice of evaluating the component against all expected transients, classifying each particular transient based on its severity and expected frequency.

The rules retain a check against a time-independent allowable stress using the primary stress from a set of Design Conditions, now determined as the bounding temperature, pressure, and nozzle loads from the Design Cycle. This is analogous to current Section I and VIII commercial practice. The design rules omit the Section III, Division 5 check against time-dependent allowable stress and the use-fraction check for several reasons:

1. This retains the direct connection to current commercial practice and does not add the complication of an additional time-dependent allowable stress check.

\footnotetext{
${ }^{1}$ R. I. Jetter, "Subsection NH-Class 1 Components in Elevated Temperature Service" in Companion Guide to the ASME Boiler and Pressure Vessel Code, Volume 1, K. R. Rao ed. ASME Press, New York, NY, 2009.

${ }^{2}$ M. H. Jawad, and R. I. Jetter, Design \& Analysis of ASME Boiler and Pressure Vessel Components in the Creep Range. ASME Press, New York, NY, 2009.
} 
2. As discussed above, the primary load check for CSP systems in unlikely to be the controlling factor. The main point of the primary load check in high temperature CSP systems is to provide a reasonable minimum section thickness, which can be done without invoking time-dependent allowables.

3. The allowable stress is based on 100,000 hour extrapolated creep properties. This is not far removed from 10-30 year design lives for actual components.

The determination of the allowable stress values is discussed below in 3-3.7. This process is essentially consistent across Section III, Division 5 and Section I/Section VIII, Division 2 and so a reasonable modification of the design rules could be to use Section I or Section VIII rules to first design the component and then apply the ratcheting, creepfatigue, and buckling checks provided in these rules. This would be consistent with the complete approach described above and yet also ensure the component passes the Section I or Section VIII criteria.

The Section III, Division 5 allowable stress has two parts: a time-independent allowable stress and a time-dependent allowable stress . is simply the lesser of the two for a given time and temperature. While the design rules use neither stress as an allowable stress, the Section III, Division 5 ratcheting and creep-fatigue rules use the values of to bound the time-independent initial stresses experienced by a component. As such, Design Option A requires values of to complete the ratcheting and creep-fatigue design checks. Section 3-3.8 describes how these values are obtained.

HBB-3222.1(c) requires a buckling check per the Section III, Division 5 rules. The present design rules provide an alternative method for assessing buckling failure.

\section{3-2.2.2. Ratcheting Strain Accumulation}

The design rules use a simplified version of the B-1 test from Section III, Division 5, Subsection HB, Subpart B, Nonmandatory Appendix T. The B-1 test is an implementation of the O'Donnell-Porowski ${ }^{3}$ approach. This approach in turn builds on the classical work of Bree ${ }^{4}$ and so the ratcheting test is most accurate for cylindrical thin-walled pressure vessels. However, it can be conservatively used for other types of structures where the peak stress is negligible. If the structure has significant peak stress Design Option C can be used.

Essentially, the design rules retain the Section III, Division 5 approach and simply remove additional margin included in the nuclear code. The ASME implementation of the method increases the core stress calculated by O'Donnell-Porowski by $25 \%$. The design rules here do not increase the core stress. As such, this method uses a bestestimate of the accumulated strain, rather than the bounding values used in Section III, Division 5. Additionally, the design rules increase the allowable accumulated stains from $1 \%$ for base metal and $1 / 2 \%$ for welds to $2 \%$ for base metal and $1 \%$ for welds. This

\footnotetext{
${ }^{3}$ W. O'Donnell, and J. Porowski, "Upper bounds for accumulated strains due to creep ratcheting" Journal of Pressure Vessel Technology, 96(3), pp. 150-154, 1974.

${ }^{4} \mathrm{~J}$. Bree, "Elastic-plastic behavior of thin tubes subjected to internal pressure and intermittent high-heat fluxes with application to fast-nuclear-reactor fuel elements" Journal of Strain Analysis for Engineering Design, 2(3), pp. 226-238, 1967.
} 
reflects the reduced consequences of failure for CSP components and is in line with previous CSP design guidance.

The O'Donnell-Porowski method uses isochronous stress-strain curves to convert stress, temperature, and time into accumulated strain. Isochronous stress strain curves are a way to graphically depict a monotonic deformation relation for a material (see 3-3.14). They are constructed from a database of monotonic tension and creep tests and provide a simple way to link stress to deformation for materials at high temperature.

\section{3-2.2.3. Creep-fatigue criteria}

Creep-fatigue interaction describes extensive experimental data showing that the combination of cyclic strain controlled deformation interspersed with holds at constant strain is more damaging than either holding at constant strain or cycling with the same strain range but no hold periods. A variety of microstructural mechanisms have been posited to explain the interaction ${ }^{5,6,7}$, but for the purposes of developing design rules it is sufficient to note the empirical phenomenon.

Creep-fatigue interaction can be quantified using a creep-fatigue interaction diagram. This requires first selecting definitions for fatigue and creep damage individually. All modern high temperature design methods define fatigue damage using Miner's rules using strain-based, temperature-dependent fatigue diagrams. These diagrams are constructed from experimental data and show the number of cycles to failure for a given combination of temperature, strain range, and $\mathrm{R}$ ratio (see Section 3-3.11). Often fullyreversed loading () is most damaging and used to construct design fatigue curves. Fatigue damage is then defined as where is the actual number of cycles at fixed strain range and temperature and is the number of cycles to failure from the fatigue diagram.

The process of going from a full 3D strain state to a scalar strain range requires the definition of an effective strain range. These rules adopt the ASME definition.

There is an ongoing disagreement as to how to quantify creep damage at constant stress or constant strain. Several methods have been proposed and are in use in current design and fitness for service standards. These techniques include time fraction, used in the ASME Boiler and Pressure Vessel Code, ductility exhaustion ${ }^{8}$, used in the RCC-MRx and R5 Codes, and the Omega method ${ }^{9}$ used in API-579/ASME FFS-1. These different methods will all lead to somewhat different predictions for rupture given the same stress/strain/time history. However, studies have shown overall

\footnotetext{
${ }^{5}$ S. W. Nam, S. C. Lee, and J. M. Lee, "The effect of creep cavitation on the fatigue life under creep-fatigue interaction" Nuclear Engineering and Design, 153(2-3), pp. 213-221, 1995.

${ }^{6} \mathrm{~J}$. Wareing, "Creep-fatigue interaction in austenitic stainless steels" Metallurgical Transactions A, 8(5), pp. 711-721, 1977

${ }^{7}$ M. Sauzay, M. Mottot, L. Allais, M. Noblecourt, I. Monnet, and J. Périnet, "Creep-fatigue behaviour of an AISI stainless steel at $550^{\circ} \mathrm{C}^{\prime}$ Nuclear Engineering and Design, 232(3), pp. 219-236, 2004.

${ }^{8}$ R. M. Goldhoff, "Uniaxial Creep-Rupture Behavior of Low-Alloy Steel Under Variable Loading Conditions" Journal of Basic Engineering, 87(2), pp. 374-378, 1965.

${ }^{9}$ M. Prager, "Development of the MPC Omega Method for Life Assessment in the Creep Range" Journal of Pressure Vessel Technology, 117(2), pp. 95-103, 1995.
} 
they are all about equally accurate ${ }^{10,11}$. These design rules adopt the ASME timefraction approach.

Time fraction is a very straightforward method for calculating a creep damage fraction. It needs a scalar effective stress measure - a map from a 3D state of stress to a scalar stress - and a database of the material rupture stress as a function of time and temperature. The rupture stress information can be derived from creep test results (see 3-3.10). Given this information creep damage is defined as where is the time at fixed stress and temperature and is the time-to-rupture for that stress and temperature.

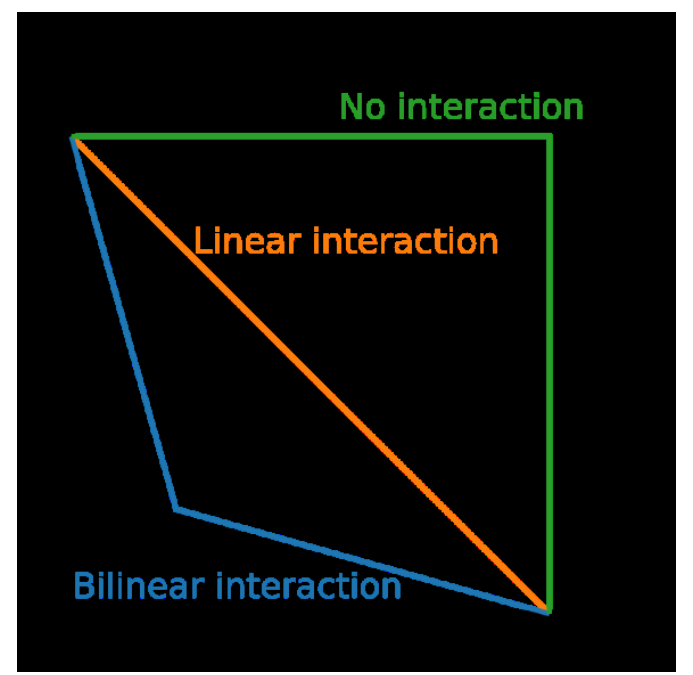

Figure 3-2.2.3.1. Various interaction types demonstrated on a creep-fatigue interaction diagram.

Given a definition of fatigue and creep damage a creep-fatigue interaction diagram can be constructed from a database of creep-fatigue test results. Creep fatigue tests, sometimes called dwell-fatigue tests, are strain-controlled cyclic tests with hold periods at constant strain on either or both of the maximum tension or maximum compression side of the cycle. Often these tests use fully reversed loading cycles, thought to be the most damaging. The full stress/strain/time hysteresis information is recorded during the test and this history used to calculate creep and fatigue damage using the corresponding definitions. Plotting the results of a number of creep-fatigue tests at different conditions produces a design envelope of the type sketched in Figure 3-2.2.3.1 (see Section 3-3.12). Note the definition of creep and fatigue damage affects the shape of the diagram - the same experimental data could produce different interaction diagrams using different definitions of damage. Therefore it is critical to use an interaction diagram calculated using consistent definitions of damage.

This process describe the generic creep-fatigue model used to calculate damage in the ASME Code and in all three design options described here. Design Option A uses the

\footnotetext{
${ }^{10}$ S.-L. Mannan, F.-Z. Xuan, X.-C. Zhang, Y.-C. Lin, S.-T. Tu, and X.-L. Yan, "Review of creep-fatigue endurance and life prediction of 316 stainless steels" International Journal of Pressure Vessels and Piping, 126-127, pp. $17-28,2014$.

${ }^{11}$ S. Zhang, and Y. Takahashi, "Evaluation of high temperature strength of a Ni-base alloy $740 \mathrm{H}$ for advanced ultra-supercritical power plant" in Proceedings from the Seventh International Conference on Advances in Materials Technology for Fossil Power Plants, 2013.
} 
ASME Section III, Division 5, Subsection HB, Subpart B design by elastic analysis rules to determine the strains, stresses, temperatures, and times required to calculate damage and check conditions against the design envelope. While the elastic method is venerable, it has been well-validated by past experience and has the important advantage over other methods in that it requires only a linear elastic stress analysis of a single cycle repetition. This means that while the design rules are somewhat complicated the design analysis is straightforward and easily accomplished.

For full details of the development of the design by elastic analysis method see the reference material on the Section III, Division 5 rules, cited above. This following provides a brief overview. This process must be repeated at each point in a component to find the limiting location.

1. Perform a linear elastic stress analysis of a loading cycle and extract the elastic strain range, using the ASME definition of effective strain range. The Section III, Division 5 rules provide methods for combining the effects of multiple types of load cycles. These rules are not relevant here, as the current design criteria work with a single Design Cycle.

2. Modify the elastically calculated strain range to account for plasticity and creep using bounding formula provided in the ASME Code.

3. Calculate the fatigue damage using the modified strain range.

4. Use one of the following two methods to construct a stress relaxation history:

a. Use the method of isochronous curves to calculate a stress relaxation history starting from the modified strain range determined above. The method of isochronous curves assumes that stress relaxation will follow the monotonic stress/strain/time relation described by the isochronous curves. This is a conservative bounding assumption - the real stress relaxation history will generally be less severe.

b. Use a differential description of the material's creep deformation to integrate a stress relaxation history starting from the strain range determined above. This approach is more accurate than the method of isochronous curves but requires solving an ordinary differential equation.

5. Use the stress relaxation history, divided by a design factor, to calculate creep damage.

6. Consult the creep-fatigue interaction diagram to determine whether the point passes the design criteria.

The modified rules for CSP structures given here follow this general process with several modifications from the ASME rules.

First, the design margin is modified to account for the relative consequences of failure between CSP and nuclear structures. The fatigue damage in the ASME nuclear code uses fatigue diagrams with factors of 20 on the number of cycles to failure and 2 on the strain range. These rules, as described in Section 3-3, adopt factors of 10 and 1.5. These rules divide the stress relaxation history by a factor 0.9 , retaining the ASME design by elastic analysis factor for creep damage. Additionally, as with the ASME approach, these rules use a statistical minimum stress to rupture to calculate creep damage, rather than the average property. The O'Donnell Porowski core stress and a 
material dependent relaxation strength are used to bound the amount of stress relaxation calculated with the method of isochronous curves. The ASME rules apply a factor of 1.25 on both quantities, here the rules do not increase these lower relaxation limits by any factor, instead using the average material property. Note the current rules provide values of the relaxation strength (see 3-3.9), whereas the current ASME rules require the designer to determine this from material test data or a separate relaxation analysis.

Second, the ASME method is simplified by disallowing the use of several alternate methods for calculating strain ranges and relaxation histories. This is done solely to simplify the design process.

Finally, as noted in Figure 3-1.1 there are two types of cyclic stress relaxation for classical high temperature structures modeled with elastic, perfectly-plastic, power-law creep material under cycles consisting of instantaneous loading, hold at constant load, and instantaneous unloading: resetting relaxation where each cycle starts out at the same, high value of stress and global relaxation where the structure follows a global, constant-load relaxation curve with small elastic transients during the load/unload periods. The global relaxation mode is highly desirable from a design point of view as these sorts of structures spend more time at lower levels of stress and hence accumulate less creep damage. The ASME Section III, Division 5 rules contain a test to determine which mode will occur for a given component, based on the classical condition of reverse plasticity causing load resets. If the structure falls into the global relaxation mode the ASME rules allow an alternate, less damaging calculation of creep damage based on a global relaxation history.

The current rules do not allow this alternate method, essentially forcing the designer to treat CSP components as if they follow a resetting relaxation history. As described in more detail below, Alloy $740 \mathrm{H}$ and other high strength nickel alloys suitable for service at the high metal temperatures envisioned in future CSP concepts are unlikely to plastically yield during service. This might suggest that CSP structures will follow a global relaxation mode.

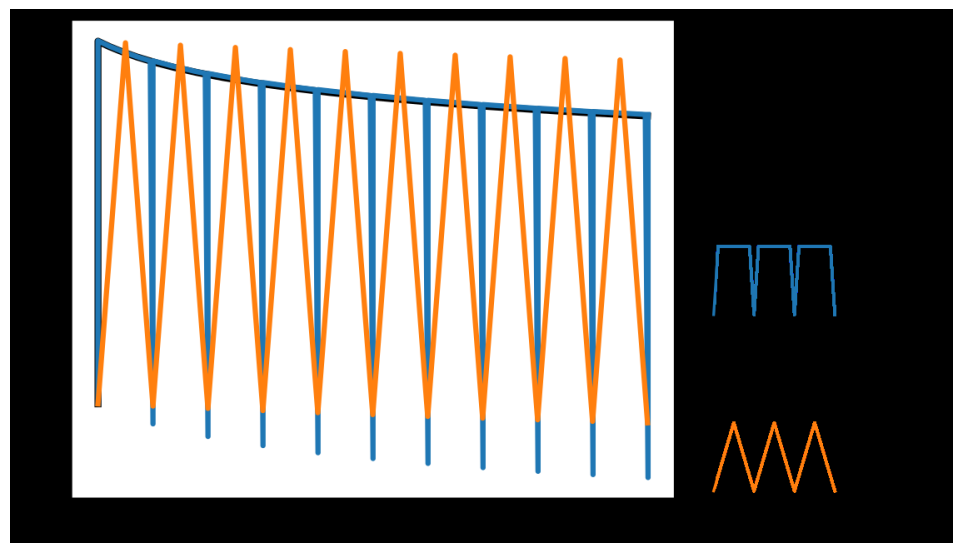

Figure 3-2.2.3.2. Stress relaxation histories for various cycles with the same total strain range but different loading cycle types. 
However, Figure 3-2.2.3.2 demonstrates a problem with the classical division of structures into global and resetting relaxation. The past work establishing these categories was predominantly aimed at nuclear applications where the components are loaded and unloaded quickly compared to long hold periods at fixed conditions. CSP facilities do not operate in this mode, as they generally load follow the incident solar radiation which increases and decreases continually through the daily operation cycle. The figure shows three relaxation histories for an elastic-power law creep material, all starting from the same initial strain: steady relaxation at fixed strain, cyclic relaxation though a fixed strain range where the strains are applied instantaneously, held fixed, and instantaneously reversed, and cyclic relaxation through the same range where the strains are gradually applied and removed in a triangle wave pattern (see inset). Both cyclic histories undergo the same total strain range and have the same total period, the only difference is in how the strains and applied and removed.

The instantaneous and gradual cycles produce very different relaxation histories. The instantaneous cycle validates the classical global relaxation mode where the cyclic relaxation history follows the steady relaxation curve with short elastic transients. In contrast, the gradual cycle produces very little global relaxation over the 10 cycles shown the diagram, more closely resembling a resetting relaxation history.

Power law creep materials relax faster at high values of strain. This behavior explains the difference between the instantaneous and global cycles. The instantaneous cycle always relaxes at the highest value of strain and therefore relaxes comparatively quickly. The gradual cycle, on average, relaxes at lower values of strain and hence much more slowly. This simple example demonstrates that creep resistance is not always a good thing - materials that creep faster also shed load faster. This example also justifies the restriction in the design rules disallowing the use of the alternate, global relaxation calculation even if the structure would qualify for the alternate using the ASME rules. CSP cycles are much more akin to the gradual load cycle in the example, as opposed to nuclear structures which operate more like the instantaneous cycle.

The component is slowly globally relaxing in Figure 3-2.2.3.2 as reverse plasticity is not causing a full cycle reset. Design Options A and B conservatively neglect this slow relaxation. Option $\mathrm{C}$ accounts for it using inelastic analysis.

\section{3-2.2.4. Buckling criteria}

Part 4 provides some perspective on the relative importance of time-independent buckling, time-dependent buckling, and the other design criteria. The fundamental conclusion is that time-independent buckling under lateral wind loading may be a significant design concern whereas time-dependent creep buckling is unlikely to constrain designs due to the low steady primary loads envisioned in future CSP systems. However, the design criteria provide methods for both time independent and creep buckling to provide guidance for systems that may have non-standard high, steady primary loads, for example systems with substantial self-weight. Additionally, the creep buckling rules come at little conceptual cost as they share a similar analysis method to the time independent buckling method. 
For time independent buckling the rules require a direct stability assessment of the structure using the constitutive response given by the time-independent (hot tensile) isochronous curves. As described in 3-3.14 these represent a best-estimate, average properties description of the monotonic tension response of the material. It is therefore reasonable to use this response to represent the deformation of a structure under timeindependent loading conditions, using standard $J_{2}$ flow theory to extend the uniaxial tensile response to 3D stress states. The design criteria requires a large-deformation inelastic analysis of the component and so directly accounts for elastic and elasticplastic buckling mechanisms. As described in Part 1 the Design Cycle must be supplemented in this analysis with any transient, non-cyclic lateral loads - for example wind loading.

The time-dependent buckling provisions use the method of isochronous curves. This approach has been successfully used to evaluate buckling in high temperature structures ${ }^{12}$ and forms the basis of the buckling exemption charts in ASME Section III, Division 5. The idea of the method is to replace a time-dependent creep analysis with a time-independent elastic-plastic analysis using the appropriate isochronous curve to represent the stress redistribution caused by creep over the design life. This concept is empirical, but has been validated by past work ${ }^{13}$.

The analysis for the time-dependent buckling check is then fundamentally the same as for the time-dependent check: a large-deformation, inelastic analysis of the component under steady-state loading. The only differences are that for the time-dependent check the designer uses the appropriate isochronous curve to represent the material's constitutive response and the loading for time-dependent buckling should only include the steady and periodic loads given in the Design Cycle and not any additional, transient lateral loads. The rational here is the evaluation should only include the loads causing significant creep deformation - brief transients like wind loading will not cause creep deformation.

The load factors used in the buckling analysis are 1.5 . This provides a $50 \%$ safety factor accounting for uncertainties in the applied loads, the deformation properties of the actual material (keeping in mind that the isochronous curves represent an average, not a lower-bound, response), and any geometric imperfections in the fabricated component that might contribute to lower the buckling load. The factor of 1.5 was extracted from the ASME Boiler \& Pressure Vessel Code Section III, Division 5 for Service Level D (most severe/least frequent) Loads. This means the current rules adopt the most aggressive/least conservative ASME factor, reflecting the lower consequences of failure in CSP versus nuclear systems.

\section{3-2.3. Design Option B}

High temperature nickel superalloys like $740 \mathrm{H}$ are designed to have high strength at elevated temperatures. Newer alloys like Alloy 617 , Alloy $740 \mathrm{H}$, and Alloy 282 are so

\footnotetext{
${ }^{12}$ D. S. Griffin, "Design Limits for Elevated-Temperature Buckling” In Welding Research Council Bulletin 443 External Pressure: Effect of Initial Imperfections and Temperature Limits, pp. 11-26, 1999.

13 ibid.
} 
strong that they are unlikely to deform plastically in service - note the yield strength for Alloy $740 \mathrm{H}$ exceeds $400 \mathrm{MPa}$ even above $800^{\circ} \mathrm{C}$. This does not mean that these materials will remain linear elastic - creep deformation can and does occur even below the time-independent yield point. However, assuming the material does not undergo time-independent plastic deformation greatly simplifies the design process. Options B and $\mathrm{C}$ take advantage of this assumption.

CSP components undergo daily cycling and will typically descend to temperatures below the creep range during the inactive night periods. This means during each daily cycle they have only a relatively short period of time to undergo stress relaxation. Additionally, high temperature nickel alloys like $740 \mathrm{H}$ are creep-resistant, meaning they undergo relatively little creep deformation under typical operating conditions.

Design Option B takes advantage of these material characteristics. Using Design Option $\mathrm{B}$ requires that the component remain linear elastic. This criteria is checked by analyzing the Design Cycle with a linear elastic stress analysis and comparing the resulting stress intensities to the temperature dependent material yield strength. As the design values of typically lower-bound the actual material properties such an analysis adequately demonstrates that the component will not yield, even accounting for uncertainty in material properties.

Design Option B uses the same primary load, ratcheting, and buckling methods as Method A. Simplifications to the O'Donnell-Porowski approach for strong materials would be possible, but the simplified process is not significantly easier to execute than the base approach required in Method A.

The simplifications in Design Option B are in the creep-fatigue analysis. The method applies two basic simplifications to the ASME Section III, Division 5, Subsection HB, Subpart B, Nonmandatory Appendix T design by elastic analysis method:

1. The elastically-calculated effective strain range used to calculate fatigue damage only needs to be modified for creep deformation, not plasticity.

2. The elastically-calculated stresses corresponding to the Design Cycle loading can be used to calculate creep damage.

The first simplification is justified as the material does not undergo time independent plastic deformation. Figure 3-1.1 describes the second simplification (compare the reset-relaxation to the CSP-type cycle). It relies on two observations made above:

1. A resetting cyclic stress relaxation history reasonably bounds the response of CSP components operating at high temperatures. High strength materials like Alloy $740 \mathrm{H}$ will not yield in service and so the elastically-calculated stresses are a reasonable starting point for a relaxation damage calculation.

2. High strength materials like Alloy $740 \mathrm{H}$ will not undergo significant stress relaxation during the relatively short cycle period typical for CSP components. As such, the elastic stress history without any additional relaxation caused by creep is reasonably representative. 
Both assumptions do involve some conservative approximation. As discussed above, CSP components will gradually undergo global relaxation, albeit at a much slower rate than a steady-state relaxation analysis would predict. However, it is conservative to ignore this slow global relaxation. Similarly, high strength materials will undergo some amount of stress relaxation caused by creep. Again, this small amount of relaxation can be conservatively neglected. Designers can use Option $\mathrm{C}$ if they want to gain the additional design life provided by a more accurate global and in-cycle relaxation analysis.

\section{3-2.4. Design Option C}

Like Option $B$ this design option takes advantage of the assumption that high strength materials like Alloy $740 \mathrm{H}$ will not yield in service. As with Option B this requires a preliminary linear-elastic analysis to confirm the Design Cycle loads do not cause yielding.

Design by inelastic analysis has long been considered the gold standard for high temperature design ${ }^{14}$ - likely to produce the most accurate, least-over conservative design analysis and the most efficient final designs. However, there are two practical problems in implementing design by inelastic analysis in engineering practice:

1. Accurate constitutive models for high temperature cyclic deformation are difficult to develop. There is comparatively little high temperature deformation data available to calibrate models and developing a mathematical description of high temperature cyclic plasticity is notably challenging.

2. A complete inelastic analysis requires the analysis to simulate the full service history of a component. For CSP components this might be 10,000 daily cycles, each requiring multiple time steps to capture the details of the daily loading cycle. This results in analysis with on the order of millions of time steps. These cannot be parallelized using current methods meaning that the calculation time becomes infeasibly long even for very small finite element models.

Design Option $\mathrm{C}$ attempts to retain some of the advantages of a design by inelastic method while overcoming these two disadvantages. This option retains the primary load and buckling criteria from Design Option A. It alters the approach for the ratcheting strain and creep-fatigue checks.

Design by inelastic analysis requires generating a full time/strain/stress history for each point of the component. Once this history has been generated the accumulated strain over the component's service life can be directly calculated and compared to appropriate service limits. Similarly, the strain/time history can be used to calculate a fatigue damage fraction, the stress/time history used to calculate a creep damage fraction, and these used in conjunction with the creep-fatigue damage envelope to assess the component against the creep-fatigue limits.

\footnotetext{
${ }^{14}$ A. K. Dhalla, Recommended practices in elevated temperature design: a compendium of breeder reactor experiences (1970-1987): Volume III - Inelastic analysis. Welding Research Council Bulletin, 1991.
} 
This design method retains the ASME effective strain range formula for converting a 3D strain history to a scalar effective strain. The Section III, Division 5 rules use the Huddleston model $\left.\right|^{15}$ for generating an effective stress from a 3D stress relaxation history for calculating creep damage. This model is more accurate than simply using the von Mises effective stress, as in the current design rules, but requires multiaxial creep rupture data to calibrate. This data is not available for Alloy $740 \mathrm{H}$ and so the current rules recommend using the von Mises stress based on experience with Alloy 617. This material is similar to $740 \mathrm{H}$ in that both are $\mathrm{y}^{\prime}$ strengthened Ni-alloys and multiaxial creep testing on Alloy 617 demonstrates that using the von Mises stress adequately captures multiaxial rupture in that material. The design rules use the von Mises strain as a metric for assessing strain limits. This choice is somewhat arbitrary, but reasonable given the use of the von Mises stress in the creep damage calculation.

For ratcheting strain the design method here doubles the pointwise ASME strain limits from $5 \%$ for base metal and $2.5 \%$ for welds to $10 \%$ for base metal and $5 \%$ for welds. Additionally, the creep damage calculation uses a safety factor of 0.9 , instead of the 0.7 recommended by ASME. Both changes reflect the lower consequences of failure for CSP systems versus nuclear components.

The key challenge is calculating a representative time/strain/stress history corresponding to many repetitions of the design cycle. The design method takes advantage of the material strength by neglecting plastic deformation. This greatly simplifies the task of constructing a material model, as an elastic-creep is sufficient to describe the material deformation.

The final constitutive model described in 3-3.15 is deliberately further simplified to a temperature and stress-dependent power law description of creep that does not use any internal variables to track material state. This greatly abstracts the representation of creep deformation - the model does not capture primary or tertiary creep - but also allows the designer to use a steady cyclic analysis of the component to describe deformation and stress relaxation over an arbitrary large number of load cycles. This means a relatively short cyclic analysis of a few repetitions of the design cycle can be used to calculate deformation and damage over the full service life of the component.

A history-independent material model of the type used here will, under repeated applications of a cyclic load history, eventually reach a cyclic steady state where the stresses and strain rates become periodic ${ }^{16}$. Design Option $\mathrm{C}$ takes advantage of this concept by requesting the designer first determine this steady, periodic response and then calculate deformation and damage over the whole cyclic history of the component as if this steady response was repeated for the entire service life.

The clear advantage of this approach is that the designer does not need to simulate the full cyclic history of the component. The steady response can generally be identified by repeating the Design Cycle for tens of applications, not thousands.

\footnotetext{
${ }^{15}$ R. L. Huddleston, “An Improved Multiaxial Creep-Rupture Strength Criterion” Journal of Pressure Vessel Technology, 107(November), pp. 421-429, 1985.

${ }^{16}$ C. O. Frederick, and P.J. Armstrong, "Convergent internal stresses and steady cyclic states of stress" Journal of Strain Analysis for Engineering Design, 1(2), pp. 154-159, 1966.
} 
There are however several disadvantages. First, as noted above, the historyindependent description of creep cannot capture real, observed material behavior like primary and tertiary creep. Tertiary creep can safely be neglected as the creep damage calculation will screen structures that enter this deformation regime. Neglecting primary creep is conservative for calculating stress relaxation damage as faster creep rates are actually helpful in relaxing stress, but not necessarily for calculating ratcheting strain accumulation. However, as creep-fatigue is likely to be the controlling design criteria for future CSP structures this approximation can be accepted.

Second, applying the steady-cyclic response to the full service history neglects the cyclic-transient part of the deformation history. Depending on the material response this might mean approximating the damage and strain accumulated over the first few hundred cycles. However, as CSP systems are typically designed for thousands of cycles this approximation is reasonable. Additionally, this design method does not completely neglect damage and strain accumulated during this period, but rather approximates the response of the component in this regime with the steady-cyclic response. This approximation is generally reasonable, even if it is inexact.

\section{3-3. Commentary on the $740 \mathrm{H}$ Material Data}

\section{3-3.1. General Criteria}

Currently, data in Section III, Division 5 of the ASME Code is provided in either graphs or tables. A more modern design code would provide equations so that the various material property correlations could be easily digitized. This set of data endeavors to provide equations, where possible. However, some of the data is still provided in tables to be compatible with current Section II properties (for example ).

\section{3-3.2. Material Specification}

The intent of this set of design rules is to allow the use of Alloy $740 \mathrm{H}$ in any non-cast product form. Currently welded tube and pipe is not included in ASME Code Case 2702, adding Alloy $740 \mathrm{H}$ for Section I use. If the Code Case is amended in the future to include welded tube these design data could be relatively easily updated with conforming allowable stress values. The weld reduction factors in 2-8 would provide a way to design seam welded material against the creep-fatigue and ratcheting limits.

Code Case 2702 includes additional requirements on the material heat treatment, providing two options ( $a$ and $b$ ) to satisfy the additional requirements. These design rules retain those additional restrictions.

\section{3-3.3. Elastic constants}

This information comes from the Alloy $740 \mathrm{H}$ material data sheet. 


\section{3-3.4. Thermal properties}

This information comes from the Alloy $740 \mathrm{H}$ material data sheet. The instantaneous coefficients of thermal expansion were calculated from the provided mean coefficients.

\section{3-3.5. Yield strength}

This data comes from ASME Code Case 2702 . The values above $800^{\circ} \mathrm{C}$ are extrapolated.

\section{3-3.6. Tensile strength}

This data comes from ASME Code Case 2702 . The values above $800^{\circ} \mathrm{C}$ are extrapolated.

\section{3-3.7. Allowable stress}

ASME Code Case 2702 provides the Section I allowable stresses for Alloy $740 \mathrm{H}$ up to $800^{\circ} \mathrm{C}$. This allowable stress is defined by the lesser of (at each temperature);

1. The minimum specified tensile strength of the material divided by 3.5 .

2. The minimum specified yield strength of the material multiplied by a factor of 0.67 or 0.9 depending on the material ductility (this criteria does not control for Alloy $740 \mathrm{H})$.

3. The minimum specified tensile strength of the material multiplied by the ratio of the average temperature-dependent tensile strength to the room temperature tensile strength multiplied by a factor of 1.1/3.5.

4. The minimum specified yield strength of the material multiplied by the ratio of the average temperature-dependent yield strength to the room temperature yield strength multiplied by a factor of 0.67 or 0.9 , depending on the material.

5. The average creep rupture strength of the material at 100,000 hours multiplied by a factor less than 0.67 .

6. The minimum creep rupture strength of the material at 100,000 hours multiplied by factor of 0.8 .

7. The full stress to cause a strain of $1 \%$ in 100,000 hours.

Full details of this calculation are provided in ASME Section II, Mandatory Appendix 1.

Section III, Division 5 uses a similar allowable stress adopted for use here. The definition of this allowable stress is identical, except where the value of the timedependent allowable stress at 300,000 hours exceeds the value defined above. This extra provision is ignored here, as these design rules do not use .

These rules adopt the values provided in ASME Code Case 2702 up to $800^{\circ} \mathrm{C}$. The remaining value at $850^{\circ} \mathrm{C}$ is in the regime controlled by creep properties and values were calculated using the rupture and creep deformation models described below.

\section{3-3.8. Allowable stress}


This is a time-independent allowable stress used in Section III, Division 5. This quantity is not used as an allowable stress in the design criteria presented here. However, it is used in the creep-fatigue and ratcheting rules to determine a typical initial cyclic relaxation stress using the criteria. As such the designer needs these values to complete a design analysis.

The definition of is provided in Section II but it is analogous to the time-independent criteria 1-4 above. The values of were then calculated from the values of and described previously and tabulated in the design document.

\section{3-3.9. Relaxation strength}

As described in Part 2, the design by elastic analysis creep-fatigue and ratcheting criteria construct a relaxation analysis based on a starting strain value. Notionally, for a power-law creep material stress relaxation would continue until the stress in the component reaches the primary stress. However, in practice material effects, quantified by backstresses in cyclic plasticity models, tend to provide a material relaxation strength - a stress below which relaxation ceases - that can be higher than the component primary stress. The design by elastic analysis process then includes rules preventing the stress from falling below the relaxation strength.

The material data in Section III, Division 5 and related ASME Code documents are nearly complete - a designer can complete a design without recourse to additional, outside information. However, the relaxation strength is an exception - it is not tabulated in the current Code. However, HBB-T-1324 does allow the designer to use a uniaxial relaxation analysis starting from a stress of to determine the relaxation strength. Relaxation models for the HBB Class A materials are not currently provided. For these design rules the tabulated relaxation strengths are based on the inelastic material model described in 3-3.15.

\section{3-3.10. Minimum stress-to-rupture}

\section{3-3.10.1. Experimental database}

The minimum stress to rupture describes the stress that will cause rupture in a given time at a given temperature with reasonable lower-bound material response. The direct experimental measurement of this value is a creep rupture test. In these tests uniaxial specimens are loaded in temperature-controlled furnaces with a dead-load stress and left to deform until they rupture. The minimal experimental measurements are the controlled dead-load stress and temperature and the corresponding rupture time. More sophisticated tests might measure the deformation as a function of time, typically using a combination of extensometers and linear variable differential transformers (LVDTs) to measure deformation directly from the specimen. 
However, it is essentially impossible to run sufficient creep tests to fully interpolate between the two experimental conditions (stress and temperature) for all values needed in a design calculation. Moreover, for some applications very long-term rupture stresses are required (30+ years), whereas the test time for the available creep test database is often much shorter, on the order of years at the most. Therefore, a predictive model for the rupture stress as a function of rupture time and temperature is first calibrated to the experimental data and then this model is used to generate design rupture stresses.

For this purpose 54 creep rupture tests on Alloy $740 \mathrm{H}$ were identified and collated. Table 3-3.10.1.1 shows the raw experimental data used to develop the rupture correlation below. The vast majority of these tests were extracted from the DOE report summarizing the fossil energy development program for Alloy $740 \mathrm{H}^{17}$, however a few confirmatory tests were completed at INL (marked with an asterisk in the table).

\begin{tabular}{lll}
\hline $\begin{array}{l}\text { Temperature } \\
\left({ }^{\circ} \mathrm{C}\right)\end{array}$ & $\begin{array}{l}\text { Rupture Stress } \\
(\mathrm{MPa})\end{array}$ & $\begin{array}{l}\text { Rupture time } \\
\text { (hours) }\end{array}$ \\
\hline 700 & 480 & 308.8 \\
700 & 320 & 3795.3 \\
700 & 480 & 392.6 \\
700 & 420 & 1082.2 \\
700 & 340 & 5227.4 \\
700 & 480 & 512.5 \\
700 & 300 & 14871.3 \\
700 & 480 & 517.4 \\
700 & 320 & 9745.1 \\
700 & 265 & 30956.7 \\
700 & 420 & 1082 \\
700 & 340 & 5688 \\
750 & 370 & 142.8 \\
750 & 320 & 358.3 \\
750 & 265 & 1275.4 \\
750 & 180 & 8034 \\
750 & 180 & 9787.9 \\
750 & 370 & 275.4 \\
750 & 300 & 984.6 \\
750 & 220 & 7201.6 \\
750 & 180 & 22896 \\
750 & 370 & 311.9 \\
750 & 320 & 658.5 \\
750 & 300 & 1020.2 \\
750 & 265 & 2185.4 \\
750 & 220 & 7355.2 \\
750 & 180 & 20789.4 \\
750 & 370 & 296.7
\end{tabular}

${ }^{17}$ R. Purgert et al. Boiler materials for ultra supercritical coal power plants. DOE technical report, 2015. 


\begin{tabular}{lll}
\hline $\begin{array}{l}\text { Temperature } \\
\left({ }^{\circ} \mathrm{C}\right)\end{array}$ & $\begin{array}{l}\text { Rupture Stress } \\
(\mathrm{MPa})\end{array}$ & $\begin{array}{l}\text { Rupture time } \\
\text { (hours) }\end{array}$ \\
\hline 750 & 320 & 484.8 \\
750 & 300 & 914.6 \\
750 & 220 & 7382.8 \\
750 & 180 & 24061 \\
750 & 300 & 723 \\
750 & 265 & 2345 \\
750 & 370 & 229.7 \\
750 & 370 & 242 \\
750 & 320 & 553 \\
750 & 180 & 18756 \\
800 & 250 & 173 \\
800 & 250 & 279 \\
800 & 180 & 1491 \\
800 & 130 & 6883 \\
800 & 180 & 1634 \\
800 & 120 & 9855 \\
800 & 110 & 15864 \\
800 & 250 & 259 \\
800 & 180 & 1497 \\
800 & 150 & 3609 \\
800 & 250 & 199 \\
800 & 100 & 17674 \\
$750^{*}$ & 265 & 3168 \\
$750^{*}$ & 320 & 861 \\
$800^{*}$ & 200 & 1535 \\
$850^{*}$ & 100 & 3053 \\
\hline 011 & 100 &
\end{tabular}

Table 3-3.10.1.1. Creep rupture database collated to define minimum stress to rupture design data. Tests marked with an asterisk were conducted at INL as part of the project sponsoring the development of these design rules.

\section{3-3.10.2. Larson-Miller correlation}

A Larson-Miller ${ }^{18}$ correlation is used to interpolate and extrapolate the rupture test data to determine design values of minimum stress-to-rupture. The Larson-Miller parameter

with being the absolute temperature, the rupture time, and a parameter, generally correlates to the logarithm of the stress to rupture. This correlation can be used to fill in values of rupture stress for various conditions and extrapolate the short-term data to longer rupture times.

Larson-Miller correlations can be generated by finding the optimal value of the parameter and the corresponding polynomial relation between the Larson-Miller

${ }^{18}$ F. R. Larson, J. Miller, "A time-temperature relationship for rupture and creep stresses" Transactions of the ASME, 74, pp. 765-771, 1952. 
parameter and the log of the rupture stress that best fit the experimental data. Figure 3-3.10.2.1 illustrates the process used to develop the log-linear Larson-Miller relation used here to establish values of the minimum rupture stress. Current ASME practice is to develop a $95 \%$ confidence lower bound prediction interval on the data and use that lower bound to determine the minimum stress to rupture. That process was followed here. The figure shows both the mean-property Larson-Miller model (used as the average stress to rupture in generating and the creep-fatigue interaction diagram) and the $95 \%$ confidence model, used here to generate the minimum stress to rupture table. The figure also shows the best-fit value of the parameter and the Pearson correlation coefficient of the log-linear relation.

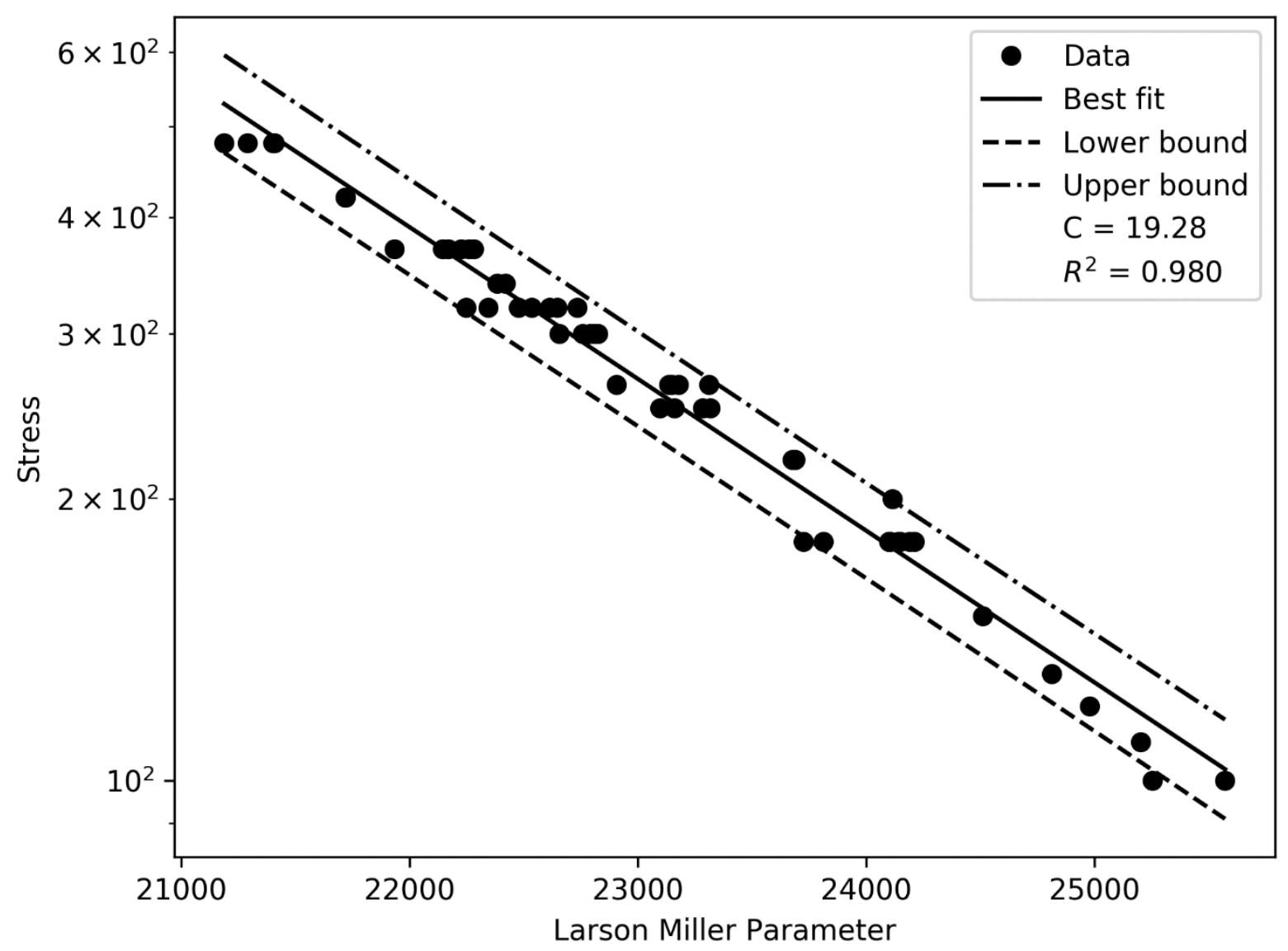

Figure 3-3.10.2.1. Larson-Miller correlation used to generate the average and minimum stress to rupture for Alloy $740 \mathrm{H}$.

\section{3-3.11. Fatigue diagrams}

\section{3-3.11.1. Experimental database}

A high temperature fatigue curve is a relation between a fixed cyclic strain range and temperature and the resulting number of cycles to failure. Typically these diagrams are generated using fully-reversed, strain-controlled fatigue tests at fixed temperature. These tests uniaxially cycle a sample over a fully-reversed strain range, holding 
temperature constant using a temperature-controlled furnace or induction heater. The test cycle is repeated until the sample fails. To protect equipment and specimens, failure may be defined by a set percentage drop in the maximum stress due to the presence of a crack. Design fatigue curves interpolate these test results, typically using strain range/cycles to failure relations for fixed temperatures.

Table 3-3.11.1.1 lists the fatigue test data used to generate the design correlations. All these tests are for fully-reversed strain cycling at a fixed temperature and strain rate. The table lists the temperature, strain range, number of cycles to failure, and the source of the data. Test results were collected from the literature and dedicated experiments run at INL as part of this project.

\begin{tabular}{|c|c|c|c|}
\hline $\begin{array}{l}\text { Temperature } \\
\left({ }^{\circ} \mathrm{C}\right)\end{array}$ & Strain range (\%) & Cycles to failure & Source \\
\hline 700 & 1.49 & 293 & $\begin{array}{l}\text { Zhang and } \\
\text { Takahashi }{ }^{19}\end{array}$ \\
\hline 700 & 1.19 & 467 & $\begin{array}{l}\text { Zhang and } \\
\text { Takahashi }\end{array}$ \\
\hline 700 & 0.97 & 1931 & $\begin{array}{l}\text { Zhang and } \\
\text { Takahashi }\end{array}$ \\
\hline 700 & 0.69 & 12046 & $\begin{array}{l}\text { Zhang and } \\
\text { Takahashi }\end{array}$ \\
\hline 700 & 0.66 & 15104 & $\begin{array}{l}\text { Zhang and } \\
\text { Takahashi }\end{array}$ \\
\hline 700 & 0.53 & 287843 & $\begin{array}{l}\text { Zhang and } \\
\text { Takahashi }\end{array}$ \\
\hline 750 & 0.60 & 14987 & INL \\
\hline 750 & 0.6 & 19023 & INL \\
\hline 750 & 0.60 & 7950 & INL \\
\hline 750 & 1.00 & 1767 & INL \\
\hline 750 & 1.00 & 1095 & INL \\
\hline 760 & 1.40 & 147 & Jena 20 \\
\hline 760 & 1.20 & 383 & Jena \\
\hline 760 & 1.01 & 671 & Jena \\
\hline 760 & 0.80 & 1457 & Jena \\
\hline 760 & 0.60 & 6566 & INL \\
\hline 800 & 1.00 & 653 & INL \\
\hline 850 & 0.40 & 19969 & INL \\
\hline 850 & 0.40 & 47048 & INL \\
\hline 850 & 1.00 & 409 & INL \\
\hline 850 & 1.00 & 402 & INL \\
\hline
\end{tabular}

Table 3-3.11.1.1. Fatigue test data collated to generate the design fatigue relations.

\footnotetext{
${ }^{19}$ S. Zhang, and Y. Takahashi, "Creep and Creep-Fatigue Deformation and Life Assessment of Ni-Based Alloy 740H and Alloy 617" In ASME 2018 Pressure Vessels and Piping Conference, pp. V06AT06A060-V06AT06A060. American Society of Mechanical Engineers, 2018.

${ }^{20} \mathrm{P}$. S. Jena et al. "Low cycle fatigue behavior of nickel base superalloy IN $740 \mathrm{H}$ at $760^{\circ} \mathrm{C}$ : Influence of fireside corrosion atmosphere" International Journal of Fatigue, 116, pp. 623-633, 2018.
} 


\section{3-3.11.2. Design fatigue curves}

Typically, strain-based fatigue curves show decreasing cycles to failure as the temperature increases at a fixed strain range. ASME procedure is to provide a set of temperature dependent curves. The designer uses the curve corresponding to the highest metal temperature at the point of interest.

The data from 3-3.11.1.1 was grouped into two sets: $700^{\circ} \mathrm{C}$ and below and $700^{\circ} \mathrm{C}$ to $850^{\circ} \mathrm{C}$. Because this is, to our knowledge, the total fatigue dataset for Alloy $740 \mathrm{H}$ the design rules use the curve based on the $700^{\circ} \mathrm{C}$ for all temperatures less than $700^{\circ} \mathrm{C}$. This is almost certainly conservative. An optimized set of design data would include fatigue tests at lower temperatures, allowing a less restrictive design fatigue correlation.

Once grouped, two inverse power law curves were fit to the data using least squares regression. These two curves, corresponding to the two temperature groups, provide the mean property fatigue correlation.

Design fatigue charts include factors of safety. The ASME nuclear code uses a factor of 2 on the strain range and 20 on the cycles to failure. Based on the lower consequences of failure for CSP systems, the design fatigue curves here use a factor of 1.5 on strain range and 10 on cycles to failure. Figure 3-3.11.2.1 shows that these factors bound the uncertainty in the fatigue data and provide a healthy design margin guarding against detrimental environmental/fatigue interactions, initial defects, and other uncertainty. 


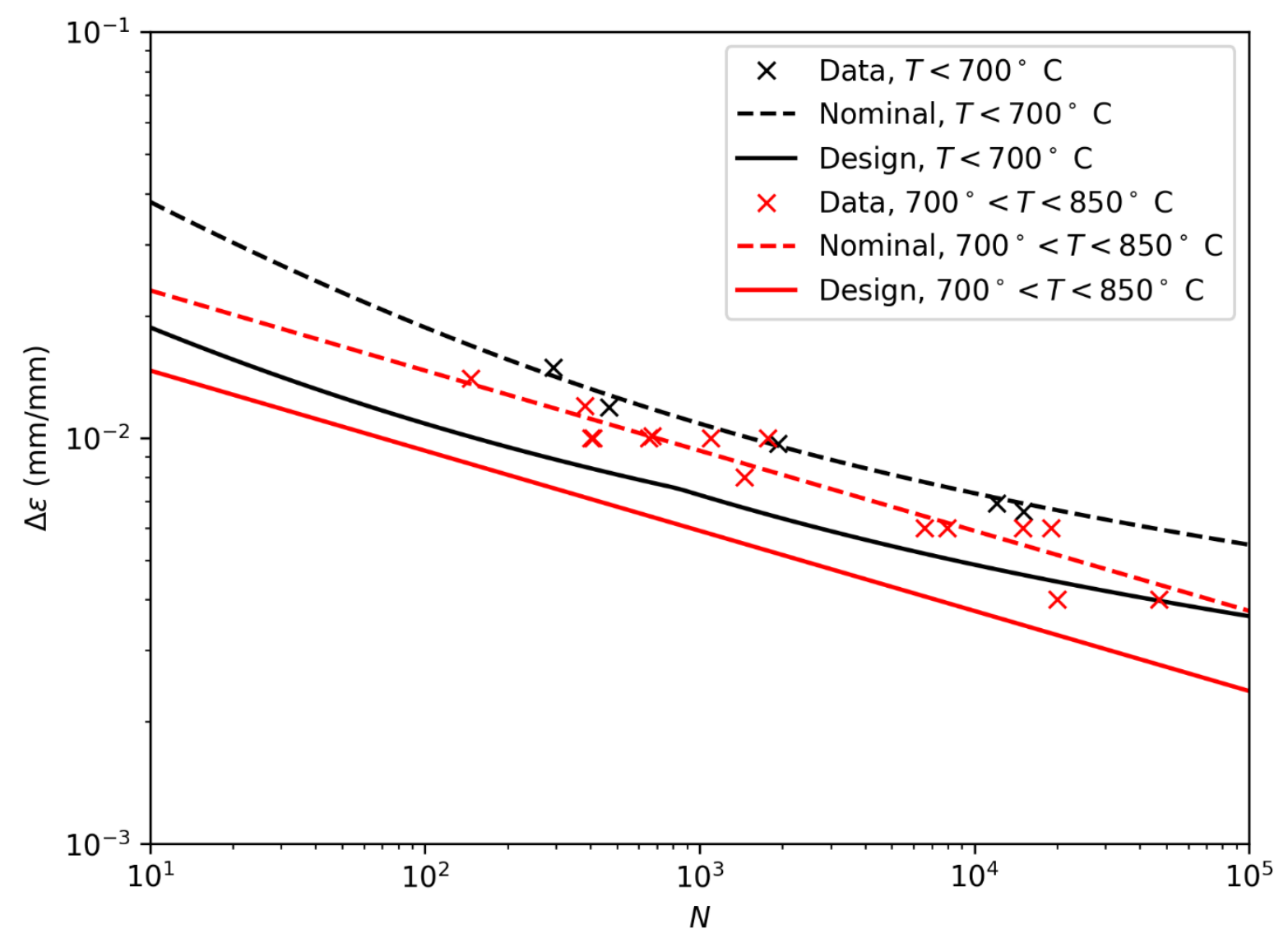

Figure 3-3.11.2.1. Chart comparing the experimental fatigue data, the mean property fatigue correlations, and the design fatigue correlations.

\section{3-3.12. Creep-fatigue damage envelope}

\section{3-3.12.1. Experimental database}

The use of a creep-fatigue interaction diagram is explained in detail above in 3-1 and 3-2.2.3. These plots are an allowable damage envelope plotting fatigue damage on one axis and creep damage on the other axis. Typically, they are generated from a set of creep-fatigue tests. Creep-fatigue tests are strain-controlled cyclic experiments at fixed temperature and fixed fully-reversed strain range. They are different from fatigue tests in that a hold period at fixed strain is included in the cycle either at the maximum tensile, maximum compression, or both ends of the cycle.

Table 3-3.12.1.1 lists the test used to generate the Alloy $740 \mathrm{H}$ creep-fatigue interaction diagram. All the tests but one were run at INL as part of this project. The single test sourced from the literature ${ }^{21}$ is marked with an asterisk. Early in the experimental program two tests with the same conditions but holds on the opposite ends of the cycle

${ }^{21}$ Zhang, Shengde, and Yukio Takahashi. "Creep and Creep-Fatigue Deformation and Life Assessment of Ni-Based Alloy 740H and Alloy 617." In ASME 2018 Pressure Vessels and Piping Conference, pp. V06AT06A060-

V06AT06A060. American Society of Mechanical Engineers, 2018. 
were used to establish that tensile holds are more damaging for Alloy $740 \mathrm{H}$. This is in agreement with similar results on other high temperature nickel alloys. As such, tensile holds were used for the remainder of the tests.

\begin{tabular}{lllll}
\hline $\begin{array}{l}\text { Temperature } \\
\left({ }^{\circ} \mathrm{C}\right)\end{array}$ & $\begin{array}{l}\text { Strain } \\
\text { range }(\%)\end{array}$ & $\begin{array}{l}\text { Hold time } \\
(\mathrm{min})\end{array}$ & Hold type & $\begin{array}{l}\text { Cycles to } \\
\text { failure }\end{array}$ \\
\hline $700^{*}$ & 0.7 & 60 & $\mathrm{~T}$ & 671 \\
750 & 0.6 & 10 & $\mathrm{~T}$ & 1958 \\
750 & 0.6 & 60 & $\mathrm{~T}$ & 1143 \\
750 & 1 & 60 & $\mathrm{~T}$ & 204 \\
750 & 1 & 600 & $\mathrm{~T}$ & 142 \\
750 & 1 & 60 & $\mathrm{~T}$ & 122 \\
750 & 1 & 60 & $\mathrm{C}$ & 187 \\
850 & 0.4 & 10 & $\mathrm{~T}$ & 2488 \\
850 & 0.4 & 10 & $\mathrm{~T}$ & 2246 \\
850 & 0.4 & 10 & $\mathrm{~T}$ & 4147 \\
850 & 1 & 10 & $\mathrm{~T}$ & 342 \\
850 & 1 & 600 & $\mathrm{~T}$ & 231 \\
\hline
\end{tabular}

Table 3-3.12.1.1. Summary of the creep-fatigue test results used to establish the design creep-fatigue damage envelope. A "T" in the Hold type column means tensile hold; a "C" means compressive hold. The single test collected from the literature is marked with an asterisk.

\section{3-3.12.2. Damage envelope}

The results of a creep-fatigue test are a stress/strain/time history and a number of cycles to failure. These results can be converted to a fatigue damage fraction by calculating the number of cycles to failure for a pure fatigue test at the experimental strain range and temperature using the mean property fatigue curve and dividing the actual number of cycles to failure by this number. Similarly, a creep damage fraction can be calculated using the time fraction approach via the integral equation

where is the time-to-rupture at a given value of uniaxial stress calculated using the mean property time to rupture correlation developed above. Notionally this integral would span the full time test data. In practice the relaxation curve at, i.e. half the experimentally-observed number of cycles to failure, is used to represent the whole test.

Figure 3-3.12.2.1 shows the experimental data, converted to creep and fatigue damage fractions and plotted on an interaction diagram. The figure also shows the interaction point selected for the design rules: $(0.05,0.05)$. The processes of converting the results of a creep-fatigue test to a point on the diagram is automatic and requires no judgement beyond selecting the fatigue and creep damage models. However, going from the collection of experimental data points to the interaction envelope is a somewhat subjective process. The creep and fatigue damage calculation procedures contain the design margin in the creep-fatigue design process and so creep-fatigue diagrams are selected based on average material properties. As such, the final interaction point does not need to bound the data - it can allow for some outliers falling underneath the curve. 
However, the final diagram should not pass through the mean of the data as the points on the diagram represent many different experimental conditions. That is, the scatter in the plot is not entirely due to variation in material properties.

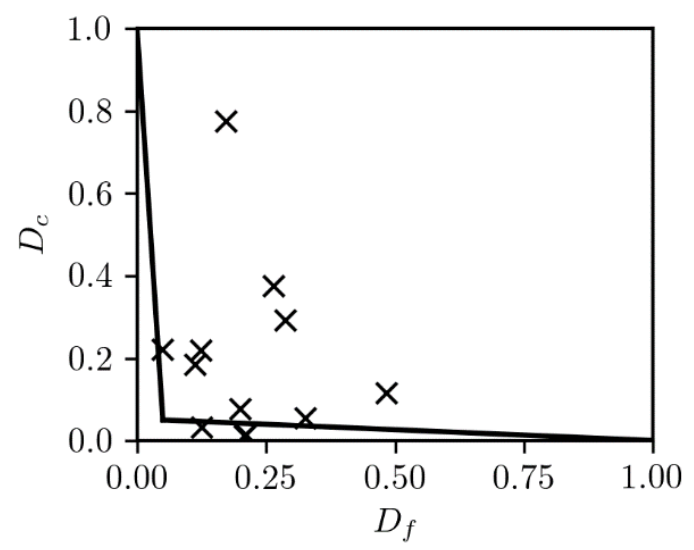

Figure 3-3.12.2.1. The creep-fatigue experiments plotted on an interaction diagram along with the final recommended damage envelope.

\section{3-3.13. Weld strength reduction factors}

Near weldments the creep-fatigue criteria apply a reduction factor on the minimum stress to rupture in the creep damage calculation. These reduction factors are typically based on cross-weldment rupture tests and may be temperature and time dependent.

The factor of 0.7 is drawn from ASME Code Case 2702, where it is specified for use in seam welded construction. The weld rupture factor is based on very limited data additional weld creep data would be required to determine a more accurate value.

Note that for seam-welded tube or pipe reduced allowable stress values would be required, in addition to the reduction factor applied to the rupture strength in the creepfatigue damage calculation procedure. As noted above in 3-3.7 the elevated temperature values of these reduced allowable stresses could be calculated in Code Case 2702 is modified in the future to allow for seam-welded tube or pipe product forms.

\section{3-3.14. Isochronous stress-strain relations}

\section{3-3.14.1. Experimental database}

ASME Section III, Division 5 design rules use hot tensile and isochronous stress strain curves to represent creep deformation, both for evaluation of the ratcheting strain limits and in assessing stress relaxation caused by creep. The isochronous curves can be read as the average stress to accumulate some amount of total strain over some period of time. The procedure used to create current Code curves for the Section III, Division 5 
materials is to first fit a material model to the available tensile and creep data and then use that model to generate the hot tensile and isochronous curves. The difficulty in this analysis stems from the need for strain data during the creep test rather than just tabulated rupture times. We adopted the same procedure to develop isochronous stress strain curves for alloy $740 \mathrm{H}$. The tensile test data used to determine the isochronous stress-strain relations were collected at INL while most of the creep test data were gathered from literature, except for four creep tests conducted at INL. The tensile test data consist of four elevated temperature tensile tests spanning from $700^{\circ} \mathrm{C}$ to $850^{\circ} \mathrm{C}$ in $50^{\circ} \mathrm{C}$ increments. Table 3-3.14.1 lists all the creep tests used. The table lists the temperature, applied constant stress, and the source of the creep test data.

\begin{tabular}{lll}
\hline Temperature $\left({ }^{\circ} \mathrm{C}\right)$ & Stress $(\mathrm{MPa})$ & Source \\
\hline 650 & 420 & Purgert and Shingledecker ${ }^{17}$ \\
700 & 265 & Purgert and Shingledecker \\
700 & 395 & Zhang and Takahashi ${ }^{19}$ \\
700 & 420 & Purgert and Shingledecker \\
700 & 430 & Zhang and Takahashi \\
700 & 520 & Zhang and Takahashi \\
750 & 150 & Purgert and Shingledecker \\
$750^{*}$ & 180 & Purgert and Shingledecker \\
750 & 220 & Purgert and Shingledecker \\
$750^{*}$ & 265 & Purgert and Shingledecker \\
750 & 265 & INL \\
750 & 320 & INL \\
750 & 320 & Purgert and Shingledecker \\
750 & 370 & Purgert and Shingledecker \\
800 & 180 & Purgert and Shingledecker \\
800 & 200 & INL \\
850 & 100 & INL \\
\hline
\end{tabular}

Table 3-3.14.1. List of creep data used to construct the isochronous stress-strain relations for alloy $740 \mathrm{H}$. Two sets of experimental data were collected for the test conditions marked with an asterisk.

\section{3-3.14.2. Strain equations}

The isochronous stress-strain curves are based on an additive, history-independent decomposition of the total strain, into elastic strain, , time-independent plastic strain, , and time-dependent creep strain, .

The hot tensile curves are the outcome of this model when, i.e. when, whereas the isochronous curves are the output of the model for some fixed, non-zero time. The elastic strain is calculated using the temperature dependent values of Young's modulus, E for Alloy $740 \mathrm{H}$. 
The plastic response of Alloy $740 \mathrm{H}$ was divided into two regions based on temperature. At temperatures below and equal to $800^{\circ} \mathrm{C}$ the composite model uses a RambergOsgood model for the plastic strain to capture the experimentally-observed smooth transition from elastic to work hardening plastic behavior. Above this temperature the model uses a Voce hardening model to capture a quick transition to a nearly perfectlyplastic response. The composite model for the plastic strain is then

All the model parameters were calibrated based on single hot tensile test data at four different temperatures $-700^{\circ} \mathrm{C}, 750^{\circ} \mathrm{C}, 800^{\circ} \mathrm{C}$, and $850^{\circ} \mathrm{C}$. We first fit the experimental data with the plasticity model (Ramberg-Osgood or Voce hardening) considering experimental elastic modulus which is then modified to match with the Young's modulus and the average yield strength. The values of the average yield strength for Alloy 740 were collected from the background document of ASME Code Case 2702. These modifications are done only in the elastic regime of the hot tensile curve and do not affect the shape of the curve in the plastic regime. Figure 3-3.14.2.1 plots the experimental (red curve) and model (black curve) hot tensile curves. Due to the unavailability of hot tensile data below $700^{\circ} \mathrm{C}$, we considered the same plasticity model constants for all the temperatures between $600^{\circ} \mathrm{C}$ and $700^{\circ} \mathrm{C}$.

To model the time-dependent strain, we adopted a simple creep model for alloy $740 \mathrm{H}$.

where is some constant, average creep rate, which is a function of temperature and stress. ASME Section III, Division 5 design isochronous curves only provide data out to $2.2 \%$ total strain which at most represents about $2 \%$ creep strain. The model also assumes that this average rate over the first $2 \%$ of creep strain is approximately equal to the average rate over the first $1 \%$ of creep strain. This allows the model to use the time-to- $1 \%$ data for calibration. To determine the average creep rate over the first $1 \%$ of creep strain two different methods were used - (1) divide the $1 \%$ creep strain by the time and (2) convert the creep curve data to a plot of creep strain rate versus creep strain and then average over the first $1 \%$ to produce a similar mean rate. These two rates were then averaged again to determine the average creep rate over the first $1 \%$ of creep strain to the applied stress and temperature. A model must be developed for this average creep rate in order to interpolate the data to all the conditions required to generate the design isochronous curves. 

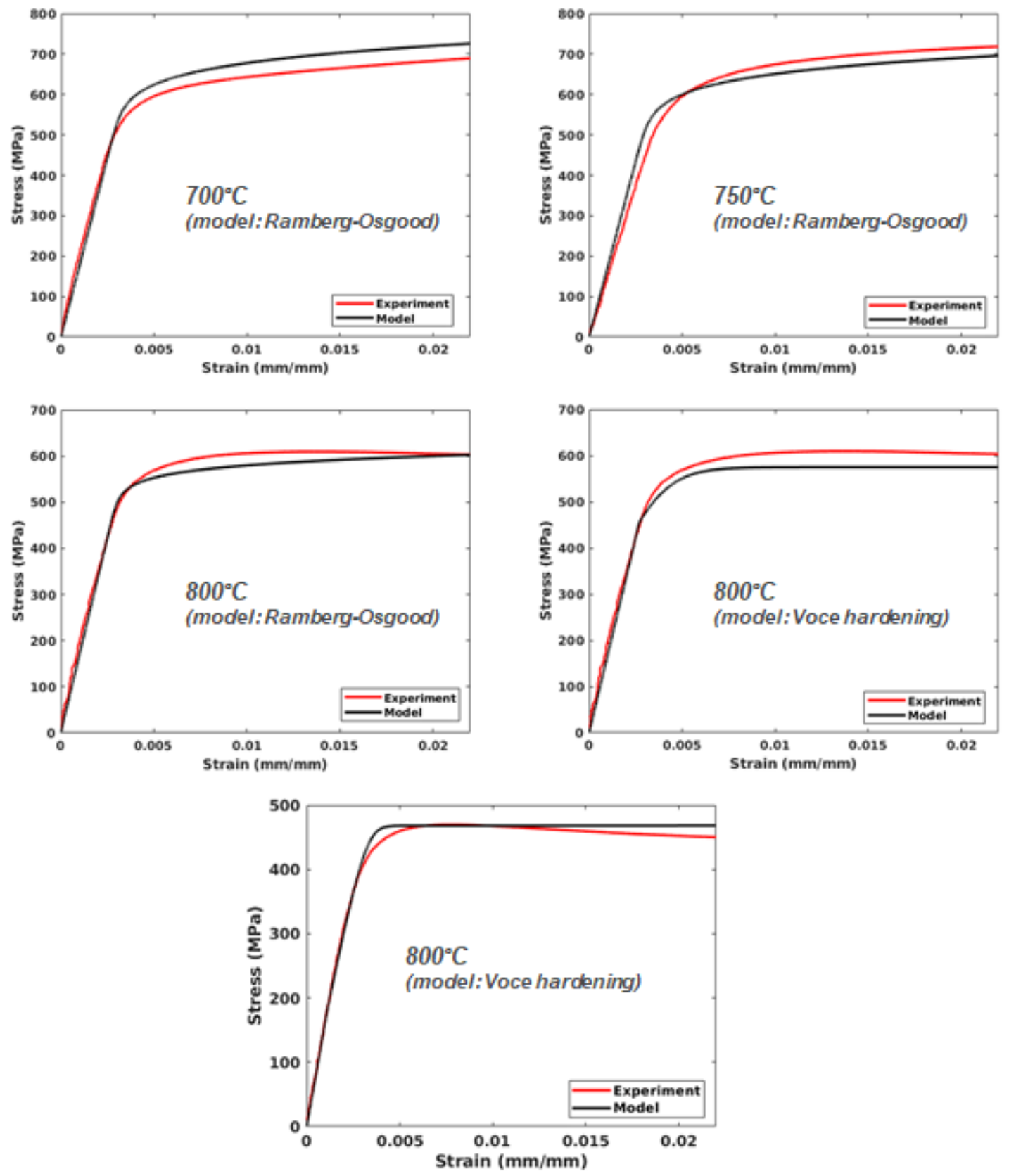

Figure 3-3.14.2.1. Experimental and hot tensile model curves for Alloy $740 \mathrm{H}$ at different temperatures.

Hot tensile model curves were determined by fitting the experimental data with the plasticity model (Ramberg-Osgood or Voce hardening) and then modified to match with the Young's modulus and average yield strength. The average yield strength data were collected from the background document of ASME Code Case 2702.

${ }^{22}$ U. F. Kocks, "Realistic constitutive relations for metal plasticity" Materials Science and Engineering: A, 317, pp. 181-187, 2001. 
We adopt a form developed by Kocks ${ }^{22}$ and Mecking ${ }^{23}$ for creep model of alloy $740 \mathrm{H}$. Their model posits a linear relation between the log-normalized material flow stress and the normalized activation energy . If this log-linear relation exists, the Kocks-Mecking model can be converted into a model for the deformation strain rate as a function of the linear fit slope and intercept.

Here is the material shear stress given as, is the Boltzmann constant, is the absolute temperature, is a characteristic Burgers vector, and is some reference strain rate. This method was successfully implemented by Messner and Sham ${ }^{24}$ for modeling the creep deformation in developing the isochronous stress-strain relationships for a similar nickel based Alloy 617. Figure 3-3.14.2.2 plots the available Alloy $740 \mathrm{H}$ creep data using the average rate to $1 \%$ creep strain as the deformation strain rate and the applied values of stress and temperature. As the Figure 3-3.14.2.2 shows, the Alloy 740 creep data nearly obeys the Kocks-Mecking form. Based on this diagram, the model for the creep strain adopted for Alloy $740 \mathrm{H}$ is

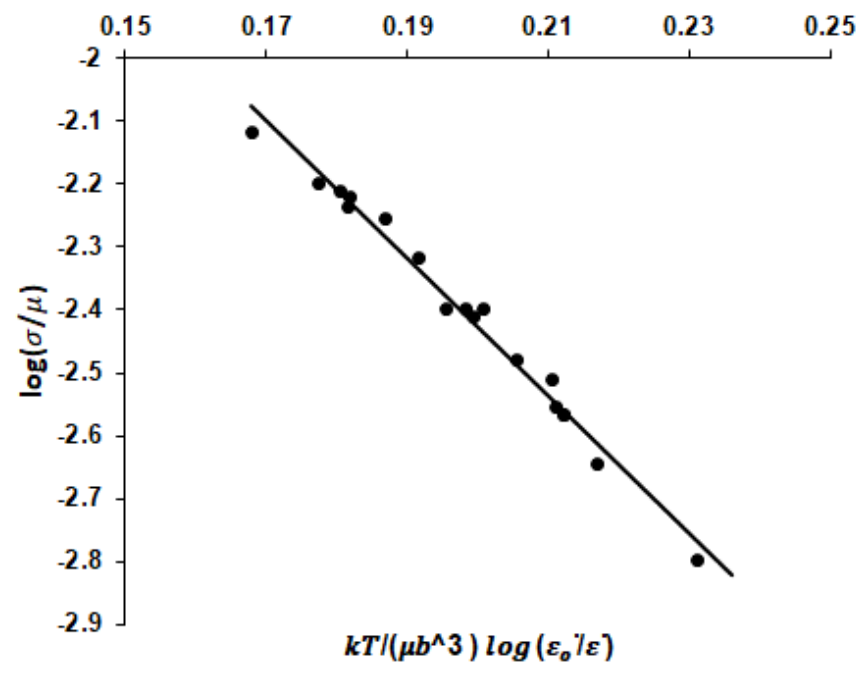

Figure 3-3.14.2.2. Kocks-Mecking diagram used to construct the model for .

\section{3-3.15. Inelastic constitutive model}

As noted above in the commentary on the design methods, assembling a complete inelastic constitutive model capable of accurately capturing details of elevated

\footnotetext{
${ }^{22}$ U. F. Kocks, "Realistic constitutive relations for metal plasticity" Materials Science and Engineering: A, 317, pp. 181-187, 2001.

${ }^{23}$ Y. Estrin, and H. Mecking, "A unified phenomenological description of work hardening and creep based on oneparameter models" Acta Metallurgica, 32, pp 57-70, 1984.

${ }^{24}$ M. C. Messner, and T-L. Sham, "Isochronous Stress-Strain Curves for Alloy 617" In the Proceedings of the ASME 2019 Pressure Vessels and Piping Conference, PVP2019-93642, 2019.
} 
temperature cyclic plasticity/creep interactions is a very complicated task that has not been completed for the vast majority of high temperature materials ${ }^{25,26,27}$.

However, Design Method C detailed above purposely uses a simplified description of the material response in order to take advantage of the steady cyclic response of the system. In the general case, the material description could be elastic, perfectly-plastic, with power law creep. However, as described in 3-2.4, for Alloy $740 \mathrm{H}$ plasticity can be neglected, leaving an elastic-creep constitutive response.

The specific inelastic model was then formulated by taking the elastic and creep strain equations from 3-3.14 and supplementing them with the standard equation for the thermal strains, using the coefficients of thermal expansion supplied in Part 2.

This constitutive model is only suitable for use with the simplified inelastic design method detailed above. It is not suitable for a full inelastic analysis capturing all the details of elevated temperature plasticity and creep-plasticity interaction. Such a model, for example using the Chaboche form ${ }^{28}$, would be much more difficult to develop and require an extensive experimental database of creep, creep-fatigue, and other cyclic tests including full stress/strain/time hysteresis information.

\section{3-3.16. Temperature limits}

\section{3-3.16.1. Minimal creep}

This temperature limit is the temperature at which the material accumulates $0.1 \%$ strain at the allowable stress over 100,000 hours. It can be determined using the information in 3-3.7 and 3-3.14 above. This particular cutoff was invented for these rules. The rational is that the allowable stress is a reasonable typical long-term stress level in components design using these rules. The $0.1 \%$ over 100,000 hour criteria is a typical ASME negligible creep threshold.

\section{3-3.16.2. ASME Section III, Division 5 limit on the O'Donnell-Porowski method}

This temperature limit is used in the O'Donnell-Porowski design-by-elastic-analysis strain limits rules. Its purpose is to ensure that one end of the load cycle is anchored at a temperature in the negligible creep regime - a necessary requirement for applying the O'Donnell-Porowski theorem. The specific temperature limit is the temperature at which at 100,000 hours. Section 3-3.8 describes the Section III, Division 5 allowable stress . is a time-dependent allowable stress used in Section III, Division 5. The details of how it is calculated from creep-data are not important, as the design document provides the

\footnotetext{
${ }^{25}$ M. Yaguchi, and Y. Takahashi, "Unified Inelastic Constitutive Model for Modified 9Cr-1Mo Steel Incorporating Dynamic Strain Aging Effect” JSME International Journal Series A, 42(1), pp. 1-10, 1999.

${ }^{26}$ M. C. Messner, V.-T. Phan, T.-L. Sham, "A Unified Inelastic Constitutive Model for the Average Engineering Response of Grade 91 Steel" In the Proceedings of the ASME 2018 Pressure Vessels and Piping Conference PVP2018-84104, 2018.

${ }^{27}$ Phan, V.-T., Messner, M. C. and Sham, T.-L. " A Unified Engineering Inelastic Model for 316H Stainless Steel.” In the Proceedings of the ASME 2019 Pressure Vessels and Piping Conference, PVP2019-93641, 2019.

${ }^{28} \mathrm{~J}$. L. Chaboche. "Constitutive equations for cyclic plasticty and cyclic viscoplasticity" International Journal of Plasticity, 5, pp. 247-302, 1989.
} 
temperature value for Alloy $740 \mathrm{H}$. 


\section{Part 4: Sample problems}

This chapter walks through two sample design problems, applying all three design methods to each problem. The structural material used in all calculations is Alloy $740 \mathrm{H}$, with design properties from Part 2 above.

\section{4-1. Sample problem 1}

\section{4-1.1. Problem description}

Figure 4-1.1 illustrates the first problem considered for evaluating design methods developed for CSP systems. This problem is an axisymmetric representation of a tube in a cavity receiver. The tube is $500 \mathrm{~mm}$ long and $2 \mathrm{~mm}$ thick. The outer diameter is 40 $\mathrm{mm}$. For simplicity, we assumed uniform heat flux on the outer surface of the tube and that the heat conduction analysis is done in the steady state, even for the design criteria which require a transient analysis. This results in linear temperature gradient along the length and thickness of the tube and therefore this problem can be treated as an axisymmetric problem. This linear temperature distribution can be fully described by providing the inner and outer tube metal temperatures as a function of time and axial position. Only two points are required to define the axial gradient. Figure 4-1.1 shows the temperature and pressure loading considered for this problem. The loading cycle includes warming up of the system in the morning, steady state operation, five cloud events each with 8 minutes hold, cooling down in the evening, and no operation during night. The design life of the tube is 30 years.

The purpose of this problem is to provide designers a simple reference problem to check their understanding of the design methods.

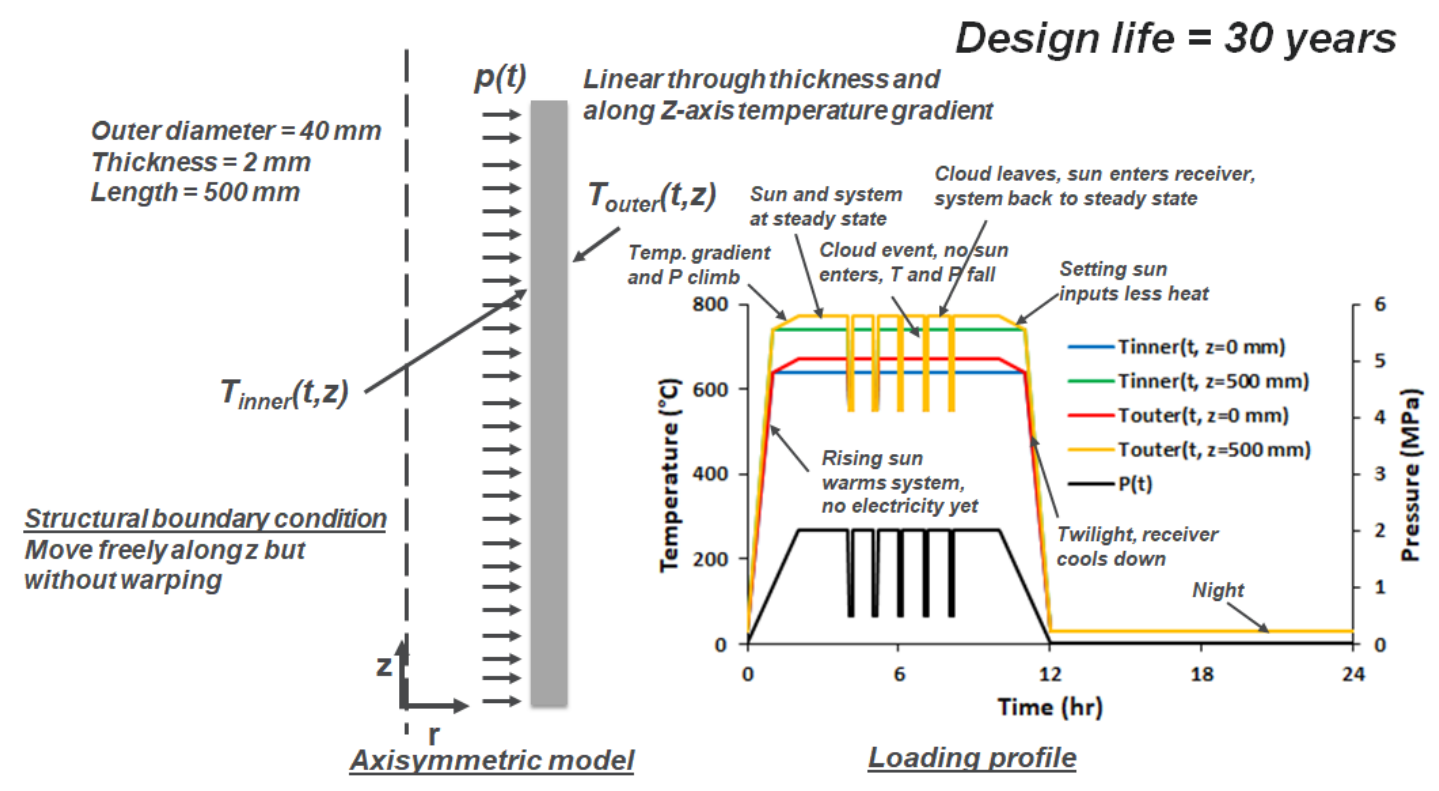


Figure 4-1.1. (Sample problem 1) An axisymmetric representation of a single tube in a cavity receiver. Loading profile shows the inner and outer wall temperature at the bottom $(z=0 \mathrm{~mm})$ and top $(z=500 \mathrm{~mm}$ ) ends of the tube, respectively, and pressure exerted on the inner wall by the salt flowing inside the tube.

\section{4-1.2. Design calculations based on Method 1}

\section{4-1.2.1. Step-1: Defining the Design Cycle}

Figure 4-1.2.1 shows the Design Cycle. The daily load cycle can be divided into two service load types - start-up/shut-down cycle and cloud events. Table provides the details of each event considered in the composite cycle.

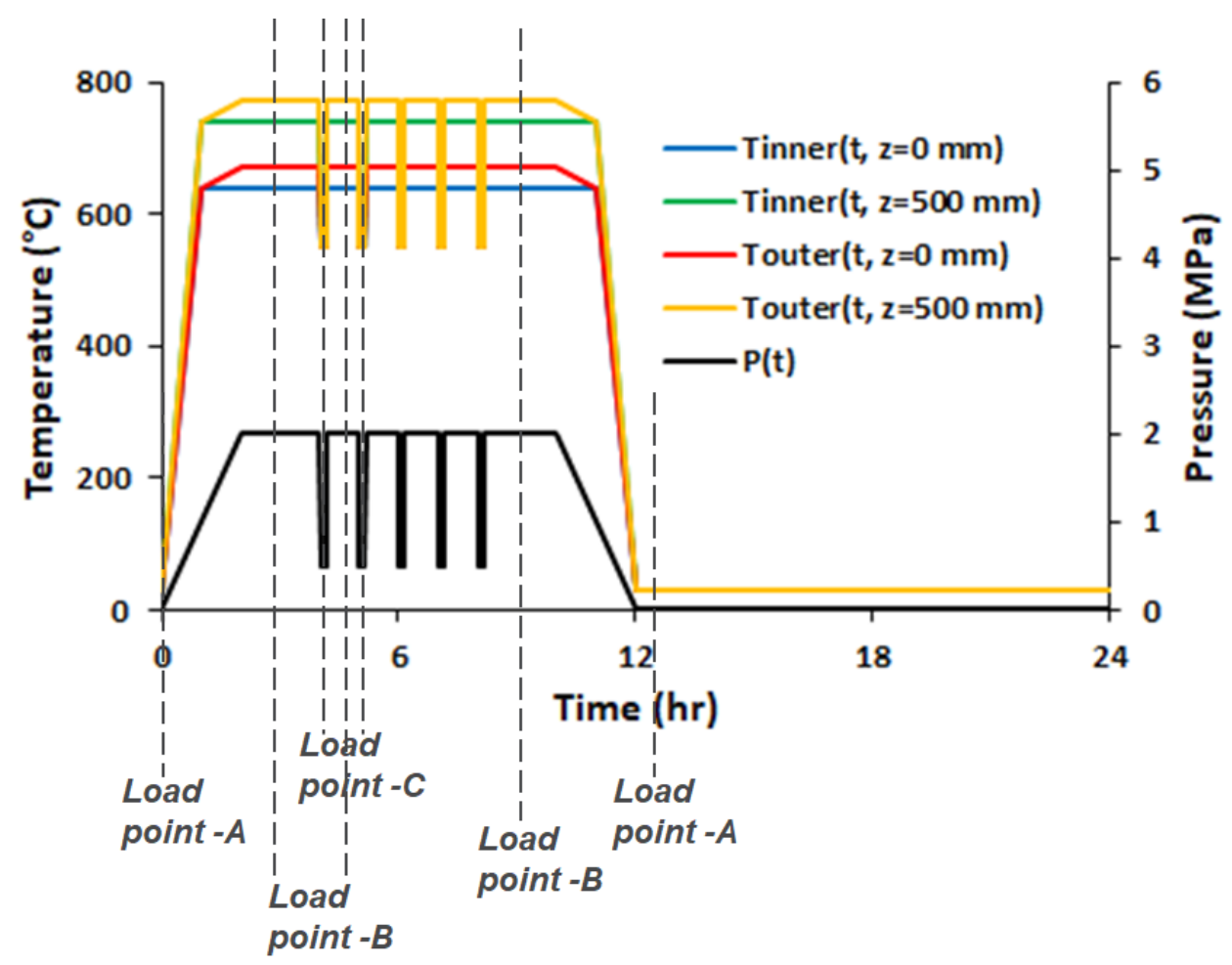

Figure 4-1.2.1 (Sample problem 1) Different load points during the loading cycle considered.

\begin{tabular}{|c|c|c|}
\hline Service load types & Associated load points and cycle period & Frequency per design cycle \\
\hline start-up/shut-down cycle & $\mathrm{A}$ and $\mathrm{B} ; 12$ hours & 1 \\
\hline cloud events & $\mathrm{B}$ and $\mathrm{C} ; 0.133$ hours & 5 \\
\hline
\end{tabular}

Table 4-1.2.1 (Sample problem 1) Service load cycles and associated load points (illustrated in Figure 4-1.2.1) in the daily load cycle and corresponding hold times.

\section{4-1.2.2. Step-2: Transient elastic thermo-mechanical analysis for each service load case and stress classification}

We used MOOSE (Multiphysics Object Oriented Simulation Environment), an open source finite element solver to perform the elastic thermo-mechanical analyses. We classify stresses due to pressure as primary load and thermal stresses caused by the 
temperature gradient as secondary load. There is no peak load.

\section{4-1.2.3. Step-3: Primary load design check}

Maximum primary load occurs at load point-B. Figure 4-1.2.3 shows the temperature distribution in the tube and stress components along the thickness of the tube at maximum wall averaged temperature location. Table 4-1.2.3 reports details of the primary load checks. First, all the stress components were linearized to divide into membrane and bending components along the stress classification line. The membrane and bending stress tensors were then used to determine the stress intensities in Table 4-1.2.3 As indicated in the table the design passes both the criteria in primary load checks.

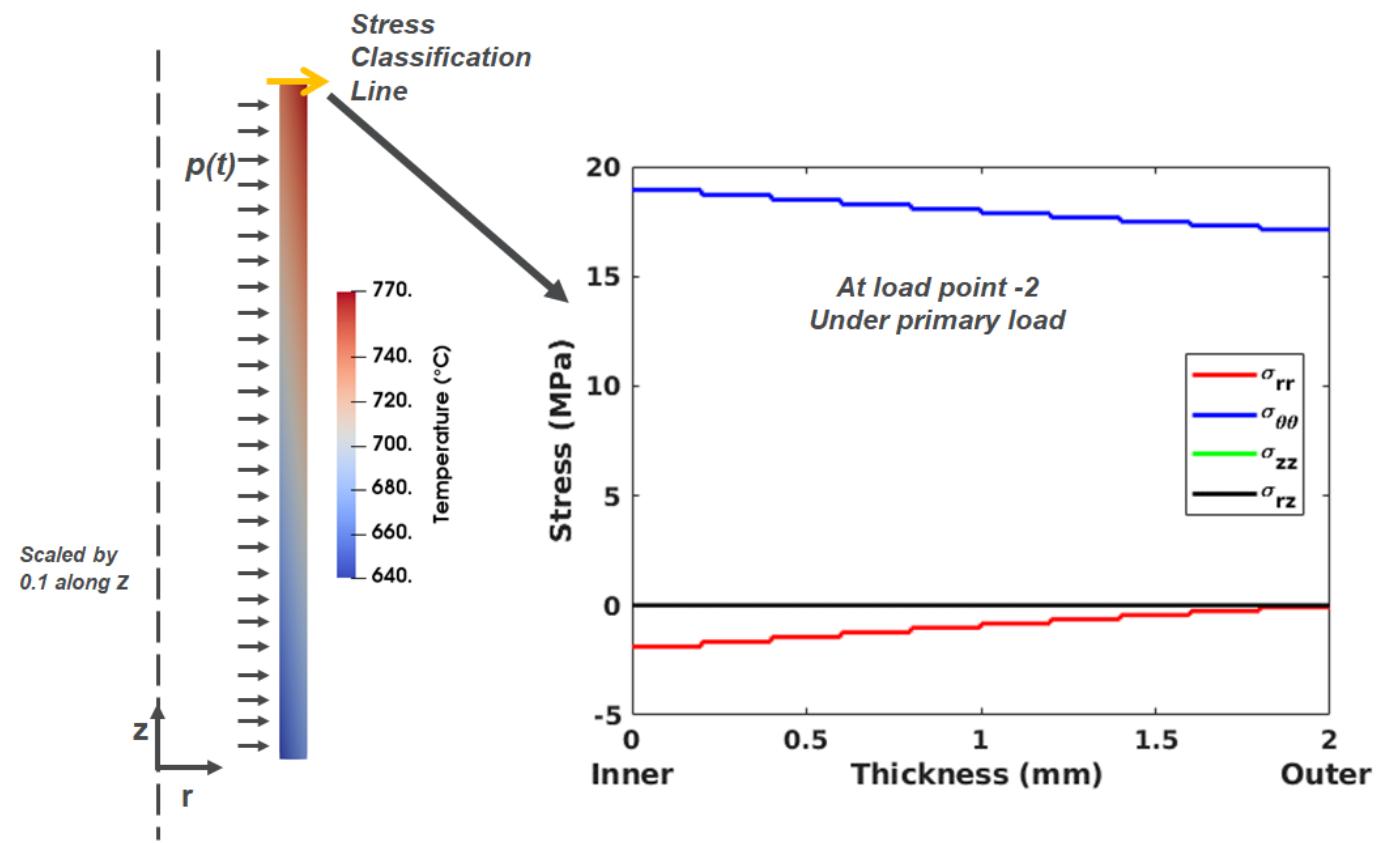

Figure 4-1.2.3. (Sample problem 1) Temperature distribution in the tube and through thickness elastic stress components at maximum wall averaged temperature location under primary load at load point -B.

\begin{tabular}{|l|c|}
\hline Max. General primary membrane stress intensity, & $18.95 \mathrm{MPa}$ \\
\hline Max. Combined primary membrane plus bending stress intensity, & $20.92 \mathrm{MPa}$ \\
\hline Maximum metal temperature, & $770^{\circ} \mathrm{C}$ \\
\hline Allowable stress, at & $64.26 \mathrm{MPa}$ \\
\hline Design criteria -1: & PASS ! \\
\hline Design criteria -2: & PASS ! \\
\hline
\end{tabular}

Table 4-1.2.3 (Sample problem 1) Primary load design checks.

\section{4-1.2.4. Step-4: Ratcheting check}

Design Method 1 uses the O'Donnell-Porowski approach, described in Section III, Division 5, HBB-1332 Test No. B-1 for ratcheting checks. In this approach, an effective creep stress parameter, $\mathrm{Z}$ is determined from a primary stress parameter, $\mathrm{X}$ and $\mathrm{a}$ 
secondary stress parameter, $\mathrm{Y}$ as shown in Figure 4-1.2.4.1 The effective creep stress parameter is used to calculate the effective creep stress which is then used to determine the ratcheting creep strain using isochronous stress-strain curves. The definition of $X$ and $Y$ are

where,

= the maximum value of the primary stress intensity, adjusted for bending via , during the cycle being evaluated.

$=$ the maximum range of the secondary stress intensity during the cycle being considered

$=$ is the value corresponds to the lower of the wall averaged temperature for the stress extremes defining secondary stress range, .

is 1.5 for across-the-wall bending of shell structures or rectangular sections, see HBB-3223 (c) (6) in Section III Division 5.

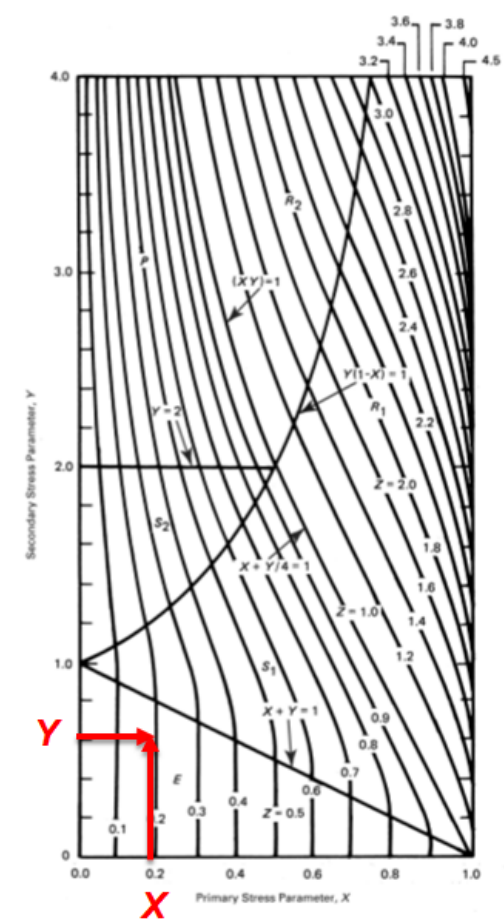

Figure 4-1.2.4.1. Illustration of determining the effective creep stress parameters from Section III, Division 5, Figure HBB-T-1332-1.

Once $Z$ is found, effective core, stress is determined from 
It should be noted that, the average wall temperature at one of the stress extremes defining the secondary stress intensity range must be below the temperature listed in Section III, Division 5, HBB-T-1323, given as for $740 \mathrm{H}$ in the description of the design method above.

The creep ratcheting strain increment for a load cycle is evaluated by entering the isochronous stress strain curves at the maximum wall temperature and effective core, stress during the load cycle with the stress held constant for the entire service life. An example of creep ratcheting strain determination is shown in Figure 4-1.2.4.2.

Since the start-up/shut-down service load includes the extreme temperature profile and the total time of the day, considering only the start-up/shut-down load should provide conservative estimation for ratcheting design. Table 4-1.2.4 provides all the calculation details of the ratcheting design check. Figure 4-1.2.4.3 shows the stress components under secondary loading at load point B. Stress components are shown at two different locations - maximum wall averaged temperature and maximum von Mises stress. As indicated in the Table 4-1.2.4, the maximum ratcheting strain in the structure is less than $2 \%$ and therefore the design passes the ratcheting check. Note that, a design must pass the ratcheting design check before it is checked for creep-fatigue damage.

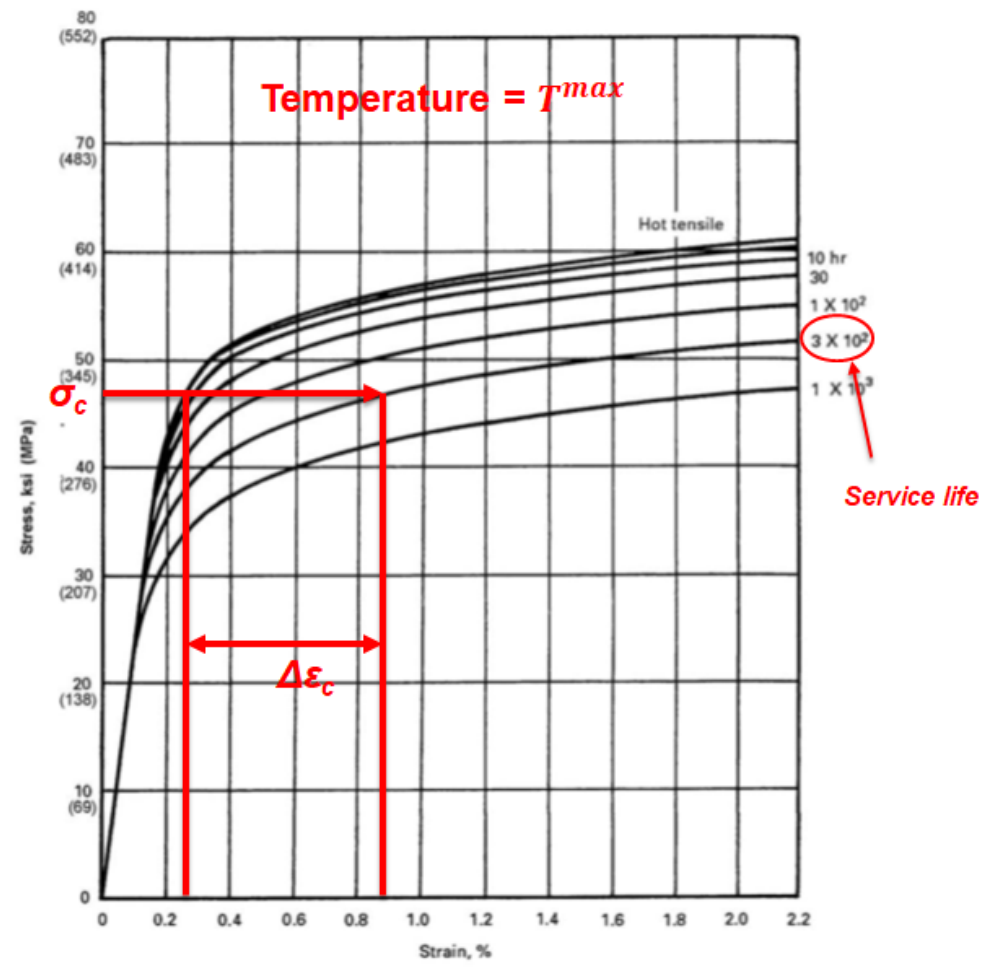

Figure 4-1.2.4.2. Illustration of determining the creep ratcheting strain increment from isochronous stress strain curves. 


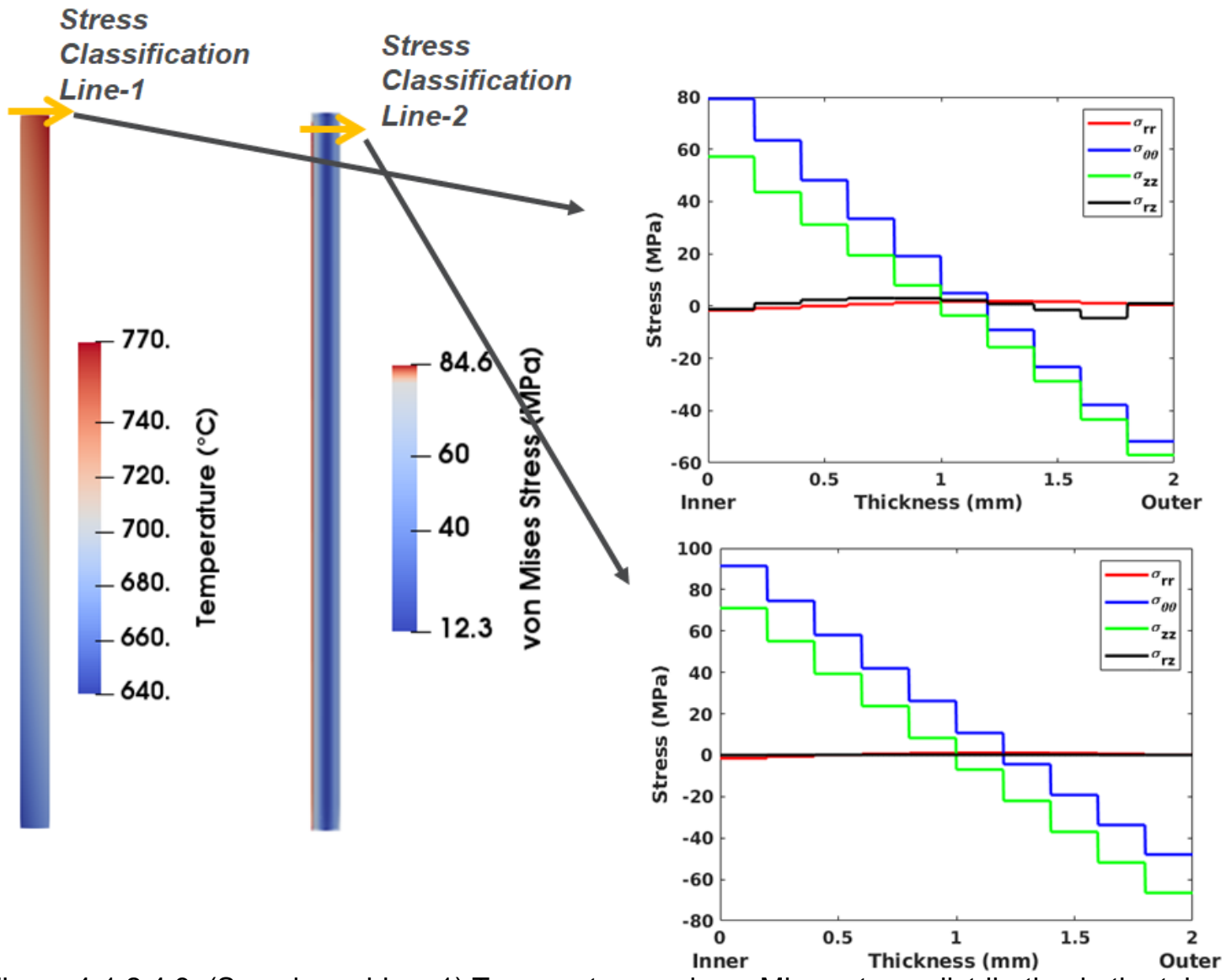

Figure 4-1.2.4.3. (Sample problem 1) Temperature and von Mises stress distribution in the tube and through thickness stress components at maximum wall averaged temperature and maximum von Mises stress locations under secondary load at load point B. 


\begin{tabular}{|l|l|l|}
\hline & $\begin{array}{l}\text { Stress classification } \\
\text { line-1 shown in Figure } \\
\mathbf{4 - 1 . 2 . 4 . 3}\end{array}$ & $\begin{array}{l}\text { Stress classification } \\
\text { line-2 shown in Figure } \\
\mathbf{4 - 1 . 2 . 4 . 3}\end{array}$ \\
\hline & $755 .{ }^{\circ} \mathrm{C}$ & $752.6^{\circ} \mathrm{C}$ \\
\hline & $30^{\circ} \mathrm{C}$ & $30^{\circ} \mathrm{C}$ \\
\hline (at ) & $770^{\circ} \mathrm{C}$ & $767.3^{\circ} \mathrm{C}$ \\
\hline & $621.0 \mathrm{MPa}$ & $621.0 \mathrm{MPa}$ \\
\hline & 1.5 & 1.5 \\
\hline & 1.25 & 1.25 \\
\hline & 20.53 & 20.53 \\
\hline & 85.06 & 96.81 \\
\hline $\begin{array}{l}\text { using Section III, } \\
\text { Division 5, Figure } \\
\text { HBB-T-1332-1 }\end{array}$ & 0.033 & 0.033 \\
\hline from & 0.137 & 0.156 \\
\hline Service life & 0.033 & 0.033 \\
\hline $\begin{array}{l}\text { Ratcheting strain at } \\
\text { the end of service life }\end{array}$ & $1.723 \mathrm{e}-5 \%$ & 20.53 \\
\hline $\begin{array}{l}\text { Ratcheting design } \\
\text { criteria: 2\% for base } \\
\text { metal }\end{array}$ & $\mathbf{P A S S !}$. & 30 years = 131400 hours \\
\hline
\end{tabular}

Table 4-1.2.4 (Sample problem 1) Ratcheting design check according to Method 1.

\section{4-1.2.5. Step-5: Creep-fatigue damage check}

According to Section III, Division 5, a design is acceptable if the creep and fatigue damage satisfy the following relation:

where $D$ is the total creep-fatigue damage and the first and second terms on the left side are fatigue damage, and creep damage, , respectively. In the fatigue damage term, is the number of repetitions of cycle type $j$ and is the number of design allowable cycles for respective cycle type; while in the creep damage term, is the allowable time duration for a given stress at the maximum temperature occurring in the time interval $k$ and is the duration of the time interval $\mathrm{k}$.

The design allowable cycles for fatigue damage is determined by entering fatigue curves at total strain range, . Total strain range, is calculated using equation HBBT-1432-16:

where is the local geometric concentration or equivalent stress concentration factor determined by dividing effective primary plus secondary plus peak stress divided by the 
effective primary plus secondary stress, is the multiaxial plasticity and Poisson ratio adjustment factor, is the creep strain increment, and is the modified maximum equivalent strain range.

is calculated using equation Section III, Division 5, HBB-T-1432-12:

where is the maximum equivalent strain range calculated from the elastic analysis of under primary and secondary loading together. is calculated according to Section III, Division 5, HBB-T-1413 with for elastic analysis. and are stresses determined by entering the isochronous stress-strain curves at and, respectively.

is determined using equation Section III, Division 5, HBB-T-1432-15:

where $\mathrm{f}$ is the inelastic multiaxial adjustment factor determined using Section III, Division 5, Figure HBB-T-1432-2 and triaxiality factor, T.F.

where $\sigma$ 's are principals stresses at the extreme of the stress cycle.

is the adjustment for inelastic biaxial Poisson's ratio determined from Section III, Division 5, Figure HBB-T-1432-3 using .

where

Here are relaxation strengths associated with the temperatures at the hot and cold extremes of the stress cycle. These values are provided above in the $740 \mathrm{H}$ design data. The hot temperature condition is defined as the maximum operating temperature of the stress cycle. The hot time is equal to the portion of service life when wall averaged temperatures exceed $425^{\circ} \mathrm{C}$. The cold temperature is defined as the colder of the two temperatures corresponding to the two stress extremes in the stress cycle. The cold time is again equal to the portion of service life when wall averaged temperatures exceed $425^{\circ} \mathrm{C}$.

The creep strain increment per stress cycle, is determined by entering the isochronous stress-strain curves at and maximum metal temperature for the stress cycle time, including hold times between transients (instead of total service life). Alternatively, the creep accumulated during the entire service life divided by the number of stress cycles during the entire service life can also be used for calculating creep strain increment per stress cycle, . We used the latter option. 
The design allowable cycles, is then calculated from design fatigue curve at maximum metal temperature and using total strain range, , as illustrated in Figure 4-1.2.5.1 Fatigue damage fraction, is then determined from the ratio between design cycles and design allowable cycles for each cycle type and then adding them together. Figure 4-1.2.5.2 shows the equivalent strain ranges from elastic analysis between load points $A$ and $B$ and between load points $B$ and $C$ along two stress classification lines. Table 4-1.2.5.1 shows the details of all the relevant calculations to determine fatigue damage fraction.

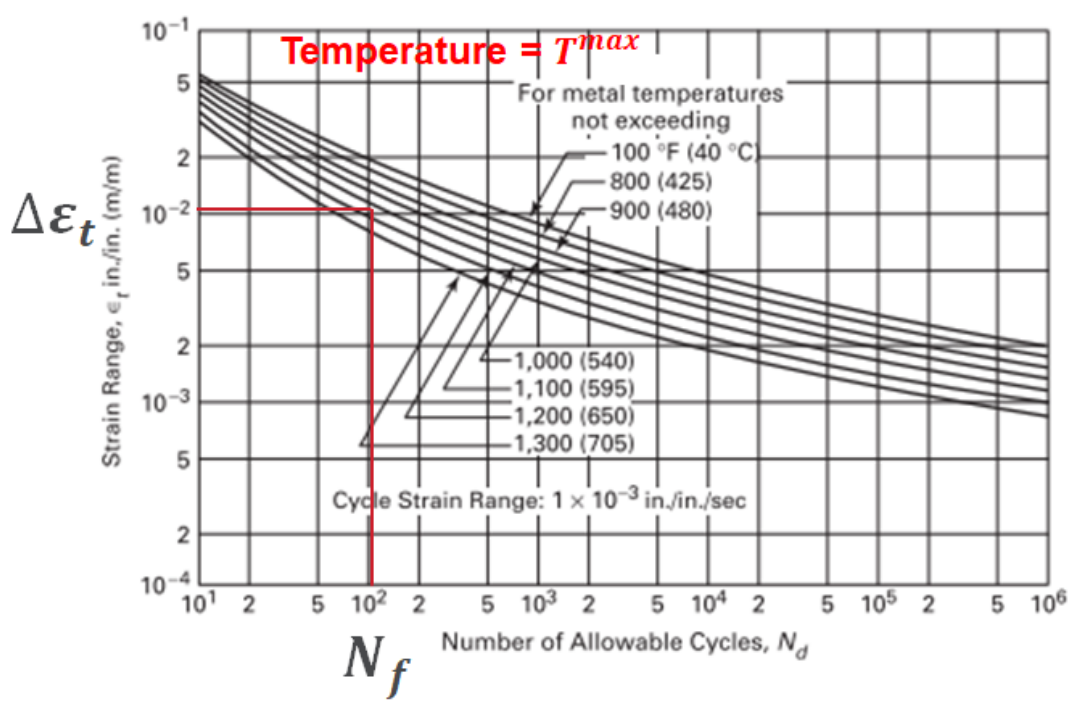

Figure 4-1.2.5.1. Illustration of determining design allowable cycles, . 

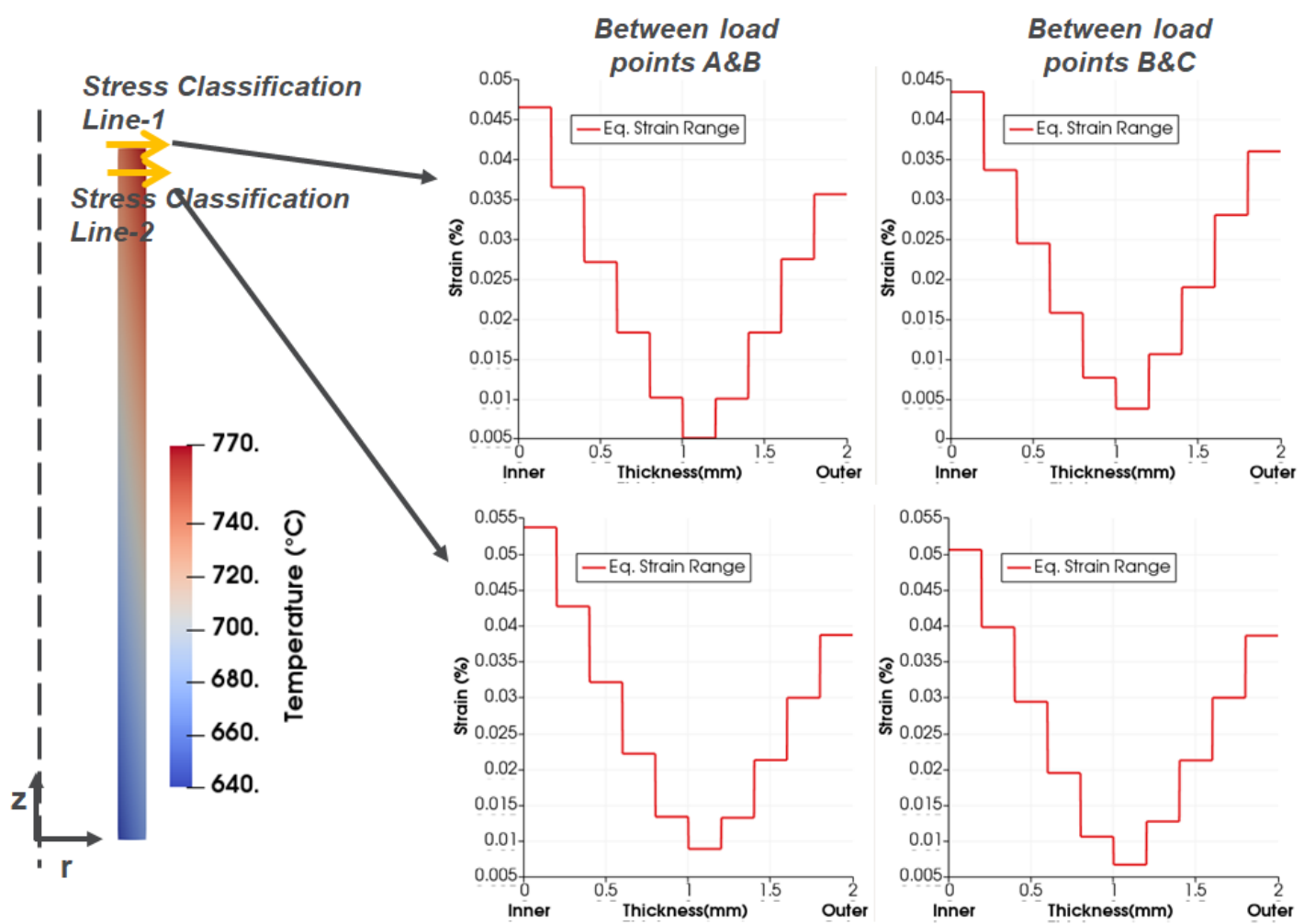

Figure 4-1.2.5.2. (Sample problem 1) Equivalent strain range from elastic analysis.

Creep damage evaluation is done in accordance to HBB-T1433(b)-option (a) but with one exception as described in the design Method 1. The lower bound stress is taken as , rather than the specified in the Code. First, stress relaxation profile is determined by entering the isochronous stress-strain curves at a strain level equal to and at hold-time temperature and determining the corresponding stress levels at varying times. However, this stress relaxation process should not be permitted to a stress level less than. This stress relaxation procedure results in a stress-time history similar to that illustrated in Figure 4-1.2.5.3 Using the stress-time history and hold-time temperature during the cycle creep damage fraction can be calculated according to the illustration in Figure 4-1.2.5.4 For creep damage fraction calculation, we only considered the start-up/shutdown service load cycle. The time duration of the cloud events is already included in the start-up/shut-down service load cycle. Creep damage is not expected during night time. Tables 4-1.2.5.2 and 4-1.2.5.3 show the details of determining creep damage fraction, from stress relaxation profile.

To determine whether the design passes the creep-fatigue damage check, the fatigue damage fraction, and creep damage fraction, are plotted on creep-fatigue interaction diagram as shown in Figure 4-1.2.5.5 If the ( point falls inside the creep-fatigue damage envelop the design passes. As seen in Figure 4-1.2.5.5, the ( points fall inside the creep-fatigue damage envelop which means the design passes for creep-fatigue damage check. 


\begin{tabular}{|c|c|c|c|c|}
\hline & \multicolumn{2}{|c|}{$\begin{array}{l}\text { At OD on stress classification line-1 } \\
\text { shown in Figure 4-1.2.5.2 }\end{array}$} & \multicolumn{2}{|c|}{$\begin{array}{l}\text { At OD on Stress classification line-2 } \\
\text { shown in Figure 4-1.2.5.2 }\end{array}$} \\
\hline & $\begin{array}{l}\text { Start-up/shut- } \\
\text { down cycle }\end{array}$ & Cloud event & $\begin{array}{l}\text { Start-up/shut- } \\
\text { down cycle }\end{array}$ & Cloud event \\
\hline & $770^{\circ} \mathrm{C}$ & $770^{\circ} \mathrm{C}$ & $767.3^{\circ} \mathrm{C}$ & $767.3^{\circ} \mathrm{C}$ \\
\hline $\begin{array}{l}\text { Hot } \\
\text { temperature }\end{array}$ & $770^{\circ} \mathrm{C}$ & $770^{\circ} \mathrm{C}$ & $767.3^{\circ} \mathrm{C}$ & $767.3^{\circ} \mathrm{C}$ \\
\hline $\begin{array}{l}\text { Cold } \\
\text { temperature }\end{array}$ & $30^{\circ} \mathrm{C}$ & $550^{\circ} \mathrm{C}$ & $30^{\circ} \mathrm{C}$ & $550^{\circ} \mathrm{C}$ \\
\hline Hot time & $\begin{array}{l}12 \mathrm{hr} *(30 * 365) \\
=131400 \mathrm{hr}\end{array}$ & 0 & $\begin{array}{l}12 \mathrm{hr} *(30 * 365) \\
=131400 \mathrm{hr}\end{array}$ & 0 \\
\hline \multirow[t]{3}{*}{ Cold time } & $\begin{array}{l}12 \mathrm{hr} *(30 * 365) \\
=131400 \mathrm{hr}\end{array}$ & $\begin{array}{l}8 \min ^{*}(30 * 365) \\
=1460 \mathrm{hr}\end{array}$ & $\begin{array}{l}12 \mathrm{hr} *(30 * 365) \\
=131400 \mathrm{hr}\end{array}$ & $\begin{array}{l}8 \min ^{*}(30 * 365) \\
=1460 \mathrm{hr}\end{array}$ \\
\hline & 107.2 MPa & $354.8 \mathrm{MPa}$ & $110.5 \mathrm{MPa}$ & $358.9 \mathrm{MPa}$ \\
\hline & Not required & 153.3 MPa & Not required & $158.4 \mathrm{MPa}$ \\
\hline \multirow[t]{14}{*}{ at } & 241.0 & Not required & 243.2 & Not required \\
\hline & $468.7 \mathrm{MPa}$ & $508.1 \mathrm{MPa}$ & $475.3 \mathrm{MPa}$ & $517.3 \mathrm{MPa}$ \\
\hline & $0.0356 \%$ & $0.0360 \%$ & $0.0387 \%$ & $0.0376 \%$ \\
\hline & $\begin{array}{l}1 \text { (no peak } \\
\text { stress) }\end{array}$ & 1 (no peak stress) & $\begin{array}{l}1 \text { (no peak } \\
\text { stress) }\end{array}$ & 1 (no peak stress) \\
\hline & $0.0356 \%$ & $0.0360 \%$ & $0.0387 \%$ & $0.0376 \%$ \\
\hline & $171700 \mathrm{MPa}$ & $171700 \mathrm{MPa}$ & $171943 \mathrm{MPa}$ & $171943 \mathrm{MPa}$ \\
\hline & $0.278 \%$ & $0.296 \%$ & $0.276 \%$ & $0.301 \%$ \\
\hline & 1 & 1 & 1 & 1 \\
\hline & 1 & 1 & 1 & 1 \\
\hline & 1 & 1 & 1 & 1 \\
\hline & 1 & 1 & 1 & 1 \\
\hline & $0.0356 \%$ & $0.0360 \%$ & $0.0387 \%$ & $0.0376 \%$ \\
\hline & $1.57 e-9 \%$ & 0 & $1.27 e-9 \%$ & 0 \\
\hline & $0.0356 \%$ & $0.0360 \%$ & $0.0387 \%$ & $0.0376 \%$ \\
\hline $\begin{array}{l}\text { Design } \\
\text { allowable } \\
\text { cycles, }\end{array}$ & 5086519 & 5047174 & 4789440 & 4892815 \\
\hline $\begin{array}{l}\text { Design } \\
\text { cycles, }\end{array}$ & $30 * 365=10950$ & $30 * 365 * 5=54750$ & $30 * 365=10950$ & $30 * 365 * 5=54750$ \\
\hline $\begin{array}{l}\text { Fatigue } \\
\text { damage } \\
\text { fraction, }\end{array}$ & \multicolumn{2}{|l|}{0.0130} & \multicolumn{2}{|l|}{0.0135} \\
\hline
\end{tabular}

Table 4-1.2.5.1. (Sample problem 1) Sample calculation of fatigue damage fraction, according to Method 1. 


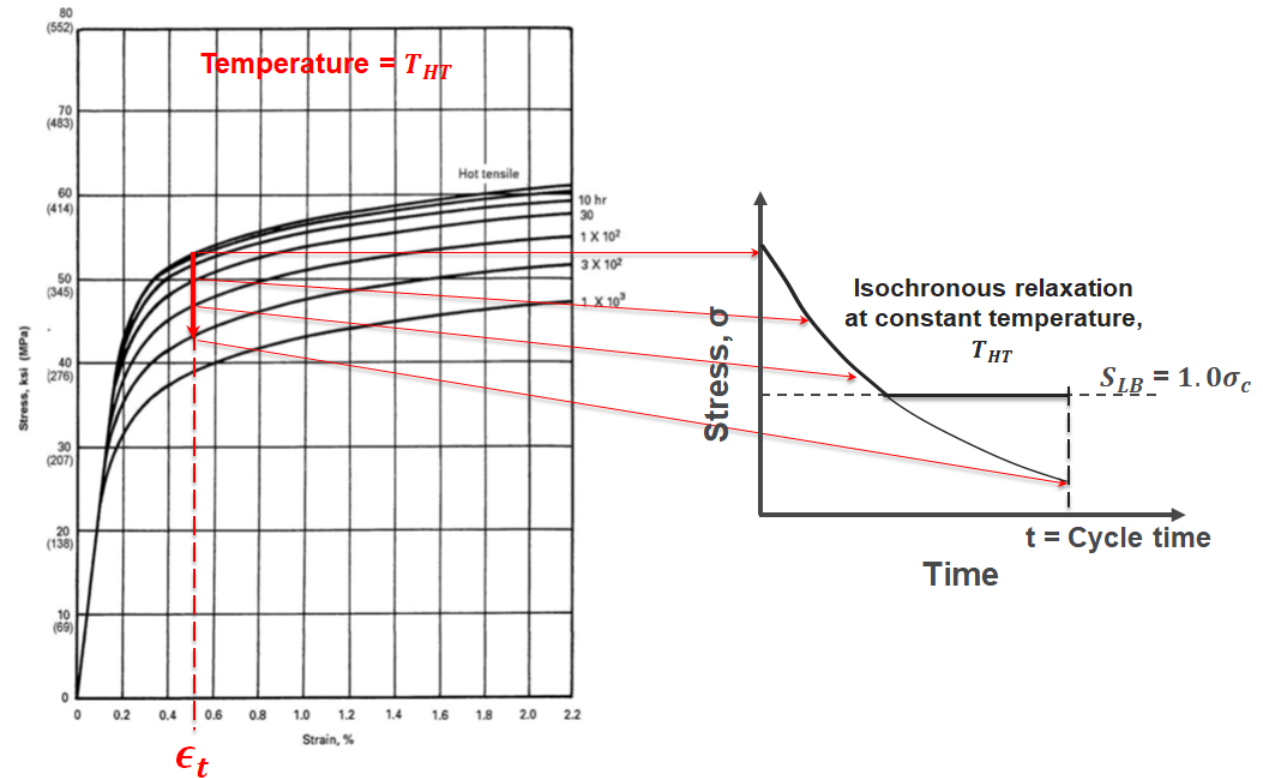

Figure 4-1.2.5.3. Illustration of determining stress relaxation profile from isochronous stress-strain curves for creep damage calculation in Method 1.

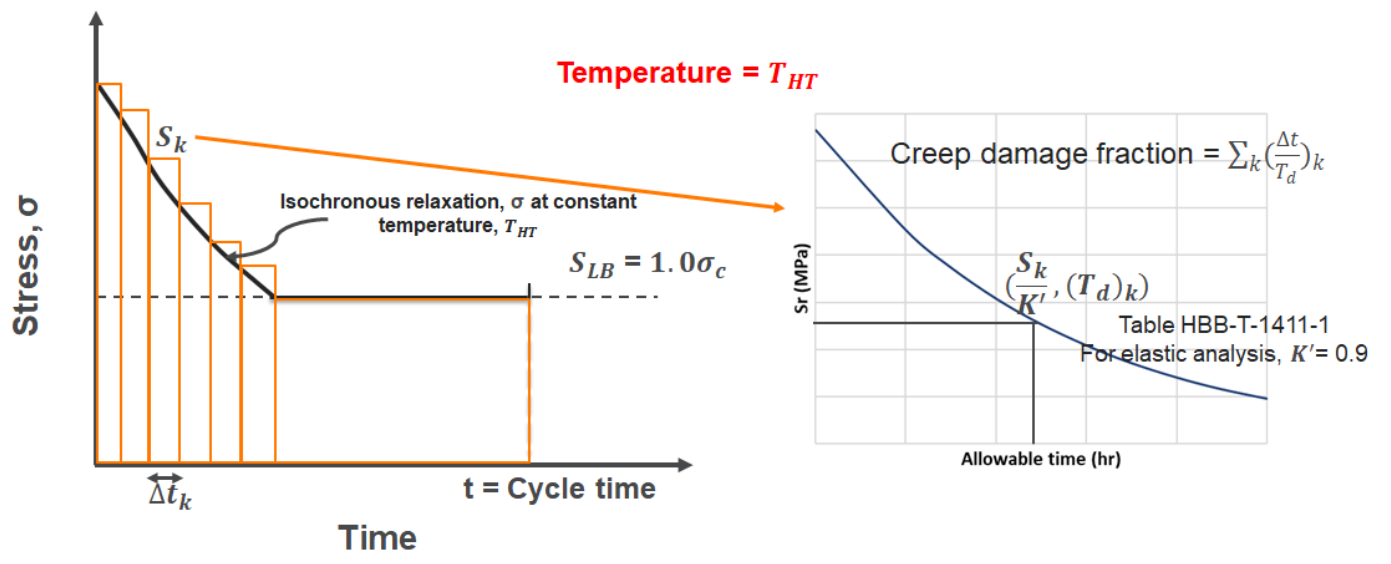

Figure 4-1.2.5.4. (Sample problem 1) Illustration of calculating creep damage fraction in Method 1. 


\begin{tabular}{|c|c|c|c|c|}
\hline & $\begin{array}{l}\text { At OD on stress } \\
\text { classification } \\
\text { line-1 shown in } \\
\text { Figure 4-1.2.5.2 }\end{array}$ & $\begin{array}{l}\text { At ID on stress } \\
\text { classification } \\
\text { line-1 shown in } \\
\text { Figure 4-1.2.5.2 }\end{array}$ & $\begin{array}{l}\text { At OD on stress } \\
\text { classification } \\
\text { line-2 shown in } \\
\text { Figure 4-1.2.5.2 }\end{array}$ & $\begin{array}{l}\text { At ID on stress } \\
\text { classification } \\
\text { line-2 shown in } \\
\text { Figure 4-1.2.5.2 }\end{array}$ \\
\hline & $\begin{array}{l}\text { Start-up/shut- } \\
\text { down cycle }\end{array}$ & $\begin{array}{l}\text { Start-up/shut- } \\
\text { down cycle }\end{array}$ & $\begin{array}{l}\text { Start-up/shut- } \\
\text { down cycle }\end{array}$ & $\begin{array}{l}\text { Start-up/shut- } \\
\text { down cycle }\end{array}$ \\
\hline & $0.0356 \%$ & $0.0465 \%$ & $0.0377 \%$ & $0.0537 \%$ \\
\hline & $770^{\circ} \mathrm{C}$ & $740^{\circ} \mathrm{C}$ & $767.3^{\circ} \mathrm{C}$ & $737.3^{\circ} \mathrm{C}$ \\
\hline & 20.53 & 20.53 & 20.53 & 20.53 \\
\hline $\begin{array}{l}\text { (Table HBB- } \\
\text { T-1411-1) for } \\
\text { elastic analysis }\end{array}$ & 0.9 & 0.9 & 0.9 & 0.9 \\
\hline $\begin{array}{l}\text { Creep damage } \\
\text { fraction per cycle } \\
\text { (from Table } \\
4-1.2 .5 .3 \text { ) }\end{array}$ & $2.02 e-5$ & $2.04 \mathrm{e}-5$ & $2.53 e-5$ & $3.23 e-5$ \\
\hline Design cycles, & $30 * 365=10950$ & $30 * 365=10950$ & $30 * 365=10950$ & $30 * 365=10950$ \\
\hline $\begin{array}{l}\text { Creep damage } \\
\text { fraction, }\end{array}$ & 0.22 & 0.22 & 0.28 & 0.35 \\
\hline
\end{tabular}

Table 4-1.2.5.2. (Sample problem 1) Sample creep damage fraction, calculation according to Method 1. 


\begin{tabular}{|c|c|c|c|c|c|c|c|c|c|c|c|}
\hline \multicolumn{6}{|c|}{$\begin{array}{l}\text { At } O D \text { on stress classification line-1 shown in Figure } \\
4-1.2 .5 .2\end{array}$} & \multicolumn{6}{|c|}{$\begin{array}{l}\text { At OD on stress classification line-2 shown in } \\
\text { Figure 4-1.2.5.2 }\end{array}$} \\
\hline $\begin{array}{c}\text { Time } \\
(\mathrm{hr})\end{array}$ & (MPa) & (MPa) & (hr) & (hr) & & $\begin{array}{c}\text { Time } \\
(h r)\end{array}$ & (MPa) & (MPa) & (hr) & (hr) & \\
\hline 0 & $6.11 \mathrm{e} 1$ & $6.79 \mathrm{e} 1$ & $5.95 \mathrm{e} 5$ & 1 & $1.68 \mathrm{e}-6$ & 0 & $6.65 \mathrm{e} 1$ & $7.39 \mathrm{e} 1$ & $4.73 \mathrm{e} 5$ & 1 & $2.11 \mathrm{e}-6$ \\
\hline 1 & $6.11 \mathrm{e} 1$ & $6.79 \mathrm{e} 1$ & $5.95 \mathrm{e} 5$ & 1 & $1.68 \mathrm{e}-6$ & 1 & $6.65 \mathrm{e} 1$ & $7.39 \mathrm{e} 1$ & $4.73 \mathrm{e} 5$ & 1 & $2.11 \mathrm{e}-6$ \\
\hline 2 & $6.11 \mathrm{e} 1$ & $6.79 \mathrm{e} 1$ & $5.95 \mathrm{e} 5$ & 1 & $1.68 \mathrm{e}-6$ & 2 & $6.65 \mathrm{e} 1$ & $7.39 \mathrm{e} 1$ & $4.73 \mathrm{e} 5$ & 1 & $2.11 \mathrm{e}-6$ \\
\hline 3 & $6.11 \mathrm{e} 1$ & $6.79 \mathrm{e} 1$ & $5.95 \mathrm{e} 5$ & 1 & $1.68 \mathrm{e}-6$ & 3 & $6.65 \mathrm{e} 1$ & $7.39 \mathrm{e} 1$ & $4.73 \mathrm{e} 5$ & 1 & $2.11 \mathrm{e}-6$ \\
\hline 4 & $6.11 \mathrm{e} 1$ & $6.79 \mathrm{e} 1$ & $5.95 \mathrm{e} 5$ & 1 & $1.68 \mathrm{e}-6$ & 4 & $6.65 \mathrm{e} 1$ & $7.39 \mathrm{e} 1$ & $4.73 \mathrm{e} 5$ & 1 & $2.11 \mathrm{e}-6$ \\
\hline 5 & $6.11 \mathrm{e} 1$ & $6.79 \mathrm{e} 1$ & $5.95 \mathrm{e} 5$ & 1 & $1.68 \mathrm{e}-6$ & 5 & $6.65 \mathrm{e} 1$ & $7.39 \mathrm{e} 1$ & $4.73 \mathrm{e} 5$ & 1 & $2.11 \mathrm{e}-6$ \\
\hline 6 & $6.11 \mathrm{e} 1$ & $6.79 \mathrm{e} 1$ & $5.95 \mathrm{e} 5$ & 1 & $1.68 \mathrm{e}-6$ & 6 & $6.65 \mathrm{e} 1$ & $7.39 \mathrm{e} 1$ & $4.73 \mathrm{e} 5$ & 1 & $2.11 \mathrm{e}-6$ \\
\hline 7 & $6.11 \mathrm{e} 1$ & $6.79 \mathrm{e} 1$ & $5.95 \mathrm{e} 5$ & 1 & $1.68 \mathrm{e}-6$ & 7 & $6.65 \mathrm{e} 1$ & $7.39 \mathrm{e} 1$ & $4.73 \mathrm{e} 5$ & 1 & $2.11 \mathrm{e}-6$ \\
\hline 8 & $6.11 \mathrm{e} 1$ & $6.79 \mathrm{e} 1$ & $5.95 \mathrm{e} 5$ & 1 & $1.68 \mathrm{e}-6$ & 8 & $6.65 \mathrm{e} 1$ & $7.39 \mathrm{e} 1$ & $4.73 \mathrm{e} 5$ & 1 & $2.11 \mathrm{e}-6$ \\
\hline 9 & $6.11 \mathrm{e} 1$ & $6.79 \mathrm{e} 1$ & $5.95 \mathrm{e} 5$ & 1 & $1.68 \mathrm{e}-6$ & 9 & $6.65 \mathrm{e} 1$ & $7.39 \mathrm{e} 1$ & $4.73 \mathrm{e} 5$ & 1 & $2.11 \mathrm{e}-6$ \\
\hline 10 & $6.11 \mathrm{e} 1$ & $6.79 \mathrm{e} 1$ & $5.95 \mathrm{e} 5$ & 1 & $1.68 \mathrm{e}-6$ & 10 & $6.65 \mathrm{e} 1$ & $7.39 \mathrm{e} 1$ & $4.73 \mathrm{e} 5$ & 1 & $2.11 \mathrm{e}-6$ \\
\hline 11 & $6.11 \mathrm{e} 1$ & $6.79 \mathrm{e} 1$ & $5.95 \mathrm{e} 5$ & 1 & $1.68 \mathrm{e}-6$ & 11 & $6.65 \mathrm{e} 1$ & $7.39 \mathrm{e} 1$ & $4.73 \mathrm{e} 5$ & 1 & $2.11 \mathrm{e}-6$ \\
\hline 12 & $6.11 \mathrm{e} 1$ & $6.79 \mathrm{e} 1$ & $5.95 \mathrm{e} 5$ & & & 12 & $6.65 \mathrm{e} 1$ & $7.39 \mathrm{e} 1$ & $4.73 \mathrm{e} 5$ & & \\
\hline \multicolumn{5}{|c|}{ Creep damage fraction per cycle } & $2.02 e-5$ & \multicolumn{5}{|c|}{ Creep damage fraction per cycle } & $2.53 e-5$ \\
\hline \multicolumn{6}{|c|}{$\begin{array}{l}\text { At ID on stress classification line-1 shown in Figure } \\
4-1.2 .5 .2\end{array}$} & \multicolumn{6}{|c|}{$\begin{array}{l}\text { At ID on stress classification line-2 shown in } \\
\text { Figure 4-1.2.5.2 }\end{array}$} \\
\hline $\begin{array}{c}\text { Time } \\
\text { (hr) }\end{array}$ & (MPa) & (MPa) & (hr) & (hr) & & $\begin{array}{c}\text { Time } \\
\text { (hr) }\end{array}$ & (MPa) & (MPa) & (hr) & (hr) & \\
\hline 0 & $8.11 \mathrm{e} 1$ & $9.01 \mathrm{e} 1$ & $5.88 \mathrm{e} 5$ & 1 & $1.70 \mathrm{e}-6$ & 0 & $9.37 \mathrm{e} 1$ & $1.04 \mathrm{e} 2$ & $3.72 \mathrm{e} 5$ & 1 & $2.69 \mathrm{e}-6$ \\
\hline 1 & $8.11 \mathrm{e} 1$ & $9.01 \mathrm{e} 1$ & $5.88 \mathrm{e} 5$ & 1 & $1.70 \mathrm{e}-6$ & 1 & $9.37 \mathrm{e} 1$ & $1.04 \mathrm{e} 2$ & $3.72 \mathrm{e} 5$ & 1 & $2.69 \mathrm{e}-6$ \\
\hline 2 & $8.11 \mathrm{e} 1$ & $9.01 \mathrm{e} 1$ & $5.88 \mathrm{e} 5$ & 1 & $1.70 \mathrm{e}-6$ & 2 & $9.37 \mathrm{e} 1$ & $1.04 \mathrm{e} 2$ & $3.72 \mathrm{e} 5$ & 1 & $2.69 \mathrm{e}-6$ \\
\hline 3 & $8.11 \mathrm{e} 1$ & $9.01 \mathrm{e} 1$ & $5.88 \mathrm{e} 5$ & 1 & $1.70 \mathrm{e}-6$ & 3 & $9.37 \mathrm{e} 1$ & $1.04 \mathrm{e} 2$ & $3.72 \mathrm{e} 5$ & 1 & $2.69 \mathrm{e}-6$ \\
\hline 4 & $8.11 \mathrm{e} 1$ & $9.01 \mathrm{e} 1$ & $5.88 \mathrm{e} 5$ & 1 & $1.70 \mathrm{e}-6$ & 4 & $9.37 \mathrm{e} 1$ & $1.04 \mathrm{e} 2$ & $3.72 \mathrm{e} 5$ & 1 & $2.69 \mathrm{e}-6$ \\
\hline 5 & $8.11 \mathrm{e} 1$ & $9.01 \mathrm{e} 1$ & $5.88 \mathrm{e} 5$ & 1 & $1.70 \mathrm{e}-6$ & 5 & $9.37 \mathrm{e} 1$ & $1.04 \mathrm{e} 2$ & $3.72 \mathrm{e} 5$ & 1 & $2.69 \mathrm{e}-6$ \\
\hline 6 & $8.11 \mathrm{e} 1$ & $9.01 \mathrm{e} 1$ & $5.88 \mathrm{e} 5$ & 1 & $1.70 \mathrm{e}-6$ & 6 & $9.36 \mathrm{e} 1$ & $1.04 \mathrm{e} 2$ & $3.72 \mathrm{e} 5$ & 1 & $2.69 \mathrm{e}-6$ \\
\hline 7 & $8.11 \mathrm{e} 1$ & $9.01 \mathrm{e} 1$ & $5.88 \mathrm{e} 5$ & 1 & $1.70 \mathrm{e}-6$ & 7 & $9.36 \mathrm{e} 1$ & $1.04 \mathrm{e} 2$ & $3.72 \mathrm{e} 5$ & 1 & $2.69 \mathrm{e}-6$ \\
\hline 8 & $8.11 \mathrm{e} 1$ & $9.01 \mathrm{e} 1$ & $5.88 \mathrm{e} 5$ & 1 & $1.70 \mathrm{e}-6$ & 8 & $9.36 \mathrm{e} 1$ & $1.04 \mathrm{e} 2$ & $3.72 \mathrm{e} 5$ & 1 & $2.69 \mathrm{e}-6$ \\
\hline 9 & $8.11 \mathrm{e} 1$ & $9.01 \mathrm{e} 1$ & $5.88 \mathrm{e} 5$ & 1 & $1.70 \mathrm{e}-6$ & 9 & $9.36 \mathrm{e} 1$ & $1.04 \mathrm{e} 2$ & $3.72 \mathrm{e} 5$ & 1 & $2.69 \mathrm{e}-6$ \\
\hline 10 & $8.11 \mathrm{e} 1$ & $9.01 \mathrm{e} 1$ & $5.88 \mathrm{e} 5$ & 1 & $1.70 \mathrm{e}-6$ & 10 & $9.36 \mathrm{e} 1$ & $1.04 \mathrm{e} 2$ & $3.72 \mathrm{e} 5$ & 1 & $2.69 \mathrm{e}-6$ \\
\hline 11 & $8.11 \mathrm{e} 1$ & $9.01 \mathrm{e} 1$ & $5.88 \mathrm{e} 5$ & 1 & $1.70 \mathrm{e}-6$ & 11 & $9.36 \mathrm{e} 1$ & $1.04 \mathrm{e} 2$ & $3.72 \mathrm{e} 5$ & 1 & $2.69 \mathrm{e}-6$ \\
\hline 12 & $8.11 \mathrm{e} 1$ & $9.01 \mathrm{e} 1$ & $5.88 \mathrm{e} 5$ & & & 12 & $9.36 \mathrm{e} 1$ & $1.04 \mathrm{e} 2$ & $3.72 \mathrm{e} 5$ & & \\
\hline \multicolumn{5}{|c|}{ Creep damage fraction per cycle } & $2.04 e-5$ & \multicolumn{5}{|c|}{ Creep damage fraction per cycle } & $3.23 e-5$ \\
\hline
\end{tabular}

Table 4-1.2.5.3. (Sample problem 1) Sample calculation to determine creep damage fraction, per cycle from stress-time history according to Method 1. 


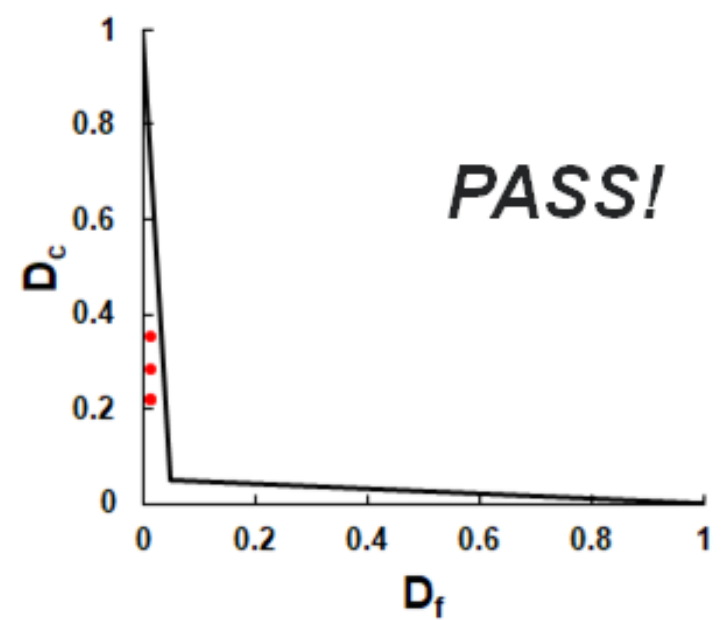

Figure 4-1.2.5.5. (Sample problem 1) Illustration of creep-fatigue design check. Plotted data are results from analysis according to Method 1.

\section{4-1.2.6. Step-6: Time-independent buckling check}

As buckling is not expected under the salt pressure and thermal loading considered in this problem and because wind load is not considered, this design check was not performed.

\section{4-1.2.7. Step-7: Time-dependent buckling check}

As buckling is not expected under the salt pressure and thermal loading considered in this problem, this design check was not performed.

4-1.3. Design calculations based on Method 2

\section{4-1.3.1. Step-1: Defining the Design Cycle}

Same as in Method 1 Step 1.

4-1.3.2. Step-2: Transient elastic thermo-mechanical analysis for each service load case and stress classification

Same as in Method 1 Step 2.

4-1.3.3. Step-3: Primary load design check

Same as in Method 1 Step 3.

\section{4-1.3.4. Step-4: Ratcheting check}

Same as in Method 1 Step 4. 


\section{4-1.3.5. Step-5: Creep-fatigue damage check}

Method 2 is applicable only if the total stress intensity remains less than for all service loading and if peak stresses are minimal.

For a design to be acceptable, the following relation must be satisfied:

where $D$ is the total creep-fatigue damage and the first and second terms on the left side are fatigue damage, and creep damage, , respectively. In the fatigue damage term, is the number of repetitions of cycle type $j$ and is the number of design allowable cycles for respective cycle type; while in the creep damage term, is the allowable time duration for a given stress at the maximum temperature occurring in the time interval $k$ and is the duration of the time interval $\mathrm{k}$.

The design allowable cycles for fatigue damage is determined by entering fatigue curves at total strain range, . Total strain range, is calculated using equation HBBT-1432-16:

where is the maximum equivalent strain range calculated from the elastic analysis of under primary and secondary loading together, according to Section III, Division 5, HBB-T-1413. is the creep strain increment per stress cycle. can be determined by entering the isochronous stress-strain curves at the O'Donnell-Porowski core stress, (determined in Method 1, Step 4) and maximum metal temperature for the stress cycle time, including hold times between transient (instead of total service life). Alternatively, can be calculated by dividing the creep strain accumulated during the entire service life by the number of stress cycles during the entire service life. We used the latter option.

Creep damage for each service load cycle is evaluated from the von Mises stress profile, determined from elastically calculated stresses, versus time profile for this load cycle. Using the stress-time profile and the hold time temperature, during the cycle, creep damage fraction can be calculated according to the illustration in Figure 4-1.3.5.1 As mentioned before, we only considered the start-up/shut-down service load cycle for creep damage fraction calculation.

Tables 4-1.3.5.1 and 4-1.3.5.2 show few sample calculations of determining creep damage fraction, and fatigue damage fraction,, respectively, according to Method 2. Similar to Method 1, Method 2 also uses creep-fatigue interaction diagram to determine whether a design passes creep-fatigue damage check. Comparing ( with the damage envelop in creep-fatigue interaction diagram, as shown in Figure 4-1.3.5.2, the design is found to be passed according to Method 2. 


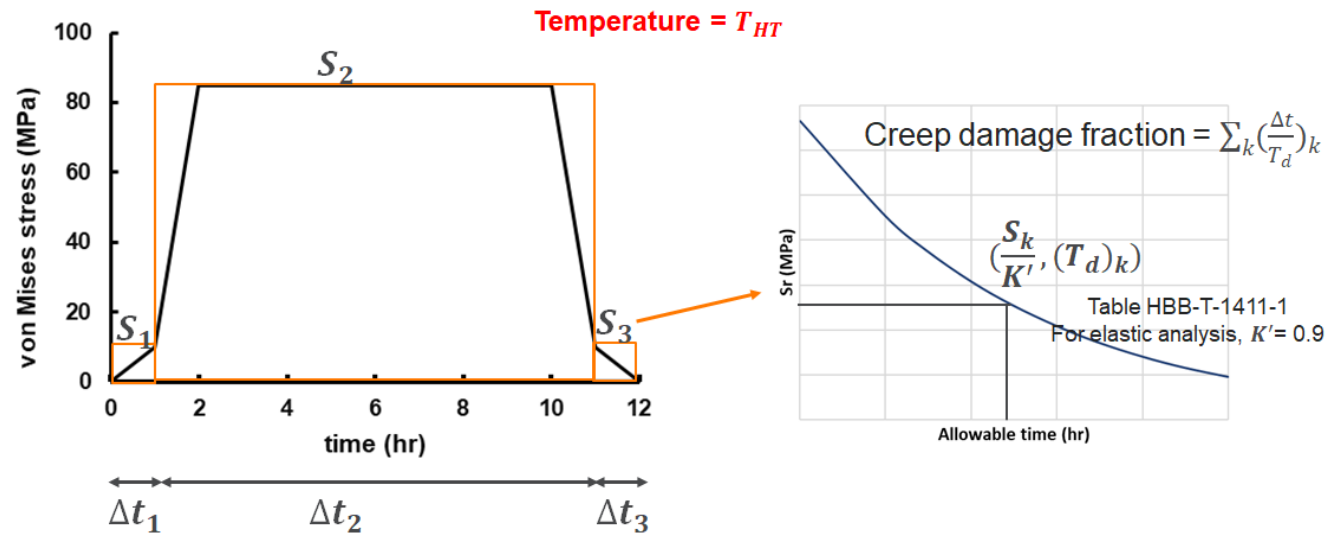

Figure 4-1.3.5.1. (Sample problem 1) Illustration of calculating creep damage fraction in Method 2.

\begin{tabular}{|c|c|c|c|c|c|c|c|c|c|c|c|}
\hline \multicolumn{6}{|c|}{$\begin{array}{l}\text { At } O D \text { on stress classification line-1 shown in Figure } \\
4-1.2 .5 .2\end{array}$} & \multicolumn{6}{|c|}{$\begin{array}{l}\text { At } O D \text { on stress classification line-2 shown in } \\
\text { Figure 4-1.2.5.2 }\end{array}$} \\
\hline \multicolumn{6}{|c|}{$\begin{array}{l}=770^{\circ} \mathrm{C} \\
=490 \mathrm{MPa} \text { (Method } 2 \text { is applicable!) }\end{array}$} & \multicolumn{6}{|c|}{$\begin{array}{l}=767.3^{\circ} \mathrm{C} \\
=492.3 \mathrm{MPa} \text { (Method } 2 \text { is applicable!) }\end{array}$} \\
\hline $\begin{array}{c}\text { Time } \\
(h r)\end{array}$ & $(\mathrm{MPa})$ & $(\mathrm{MPa})$ & (hr) & (hr) & & $\begin{array}{c}\text { Time } \\
(h r)\end{array}$ & (MPa) & (MPa) & (hr) & (hr) & \\
\hline 0 & 0 & - & - & - & - & 0 & 0 & - & - & - & - \\
\hline 1 & 7.88 & 8.76 & $1.47 \mathrm{e} 7$ & 1 & $6.80 \mathrm{e}-8$ & 1 & 9.05 & 10.06 & $1.37 \mathrm{e} 7$ & 1 & $7.23 e-8$ \\
\hline 2 & 57.17 & 63.52 & $7.55 \mathrm{e} 5$ & 10 & $1.32 \mathrm{e}-5$ & 2 & 59.93 & 66.59 & $6.95 \mathrm{e} 5$ & 10 & $1.44 \mathrm{e}-5$ \\
\hline 10 & 57.17 & - & - & - & - & 10 & 59.93 & - & - & - & - \\
\hline 11 & 7.88 & 8.76 & $1.47 \mathrm{e} 7$ & 1 & $6.80 \mathrm{e}-8$ & 11 & 9.05 & 10.06 & $1.37 \mathrm{e} 7$ & 1 & $7.23 \mathrm{e}-8$ \\
\hline 12 & 0 & - & - & - & - & 12 & 0 & - & - & - & - \\
\hline \multicolumn{5}{|c|}{ Creep damage fraction per cycle } & $1.33 e-5$ & \multicolumn{5}{|c|}{ Creep damage fraction per cycle } & $1.45 e-5$ \\
\hline \multicolumn{5}{|c|}{ Creep damage fraction, } & 0.15 & \multicolumn{5}{|c|}{ Creep damage fraction, } & 0.16 \\
\hline \multicolumn{6}{|c|}{$\begin{array}{l}\text { At ID on stress classification line-1 shown in Figure } \\
4-1.2 .5 .2\end{array}$} & \multicolumn{6}{|c|}{$\begin{array}{l}\text { At ID on stress classification line-2 shown in } \\
\text { Figure 4-1.2.5.2 }\end{array}$} \\
\hline \multicolumn{6}{|c|}{$\begin{array}{l}=740^{\circ} \mathrm{C} \\
=512 \mathrm{MPa} \text { (Method } 2 \text { is applicable!) }\end{array}$} & \multicolumn{6}{|c|}{$\begin{array}{l}=737.3^{\circ} \mathrm{C} \\
=513 \mathrm{MPa}(\text { Method } 2 \text { is applicable!) }\end{array}$} \\
\hline $\begin{array}{c}\text { Time } \\
(h r)\end{array}$ & (MPa) & (MPa) & $(h r)$ & $(h r)$ & & $\begin{array}{c}\text { Time } \\
(h r)\end{array}$ & (MPa) & (MPa) & $(h r)$ & (hr) & \\
\hline 0 & 0 & - & - & - & - & 0 & 0 & - & - & - & - \\
\hline 1 & 9.72 & 10.80 & $1.58 \mathrm{e} 7$ & 1 & $6.33 \mathrm{e}-8$ & 1 & 10.55 & 11.7 & $1.60 \mathrm{e} 7$ & 1 & $6.25 \mathrm{e}-8$ \\
\hline 2 & 74.01 & 82.23 & $8.16 \mathrm{e} 5$ & 10 & $1.23 \mathrm{e}-5$ & 2 & 86.03 & 95.59 & $5.25 \mathrm{e} 5$ & 10 & $1.90 \mathrm{e}-5$ \\
\hline 10 & 74.01 & - & - & - & - & 10 & 86.03 & - & - & - & - \\
\hline 11 & 9.72 & 10.8 & $1.58 \mathrm{e} 7$ & 1 & $6.33 \mathrm{e}-8$ & 11 & 10.55 & 11.7 & $1.60 \mathrm{e} 7$ & 1 & $6.25 \mathrm{e}-7$ \\
\hline 12 & 0 & - & - & - & - & 12 & 0 & - & - & - & - \\
\hline \multicolumn{5}{|c|}{ Creep damage fraction per cycle } & $1.36 e-5$ & \multicolumn{5}{|c|}{ Creep damage fraction per cycle } & $1.91 e-5$ \\
\hline \multicolumn{5}{|c|}{ Creep damage fraction, } & 0.15 & \multicolumn{5}{|c|}{ Creep damage fraction, } & 0.21 \\
\hline
\end{tabular}

Table 4-1.3.5.1. (Sample problem 1) Sample calculation to determine creep damage fraction, per cycle from stress-time history according to Method 2. 


\begin{tabular}{|l|l|l|l|l|}
\hline & \multicolumn{2}{|l|}{$\begin{array}{l}\text { At OD on stress classification line-1 } \\
\text { shown in Figure 4-1.2.2 }\end{array}$} & \multicolumn{2}{l|}{$\begin{array}{l}\text { At OD on Stress classification line-2 } \\
\text { shown in Figure 4-1.5.2 }\end{array}$} \\
\hline & $\begin{array}{l}\text { Start-up/shut-down } \\
\text { cycle }\end{array}$ & Cloud event & $\begin{array}{l}\text { Start-up/shut-down } \\
\text { cycle }\end{array}$ & Cloud event \\
\hline & $770^{\circ} \mathrm{C}$ & $770^{\circ} \mathrm{C}$ & $767.3^{\circ} \mathrm{C}$ & $767.3^{\circ} \mathrm{C}$ \\
\hline & $0.0356 \%$ & $0.0360 \%$ & $0.0377 \%$ & $0.0376 \%$ \\
\hline & $1.10 \mathrm{e}-6 \%$ & 0 & $1.10 \mathrm{e}-6 \%$ & 0 \\
\hline & $0.0356 \%$ & $0.0360 \%$ & $0.0377 \%$ & $0.0376 \%$ \\
\hline $\begin{array}{l}\text { Design } \\
\text { allowable } \\
\text { cycles, }\end{array}$ & 5086519 & 5047174 & 4883326 & 4892815 \\
\hline $\begin{array}{l}\text { Design } \\
\text { cycles, }\end{array}$ & $30^{*} 365=10950$ & $30^{*} 365^{*} 5=54750$ & $30^{*} 365=10950$ & $30^{*} 365^{*} 5=54750$ \\
\hline $\begin{array}{l}\text { Fatigue } \\
\text { damage } \\
\text { fraction, }\end{array}$ & $\mathbf{0 . 0 1 3 0}$ & & $\mathbf{0 . 0 1 3 4}$ & \\
\hline
\end{tabular}

Table 4-1.3.5.2. (Sample problem 1) Sample calculations of determining fatigue damage fraction, according to Method 2.

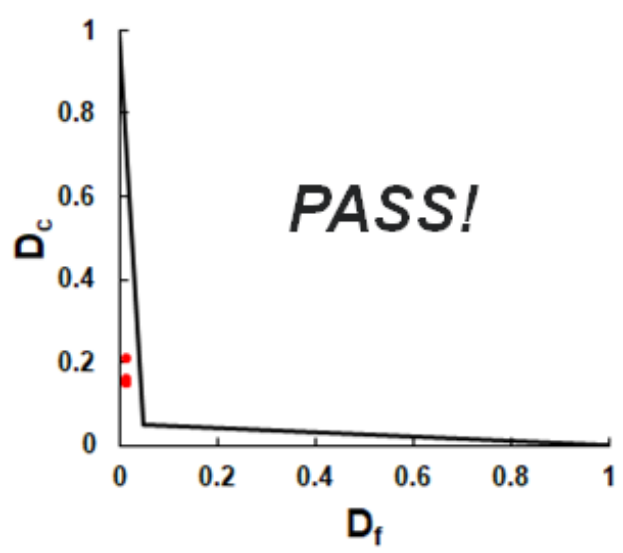

Figure 4-1.3.5.2. (Sample problem 1) Illustration of creep-fatigue design check. Plotted data are results from analysis according to Method 2.

\section{4-1.3.6. Step-6: Time-independent buckling check}

Same as in Method 1 Step 6.

\section{4-1.3.7. Step-7: Time-dependent buckling check}

Same as in Method 1 Step 7.

\section{4-1.4. Design calculations based on Method 3}

This method is applicable only if the elastically-calculated stresses remain below the material yield stress, . In the discussion of design calculation based on Method 2, it is shown that the elastically-calculated stress for this sample problem is always less than and therefore Method 3 is applicable. 
For primary load design, Method 3 uses the same procedures in Method 1 which is based on elastic analysis. For ratcheting and creep-fatigue design checks, however, this method uses inelastic analysis where material's constitutive response is described by an elastic-creep model. The description of the elastic-creep material model is provided above. Design calculations related to ratcheting and creep-fatigue damage are discussed for Method 3.

\section{4-1.4.1. Step-1: Defining the Design Cycle}

Same as in Method 1 Step 1.

\section{4-1.4.2.}

Step-2a: Transient elastic thermo-mechanical analysis for each service load case and stress classification (for primary load design check)

Same as in Method 1 Step 2.

Step-2b: Transient elastic-creep thermo-mechanical analysis for each service load case (for ratcheting and creep-fatigue evaluation)

We used MOOSE (Multiphysics Object Oriented Simulation Environment), an open source finite element solver to perform the transient elastic-creep thermo-mechanical analyses under the loading conditions mentioned in Step 1. The analysis was repeated until a steady state cyclic response was achieved.

\section{4-1.4.3. Step-3: Primary load design check}

Same as in Method 1 Step 3.

\section{4-1.4.4. Step-4: Ratcheting check}

To determine ratcheting strain Method 3 requires to run the analysis using elastic-creep material model, described above, and monitor the maximum effective strain, at the beginning and end of the cycle. The criterion is that the ratcheting strain does not exceed $10 \%$ at any point of the structure for base metal. Figure 4-1.4.4 plots the maximum effective strain at the critical tube location as a function of cycle count. Extrapolating the maximum effective strain out to design life of the tube, i.e. 30 years $(=30 * 365$ cycles), gives the ratcheting strain of $0.00565 \%$ which is less than $10 \%$. 


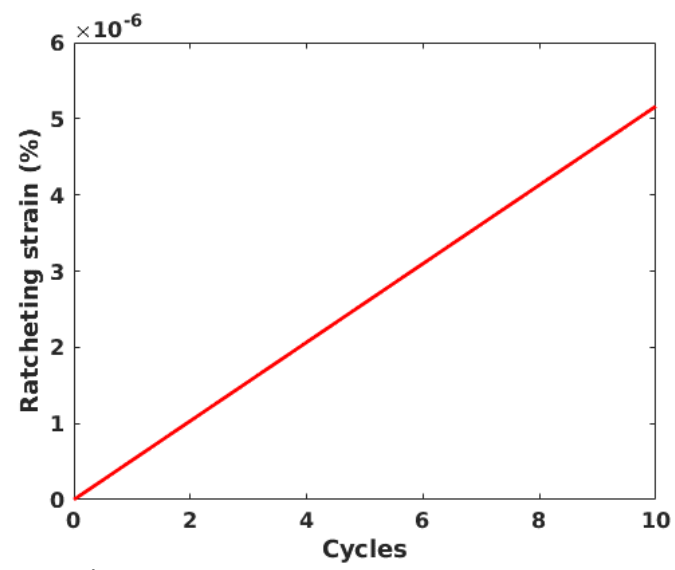

Figure 4-1.4.4. (Sample problem 1) Maximum ratcheting strain in the structure versus number of cycles determined from elastic-creep thermo-mechanical analysis.

\section{4-1.4.5. Step-5: Creep-fatigue damage check}

Once steady cyclic response was achieved in the analysis, the temperature, stress, strain, time history for a single cycle of the periodic loading were extracted. To determine fatigue damage fraction, the effective strain range, was first computed from the strain history according to Section III, Division 5, HBB-T-1413 with for inelastic analysis. Fatigue damage fraction, was then calculated from using rainflow counting and Miner's rule. Figure 4-1.4.5.1 plots temperature, von Mises stress, and effective strain range profiles at four critical locations of the tube after a steady cyclic response was achieved. Table 4-1.4.5.1 shows details of the fatigue damage fraction calculation according to Method 3 . The von Mises effective stress, was used to determine the creep damage fraction. Figure 4-1.4.5.2 illustrates the method of creep damage fraction, calculation and Table 4-1.4.5.2 reports details of the calculation for four critical locations in the structure. All four sets of ( fall inside the damage envelop in the creep-fatigue interaction diagram, as shown in Figure 4-1.4.5.3, which means according to Method 3 the design passes creep-fatigue damage check.

Note, according to Table HBB-1411-1 in Section III, Division 5 of ASME Code, a design margin (i.e, ) is applied to the effective stress while determining the allowable rupture time from the design rupture table. ASME Code recommends to use for elastic analysis and for inelastic analysis. However, the history behind the ASME stress factors is somewhat murky and given the lower consequences of failure for CSP systems, the design method developed here uses for all analysis methods, including the inelastic analysis. 

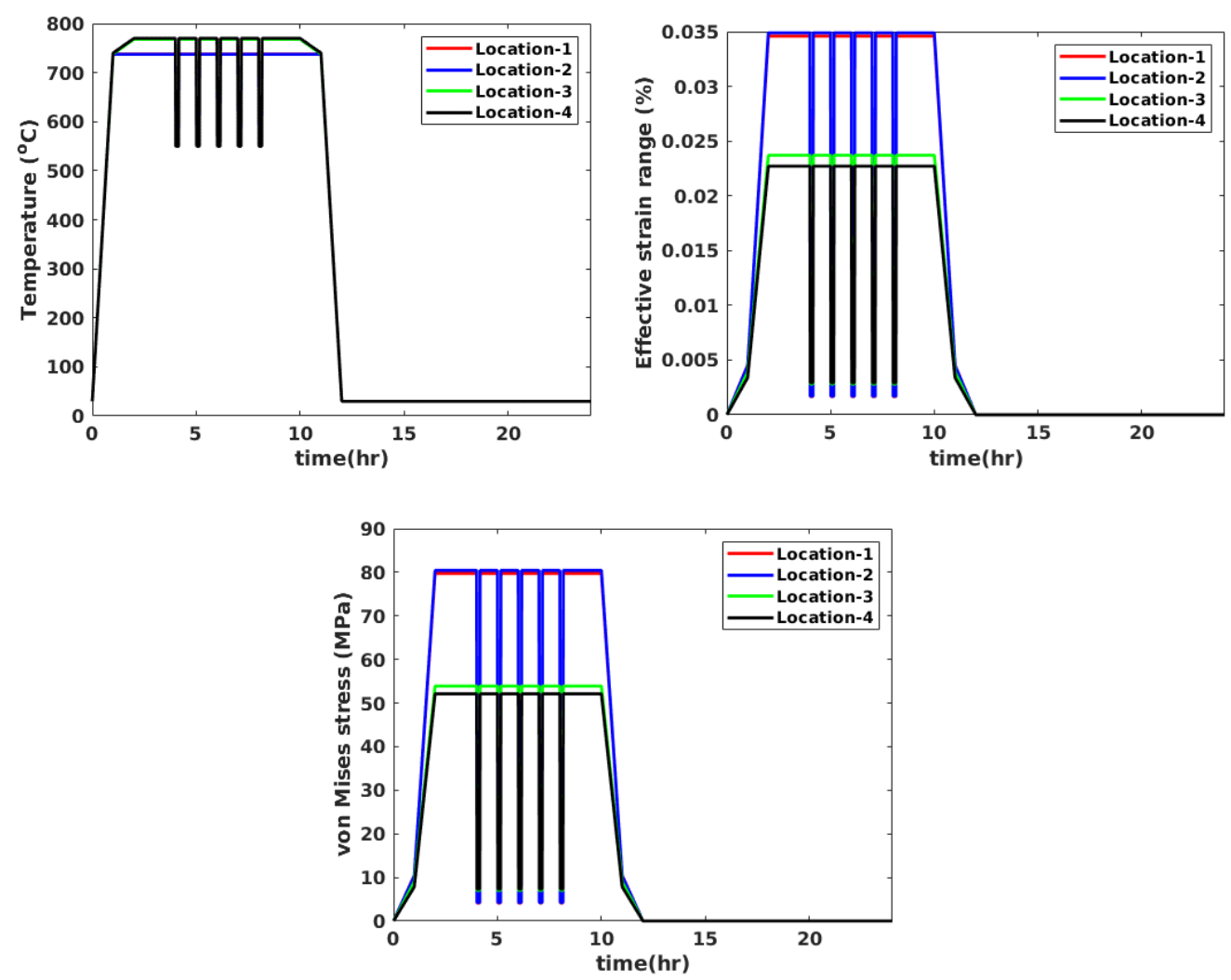

Figure 4-1.4.5.1. (Sample problem 1) Temperature, effective strain range, and von Mises stress profiles at four critical location of the tube after a steady cyclic response is achieved in the elastic-creep thermomechanical analysis.

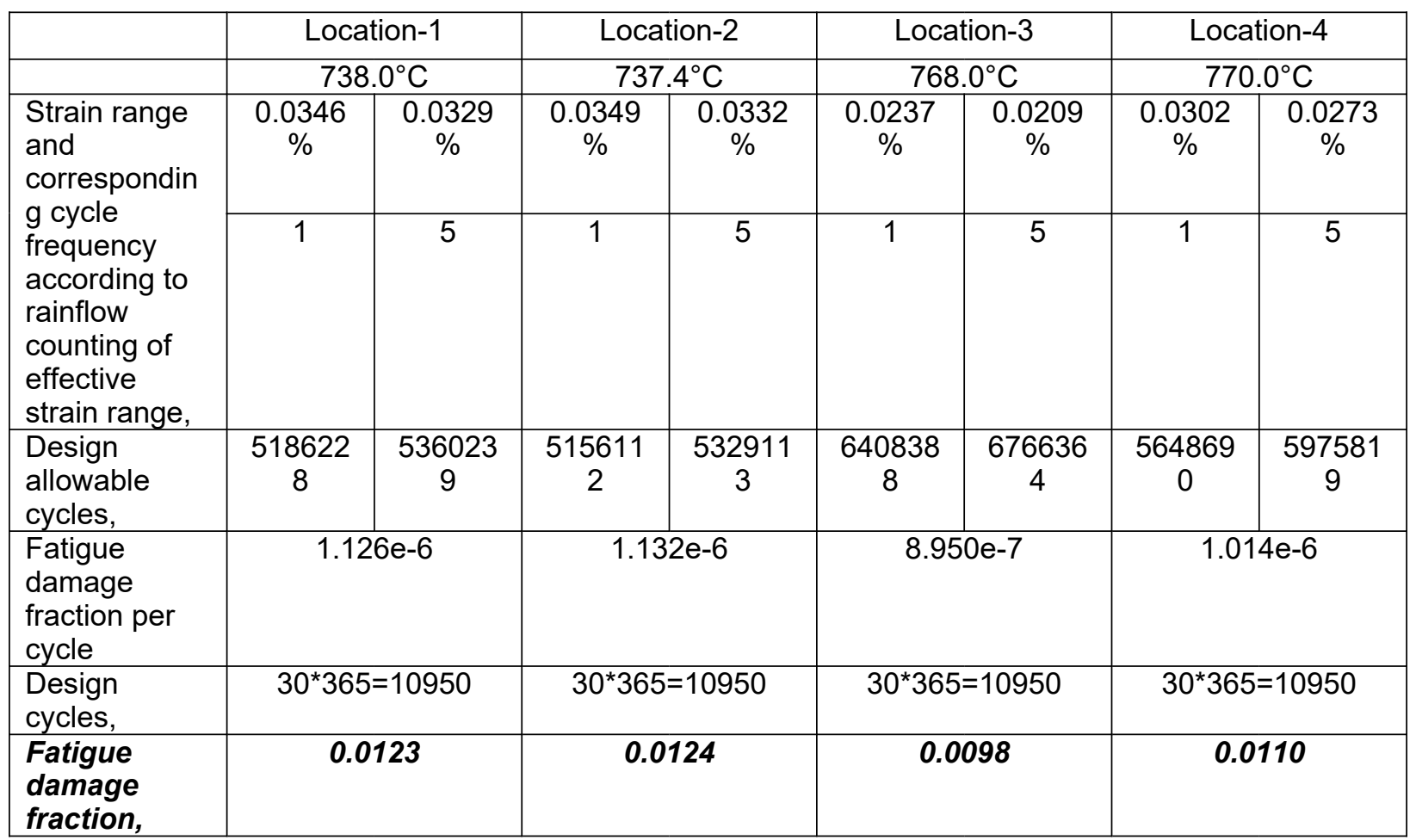


Table 4-1.4.5.1. (Sample problem 1) Sample calculation of determining fatigue damage fraction, according to Method 3.

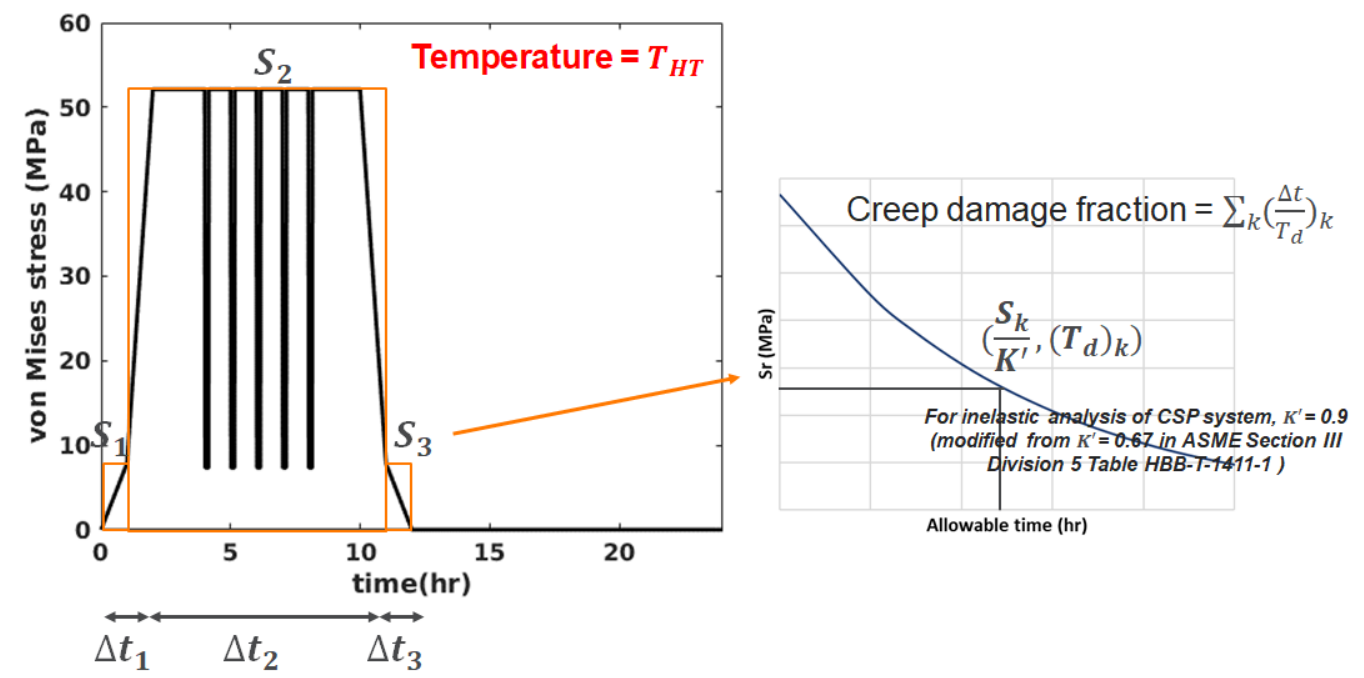

Figure 4-1.4.5.2. Illustration of calculating creep damage fraction in Method 3.

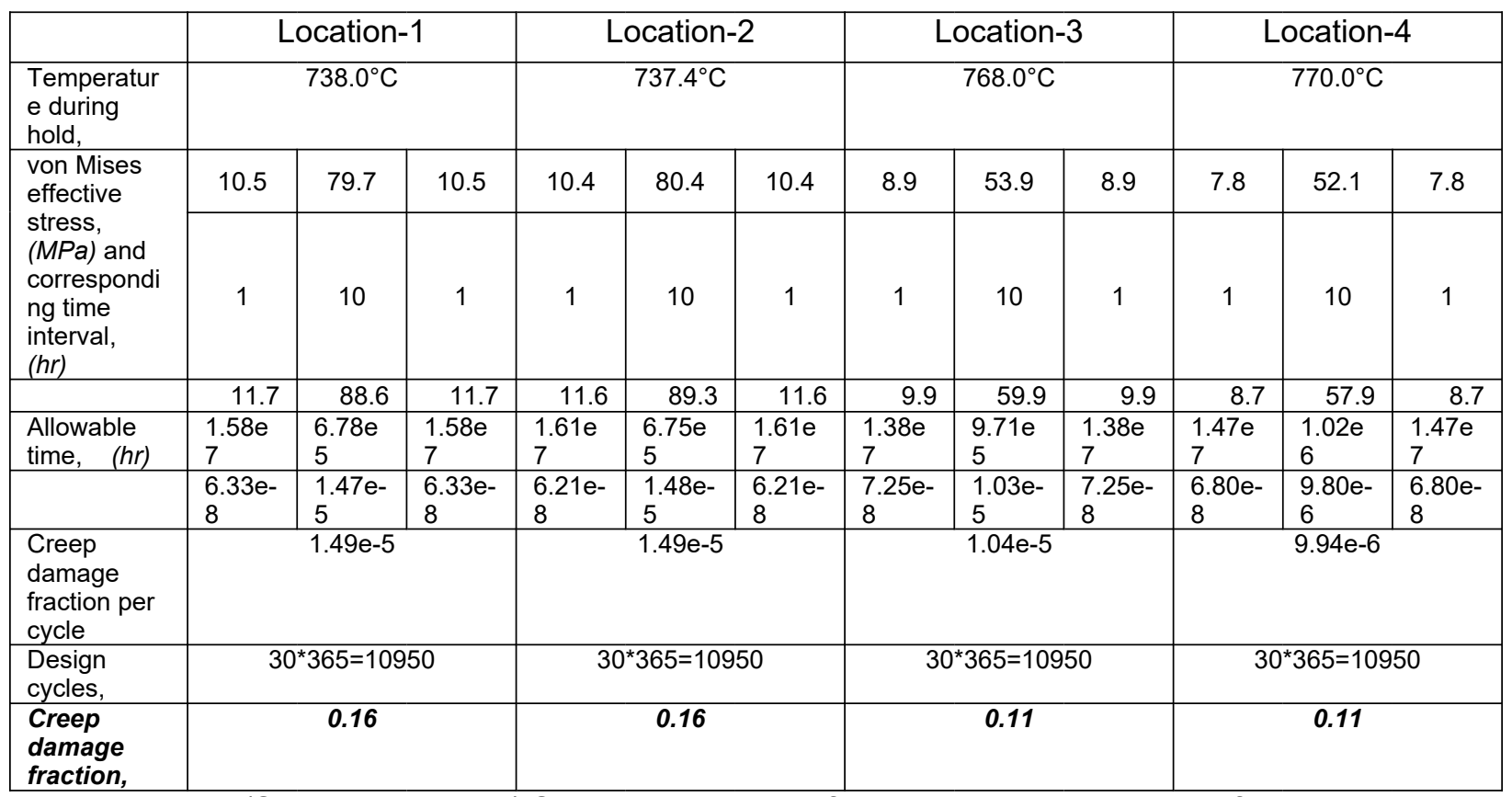

Table 4-1.4.5.2. (Sample problem 1) Sample calculation of determining creep damage fraction, according to Method 3. 


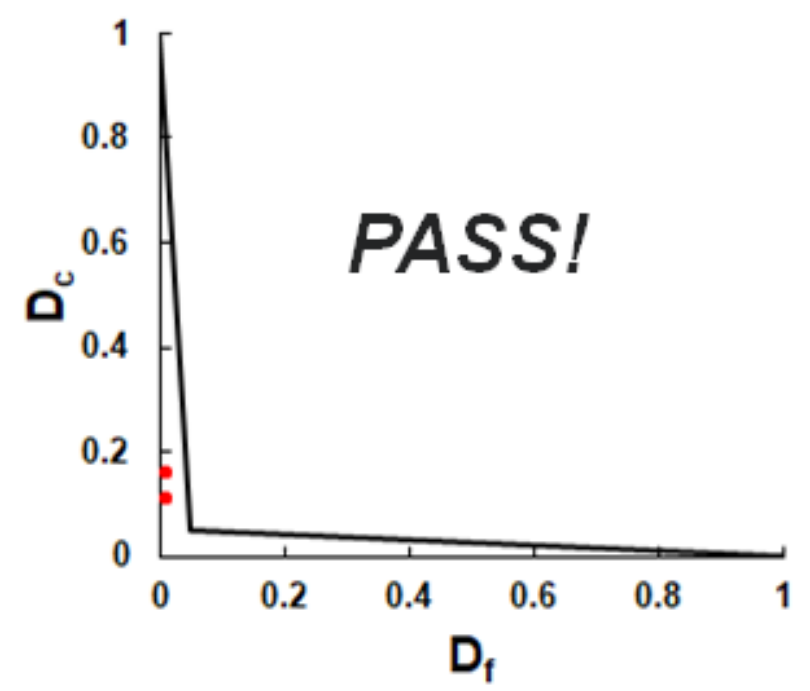

Figure 4-1.4.5.3. (Sample problem 1) Illustration of creep-fatigue design check. Plotted data are results from analysis according to Method 3.

\section{4-1.4.6. Step-6: Time-independent buckling check}

Same as in Method 1 Step 6.

\section{4-1.4.7. Step-7: Time-dependent buckling check}

Same as in Method 1 Step 7.

\section{4-2. Sample problem 2}

\section{4-2.1. Problem description}

For sample problem 2 we considered a tube in an external tubular receiver. The receiver has parabolic reflectors at the back of the tubes which help reduce the variation in the circumferential heat flux distribution on the tube. Figure 4-2.1.1 shows the schematic of the tubular receiver. The tube is $10.5 \mathrm{~m}$ long, $42.2 \mathrm{~mm}$ diameter, and 1 $\mathrm{mm}$ thick. Heat flux on the tube is non uniform along both the length and circumference. 
We considered only one type of cycle for this problem which represent heat flux on the day of spring equinox. Figure 4-2.1.2 plots the loading profiles of maximum flux incident, salt inlet and outlet temperature, and salt pressure during day (10 hrs). Table 4-2.1.1 lists values of flux incident loading at noon (i.e. time $=5 \mathrm{hr}$ in Figure 4-2.1.2) for different locations on the tube outer surface. To determine the wind load on the receiver for timeindependent buckling check, we considered the external receiver located in an open terrain in the U.S. and $100 \mathrm{~m}$ above the ground.

The salt considered for this problem is $\mathrm{MgCl} / \mathrm{KCl}$ (mole: $32 / 68 \%$ ) binary molten salt. The mass flow rate of the salt is $44.5 \mathrm{~kg} / \mathrm{s}$. Salt inlet and outlet temperatures are $700^{\circ} \mathrm{C}$ and $720^{\circ} \mathrm{C}$, respectively. To determine the convective heat transfer coefficient between salt and metal Gnielinski correlation29 for turbulent flow (forced convection) in tubes was used.

$$
\text { ; forand }
$$

where is the Nusselt number, is the Reynolds number, is the Prandtl number, and is the Darcy friction factor which can be obtained from the following equation.

All the required properties of salt, as listed in Table 4-2.1.2, to determine convective heat transfer coefficient were taken from 30 . Note the pressure loading profile shown in Figure 4-2.1.2 was selected based on the pressure loss due to friction and elevation. We assumed a surface roughness of $0.049 \mathrm{~mm}$ to determine the frictional pressure loss. In the heat transfer calculation for this sample problem, we also considered heat loss due to radiation and natural convection of air. The convective heat transfer coefficient of air is assumed to be. For structural boundary condition, we considered the tube can freely expand both in radial and axial direction but no warping in the axial direction. The design life of the tube is considered to be 4.4 years. Design calculations according all three methods are provided below.

\footnotetext{
${ }^{29}$ V. Gnielinski, "Neue Gleichungen für den Wärme-und den Stoffübergang in turbulent durchströmten Rohren und Kanälen" Forschung im Ingenieurwesen A, 41(1), pp. 8-16, 1975.

${ }^{30}$ Xu, X, X. Wang, P. Li, Y. Li, Q. Hao, B. Xiao, H. Elsentriecy, and D. Gervasio, "Experimental Test of Properties of $\mathrm{KCl}-\mathrm{MgCl} 2$ Eutectic Molten Salt for Heat Transfer and Thermal Storage Fluid in Concentrated Solar Power Systems" Journal of Solar Energy Engineering, 140(5), pp. 051011, 2018.
} 


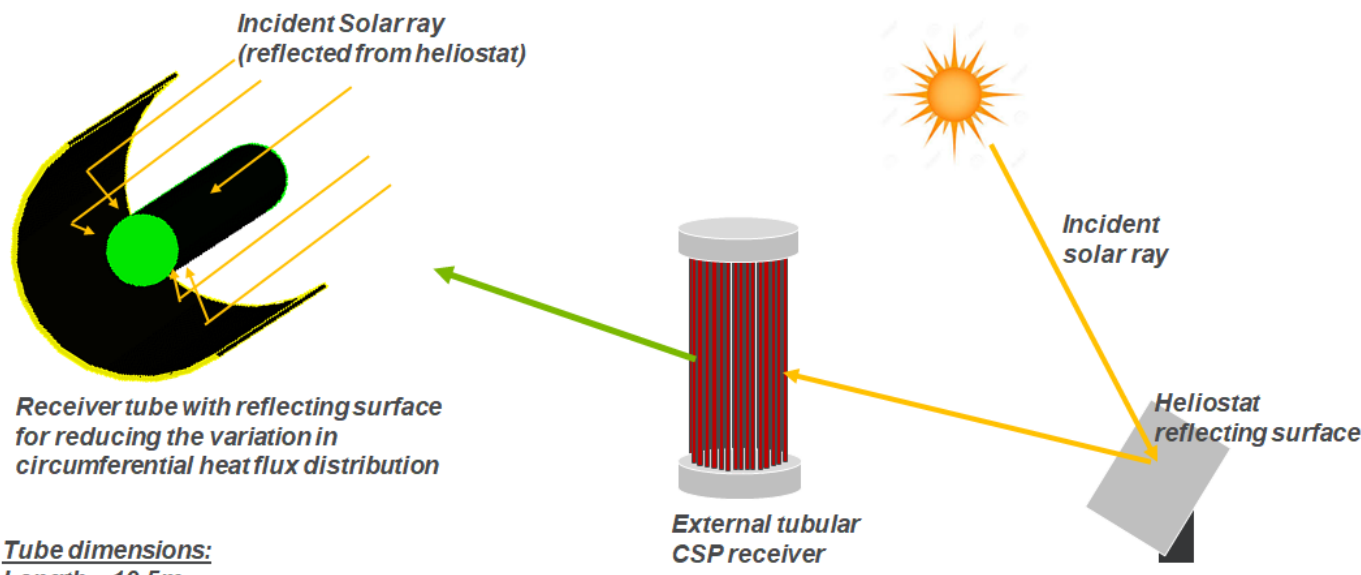

\section{Length $=10.5 \mathrm{~m}$}

Outer diameter $=42.2 \mathrm{~mm}$

Thickness $=1 \mathrm{~mm}$

Figure 4-2.1.1. (Sample problem 2) Schematic of an external tubular receiver.
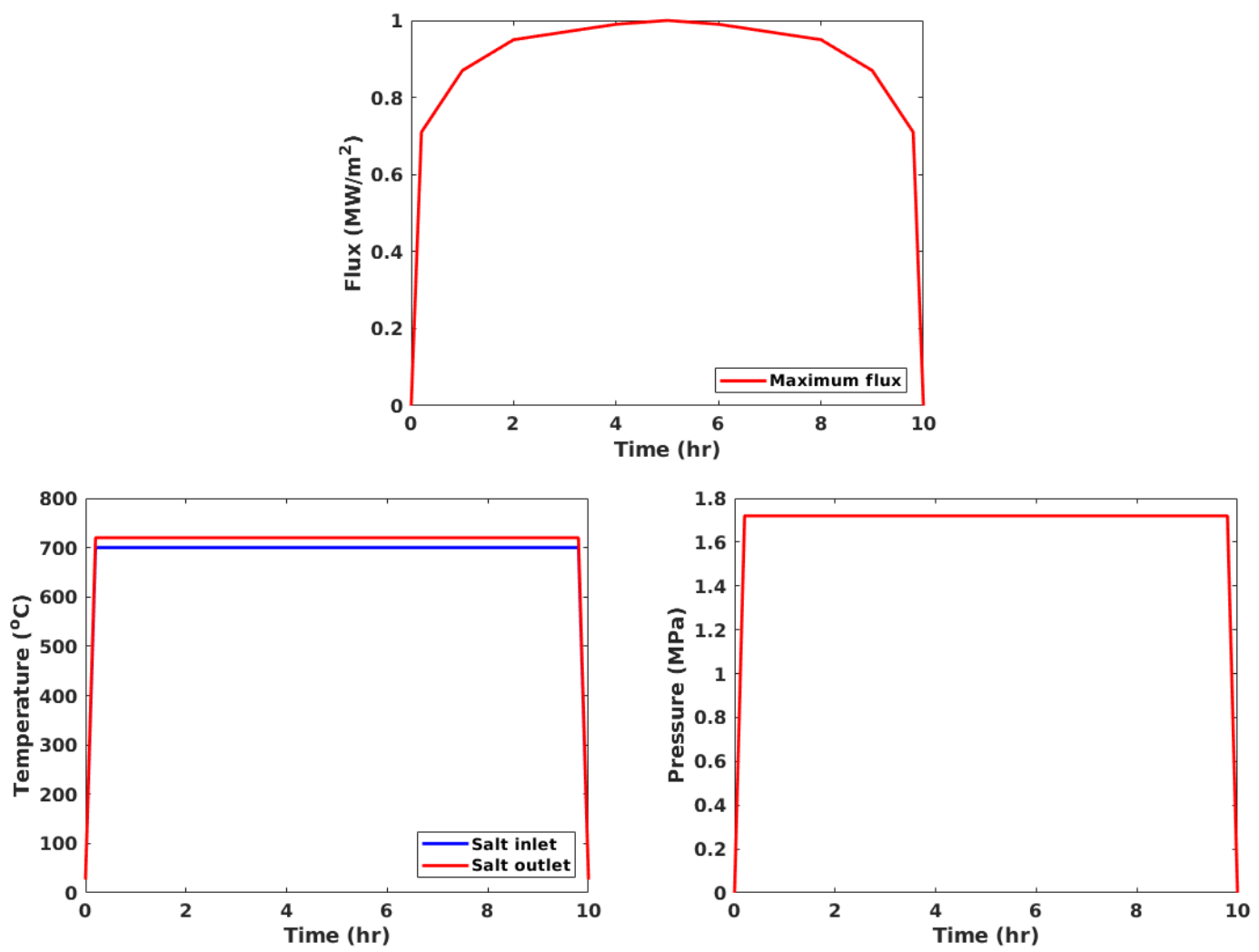

Figure 4-2.1.2. (Sample problem 2) Loading profiles of maximum flux incident, salt inlet and outlet temperature, and salt pressure during day. Only one type of cycle is considered. Receiver operation time per day is 10 hours. Loading profiles shown are only for the tube considered for design study. 


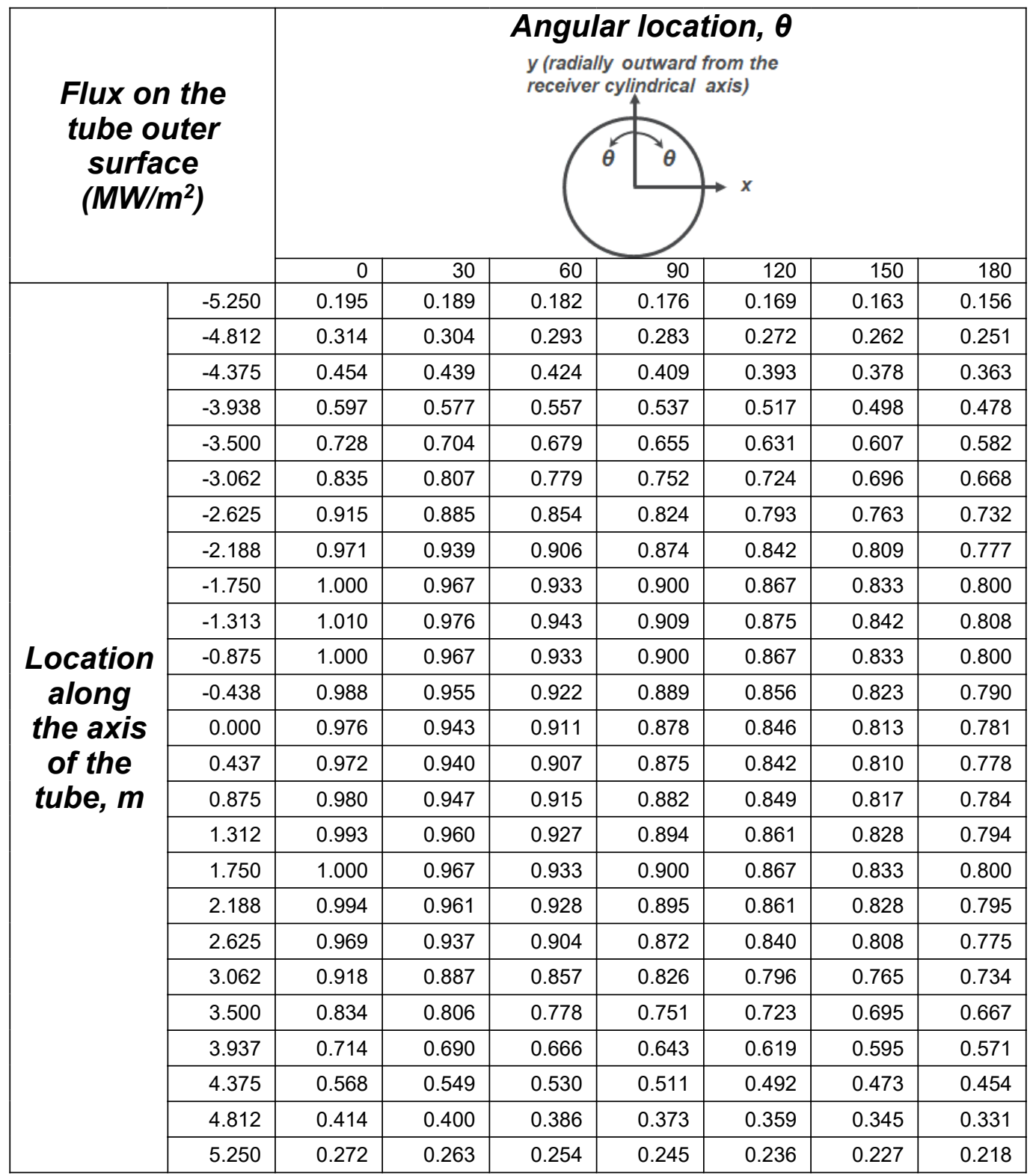

Table 4-2.1.1. (Sample problem 2) Flux incident loading at noon.

\begin{tabular}{|l|l|}
\hline Properties & Values as function of temperature, \\
\hline Heat capacity, & \\
\hline Density, & \\
\hline Viscosity, & \\
\hline Thermal conductivity, & \\
\hline
\end{tabular}

Table 4-2.1.2. (Sample problem 2) Temperature dependent properties of $\mathrm{MgCl}_{2} / \mathrm{KCl}$ (mole: $32 / 68 \%$ ) binary molten salt taken from ${ }^{30}$.

\section{4-2.2. Design calculations based on Method 1}

\section{4-2.2.1. Step-1: Defining the Design Cycle}


The loading profile is shown in Figure 4-2.1.2.

\section{4-2.2.2. Step-2: Transient elastic thermo-mechanical analysis for each service load case and stress classification}

We used MOOSE (Multiphysics Object Oriented Simulation Environment), an open source finite element solver to perform the elastic thermo-mechanical analyses. We classify pressure as primary load and temperature gradient as secondary load. There is no peak load.

\section{4-2.2.3. Step-3: Primary load design check}

Figure 4-2.2.3.1 shows the heat flux and tube outer wall temperature distribution at noon. Figure 4-2.2.3.2 shows through thickness elastic stress components at noon at a critical location of the tube.

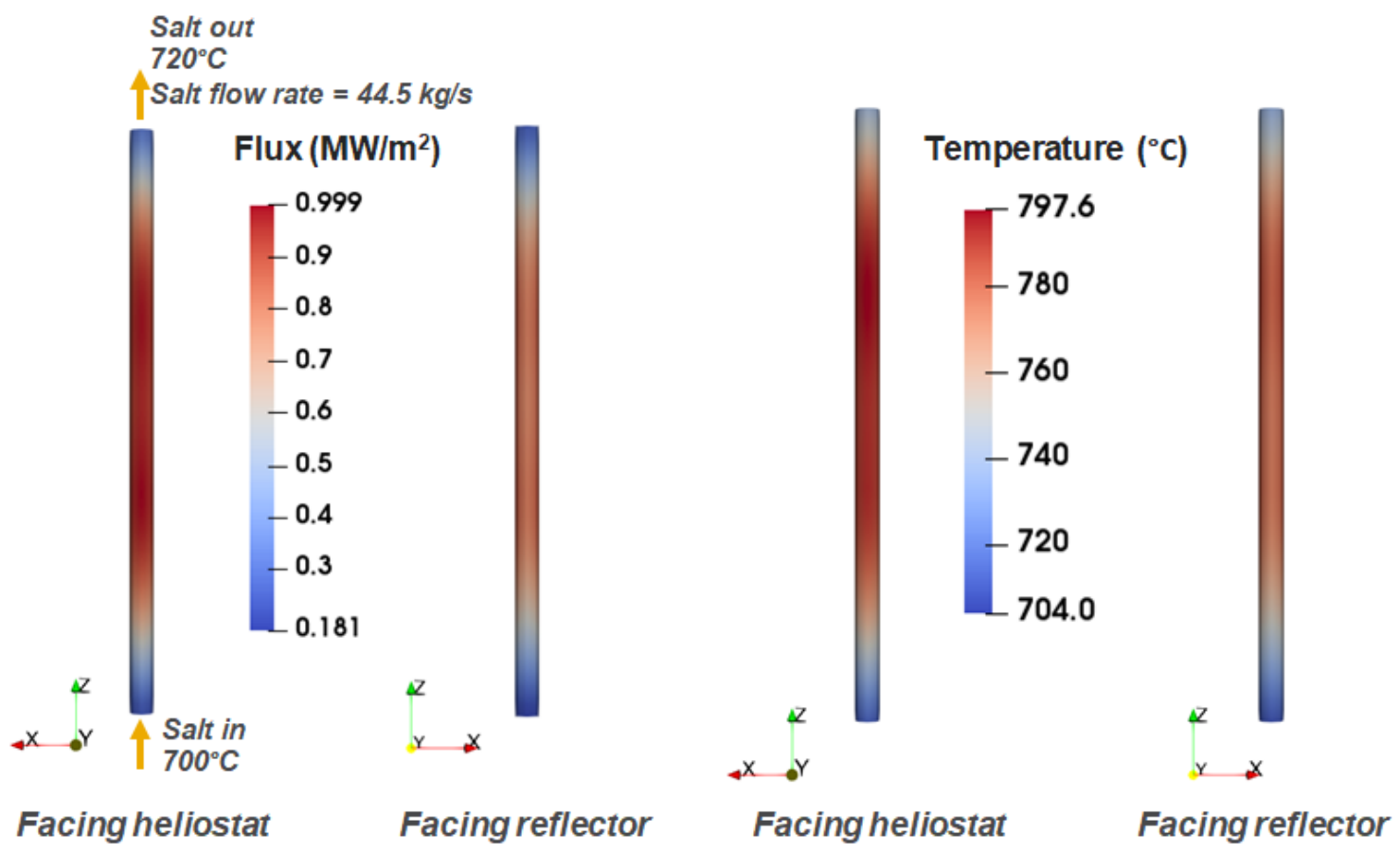

Figure 4-2.2.3.1. (Sample problem-2) Contour plot of flux incident on tube and tube outer wall temperature at noon. 

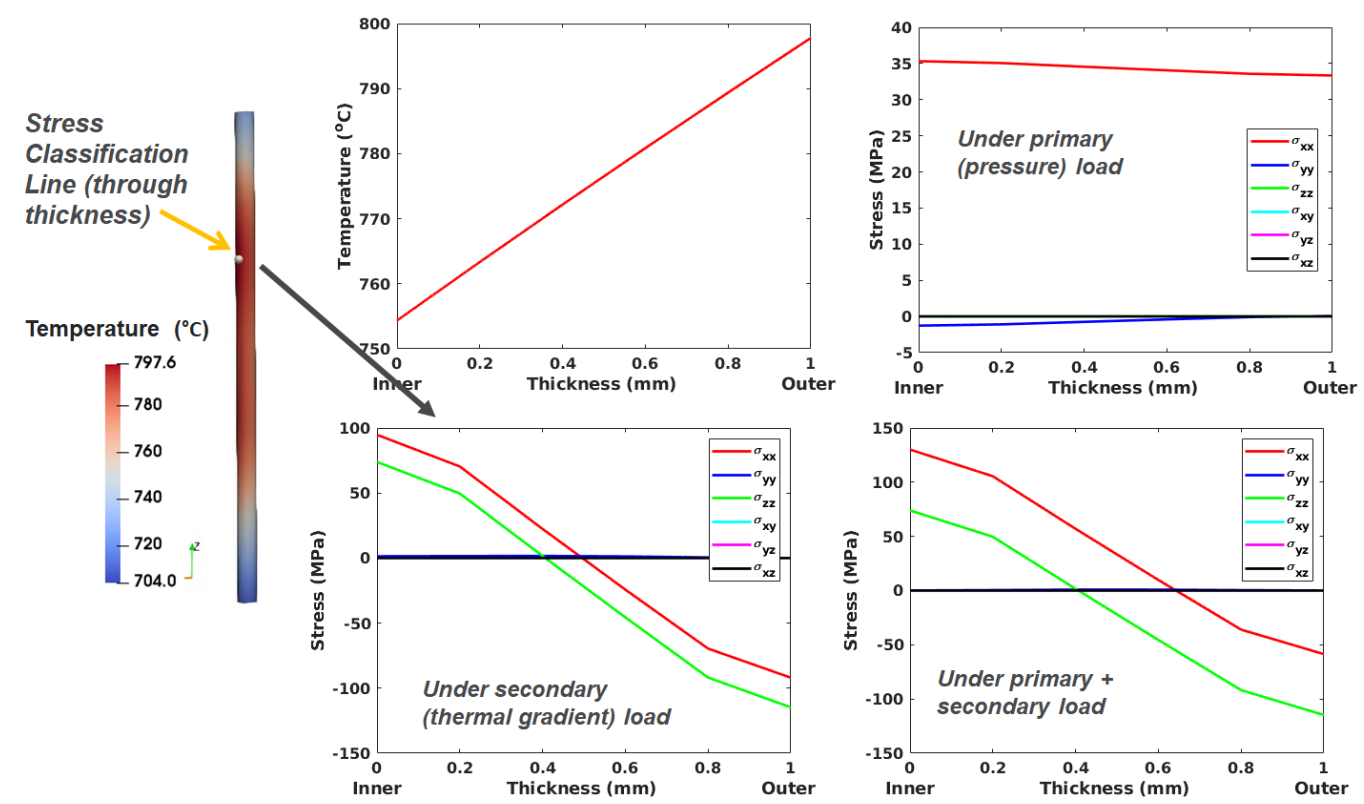

Figure 4-2.2.3.2. (Sample problem-2) Through thickness temperature and elastic stresses at a critical location of the tube at noon.

Maximum primary load occurs at noon. Table 4-2.2.3 reports details of the primary load checks. First, all the stress components were linearized to divide into membrane and bending components along the stress classification line. The membrane and bending stress components were then used to determine the stress intensities in Table 4-2.2.3 As indicated in the table the design passes both the criteria in primary load checks.

\begin{tabular}{|l|c|}
\hline Max. General primary membrane stress intensity, & $34.90 \mathrm{MPa}$ \\
\hline Max. Combined primary membrane plus bending stress intensity, & $36.76 \mathrm{MPa}$ \\
\hline Maximum metal temperature, & $797.6^{\circ} \mathrm{C}$ \\
\hline Allowable stress, at & $36.89 \mathrm{MPa}$ \\
\hline Design criteria -1: & PASS ! \\
\hline Design criteria -2: & PASS ! \\
\hline
\end{tabular}

Table 4-2.2.3. (Sample problem-2) Primary load design checks along the stress classification line shown in Figure 4-2.2.3.2.

\section{4-2.2.4. Step-4: Ratcheting check}

Design method 1 uses the O'Donnell-Porowski approach, described in Section III, Division 5, HBB-1332 for ratcheting checks. In this approach, an effective creep stress parameter, $Z$ is determined from a primary stress parameter, $X$ and a secondary stress parameter, $Y$ as shown in Figure 4-1.2.4.1 The effective creep stress parameter is used to calculate the effective creep stress which is then used to determine the ratcheting creep strain using isochronous stress-strain curves. The definition of $X$ and $Y$ are

where, 
= the maximum value of the primary stress intensity, adjusted for bending via, during the cycle being evaluated.

$=$ the maximum range of the secondary stress intensity during the cycle being considered

$=$ is the value corresponds to the lower of the wall averaged temperature for the stress extremes defining secondary stress range, .

is 1.5 for across-the-wall bending of shell structures or rectangular sections, see HBB-3223 (c) (6) in Section III Division 5. Once Z is found, effective core, stress is determined from

It should be noted that, the average wall temperature at one of the stress extremes defining the secondary stress intensity range must be below the temperature listed in Section III, Division 5, HBB-T-1323, given as for $740 \mathrm{H}$ in the description of the design Method 1. The creep ratcheting strain increment for a load cycle is evaluated by entering the isochronous stress strain curves at the maximum wall temperature and effective core, stress during the load cycle with the stress held constant for the entire service life. An example of creep ratcheting strain determination is shown in Figure 4-1.2.4.2 Table 4-2.2.4 provides all the calculation details of the ratcheting design check. As indicated in the table, the design passes the ratcheting check.

\begin{tabular}{|c|c|}
\hline & $\begin{array}{l}\text { Stress classification line shown in Figure } \\
\text { 4-2.2.3.2 }\end{array}$ \\
\hline & $776.4^{\circ} \mathrm{C}$ \\
\hline & $30^{\circ} \mathrm{C}$ \\
\hline & $797.6^{\circ} \mathrm{C}$ \\
\hline (at ) & $621.0 \mathrm{MPa}$ \\
\hline & 1.5 \\
\hline & 1.25 \\
\hline & $36.39 \mathrm{MPa}$ \\
\hline & $114.76 \mathrm{MPa}$ \\
\hline & 0.0586 \\
\hline & 0.184 \\
\hline $\begin{array}{l}\text { using Section III, Division 5, Figure HBB- } \\
\text { T-1332-1 }\end{array}$ & 0.0586 \\
\hline from & 36.39 \\
\hline Service life & 4.4 years $=16060$ hours \\
\hline Ratcheting strain at the end of service life & $6.93 \mathrm{e}-4 \%$ \\
\hline Ratcheting design criteria: $2 \%$ for base metal & PASS! \\
\hline
\end{tabular}

Table 4-2.2.4. (Sample problem-2) Ratcheting design checks according to Method 1.

\section{4-2.2.5. Step-5: Creep-fatigue damage check}


According to Section III, Division 5, a design is acceptable if the creep and fatigue damage satisfy the following relation:

where $D$ is the total creep-fatigue damage and the first and second terms on the left side are fatigue damage, and creep damage, , respectively. In the fatigue damage term, is the number of repetitions of cycle type $\mathrm{j}$ and is the number of design allowable cycles for respective cycle type; while in the creep damage term, is the allowable time duration for a given stress at the maximum temperature occurring in the time interval $k$ and is the duration of the time interval $\mathrm{k}$.

The design allowable cycles for fatigue damage is determined by entering fatigue curves at total strain range, . Total strain range, is calculated using equation HBBT-1432-16:

where is the local geometric concentration or equivalent stress concentration factor determined by dividing effective primary plus secondary plus peak stress divided by the effective primary plus secondary stress, is the multiaxial plasticity and Poisson ratio adjustment factor, is the creep strain increment, and is the modified maximum equivalent strain range.

is calculated using equation Section III, Division 5, HBB-T-1432-12:

where is the maximum equivalent strain range calculated from the elastic analysis of under primary and secondary loading together. is calculated according to Section III, Division 5, HBB-T-1413 with for elastic analysis. and are stresses determined by entering the isochronous stress-strain curves at and, respectively.

is determined using equation Section III, Division 5, HBB-T-1432-15:

where $f$ is the inelastic multiaxial adjustment factor determined using Section III, Division 5, Figure HBB-T-1432-2 and triaxiality factor, T.F.

where $\sigma$ 's are principals stresses at the extreme of the stress cycle.

is the adjustment for inelastic biaxial Poisson's ratio determined from Section III, Division 5, Figure HBB-T-1432-3 using . 
where

Here are relaxation strengths associated with the temperatures at the hot and cold extremes of the stress cycle. These values are provided above in the $740 \mathrm{H}$ design data. The hot temperature condition is defined as the maximum operating temperature of the stress cycle. The hot time is equal to the portion of service life when wall averaged temperatures exceed $425^{\circ} \mathrm{C}$. The cold temperature is defined as the colder of the two temperatures corresponding to the two stress extremes in the stress cycle. The cold time is again equal to the portion of service life when wall averaged temperatures exceed $425^{\circ} \mathrm{C}$.

The creep strain increment per stress cycle, is determined by entering the isochronous stress-strain curves at and maximum metal temperature for the stress cycle time, including hold times between transients (instead of total service life). Alternatively, the creep accumulated during the entire service life divided by the number of stress cycles during the entire service life can also be used for calculating creep strain increment per stress cycle,. We used the latter option.

The design allowable cycles, is then calculated from design fatigue curve at maximum metal temperature and using total strain range, . Fatigue damage fraction, is then determined from the ratio between design cycles and design allowable cycles for each cycle type and then adding them together. Note, we considered only one type of cycle in the sample problem 2. Table 4-2.3.5.1 shows the details of all the relevant calculations to determine fatigue damage fraction.

Creep damage evaluation is done in accordance to HBB-T1433(b)-option (a) but with one exception as described in the design Method 1. The lower bound stress is taken as , rather than the specified in the Code. First, stress relaxation profile is determined by entering the isochronous stress-strain curves at a strain level equal to and at hold-time temperature and determining the corresponding stress levels at varying times. However, this stress relaxation process should not be permitted to a stress level less than. This stress relaxation procedure results in a stress-time history. Using the stress-time history and hold-time temperature during the cycle creep damage fraction can be calculated according to the illustration in Figure 4-1.2.5.4. Tables 4-2.3.5.2 and 4-2.3.5.3 show the details of determining creep damage fraction, from stress relaxation profile.

To determine whether the design passes the creep-fatigue damage check, the fatigue damage fraction, and creep damage fraction, are plotted on creep-fatigue interaction diagram as shown in Figure 4-2.3.5.1 As indicated in the figure, the ( points fall inside the creep-fatigue damage envelop which means the design passes for creep-fatigue damage check. 


\begin{tabular}{|c|c|c|}
\hline & $\begin{array}{l}\text { At OD on stress classification line } \\
\text { shown in Figure 4-2.2.3.2 }\end{array}$ & $\begin{array}{l}\text { At ID on stress classification line } \\
\text { shown in Figure 4-2.2.3.2 }\end{array}$ \\
\hline & $797.6^{\circ} \mathrm{C}$ & $754.4^{\circ} \mathrm{C}$ \\
\hline Hot temperature & $797.6^{\circ} \mathrm{C}$ & $754.4^{\circ} \mathrm{C}$ \\
\hline Cold temperature & $30^{\circ} \mathrm{C}$ & $30^{\circ} \mathrm{C}$ \\
\hline Hot time & $10 \mathrm{hr}^{*}\left(4.4^{*} 365\right)=16060 \mathrm{hr}$ & $10 \mathrm{hr}^{*}\left(4.4^{*} 365\right)=16060 \mathrm{hr}$ \\
\hline \multirow[t]{3}{*}{ Cold time } & $14 \mathrm{hr}^{*}\left(30^{*} 365\right)=22484 \mathrm{hr}$ & $14 \mathrm{hr}^{*}\left(30^{*} 365\right)=22484 \mathrm{hr}$ \\
\hline & $78.4 \mathrm{MPa}$ & $126.4 \mathrm{MPa}$ \\
\hline & Not required & Not required \\
\hline \multirow[t]{14}{*}{ at } & $218.9 \mathrm{MPa}$ & $253.5 \mathrm{MPa}$ \\
\hline & $406.8 \mathrm{MPa}$ & $506.7 \mathrm{MPa}$ \\
\hline & $0.0569 \%$ & $0.0644 \%$ \\
\hline & 1 (no peak stress) & 1 (no peak stress) \\
\hline & $0.0569 \%$ & $0.0644 \%$ \\
\hline & $169216 \mathrm{MPa}$ & $173104 \mathrm{MPa}$ \\
\hline & $0.240 \%$ & $0.293 \%$ \\
\hline & 1 & 1 \\
\hline & 1 & 1 \\
\hline & 1 & 1 \\
\hline & 1 & 1 \\
\hline & $0.0569 \%$ & $0.0644 \%$ \\
\hline & $4.315 e-7 \%$ & $1.925 \mathrm{e}-8 \%$ \\
\hline & $0.0569 \%$ & $0.0644 \%$ \\
\hline $\begin{array}{l}\text { Design allowable } \\
\text { cycles, }\end{array}$ & 3363890 & 2908103 \\
\hline Design cycles, & $4.4 * 365=1602$ & $4.4^{*} 365=1606$ \\
\hline $\begin{array}{l}\text { Fatigue damage } \\
\text { fraction, }\end{array}$ & $4.774 e-4$ & $5.522 e-4$ \\
\hline
\end{tabular}

Table 4-2.3.5.1. (Sample problem-2) Sample calculation of determining fatigue damage fraction, according to Method 1.

\begin{tabular}{|l|l|l|}
\hline & $\begin{array}{l}\text { At OD on stress classification } \\
\text { line shown in Figure 4-2.2.3.2 }\end{array}$ & $\begin{array}{l}\text { At ID on stress classification } \\
\text { line shown in Figure 4-2.2.3.2 }\end{array}$ \\
\hline & $0.0569 \%$ & $0.0644 \%$ \\
\hline & $797.6^{\circ} \mathrm{C}$ & $754.4^{\circ} \mathrm{C}$ \\
\hline & $42.17 \mathrm{MPa}$ & $42.17 \mathrm{MPa}$ \\
\hline $\begin{array}{l}\text { (Table HBB-T-1411-1) for } \\
\text { elastic analysis }\end{array}$ & 0.9 & 0.9 \\
\hline $\begin{array}{l}\text { Creep damage fraction per } \\
\text { cycle (from Table 4-2.3.5.3) }\end{array}$ & $6.05 \mathrm{e}-4$ & $1.45 \mathrm{e}-4$ \\
\hline Design cycles, & $4.4^{\star} 365=1602$ & $4.4^{\star} 365=1602$ \\
\hline Creep damage fraction, & $\mathbf{0 . 9 7}$ & $\mathbf{0 . 2 3}$ \\
\hline
\end{tabular}

Table 4-2.3.5.2. (Sample problem-2) Sample creep damage fraction, calculation according to Method 1. 


\begin{tabular}{|c|c|c|c|c|c|c|c|c|c|c|c|}
\hline \multicolumn{6}{|c|}{$\begin{array}{c}\text { At } O D \text { on stress classification line shown in } \\
\text { Figure 4-2.2.3.2 }\end{array}$} & \multicolumn{6}{|c|}{$\begin{array}{l}\text { At ID on stress classification line shown in } \\
\text { Figure 4-2.2.3.2 }\end{array}$} \\
\hline $\begin{array}{c}\text { Time } \\
(\mathrm{hr})\end{array}$ & $(\mathrm{MPa})$ & $(\mathrm{MPa})$ & (hr) & (hr) & & $\begin{array}{c}\text { Time } \\
(\mathrm{hr})\end{array}$ & (MPa) & (MPa) & $(h r)$ & (hr) & \\
\hline 0 & 96.28 & 106.98 & 16341 & 1 & $6.12 \mathrm{e}-05$ & 0 & 111.48 & 123.87 & 68686 & 1 & $1.46 \mathrm{e}-05$ \\
\hline 1 & 96.25 & 106.94 & 16378 & 1 & $6.11 \mathrm{e}-05$ & 1 & 111.47 & 123.86 & 68718 & 1 & $1.46 \mathrm{e}-05$ \\
\hline 2 & 96.20 & 106.89 & 16424 & 1 & $6.09 \mathrm{e}-05$ & 2 & 111.46 & 123.84 & 68782 & 1 & $1.45 \mathrm{e}-05$ \\
\hline 3 & 96.17 & 106.86 & 16452 & 1 & $6.08 \mathrm{e}-05$ & 3 & 111.46 & 123.84 & 68782 & 1 & $1.45 \mathrm{e}-05$ \\
\hline 4 & 96.13 & 106.81 & 16498 & 1 & $6.06 \mathrm{e}-05$ & 4 & 111.45 & 123.83 & 68814 & 1 & $1.45 \mathrm{e}-05$ \\
\hline 5 & 96.09 & 106.77 & 16535 & 1 & $6.05 \mathrm{e}-05$ & 5 & 111.44 & 123.82 & 68846 & 1 & $1.45 \mathrm{e}-05$ \\
\hline 6 & 96.06 & 106.73 & 16573 & 1 & $6.03 e-05$ & 6 & 111.43 & 123.81 & 68878 & 1 & $1.45 \mathrm{e}-05$ \\
\hline 7 & 96.02 & 106.69 & 16610 & 1 & $6.02 \mathrm{e}-05$ & 7 & 111.43 & 123.81 & 68878 & 1 & $1.45 \mathrm{e}-05$ \\
\hline 8 & 95.98 & 106.64 & 16657 & 1 & $6.00 \mathrm{e}-05$ & 8 & 111.42 & 123.80 & 68910 & 1 & $1.45 \mathrm{e}-05$ \\
\hline 9 & 95.94 & 106.60 & 16695 & 1 & $5.99 \mathrm{e}-05$ & 9 & 111.41 & 123.79 & 68942 & 1 & $1.45 \mathrm{e}-05$ \\
\hline 10 & 95.91 & 106.57 & 16723 & & & 10 & 111.41 & 123.79 & 68942 & & \\
\hline \multicolumn{5}{|c|}{ Creep damage fraction per cycle } & $6.05 e-4$ & \multicolumn{5}{|c|}{ Creep damage fraction per cycle } & $1.45 \mathrm{e}-4$ \\
\hline
\end{tabular}

Table 4-2.3.5.3. (Sample problem-2) Sample calculation of creep damage fraction, per cycle from stresstime history according to Method 1.

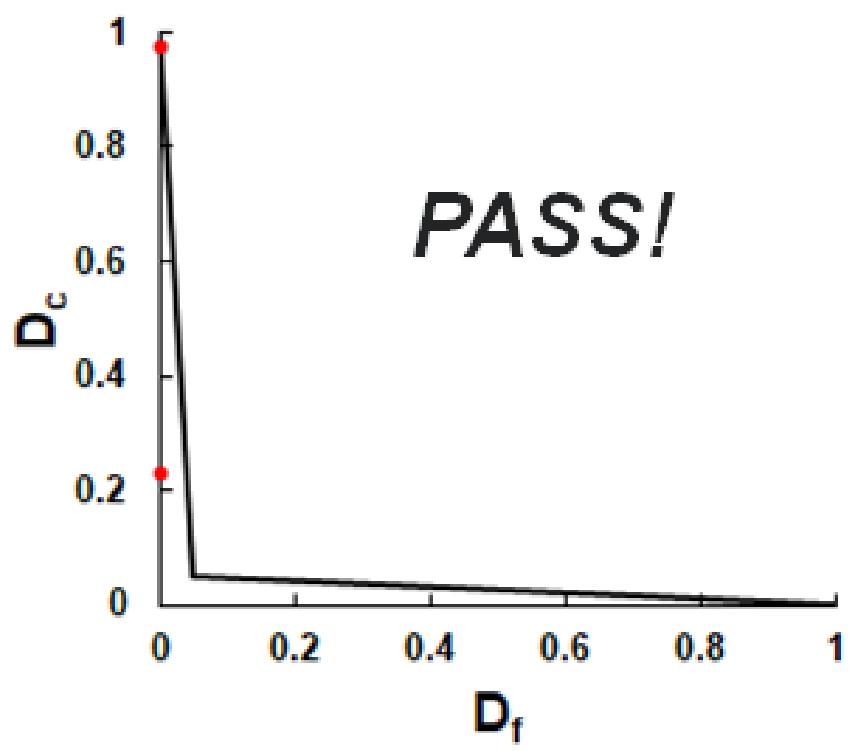

Figure 4-2.3.5.1. (Sample problem-2) Illustration of creep-fatigue design check. Plotted data are results from analysis according to Method 1.

\section{4-2.2.6. Step-6: Time-independent buckling check}

Since this is a tube in an external receiver, wind load should be considered in the timeindependent buckling check. To determine the design wind load on the receiver tube, we first determine the wind pressure along the wind direction. We adopted the method provided in ASME STS-1-2016 Steel Stacks ${ }^{31}$ for calculating the wind pressure. According to Equation 4-4 in STS-1-2016, the deign wind pressure along the wind direction is,

${ }^{31}$ American Society of Mechanical Engineers Code for Steel Stacks, ASME STS-1-2016. 
i.e.

where is the wind speed in $\mathrm{mph}$, is the importance factor, is the topographic factor, and is the velocity pressure exposure coefficient evaluated at height, .

Importance factor, can be determined according to Tables I-2 and I-3 in STS-1-2016 Mandatory Appendix I. As a part of a power generation facility, the CSP receiver falls under category IV in Table I-2. From Table I-3 for category IV structure, the importance factor is found to be 1.15. Considering the CSP tower located in an open terrain, is 1 according to Fig. I-2 in STS-1-2016 Mandatory Appendix I. is determined from Table I-4 in STS-1-2016 Mandatory Appendix I. This table provides the values of as a function of height, and the exposure category of the structure. According to Paragraph 4.3.3.4 of STS-1-2016, the exposure category for a structure located in an open terrain is C. As mentioned in the problem definition, the CSP receiver stands on a $100 \mathrm{~m}$ tall tower which makes the value of to vary from 1.61 at the bottom of the receiver to 1.66 at the top of the receiver.

A structure under wind load is analyzed by computing the total force exerted on the structure from the drag coefficient for the whole structure and the design wind pressure. Then, use the computed force to determine stresses on the structure. However, this method cannot be applied for analyzing individual tube of a CSP receiver. We, therefore, used a pressure coefficient, to determine the distribution of wind pressure around the receiver and use the maximum positive and negative values of the distributed wind pressure as wind load on the tube. The value of depends on the geometry and dimensions of the structure. The overall structure of the external receiver considered for this design problem can be considered as a cylinder. The variation in around a cylindrical structure can be determined from the following equation ${ }^{32}$.

where is the diameter of the whole receiver which is $8.5 \mathrm{~m}$ for our design problem, is the height of the receiver which should be approximately equal to the length of the tube, and is the circumferential coordinate from the direction of wind. The distribution of along the circumference of the external receiver considered in this sample problem is shown in Figure 4-2.2.6.1.

${ }^{32}$ C. Lei, and J. M. Rotter, "Buckling of anchored cylindrical shells of uniform thickness under wind load" Engineering Structures, 41, pp. 199-208, 2012. 


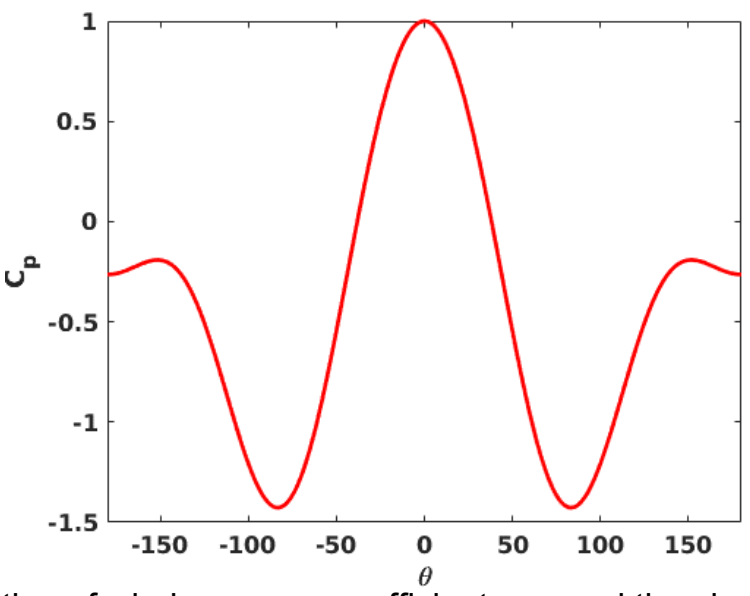

Figure 4-2.2.6.1. Distribution of wind pressure coefficient, around the circumference of the external cylindrical receiver. Receiver diameter, and height, . is along the direction of wind velocity.

By multiplying with, the distribution of design wind pressure around the cylindrical external receiver can be found. Depending on the location of the tube with respect to the wind direction the value of and the corresponding design wind pressure acting on the tube will vary. Considering wind can blow from any direction, the maximum acting positive and negative design wind pressure on the tube, according to Figure 4-2.2.6.1, are and -1.43 , respectively. Thus, the buckling analysis is performed for two cases of design wind load - the maximum positive wind pressure which pushes the tube toward the cylindrical axis of the overall receiver and the maximum negative wind pressure which radially pulls the tube away from the overall cylindrical shape of the receiver. For structural analysis, the design wind pressure load is applied as a pressure field on the outer half (that faces heliostat) of the outer surface of the tube. The direction of the positive pressure field is toward the cylindrical axis of the overall receiver.

To determine, a design wind speed is required. For time-independent buckling check, we considered the conventional $3 \mathrm{~s}$ gust wind speed used in design codes for tall structures. According to Figure I-1 in STS-1-2016 Mandatory Appendix I, the maximum 3 s gust wind speed in the U.S. open terrains (excluding the coastal area) varies between $85 \mathrm{mph}$ and $90 \mathrm{mph}$. We, therefore, used $90 \mathrm{mph}$ wind speed in our design calculations for time-independent buckling check. Table 4-2.2.6.1 tabulates the wind load applied on the receiver tube for buckling analysis.

\begin{tabular}{|c|c|c|c|c|c|c|}
\hline & $\begin{array}{l}\text { Design wind } \\
\text { load }(\mathrm{MPa})\end{array}$ & $\begin{array}{c}V \\
m p h\end{array}$ & & & & \\
\hline Case-1 & & & 1.0 & & & Varies linearly from \\
\hline Case-2 & & 90.0 & -1.43 & 1.15 & 1.0 & $\begin{array}{c}\text { tube) to } 1.66 \text { (top of } \\
\text { the tube) }\end{array}$ \\
\hline
\end{tabular}

Table 4-2.2.6.1. Applied design wind load on the tube for time-independent buckling analysis.

According to the design methods developed for the high temperature components, timeindependent buckling can be checked by analyzing the structure assuming a constitutive response given by the hot tensile curves and a load factor of 1.5. Note that, the load factor 1.5 is a slight reduction from the ASME Section III Division 5 HBB factor 
of 1.67 , reflecting the lower consequences of failure for CSP systems. Thus, we used a load factor of 1.5 on the primary internal pressure load due to the salt pressure and on the thermal loading due to the temperature gradient. To apply the load factor on thermal loading in finite element calculations we multiplied the coefficient of thermal expansion, CTE by 1.5. In the case of wind load, the design wind load expression, provided in Table 4-2.2.6.1, already includes several safety factors and therefore we did not use any additional load factor. Table 4-2.2.6.2 lists all the factors used for different types of loads.

\begin{tabular}{|c|c|c|}
\hline & Load fators & Notes \\
\hline $\begin{array}{l}\text { Design primary } \\
\text { salt pressure }\end{array}$ & 1.5 & \\
\hline $\begin{array}{l}\text { Design thermal } \\
\text { load }\end{array}$ & 1.5 & $\begin{array}{l}\text { Applied through multiplying the } \\
\text { CTE with the load factor }\end{array}$ \\
\hline $\begin{array}{l}\text { Design wind } \\
\text { load }\end{array}$ & 1.0 & $\begin{array}{c}\text { Several safety factors are } \\
\text { already included in the design } \\
\text { load }\end{array}$ \\
\hline
\end{tabular}

Table 4-2.2.6.2. Factors applied on different types of loads for buckling checks.

The constitutive response of alloy $740 \mathrm{H}$ described by the hot tensile or isochronous stress strain curves can be implemented in commercial finite element software such as Abaqus by providing the tabulated values of flow stress and corresponding plastic strain. However, this option is not yet available in the open source finite element package we used for this project. We, therefore, used an elastic perfectly-plastic material model already implemented into our finite element solver for analyzing the structure for buckling checks. Figure 4-2.2.6.2 plots in red the hot tensile curves at different temperatures for alloy $740 \mathrm{H}$. Curves in black represent the elastic perfectlyplastic material models used in the finite element calculations. As seen in Figure 4-2.2.6.2, the curves for elastic perfectly-plastic material models are the original stressstrain curves without the hardening portion which means use of these models would be a more conservative estimation of the buckling. 

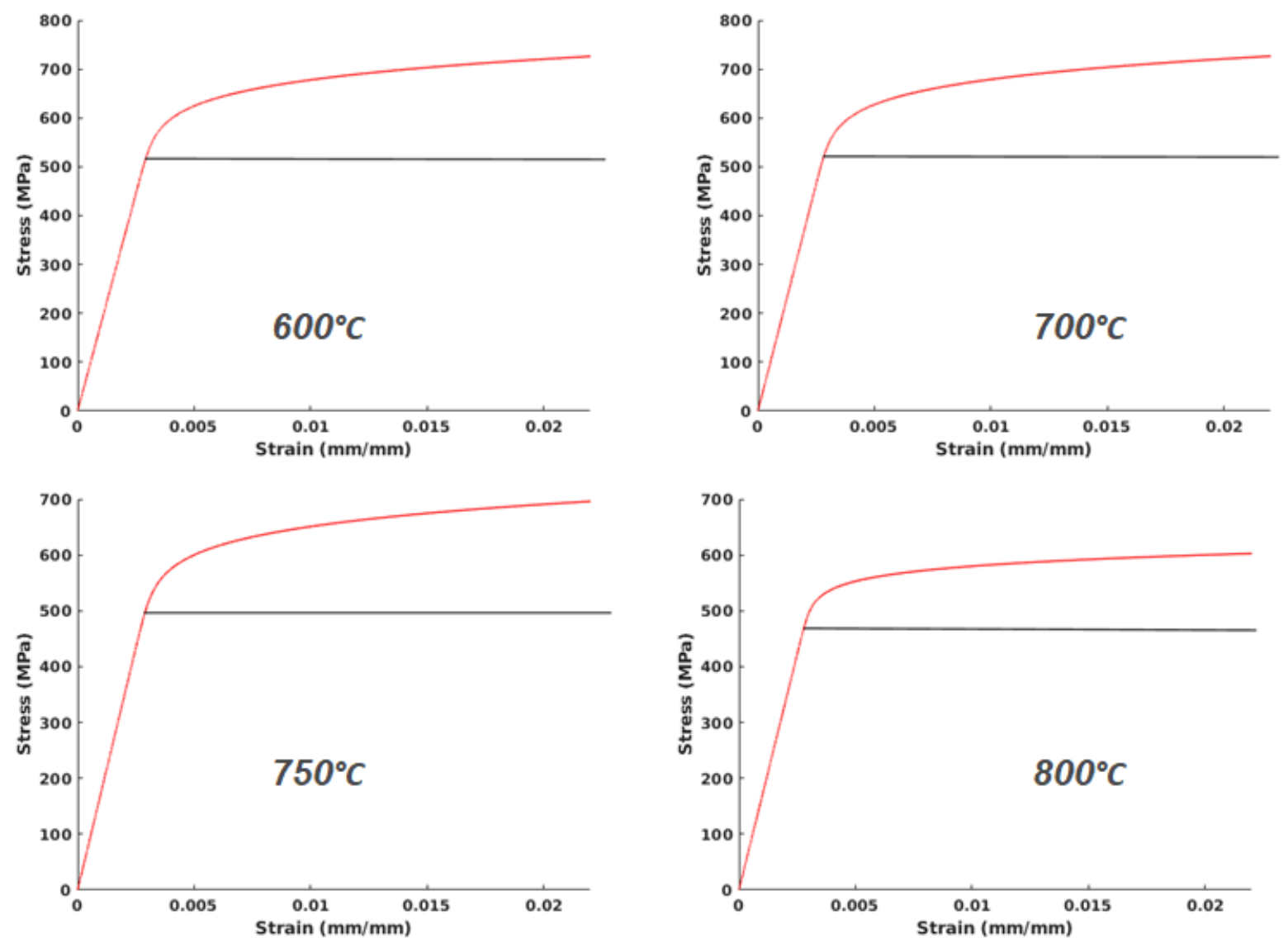

Figure 4-2.2.6.2. Plots in red are hot tensile curves and plots in black represent the elastic perfectlyplastic material models used in finite element simulation for buckling analysis.

We performed two separate thermo-mechanical analyses of the receiver for timeindependent buckling checks. The flux, salt inlet and outlet temperatures, and salt pressure are the same for both cases. While the wind load varies between the two cases by the value of provided in Table 4-2.2.6.1. In both loading cases the finite element solver reaches to a solution implying that the tube passes the time-independent buckling check. Figure 4-2.2.6.3 illustrates the temperature, von Mises stress, and radial (with respect to the cylindrical axis of the overall receiver) displacement distribution of the tube under the applied for time-independent buckling check. 


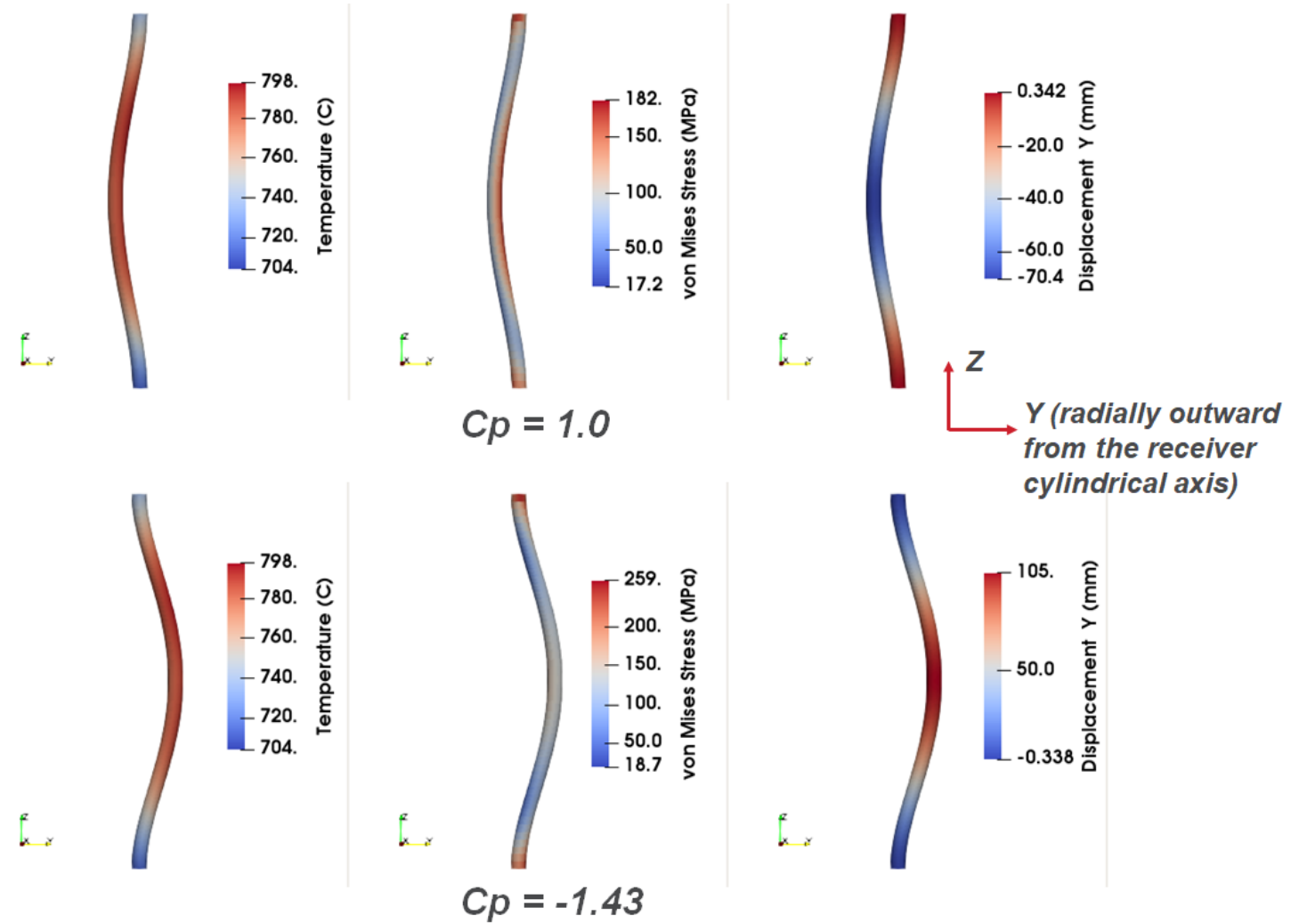

Figure 4-2.2.6.3. Distribution of temperature, von Mises stress, and radial (with respect to the cylindrical axis of the whole receiver) displacement at noon under the load applied for time-independent buckling check.

\section{4-2.2.7. Step-7: Time-dependent buckling check}

As time-dependent buckling is not expected under the salt pressure and thermal loading considered in this problem, this design check was not performed.

4-2.3. Design calculations based on Method 2

4-2.3.1. Step-1: Defining the Design Cycle

Same as in Method 1 Step 1.

4-2.3.2. Step-2: Transient elastic thermo-mechanical analysis for each service load case and stress classification

Same as in Method 1 Step 2.

4-2.3.3. Step-3: Primary load design check

Same as in Method 1 Step 3. 


\section{4-2.3.4. Step-4: Ratcheting check}

Same as in Method 1 Step 4.

\section{4-2.3.5. Step-5: Creep-fatigue damage check}

Method 2 is applicable only if the primary plus secondary stress intensity remains less than for all service loading and if peak stresses are minimal.

For a design to be acceptable, the following relation must be satisfied:

where $D$ is the total creep-fatigue damage and the first and second terms on the left side are fatigue damage, and creep damage, , respectively. In the fatigue damage term, is the number of repetitions of cycle type $\mathrm{j}$ and is the number of design allowable cycles for respective cycle type; while in the creep damage term, is the allowable time duration for a given stress at the maximum temperature occurring in the time interval $\mathrm{k}$ and is the duration of the time interval $\mathrm{k}$.

The design allowable cycles for fatigue damage is determined by entering fatigue curves at total strain range, . Total strain range, is calculated using equation HBBT-1432-16:

where is the maximum equivalent strain range calculated from the elastic analysis of under primary and secondary loading together, according to Section III, Division 5, HBB-T-1413. is the creep strain increment per stress cycle. can be determined by entering the isochronous stress-strain curves at the O'Donnell-Porowski core stress, (determined in Method 1, Step 4) and maximum metal temperature for the stress cycle time, including hold times between transient (instead of total service life). Alternatively, can be calculated by dividing the creep strain accumulated during the entire service life by the number of stress cycles during the entire service life. We used the latter option.

Creep damage for each service load cycle is evaluated from the von Mises stress profile, determined from elastically calculated stresses, versus time profile for this load cycle. Using the stress-time profile and the hold time temperature, during the cycle, creep damage fraction can be calculated according to the illustration in Figure 4-2.3.5.1.

Tables 4-2.3.5.1 and 4-2.3.5.2 show example calculations of determining creep damage fraction, and fatigue damage fraction,, respectively, according to Method 2. Comparing ( with the damage envelop in creep-fatigue interaction diagram, as shown in Figure 4-2.3.5.2, the design is found to be passed according to Method 2. 


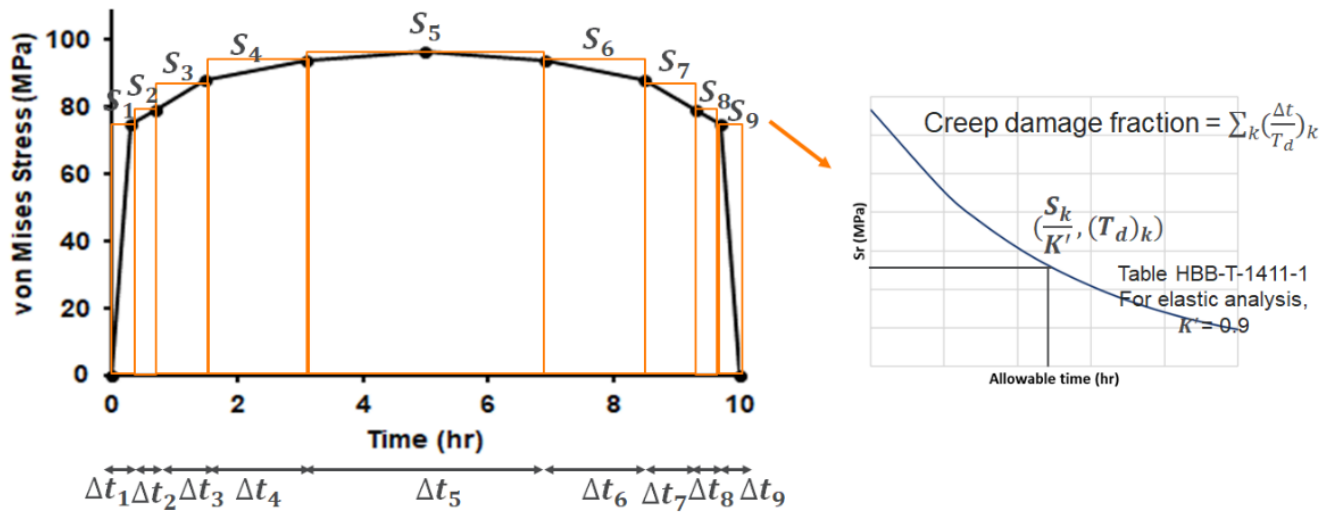

Figure 4-2.3.5.1. (Sample problem-2) Illustration of calculating creep damage fraction in Method 2.

At OD on stress classification line shown in Figure 4-2.2.3.2
\begin{tabular}{|c|c|c|c|c|c|}
$=797.6^{\circ} \mathrm{C}$ \\
$=465.2 \mathrm{MPa}$ (Method 2 is applicable!) \\
\hline Time (hr) & (MPa) & (MPa) & (hr) & (hr) & \\
\hline 0.3 & 74.40 & 82.66 & 73194 & 0.3 & $4.10 \mathrm{e}-06$ \\
\hline 0.7 & 78.79 & 87.55 & 53047 & 0.4 & $7.54 \mathrm{e}-06$ \\
\hline 1.5 & 87.99 & 97.77 & 27470 & 0.8 & $2.91 \mathrm{e}-05$ \\
\hline 3.1 & 93.71 & 104.13 & 19190 & 1.6 & $8.34 \mathrm{e}-05$ \\
\hline 5 & 96.30 & 107.00 & 16322 & 3.8 & $2.33 \mathrm{e}-04$ \\
\hline 6.9 & 93.71 & 104.13 & 19190 & 1.6 & $8.34 \mathrm{e}-05$ \\
\hline 8.5 & 87.99 & 97.77 & 27470 & 0.8 & $2.91 \mathrm{e}-05$ \\
\hline 9.3 & 78.79 & 87.55 & 53047 & 0.4 & $7.54 \mathrm{e}-06$ \\
\hline 9.7 & 74.40 & 82.66 & 73194 & 0.3 & $4.10 \mathrm{e}-06$ \\
\hline 10 & 0 & 0 & & & \\
\hline \multicolumn{7}{|c|}{ Creep damage fraction, } \\
\hline
\end{tabular}

Table 4-2.3.5.1. (Sample problem-2) Sample calculation of creep damage fraction, per cycle from stresstime history according to Method 2.

\begin{tabular}{|l|l|}
\hline & At OD on stress classification line shown in Figure 4-2.2.3.2 \\
\hline & $797.6^{\circ} \mathrm{C}$ \\
\hline & $0.0569 \%$ \\
\hline & $4.315 \mathrm{e}-7 \%$ \\
\hline & $0.0569 \%$ \\
\hline Design allowable cycles, & 3363890 \\
\hline Design cycles, & $4.4 * 365=1602$ \\
\hline Fatigue damage fraction, & $\mathbf{4 . 7 7 4 e - 4}$ \\
\hline
\end{tabular}

Table 4-2.3.5.2. (Sample problem-2) Sample calculation of fatigue damage fraction, according to Method 2. 


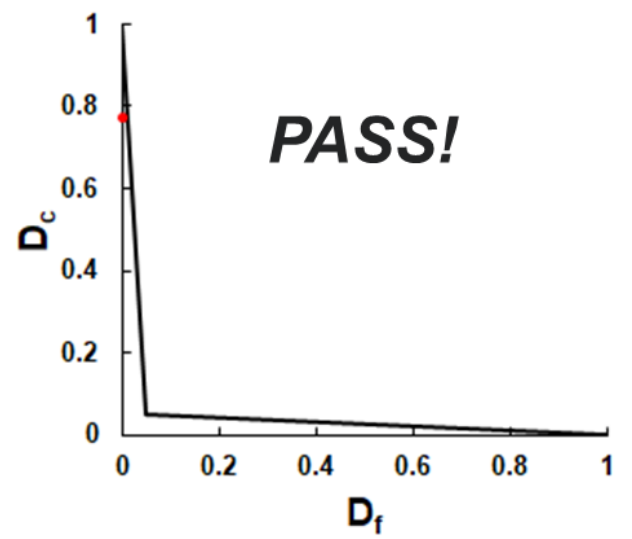

Figure 4-2.3.5.2. (Sample problem-2) Illustration of creep-fatigue design check. Plotted data are results from analysis according to Method 2.

\section{4-2.3.6. Step-6: Time-independent buckling check}

Same as in Method 1 Step 6.

\section{4-2.3.7. Step-7: Time-dependent buckling check}

Same as in Method 1 Step 7.

4-2.4. Design calculations based on Method 3

\section{4-2.4.1. Step-1: Defining the Design Cycle}

Same as in Method 1 Step 1.

\section{4-2.4.2.}

Step-2a: Transient elastic thermo-mechanical analysis for each service load case and stress classification (for primary load design check)

\section{Same as in Method 1 Step 2.}

Step-2b: Transient elastic-creep thermo-mechanical analysis for each service load case (for ratcheting and creep-fatigue evaluation)

We used MOOSE (Multiphysics Object Oriented Simulation Environment), an open source finite element solver to perform the transient elastic-creep thermo-mechanical analyses under the loading conditions mentioned in Step 1. The analysis was repeated until a steady state cyclic response was achieved.

\section{4-2.4.3. Step-3: Primary load design check}

Same as in Method 1 Step 3. 


\section{4-2.4.4. Step-4: Ratcheting check}

To determine ratcheting strain Method 3 requires to run the analysis using elastic-creep material model, described above, and monitor the maximum effective strain, at the beginning and end of the cycle. The criterion is that the ratcheting strain does not exceed $10 \%$ at any point of the structure for base metal. Figure 4-2.4.4 plots the maximum effective strain at the critical tube location as a function of cycle count. Extrapolating the maximum effective strain out to design life of the tube, i.e. 4.4 years $\left(=4.4^{\star} 365\right.$ cycles $)$, gives the ratcheting strain of $0.745 \%$ which is less than $10 \%$.

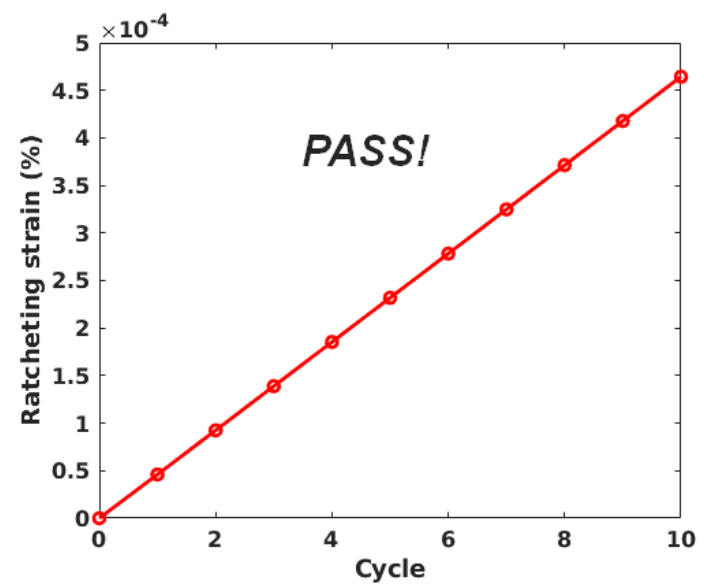

Figure 4-2.4.4. (Sample problem-2) Maximum ratcheting strain in the structure versus number of cycles determined from elastic-creep thermo-mechanical analysis.

\section{4-2.4.5. Step-5: Creep-fatigue damage check}

Once steady cyclic response was achieved in the analysis, the temperature, stress, and strain-time history for a single cycle of the periodic loading were extracted. Figure 4-2.4.5.1 plots the temperature, and the steady cyclic effective strain range and von Mises effective stress at the critical location of the tube. Details of the fatigue damage fraction calculation is provided in Table 4-2.4.5.1. The tube experiences negligible fatigue damage. Figure 4-2.4.5.2 illustrates creep damage fraction evaluation from the steady cyclic von Mises effective stress profile. Detailed calculation of creep damage fraction is provided in Table 4-2.4.5.2. Comparing ( with the damage envelop in creepfatigue interaction diagram, as shown in Figure 4-2.4.5.3, the design is found to be passed according to Method 3. 

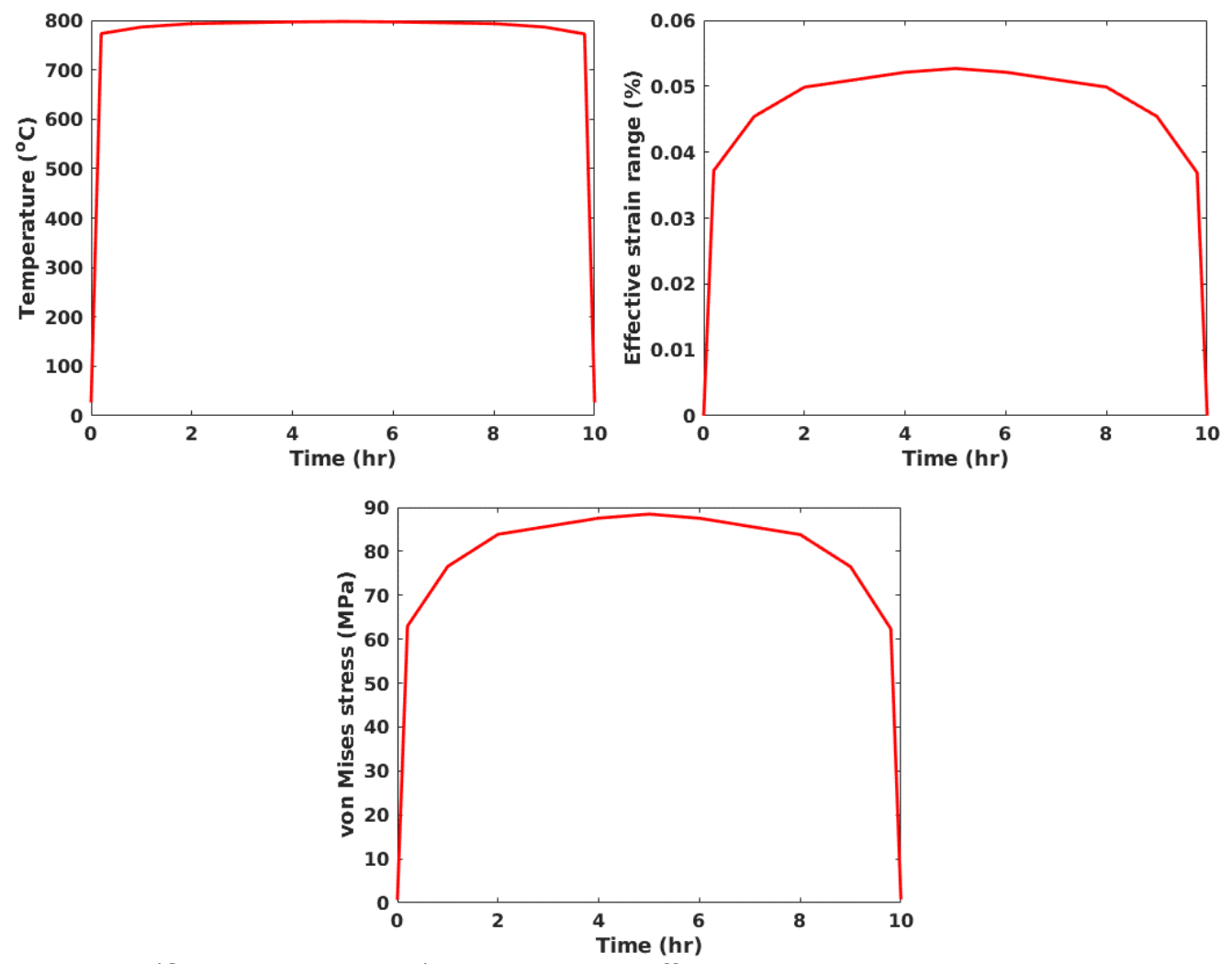

Figure 4-2.4.5.1. (Sample problem-2) Temperature, effective strain range, and von Mises stress profiles at the critical location of the tube after a steady cyclic response is achieved in the elastic-creep thermomechanical analysis.

\begin{tabular}{|l|c|}
\hline & At the critical location \\
\hline & $797.6^{\circ} \mathrm{C}$ \\
\hline Strain range and corresponding cycle frequency & $0.0527 \%$ \\
\cline { 2 - 2 } according to rainflow counting of effective strain range, & 1 \\
\hline Design allowable cycles, & 3649654 \\
\hline Design cycles, & $4.4^{*} 365=1606$ \\
\hline Fatigue damage fraction, & $\mathbf{4 . 4 0 e - 4}$ \\
\hline
\end{tabular}

Table 4-2.4.5.1. (Sample problem-2) Sample calculation of fatigue damage fraction, according to Method 3. 

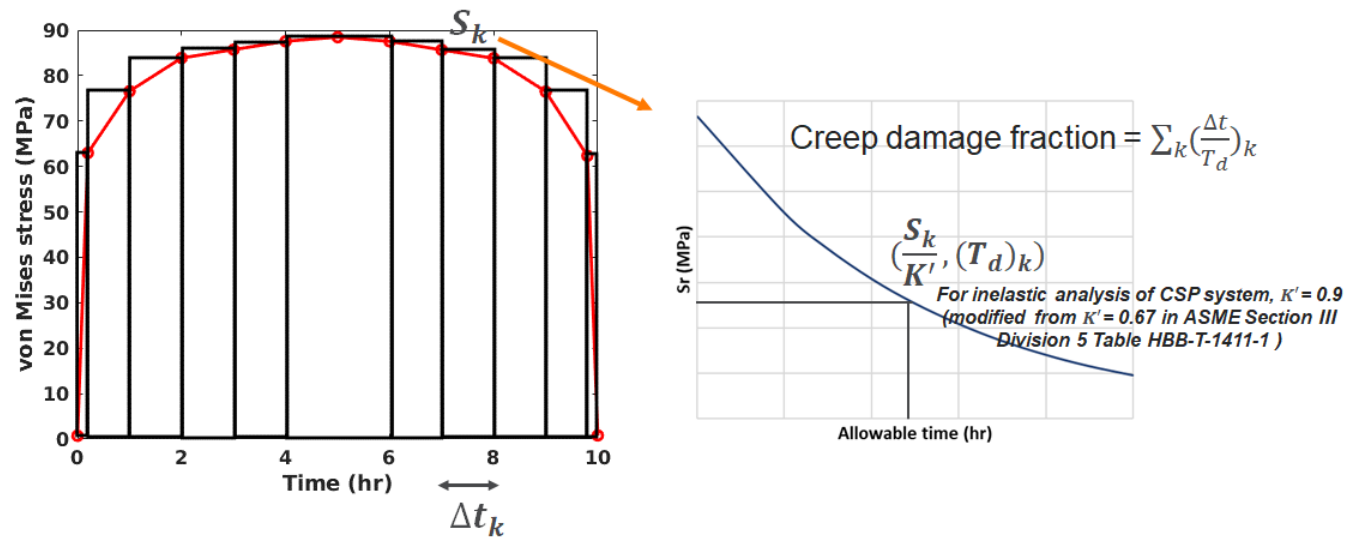

Figure 4-2.4.5.2. (Sample problem-2) Illustration of calculating creep damage fraction in Method 3.

\begin{tabular}{|c|c|c|c|c|c|}
\hline \multicolumn{6}{|c|}{ At the critical location } \\
\hline \multicolumn{6}{|c|}{$\begin{array}{l}=797.6^{\circ} \mathrm{C} \\
=465.2 \mathrm{MPa} \text { (Method } 3 \text { is applicable!) }\end{array}$} \\
\hline Time (hr) & (MPa) & (MPa) & (hr) & (hr) & \\
\hline 0.2 & 62.98 & 69.98 & 168661 & 0.2 & $1.19 \mathrm{e}-06$ \\
\hline 1.0 & 76.57 & 85.08 & 62412 & 0.8 & $1.28 \mathrm{e}-05$ \\
\hline 2.0 & 83.87 & 93.19 & 36594 & 1 & $2.73 e-05$ \\
\hline 3.0 & 85.71 & 95.23 & 31995 & 1 & $e-05$ \\
\hline 4.0 & 87.55 & 97.28 & 28240 & 1 & $e-05$ \\
\hline 5.0 & 88.47 & 98.30 & 26661 & 2 & $7.50 \mathrm{e}-05$ \\
\hline 6.0 & 87.53 & 97.26 & 28271 & 1 & $3.54 \mathrm{e}-05$ \\
\hline 7.0 & 85.66 & 95.18 & 32100 & 1 & $3.12 \mathrm{e}-05$ \\
\hline 8.0 & 83.81 & 93.12 & 36763 & 1 & $2.72 \mathrm{e}-05$ \\
\hline 9.0 & 76.49 & 84.99 & 62785 & 0.8 & $1.27 e-05$ \\
\hline 9.8 & 62.34 & 69.27 & 176732 & 0.2 & $1.13 \mathrm{e}-06$ \\
\hline 10 & 0 & & & & \\
\hline \multicolumn{5}{|c|}{ Creep damage fraction per cycle } & $2.91 e-4$ \\
\hline \multicolumn{5}{|c|}{ Creep damage fraction, } & 0.47 \\
\hline
\end{tabular}

Table 4-2.4.5.2. (Sample problem-2) Sample calculation of creep damage fraction, according to Method 3.

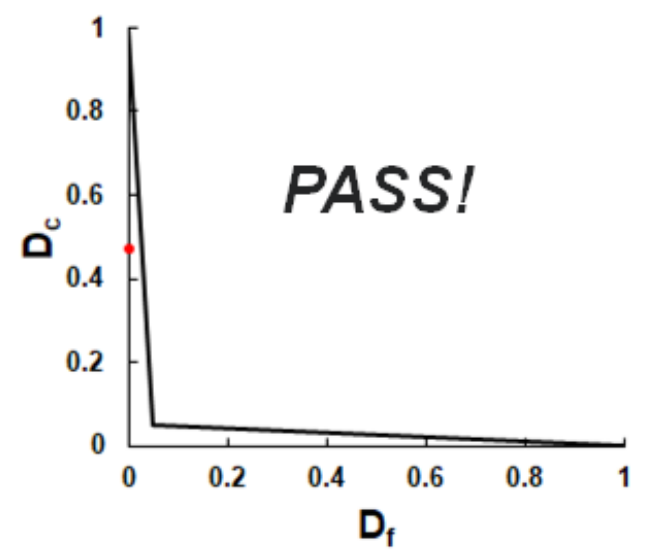

Figure 4-2.4.5.3. (Sample problem-2) Illustration of creep-fatigue design check. Plotted data are results from analysis according to Method 3. 
4-2.4.6. Step-6: Time-independent buckling check

Same as in Method 1 Step 6.

4-2.4.7. Step-7: Time-dependent buckling check

Same as in Method 1 Step 7. 


\section{Acknowledgements}

This work was funded by the U.S. Department of Energy through the Office of Energy Efficiency and Renewable Energy, Solar Energy Technologies Office, CSP Program.

We gratefully acknowledge the guidance of Mark Lausten, the DOE project manager for this project as well as the contributions of Robert Jetter who served as a high temperature design consultant in the development of the design rules and corresponding material data. 